\title{
SEISMIC DESIGN AND EVALUATION GUIDELINES FOR THE DEPARTMENT OF ENERGY HIGH-LEVEL WASTE STORAGE TANKS AND APPURTENANCES
}

\author{
K. Bandyopadhyay, A. Cornell, C. Costantino,
} R. Kennedy, C. Miller and A. Veletsos*

\author{
January 1993
}

ENGINEERING RESEARCH AND APPLICATIONS DIVISION DEPARTMENT OF NUCLEAR ENERGY BROOKHAVEN NATIONAL LABORATORY, ASSOCIATED UNIVERSITIES, INC.

UPTON, NEW YORK 11973

\section{Prepared for the}

OFFICE OF ENVIRONMENTAL RESTORATION AND WASTE MANAGEMENT

UNITED STATES DEPARTMENT OF ENERGY

CONTRACT NO. DE-ACO2-76CH0OO16

*Authors' names are listed in alphabetical order. 


\section{3}

This report is printed on paper containing at least 50 percent recycled materials, with 10 percent post consumer waste.

\section{DISCLAIMER}

This report was prepared as an account of work sponsored by an agency of the United States Government. Neither the United States Government nor any agency thereof, nor any of their employees, nor any of their contractors, subcontractors, or their employees, makes any warranty, express or implied, or assumes any legal liability or responsibility for the accuracy, completeness, or usefulness of any information, apparatus, product, or process disclosed, or represents that its use would not infringe privately owned rights. Reference herein to any specific commercial product, process, or service by trade name, trademark, manufacturer, or otherwise, does not necessarily constitute or imply its endorsement, recommendation, or favoring by the United States Government or any agency, contractor or subcontractor thereof. The views and opinions of authors expressed herein do not necessarily state or reflect those of the United States Government or any agency, contractor or subcontractor thereof.

\section{Printed in the United States of America}

Available from

National Technical Information Service

U.S. Department of Commerce

5285 Port Royal Road

Springfield, VA 22161

NTIS price codes:

Printed Copy: A15; Microfiche Copy: A01 
The DOE Tank Seismic Experts Panel that authored this report consists of the following members in alphabetical order:

\author{
Kamal Bandyopadhyay \\ Allin Cornell \\ Carl costantino \\ Robert Kennedy \\ Charles Miller
}

Anestis Veletsos

The work was directed by DOE Program Manager Dr. Howard Eckert. 
This document provides guidelines for the design and evaluation of underground high-level waste storage tanks due to seismic loads. Attempts were made to reflect the knowledge acquired in the last two decades in the areas of defining the ground motion and calculating hydrodynamic loads and dynamic soil pressures for underground tank structures. The application of the analysis approach is illustrated with an example.

The guidelines are developed for a specific design of underground storage tanks, namely double-shell structures. However, the methodology discussed is applicable for other types of tank structures as well. The application of these and of suitably adjusted versions of these concepts to other structural types will be addressed in a future version of this document. 
TABLE OF CONTENTS

Page No.

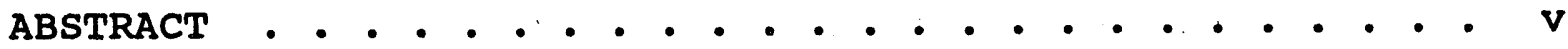

TABLE OF CONTENTS . . . . . . . . . . . . . . vii

LIST OF TABLES . . . . . . . . . . . . . . . xiii

LIST OF FIGURES . . . . . . . . . . . . . . . . . xvi

ACKNOWLEDGEMENTS . . . . . . . . . . . . . . xviii

CHAPTER 1 - INTRODUCTION . . . . . . . . . . . 1-1

1.1 BACKGROUND . . . . . . . . . . . . . . . 1-1

1.2 TANK FARMS ................ . . . $1-1$

1.3 OVERVIEW OF SEISMIC GUIDELINES . . . . . . . . . . 1-2

1.4 NOTATION . . . . . . . . . . . . . 1-5

REFERENCES ................. . . 1-7
\end{abstract}

CHAPTER 2 - CONSIDERATIONS IN DEVELOPMENT OF GUIDELINES - 2-1

2.1 INTRODUCTION . . . . . . . . . . . . . . $2-1$

2.2 TECHNICAL ISSUES ................ $2-1$

REFERENCES ................ . . 2-6

CHAPTER 3 - SEISMIC CRITERIA . . . . . . . . . . 3-1

3.1 INTRODUCTION . . . . . . . . . . . . . . . . 3-1

3.2 FUNDAMENTAL CONCEPTS .............. . . $3-2$

3.3 DESIGN BASIS EARTHQUAKE GROUND KOTION . . . . . . $3-7$

3.3.1 Probabilistic Definition of Ground Motion . . 3-7

3.3.2 Design Basis Earthquake Response Spectra . . 3-9

3.4 ANALYSIS OF SEISMIC DEMAND (RESPONSE) • • • • . . 3-13

3.5 DAMPING . . . . . . . . . . . . . . . . 3-15

3.6 MATERIAL STRENGTH PROPERTIES .......... . . 3-16

3.7 CAPACITIES . . . . . . . . . . . . . . . 3-17

3.8 LOAD COMBINATIONS AND ACCEFTANCE CRITERIA . . . . 3-19

3.9 INELASTIC ENERGY ABSORPTION FACTOR . . . . . . . . . 3-22

3.10 BASIC SEISMIC CRITERION AND GENERAL APPROACH TO

COMPLIANCE . . . . . . . . . . . . . . 3-27 
TABLE OF CONTENTS (Continued)

3.10.1 The Basic Seismic Criterion . . . . . . 3-27

3.10.2 The General Approach to Compliance . . . . 3-28

3.11 BENCHMARKING DETERMINISTIC SEISMIC EVALUATION

PROCEDURE AGAINST BASIC SEISMIC CRITERION • • • • • 3-29

REFERENCES . . . . . . . . . . . . . . . . 3-32

NOTATION . . . . . . . . . . . . . . . $3-35$

CHAPTER 4 - EVALUATION OF HYDRODYNAMIC EFFECTS IN TANKS - 4-1

4.1 OBJECTIVES AND SCOPE . . . . . . . . . . . . . . . . 4-1

4.2 RESPONSES OF INTEREST AND MATERIAL OUTLINE . . . . . 4-3

4.3 EFFECTS OF HORIZONTAL COMPONENT OF SHAKING . . . . . 4-4

4.3.1 General . . . . . . . . . . . . . 4-4

4.3.2 Hydrodynamic Wall Pressure . . . . . . . 4-5

4.3.2.1 Natural Sloshing Frequencies . . . 4-8

$\begin{array}{ll}4.3 .2 .2 & \text { Fundamental Natural Frequency of } \\ & \text { Tank-Liquid System . . . . . . 4-9 }\end{array}$

4.3.2.3 Maximum Values of Wall Pressures . . 4-12

4.3.2.4 Relative Magnitudes of Impulsive and

4.3.2.5 Response of Partially Filied Tanks $44-14$

4.3.3 Evaluation of Critical Effects . . . . . . 4-14

4.3.4 Total Hydrodynamic Force . . . . . . . . 4-16

4.3.5 Critical Tank Forces . . . . . . . . . 4-17

4.3.5.1 Base Shear... . . . . . . . . 4-17

4.3.5.2 Bending Moments Across Normal Tank

Sections............. 4-18

4.3.6 Effects of Tank Inertia . . . . . . . . . 4-22

4.3.7 Hydrodynmaic Forces Transmitted to Tank

support ................... 4-23

4.3.8 Modeling of Tank-Liquid System . . . . . 4-26

4.4 EFFECTS OF ROCKING COMPONENT OF BASE MOTION • • • - 4-27

4.5 EFFECTS OF VERTICAI COMPONENT OF BASE MOTION • • • . 4-28

4.5.1 Hydrodynamic Effects . . . . . . . . . 4-28

4.5.2 Effects of Tank Inertia... . . . . . . 4-29

4.5.3 Combination With other Effects .. . . . . 4-30

4.5.4 Modeling of Tank-Liquid System . . . . . 4-31 
TABLE OF CONTENTS (Continued)

4.6 EFFECTS OF SOIL-STRUCTURE INTERACTION . . . . . . 4-31

4.7 SURFACE DISPLACEMENTS OF LIQUID . . . . . . . . 4-32 REFERENCES ................ 44-34 NOTATION ............... . . 4-36

CHAPTER 5 - SEISMIC CAPACITY OF METAL FLAT-BOTTOM
VERTICAL LIQUID STORAGE TANKS . . . . . . . 5-1

5.1 INTRODUCTION . . . . . . . . . . . . . . 5-1

5.2 SLOSH HEIGHT CAPACITY . . . . . . . . . . . 5-5

5.3 HOOP TENSION CAPACITY . . . . . . . . . . . . 5-6

5.4 MAXIMUM PERMISSIBLE AXIAL COMPRESSION OF TANK SHELL 5-7

5.5 MOMENT CAPACITY AWAY FROM TANK BASE . . . . . . . 5-11

5.6 ANCHORAGE CAPACITY AT TANK BASE . . . . . . . . . 5-11

5.7 BASE MOMENT CAPACITY OF FULLY ANCHORED TANKS . . . . 5-12

5.8 BASE MOMENT CAPACITY OF PARTIALLY ANCHORED OR

UNANCHORED TANKS ............. . 5-12

5.9 PERMISSIBLE UPLIFT DISPLACEMENT . . . . . . . . . . 5-15

5.10 FLUID HOLD-DOWN FORCE . . . . . . . . . . . 5-16

5.10 .1 Anchored Tanks . . . . . . . . . 5-16

5.10 .2 Unanchored Tank ......... 5-20

5.11 BASE SHEAR CAPACITY . . . . . . . . . . . 5-22

5.12 OTHER CAPACITY CHECKS .. . . . . . . . . . . 5-23

5.13 TOP SUPPORTED TANKS ... . . . . . . . . . 5-24

REFERENCES ................ . . 5-25

NOTATION . . . . . . . . . . . . . 5-28

CHAPTER 6 - EVALUATION OF SOIL-VAULT INTERACTION . . . 6-1

6.1 INTRODUCTION . . . . . . . . . . . . . . 6-1

6.2 SOIL PROPERTIES ................ . 6-3

6.3 FREE FIELD MOTION ................ 6 . $6-4$

6.4 VERTICAL SSI CALCULATIONS . . . . . . . . . . 6-6

6.5 HORIZONTAL SSI CALCULATIONS . . . . . . . . . 6-7

6.5 .1 CONDITIONS FOR NEGLECTING HORIZONTAL/ROCKING

6.5 .2 CRITERIA FOR PERFORMING HORIZONTAL SSI
CALCULATIONS . . . . . . . . . 6-9 


\section{TABLE OF CONTENTS (Continued)}

6.5.2.1 LUMPED PARAMETER MODEL USING TIME

HISTORY ANALYSIS ............. 6-10

6.5.2.2 CONTINUUM MODEL USING TIME HISTORY

ANALYSIS . . . . . . . . . . . . . 6-15

6.5.2.3 LUMPED PARAMETER MODEL USING A RESPONSE

SPECTRUM ANALYSIS • . . . . . . . . 6-19

6.6 VAULT-VAULT INTERACTION . . . . . . . . . . . 6-20

REFERENCES . . . . . . . . . . . . . . . . 6-21

NOTATION . . . . . . . . . . . . . . . . 6-22

CHAPTER 7 - CRITERIA FOR UNDERGROUND PIPING . . . . . . 7-1

7.1 INTRODUCTION • . . . . . . . . . . . . . . . . . . . 7-1

7.2 REQUIRED SEISMIC AND SOIL DATA . . . . . . . . . . . $7-2$

7.3 ANALYSIS LOADS AND CONDITIONS . . . . . . . . . . . $7-3$

7.4 ANALYSIS PROCEDURES . . . . . . . . . . . . . . . 7-5

7.4.1 NORMAL OPERATING LOADS . . . . . . . . . 7-5

7.4 .2 EXTERNAL SOIL LOADINGS . . . . . . . . . . 7-5

7.4 .3 TRANSIENT DIFFERENTIAL MOVEMENTS . . . . . . 7-6

7.4 .4 PERMANENT DIFFERENTIAL MOVEMENTS . . . . . . 7-10

7.5 DESIGN RECOMMENDATIONS . . . . . . . . . . . 7-11

7.5.1 CONCRETE CONDUIT REQUIREMENTS . . . . . . . 7-12

7.5 .2 STEEL PIPING OR CONDUIT COMPONENTS . . . . $7-13$

REFERENCES . . . . ................ . 7-16

NOTATION • . • . . . . . . . . . . . . . 7-19

CHAPTER 8 - SEISMIC QUALIFICATION OF EQUIPMENT - • • - 8-1

8.1 GENERAL APPROACH . . . . . . . . . . . . . . . 8-1

8.2 EXISTING STANDARDS . . . . . . . . . . . . . . . . $8-2$

8.3 QUALIFICATION LEVEL . . . . . . . . . . . . . . 8-3

8.3.1 Justification for RRS Amplification Factor . 8-4

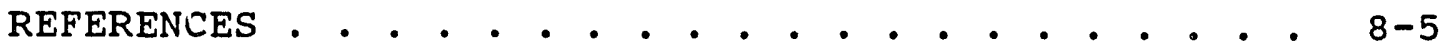

NOTATION • . . . . . . . . . . . . . . . 8-6 
APPENDIX A - DEDRIVATION OF REQUIRED LEVEL OF SEISMIC DESIGN CONSERVATISM TO ACHIEVE A SPECIFIED REDUCTION RATIO •. . . . . . . . . . . A-1 REFERENCES • . . . . . . . . . . . . . . . A-9 NOTATION . . . . . . . . . . . . . . . . A-10

APPENDIX B - VALIDATION OF BASIC SEISMIC DESIGN CRITERIA OF APPENDIX A . . . . . . . . . . . . . . $\mathrm{B}-1$

B.1 CONCLUSION . . . . . . . . . . . . . . . . B-2

REFERENCE •. . . . . . . . . . . . . . . B-4

NOTATION . . . . . . . . . . . . . . . B-5

APPENDIX C - DEMONSTRATION THAT SEISMIC CRITERIA ACHIEVE DESIRED HAZARD TO RISK REDUCTION RATIO . . . C-1

C.1 INTRODUCTION . . . . . . . . . . . . . . . C-1

C. 2 SEISMIC DEMAND . . . . . . . . . . . . . . . . C-3

C.3 NON-SEISMIC DEMAND . . . . . . . . . . . . . . . C-3

C.4 INELASTIC ENERGY ABSORPTION FACTOR . . . . . . . . C C-4

C.5 CAPACITY . . . . . . . . . . . . . . . . . C-5

C.5.1 LOW-DUCTILITY FAILURE MODES . . . . . . . C-5

C.5.2 DUCTILE FAILURE MODES . . . . . . . . . . . . C-6

C. 6 COMPARISON OF FACTOR OF SAFETY OF SEISMIC CRITERIA

WITH REQUIRED FACTOR OF SAFETY . . . . . . .....

C. 7 MINIMUM REQUIRED RATIO OF TRS TO RRS FOR EQUIPMENT

QUALIFIED BY TEST • . . . . . . . . . . . . . C-8

REFERENCES . . . . . . . . . . . . . . . . C-11

NOTATION •. . . . . . . . . . . . . . . C-12

APPENDIX D - GUIDANCE ON ESTIMATING THE INELASTIC ENFRGY ABSORPTION FACTOR F $\mu$. . . . . . . . . D-1

D. 1 INTRODUCTION . . . . . . . . . . . . . . . . . . . . D-1

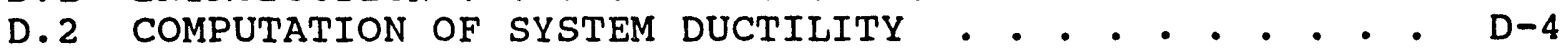

D.3 COMPUTATION OF INELASTIC ENERGY ABSORPTION FACTOR - D-5

REFERENCES . . . . . . . . . . . . . . . . . D-7

NOTATION • . . . . . . . . . . . . . . D-8 
TABLE OF CONTENTS (Continued)

APPENDIX E - MEMBRANE SOLUTIONS FOR TOP-CONSTRAINED TANKS E-1

APPENDIX F - AN EXAMPLE FOR DETERMINATION OF SEISMIC RESPONSE AND CAPACITY OF A FLAT BOTTOM

VERTICAL LIQUID STORAGE TANK ....... . F-1

F.1 INTRODUCTION . . . . . . . . . . . . . . . F-1

F.2 SEISMIC RESPONSE . . . . . . . . . . . . . F-2

F.2.1 Horizontal Impulsive Response . . . . . . F-3

F.2.2 Horizontal Convective (Sloshing) Mode

F.2.3 Vertical Liquid Mode Response . . . . . . : F-8

F.2.4 Combined Demand . . . . . . . . . . . F-9

F.3 CAPACITY ASSESSMENTS . . . . . . . . . . . F-10

F.3.1 Slosh Height Capacity . . . . . . . . F-11

F.3.2 Hoop Tension Capacity . . . . . . . . F-12

F.3.3 Maximum Permissible Axial Compression of

Tank Wall . . . . . . . . . . F-12

F.3.4 Moment Capacity Away From Tank Base . . . F-13

F.3.5 Anchorage Capacity at Tank Base . . . . . . F-14

F.3.6 Anchorage Requirement for Fully Anchored

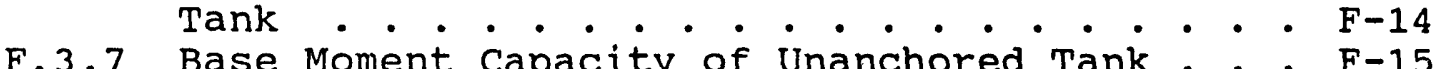

F.3.8 Base Moment Capacity of Partially Anchored

F.3.9 Base shear capacity : : : : : : : ${ }^{\mathrm{F}-17}$

REFERENCES . . . . . . . . . . . . . F-21

NOTATION . . . . . . . . . . . . . F-22

APPENDIX G - LUMPED PARAMETER SSI ANALYSES . . . . . . G-1

G.1 INTRODUCTION . . . . . . . . . . . . . . . . . . G-1

G.2 HORIZONTAL/ROCKING SSI COEFFICIENTS ........ G-2

G.3 VERTICAL SSI COEFFICIENTS . . . . . . . . . . . G-5

REFERENCES . . . . . . . . . . . . . . G G-7

NOTATION . . . . . . . . . . . . . G-9 
IIST OF TABLES

Table

Page

3.1 Example DBE PGA Values Based Upon Figure 3.2

Hazard Curves . . . . . . . . . . . . . 3-37

3.2 Recommended Damping Values . . . . . . . . . . 3-38

3.3 Inelastic Energy Absorption Factors $F_{\mu D} \cdot{ } \cdot \cdot \cdot \cdot{ }^{-}$3-39

4.1 Values of Dimensionless Function $c_{1}(\eta)$ in

Expression for Impulsive Component of Wall

Pressure ................ . . . . . . 4-41

4.2 Values of Factors in Expressions for Impulsive

and Convective Components of Hydrodynamic Effects

in Tanks . . . . . . . . . . . . . . . . . . . . 4-42

4.3 Values of Coefficients in Expressions for

Fundamental Impulsive Frequencies of Lateral and

Vertical Modes of Vibration of Roofless steel

Tanks Filled with Water; $t_{t w} / R=0.001$,

$\rho_{\ell} / \rho_{\mathrm{t}}=0.127, \nu_{\mathrm{t}}=0.3 \cdot . \cdot . \cdot . \cdot \cdot \cdot . \cdot . \cdot . \cdot 4-43$

4.4 Values of Coefficient $\alpha_{c 1}$ in Expression for

Convective Component of Base shear in Top-

Constrained Tanks .. . . . . . . . . . . . . . 4-44

4.5 Values of Dimensionless Function $d_{1}(\eta)$ in

Expression for Impulsive Component of Bending

Moment Across Normal Sections for Cantilevę Tanks . 4-45

4.6 Values of Dimensionless Function $d_{c 1}(\eta)$ in

Expression for Convective Component of Bending

Moment Across Normal Sections for Cantilever Tanks . 4-46

4.7 Values of Dimensionless Function $d_{1}(\eta)$ in

Expression for Impulsive Component of Bending

Moment Across Normal Sections for Tanks with

Roller at Top . . . . . . . . . . . . . . . 4-47

4.8 Values of Dimensionless Function $\mathrm{d}_{\mathrm{c} 1}(\eta)$ in

Expression for Conveçtive Component of Bending

Moment Across Normal Sections for Tanks with

Roller at Top . . . . . . . . . . . . . . 4-48

4.9 Values of Dimensionless Function $d_{1}(\eta)$ in

Expression for Impulsive Component of Bending

Moment Across Normal Sections for Tanks Hinged

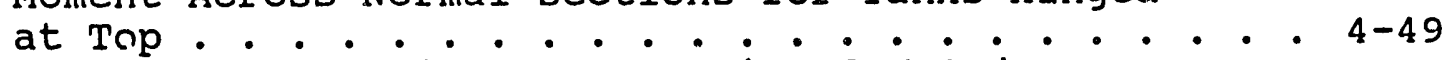

4.10 Válues of Dimensionless Function $d_{c 1}(\eta)$ in

Expression for Convective Component of Bending

Moment Across Normal Sections for Tanks with

Hinged at Top . . . . . . . . . . . . . . 4-50

4.11 Effect of Poisson's Ratio of Tank Material on

Values of Dimensionless Functions in Expression

for Impulsive and Convective Components of

Bending Moment Across Normal Sections for Tanks

with $\mathrm{H}_{\ell} / \mathrm{R}=0.75$ and Roller Support at Top . . . 4-51 
LIST OF TABLES (Continued)

Table

Page

5.1 Tánk Parameters . . . . . . . . . . . . . 5-31

7.1 Seismic Coefficients for Estimating Ground

Stain . . . . . . . . . . . . . . . 7-20

7.2 Effective Friction Angle $\left(\phi_{a}\right)$ in Degrees . . . . . 7-20

7.3 Effective Adhesion $\left(C_{a}\right)$ for Cohesive Soils . . . . 7-21

A.1 Typical Ground Motion Ratios and Hazard Slope

Parameters . . . . . . . . . . . . . . . . A-11

A. 2a Maximum and Minimum Required safety Factors $F_{P R}$

to Achieve a Risk Reduction Ratio of $R_{h}=20$ for

Capacities $C_{p}$ Defined at Various Failure

Probabilities and Various $f_{A}$ Values . . . . . . . A-12

A.2b Maximum and Minimum Required Safety Factors $F_{P R}$

to Achieve a sisk Reduction Ratio of $R_{R}$ Equals

10 for Capacities $C_{p}$ Defined at Various

Failure Probabilities and Various $i_{a}$ Values . . . A-13

A.2C Maximum and Minimum Required Safety Factors

$F_{P R}$ to Achieve a Risk Reduction Ratio of

$R_{R}=5$ for Capacities $C_{p}$ Defined at Various

Failure Probabilities and Various $f_{a}$ Values . . . A-14

A.2d Maximum and Minimum Required Safety Factors

$F_{P R}$ to Achieve a Risk Reduction Ratio of

$R_{\mathrm{R}}=2$ for Capacities $C_{p}$ Defined at Various

Failure Probabilities and Various $f_{a}$ Values . . . A-15

A.3 DBE Factors, Factors of Safety, and seismic

Load Factors Required to Achieve Various

Risk Reduction Ratios . . . . . . . . . . . A-16

A. 4 Required Factors of Safety, $F_{P R}$, for Various

Values of $R, A_{R}$, and $\beta$. . . . . . . . . . . A-17

B.1 Probabilities for Hazard Curves A and B from

Figure A.1 . . . . . . . . . . . . . . . B-6

B.2a Minimum Acceptable Failure Capacity and

Resulting Annual Probability of Unacceptable

Performance $P_{F}$ for Hazard Curve A . . . . . . . . B-7

B.2b Minimum Acceptable Failure Capacities and

Resulting Annual Probability of Unacceptable

Performance $P_{F}$ for Hazard Curve $B$. . . . . . . B-8

B. 3 Solution of Equation B.1 for Hazard Curve B,

$\mathrm{P}_{\mathrm{H}}=1 \times 10^{-3}, \mathrm{R}_{\mathrm{R}}=10, \mathrm{C}_{50 \%}=0.376 \mathrm{~g}, \beta=0.40 .$. . $\mathrm{B}-9$

Hazard Slope Ratio $A_{R}$ in Excess of 2.25 . . . . . . B-9

C.1 Estimated Factors of Conservatism and

Variability . . . . . . . . . . . . . . . C-14

C.2 Comparison of Achieved Safety Factor with Required
Safety Factor for Low-Ductility Failure Mode . . c-15 


\section{LIST OF TABLES (Continued)}

Table

Page

c. 3 Comparison of Achieved Safety Factor with Required Safety Factor for Ductile Failure Mode . . . . . . . . . . . . . . C-16

D.1 Elastic Response to Reference 1.0g NUREG/CR-0098 Spectrum . . . . . . . . . . . . . D-9

F.1 Spectral Amplification Factors for Horizontal Elastic Response . . . . . . . . . . . . . F-27

F.2 Hydrostatic and Hydrodynamic Pressures at Various Locations Above Base. . . . . . . . . F-28

F.3 Base Moment Capacity for the Unanchored Tank. . . . F-29

F.4 Base Moment Capacity for t'ie Partially Anchored

Tank . . . . . . . . . . . . . . F-30 
1.1 A Typical Single-Shell Tank . . . . . . . . . . 1-8

1.2 A Typical Double-Shell Tank . . . . . . . . . . 1-8

1.3 Tank with a Central Column . . . . . . . . . . . 1-9

1.4 Tank with Concentric Columns . . . . . . . . . . . . 1-10

1.5 Tank with Concentric Columns and other Superstructures . . . . . . . . . . . . . . 1-11

1.6 Free Standing Tank . . . . . . . . . . . . . 1-12

1.7 A Typical Bin Set . . . . . . . . . . . . . 1-13

3.1 Typical Probabilistic Seismic Hazard Curve . . . . 3-40

3.2 Other Representative Probabilistic Hazard Curves . . 3-41

4.1 Systems Considered . . . . . . . . . . . . . 4-52

4.2 Dimensionless Functions in Expressions for

Impulsive and Convective Components of

Hydrodynamic Wall Pressure for Tanks with

$\mathrm{H}_{\ell} / \mathrm{R}=0.75 \quad$. . . . . . . . . . . . . . . . 4 4-53

4.3 Dimensionless Functions in Expressions for

Impulsive and Fundamental Convective components

of Hydrodynamic Base Pressure for Tanks with

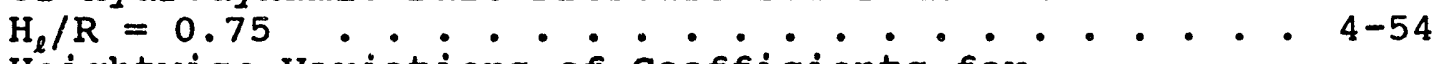

4.4 Heightwise Variations of Coefficients for

Bending Moments Across Normal Sections of

Tanks with Different Conditions of Support at

the Top; $\mathrm{H}_{\ell} / \mathrm{R}=0.75$.............. . . 4-55

4.5 Forces Transmitted by Tank to supporting

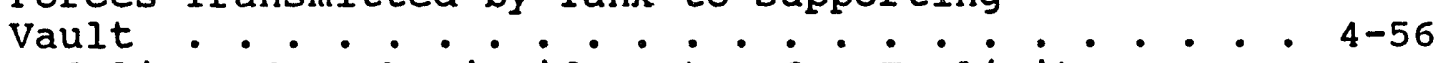

4.6 Modeling of Tank-Liquid System for Explicit

Purpose of Evaluating Total Hydrodynamic

Forces Transmitted to Supporting Vault . . . . . . 4-57

5.1 Example Tank . . . . . . . . . . . . . . . . . 5-32

5.2 Increase in Axial-Compressive Buckling-stress

Coefficient of Cylinders Due to Internal

Pressure . . . . . . . . . . . . . . . 5-33

5.3 Vertical Loading on Tank Wall at Base . . . . . . 5-34

5.4 Schematic Illustration of Anchor Tank Bottom

Behavior at Tensile Region of Tank Wall . . . . 5-35

5.5 Schematic Illustration of Unanchored Tank

Bottom Behavior at Tensile Region of Tank

Wall. . . . . . . . . . . . . . 5-36

6.1 Model for Tank-Fluid System . . . . . . . . . . 6-24

A.1 Typical Probabilistic Seismic Hazard Curves . . . A-18

D.1 Three Story Shear Wall structure . . . . . . . . D-10 


\section{IIST OF FIGURES (Continued)}

Figure

Page

F.1 Example Tank . . . . . . . . . . . . . F-31

F.2 Elastic Design Spectrum, Horizontal Motion... . F-32

G.1 Lumped Parameter SSI Model . . . . . . . . . G-11

G.2 Amplification of Free Field Motion Resulting

from SSI Effects.............. G-12 


\section{ACKNOWLEDGMENTS}

The authors interacted with a number of individuals and organizations in the course of preparing the guidelines presented in this report. These interactions focused on the characterization of waste storage tanks, vaults and their contents; the definition of the topics to be addressed in the report; and the effect of the proposed criteria on the safety evaluation of existing tanks and the design of new tanks. The authors gratefully acknowledge the support, technical assistance and review comments received from this group. The following is a list of the major contributors:

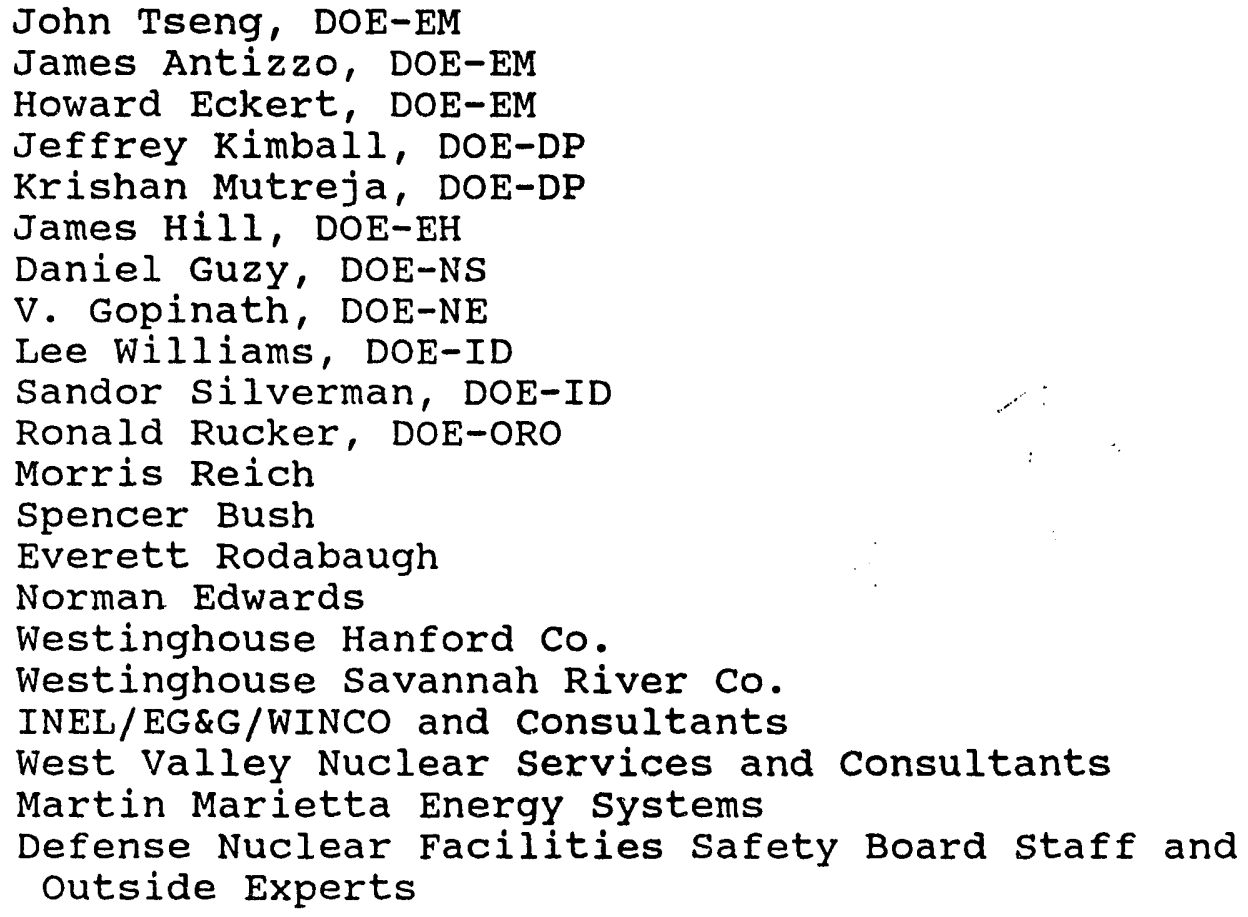

The authors also thank Marjorie Chaloupka for her dedicated role in preparing this report. 
CHAPTER 1

INTRODUCTION

\subsection{BACKGROUND}

A large number of high-level waste (HLW) storage tanks and bins exist at various DOE facilities. These tanks and bins are mostly underground and contain large quantities of radionuclides. General guidelines, such as DOE order $6430.1 \mathrm{~A}$ (Reference 1.1) and UCRL-15910 (Reference 1.2), are available to perform seismic evaluations of DOE facilities. Specific criteria are required, however, for application to the underground HLW tanks. In addition, seismic analysis procedures and acceptance criteria are needed for design of new tanks. This report has been prepared in response to these needs, and provides guidelines for seismic evaluation of existing tanks and design of new ones.

\subsection{TANK FARMS}

The primary purpose of the HLW tanks is to store the waste for a temporary period awaiting further processing and permanent disposal. They contain liquid waste of various density and viscosity levels. Suspended solid particles tend to settle towards the bottom of the tank and, in many instances, develop "sludge" or "saltcake" underneath the liquid supernatant.

Tanks are typically built in clusters and maintained in an area called a "tank farm." A tank farm contains a group of tanks placed side-by-side in both directions and separated from each other by a soil barrier of width 15-25 feet. The tank structures are basically of two different designs: single-shell and double-shell. A single-shell tank is a completel/ enclosed cylindrical reinforced concrete structure lined ith steel plates along the wetted perimeter (Figure 1.1). A double-shell structure consists of a completely enclosed steel tank within a 
reinforced concrete tank or vault (Figure 1.2). The steel tank contains the waste and the concrete vault retains the soil pressure and may also act as a secondary confinement.

There are variations of these two basic designs. For example, instead of a domed roof as shown in Figures 1.1 and 1.2 , some tanks are designed with flat roofs supported by a single or a group of concentric columns (Figures 1.3, 1.4 and 1.5). In one tank farm, the steel tanks containing wastes are free-standing similar to above-ground tanks, and are enclosed by pre-cast or cast-in-situ octagonal concrete vaults (Figure 1.6). The unique details of all existing tanks are not necessarily illustrated in these figures. Moreover, the design concept of future tanks may be different. For example, in a new tank farm the primary tanks may be built on a common footing enclosed by a large concrete vault or can have a superstructure such as a weather enclosure. In order to satisfy the confinement regulation, all new tanks are expected to be designed as double-shell structures.

The entire tank structure is below the ground surface with a soil cover up to 10 feet. Most tanks can contain approximately one million gallons of waste. The tank diameter is in the range of 75-80 feet and the maximum height of the iiquid waste is 3040 feet. There are a few smaller tanks. For example, there are tanks with a capacity of $750,000,300,000$ or 55,000 gallons each.

on the other hand, bin sets are used to store processed granular waste such as calcined products. A bin set consists of a cluster of long steel cylinders enclosed in a partially or completely underground reinforced concrete cylindrical structure (Figure 1.7).

\subsection{OVERVIEW OF SEISMIC GUIDELINES}

This report provides guidelines for treating earthquake loading 
in the design and evaluation of HLW storage tanks. The guidelines are applicable to the primary tank, secondary liner, concrete vault, transfer piping and other components that are required to maintain the confinement function of a tank farm. Certain components are specifically addressed in this report and general guidelines are provided for others. The guidelines include a definition of the design basis earthquake ground motion, simplified methods for determination of soil-structure and liquid-structure interaction effects, analytical techniques to compute the member forces, and the structural acceptance criteria. The interpretation and use of the guidelines are illustrated through an example included in this report.

The approach adopted for developing the guidelines is discussed in chapter 2. The guidelines are developed primarily for double-shell tanks due to an immediate need for designing new double-shell tanks. However, some of these guidelines are generally applicable for single-shell tanks as well. Additional work is required to address certain other aspects of the singleshell tanks and various types of waste contents such as viscous liquids and granular solid wastes. This report is expected to be revised for inclusion of these additional criteria when they become available.

The general criteria are described in chapter 3. The seismic criteria aim at achieving, a desired performance goal (e.g., confinement of $\mathrm{HLW}$ ) expressed in probabilistic terms. This performance goal is achieved by use of probabilistic seismic hazard estimates in terms of a site-specific design response spectrum. Thus, the design basis earthquake (DBE) ground motion is determined by correlating probabilistic measures of the performance goal and the seismic hazard. Once the DBE ground motion is obtained, the remaining evaluations such as the structural analysis and design are based on deterministic methods. Acceptable material properties such as strength, 
damping and inelastic energy absorption factors are also discussed in chapter 3. The appropriate load combinations and the corresponding acceptance criteria are also described.

The criteria for evaluation of hydrodynamic effects in tanks are described in Chapter 4. Simplified methods are presented for both rigid and flexible tanks. Since for many of the doubleshell tanks the primary steel tank is supported at the top by the concrete vault structure, formulation is provided for topconstrained as well as free-standing tanks. Results are applicable for wastes of various densities. However, it is assumed that the waste is a non-viscous liquid (i.e., viscosity same as water).

Chapter 5 provides an approach for determination of the seismic capacity of flat-bottom vertical liquid storage tanks. Formulas are presented for both anchored and unanchored tanks. Various failure mechanisms of the tank components are considered. The approach adopted for determination of the capacity requires developing a nominal minimum ultimate strength capacity of the tank and then applying appropriate strength reduction factors that will provide factors of safety consistent with those discussed in Chapter 3 and Appendix $c$.

The criteria for computation of soil pressure due to seismic loads and in-vault response spectra that can be used to qualify equipment are provided in Chapter 6. Simplified methods are described for consideration of the soil-structure interaction effect.

The above chapters concentrate on the tank structure. Evaluation guidelines for underground transfer piping are provided in chapter 7. Guidelines for consideration of potential for liquefaction are also included in this chapter.

Seismic qualification of equipment is discussed in chapter 8. 
The available qualification approaches are described and the applicable standards are cited. The qualification level required to satisfy the general seismic criteria presented in Chapter 3 is also addressed.

The supporting technical information that was used in developing the criteria is presented in the appendices. Appendix $A$ expands on the idea of the performance goal and demonstrates how a desired goal can be achieved by using the basic seismic criteria factors presented in chapter 3. Two typical mean probabilistic seismic hazard curves are used for illustration purposes. Validation of the basic seismic design criteria presented in Appendix $A$ is demonstrated in Appendix B. Appendix $C$ demonstrates how the seismic criteria presented in this report achieve a desired reduction of the ratio of the hazard frequency and the seismic risk frequency. Results are presented for both ductile and low-ductile failure modes. Appendix D includes guidance on estimation of the inelastic energy absorption factor. Appendix $E$ provides formulations for the membrane solution of metal tanks constrained on top. The application of the criteria in computation of the seismic response and tank capacity is illustrated by considering an example in Appendix F. Appendix G provides a set of coefficients that can be used for soil-tank interaction analysis with the help of a lumped parameter model.

\subsection{NOTATION}

A large number of symbols are used in the report to represent various parameters. Attempts were made for being consistent with notation used in national standards and codes and in common literature. A set of general notation is used to denote major parameters (such as force, moment, acceleration, etc.). certain symbols represent more than one parameter; however, due to their unique applications, they are expected to convey clear meanings. The symbols used in various chapters either are made with

$$
1-5
$$


subscripts to the set of general notation and convey the same general meaning or are completely new. In any event, the symbols used in each chapter are separately listed and defined in that chapter after the Reference section and may not be identical with symbols used in other chapters. This provides the flexibility needed for consistency with commonly used notation in a particular field of engineering, such as, seismic hazards, fluid dynamics, soil mechanics and general structural design. Certain minor symbols used for intermediate steps and clearly defined in the text next to the equations are omitted from the notation lists. 


\section{REFERENCES}

1.1 DOE Order 6430.1A, "General Design Criteria", 1989.

1.2 "Design and Evaluation Guidelines for Department of Energy Facilities subjected to Natural Phenomena Hazards", UCRL15910, June 1990 . 


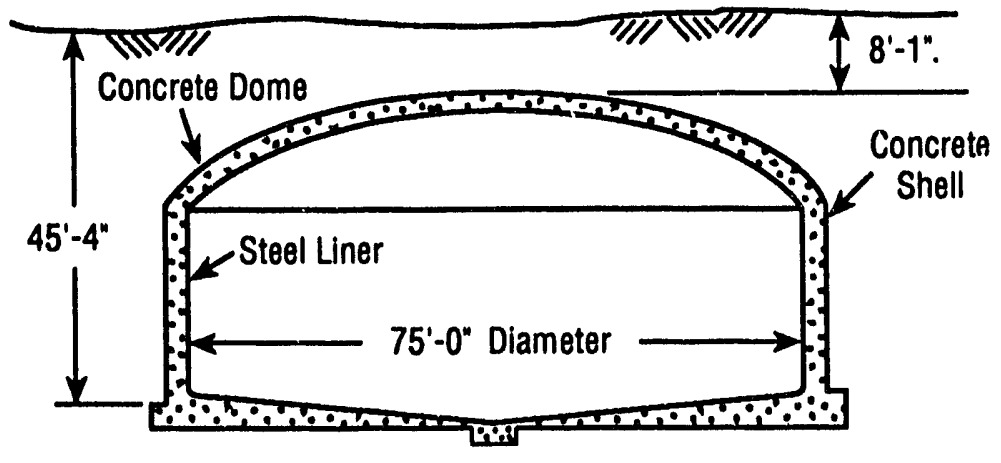

Figure 1.1 A Typical single-shell Tank

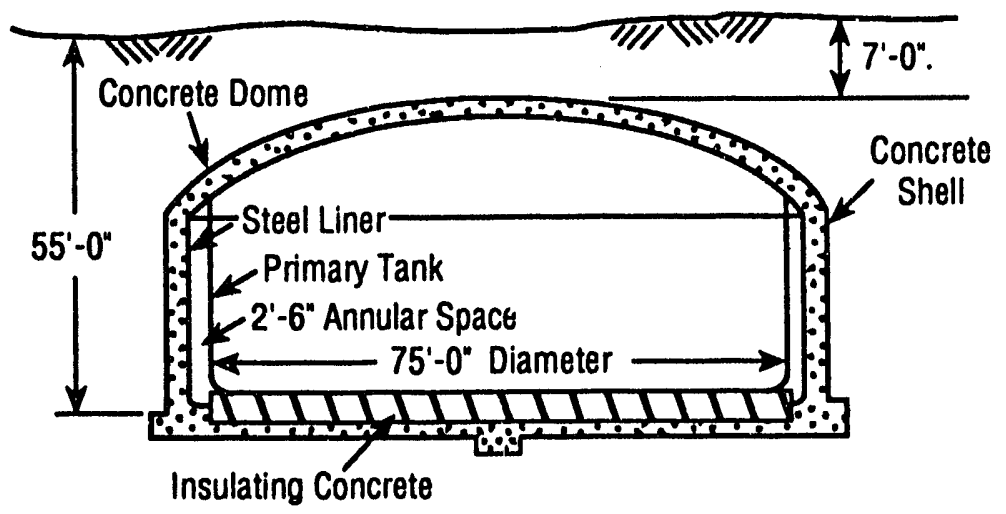

Figure 1.2 A Typical Double-Shell Tark 


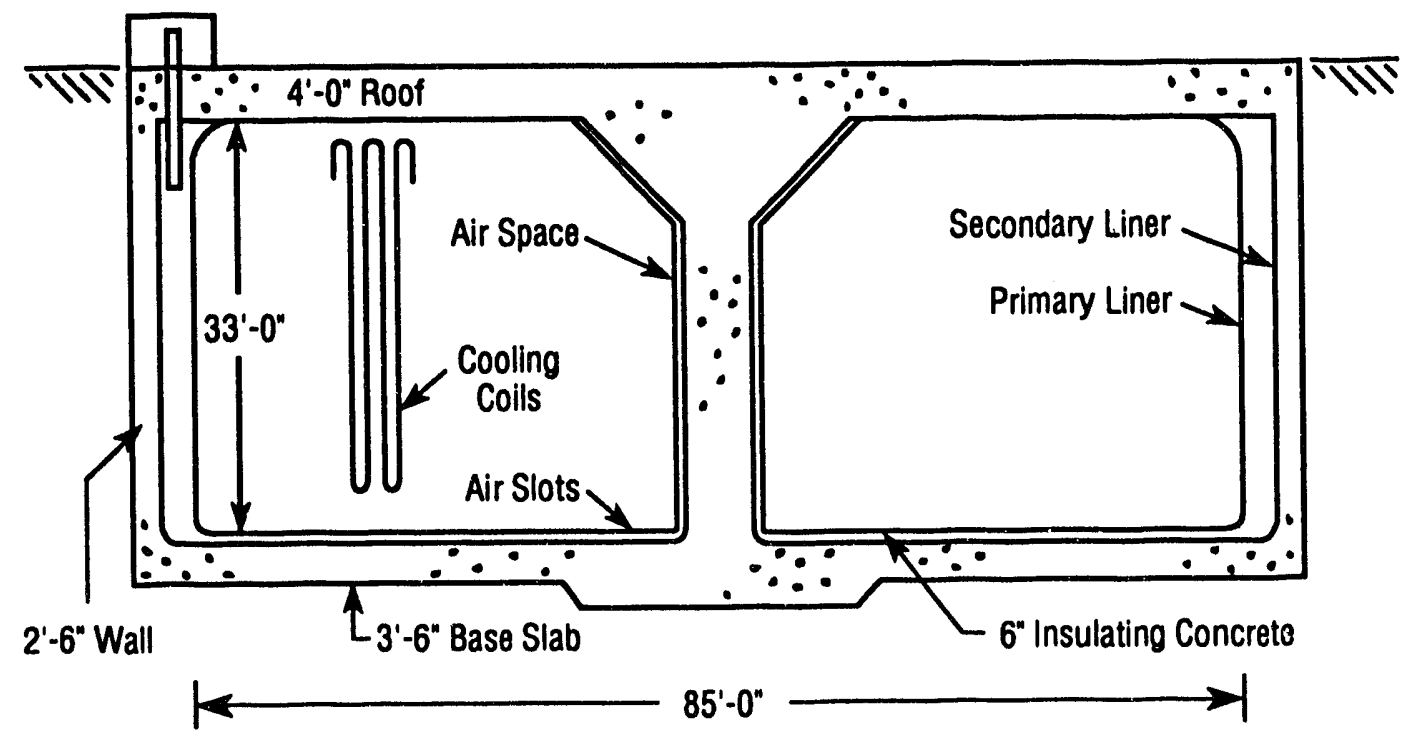

Figure 1.3 Tank with a Central Column 


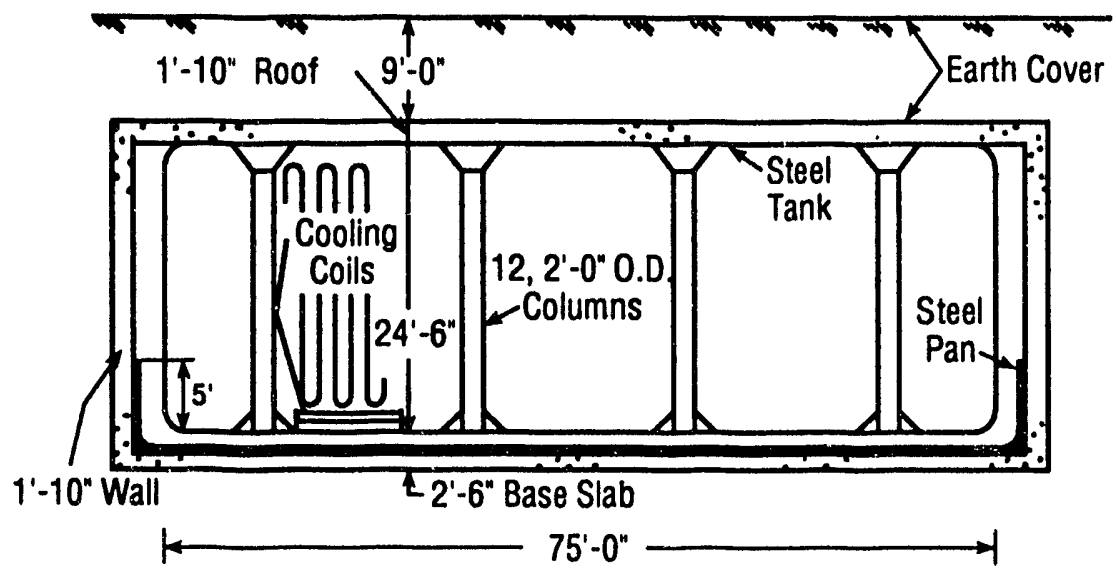

Figure 1.4 Tank with Concentric Columns 


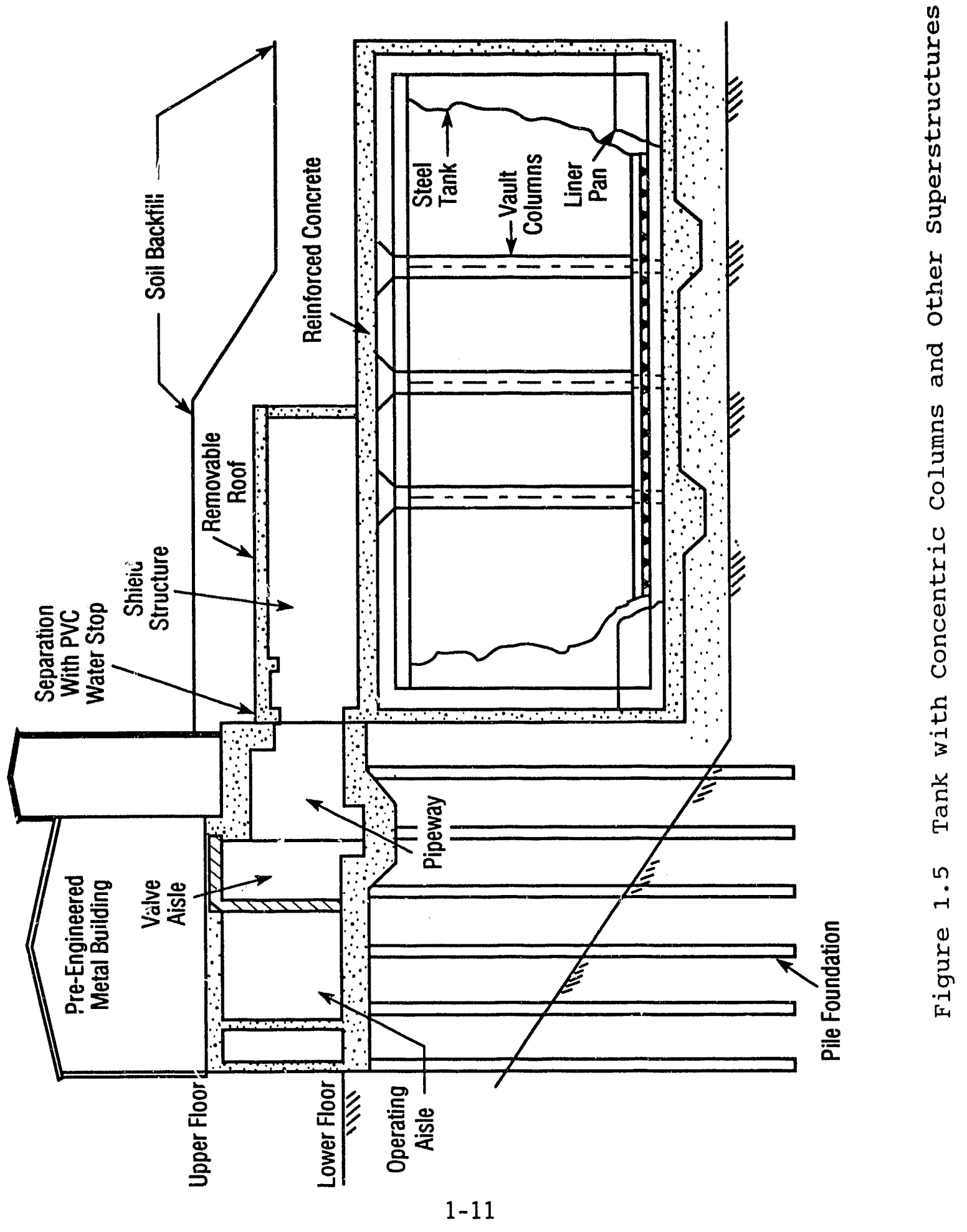




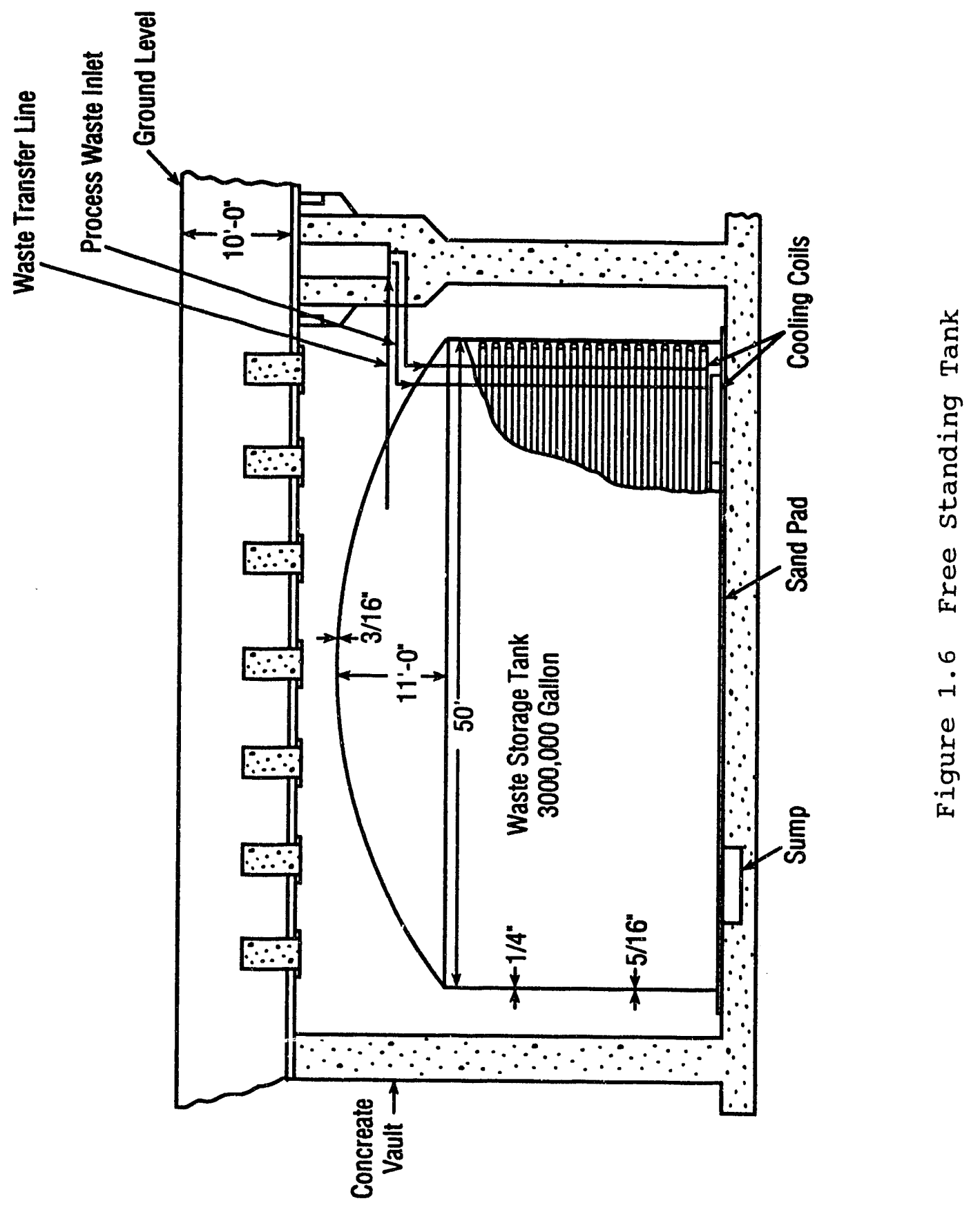




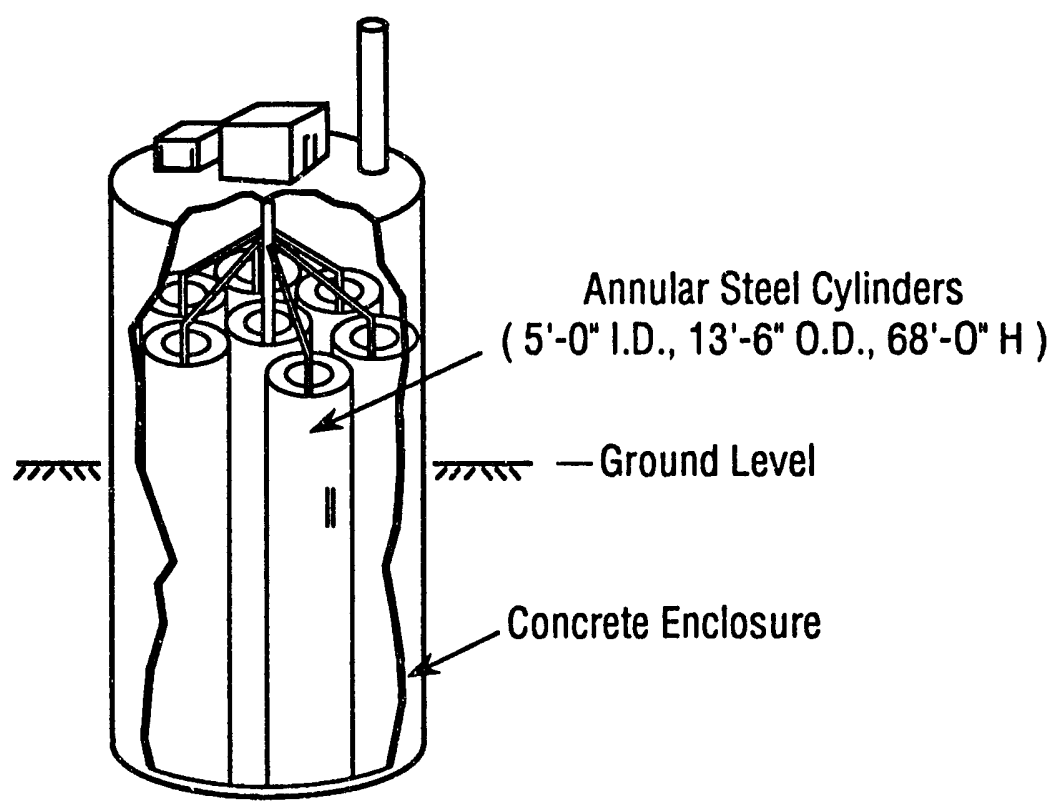

Figure 1.7 A Typical Bin set

$1-13$ 
CHAPTER 2

CONSIDERATIONS IN DEVELOPMENT OF GUIDELINES

\subsection{INTRODUCTION}

The principal philosophy that was considered in developing the seismic design and evaluation criteria is to make maximum use of the existing guidelines. DOE order 6430.1A (Reference 2.1) provides a set of general design criteria for the DOE facilities. UCRL-15910 (Reference 2.2) provides specific guidelines for design and evaluation of DOE facilities due to earthquake and other natural phenomena such as wind and flood. The graded approach adopted in UCRL-15910 is also used and further expanded in this report for developing guidelines for the tanks. other analysis methods, design details and acceptance criteria delineated in the UCRL document are used to the extent they are applicable to the underground tanks. UCRL15910 is intended for general DOE facilities and not specifically prepared for the tanks. Therefore, the next step in the criteria development is to address the special features of the underground tank and bin structures and identify the technical issues that are not addressed by the existing guidelines. The final step in the criteria development is to address the technical issues that have been identified to be unique for the underground tanks and combine the resolutions with the existing guidelines. This chapter contains discussions on the various criteria development steps as discussed above.

\subsection{TECHNICAL ISSUES}

Most of the technical issues that were considered for development of the seismic guidelines are due to unique structural and dynamic features of the underground tanks. Although seismic evaluation techniques for aboveground tanks have greatly advanced since the mid-1970's, and the design 
criteria for these tanks are available, evaluation guidelines for underground tanks are relatively scarce. There are diversities of the tank designs in the DOE tank farms. For example, some tanks are free-standing, some are partially connected to the encasing concrete vaults and some use the concrete vaults as a partial confinement barrier. In addition, the waste contents in many tanks are not necessarily uniform and not completely in the liquid state. Moreover, in many tanks the waste products are believed to have settled forming layers near the bottom. Therefore, the fluid-tank interartion methods available for a dynamic analysis may not be directly applicable to the HLW storage tanks. Furthermore, for certain tanks, crust formation may not allow sloshing as assumed in standard hydrodynamic load calculation methods. These special design features and waste characteristics of the waste storage tanks are not addressed in the existing literature.

The above issues were considered in developing the guidelines presented in this report. The evaluation techniques for aboveground tanks were extended and supplemented with specific design considerations for the underground tanks. Some additional technical issues were considered in this report for development of the criteria since certain guidelines recommended in existing documents such as UCRL-15910 would require updating to incorporate lessons learned from recent studies in these areas.

These technical issues and the extent to which they are addressed by the guidelines presented in this report are briefly discussed in the following paragraphs. A further elaboration of some of these issues is included in the subsequent chapters where the guidelines are provided.

Site-Specific Hazard Curves - The current version of UCRL-15910 (Reference 2.1) recommends the use of site-specific hazard curves for moderate and high hazard facilities, as does the DOE "Interim Position" (Reference 2.3). However, UCRL-15910 permits 
the use of the hazard estimates published in UCRL-53582 (Reference 2.4) for this purpose; but the guidelines presented in this report require more recent hazard curves for HLW storage tanks.

Soil Pressure - Since the tank structures are underground, computation of the soil pressure on tank walls due to an earthquake is an important element of the seismic evaluation. Simplified methods were developed and are presented in this report to determine the soil pressure including soil-structure interaction effects. The simplified methods are based on lumped parameter soil-structure-interaction models that have been used extensively and successfully in seismic response analyses of nuclear power plant facilities. However, the degree of applicability of these models to the broad vaults of relatively small height-to-radius ratios has not yet adequately been assessed. Studies are currently underway to make this assessment and, if necessary, to recommend appropriate improvements.

Liquid Dynamic Loads - The pressure loads in cantilever tanks due to water-type liquid can be determined by use of classical solution techniques available in the literature. However, most of the existing HLW steel tanks are unanchored at the base and some are attached to the concrete enclosure on top. In order to address such special characteristics, techniques were developed for solution of top-constrained tanks and are described in the report. The liquid wastes in most HLW storage tanks contain suspended solids and, in many instances, become viscous or even semi-solid materials if remain stored for a long time. The density of the waste product typically varies over the depth as a result of chemical reaction, crystallization and settling of suspended solid particles. The formulation presented in this report was derived for non-viscous uniform water-type liquids. Viscous liquids are expected to manifest higher damping, and

$$
2-3
$$


produce lower sloshing and a greater liquid mass participating in the impulsive mode. A sufficiently viscous liquid may even transfer shear directly to the base. An analytical study indicates that for liquids with viscosity up to 10,000 centipoise (CP)* the change in the liquid dynamic characteristics is insignificant (Reference 2.5). The applicability of the results to other waste characteristics will be addressed by a future revision of this report.

Unanchored Tanks - As mentioned above, available classical methods provide solution only of anchored tanks. The evaluation of the seismic demand for unanchored tanks is considerably more complex than for anchored systems, and the available methods of analysis have not yet reached the levels of sophistication and simplicity required for design applications. The seismic response of the tank-liquid system in this document is computed on the assumption that the tank is anchored at the base so that it cannot slide or uplift. On the other hand, the seismic capacity of the tank is evaluated for both anchored and unanchored conditions, giving due regard to the nonlinear resistance of the uplifting base. The combination of approaches employed herein is believed to be sufficiently accurate for design of both anchored and unanchored tanks and to lead to conservative results.

Single-Shell Tanks - As described in Chapter 1, the concrete enclosure of a single-shell tank retains the soil pressure as well as contains the liquid waste. Thus, the concrete wall is subjected to two opposing static pressure loads. However, in a dynamic situation, the time phasing of these two pressure components will determine whether they should be additive. This aspect was not addressed in this report and requires further

\footnotetext{
"It is believed that a viscosity level of $10,000 \mathrm{CP}$ represents an upper-bound value for the currently available liquids in many tank farms. The sludge at the bottom of the tank, of course, can have a higher viscosity level and could be considered as an elastic solid.
} 
study. However, a design based on two separate considerations, namely the soil pressure without the liquid pressure and the liquid pressure without the soil pressure will be conservative. This will be further discussed in a subsequent revision to this report.

Granular Materials in Bins - Bins contain a granular material obtained as a result of processing the liquid waste. This material will produce dynamic pressure in a bin to some extent similar to the hydrodynamic (impulsive) pressure in a tank. However, a part of the inertia load of the bin content can be transferred directly to the base. This aspect is not addressed in this report and requires further study. However, in the absence of a more refined set of criteria, the mass of the entire quantity of the granular material can be conservatively used to determine the dynamic pressure on the bin walls.

Underground Piping - Acceptance criteria for underground piping are not explicitly discussed in current versions of available piping codes. Procedures to evaluate stresses and strains induced in underground piping and conduit from seismic effects together with criteria to be used as a basis for acceptance are presented in this report. Analysis procedures to be used to assess both transient effects due to wave passage and support point movements as well as long term permanent ground displacements are considered in the evaluation. Modifications to current procedures have been recommended to include seismic effects within the criteria. since stresses induced in underground piping are considered as self-limiting by the induced ground displacements, these modifications have been based on consideration of seismic-induced stresses as secondary and modifications to the acceptance criteria made to those sections of the applicable codes treating these load types. 


\section{REFERENCES}

2.1 DOE Order 6430.1A, "General Design Criteria," 1989.

2.2 "Design and Evaluation on Guidelines for Department of Energy Facilities Subjected to Natural Phenomena Hazards," UCRL-15910, June 1990.

2.3 Interim Standard on "Use of Lawrence Livermore National Laboratory and Electric Power Research Institute Probabilistic Seismic Hazard Curves," Department of Energy Seismic Working Group, Issued in March 1992.

2.4 Natural Phenomena Hazards Modeling Project: "Seismic Hazards for Department of Energy Sites," UCRL-53582, Rev. 1,1984 .

2.5 "Effect of Viscosity on Seismic Response of Waste storage Tanks," Argonne National Laboratory Report ANL/RE-92/2, June 1992 . 


\section{CHAPTER 3}

\section{SEISMIC CRITERIA}

\subsection{INTRODUCTION}

The objective of seismic design is to limit the likelihood of unacceptable performance to a specified, low value. In this document it is presumed that such a specified value (or, possibly, suite of values for different components and structures) has been provided to the seismic design team by those responsible for overall project safety. This specified performance value depends on factors such as the consequences of failure. Unfortunately, future seismic ground motions, as well as structure and component responses and capacities, are subject to varying degrees of randomness and uncertainty, complicating the development of simple, but accurate design procedures.

The engineering challenge is to achieve the performance goals, i.e., the specified low probabilities of failure, in a practical, cost-effective manner in the face of these multiple uncertainties. This chapter provides the guidance to meet this objective successfully.

After a discussion of the nature of the problem, Chapter 3 presents a design or evaluation scheme that separates the problem into its customary two phases: (1) the design basis earthquake ground motion (DBE) and (2) the response and capacity criteria. The former element is discussed in section 3.3. Sections 3.4 to 3.9 present a set of practical response and capacity criteria that together with the DBE defined in section 3.3 will meet any specified performance goal. Finally, sections 3.10 and 3.11 (supported by Appendices A, B and C) present the basic criterion, reasoning and analysis underlying these recommendations, as well as permissible alternatives and generalizations that will achieve the same performance goals. An application of these concepts and 
generalizations will not only confirm the technical soundness of the criteria and factors outlined in sections 3.3 through 3.9, but also lead to alternative analysis procedures that may prove more effective in particular circumstances.

\subsection{FUNDAMENTAL CONCEPTS}

Elementary structural safety theory (e.g., Reference 3.1) as practiced, for example, in seismic probabilistic risk assessments (PRAs), requires that calculations of the failure probability for a given design be conducted by a formal integration of the probability distributions of the loads and capacities. This probability can then be compared to the specified performance goal to establish design adequacy. Such an integration will properly reflect the uncertainties in both major elements of the problem. Practical design demands simpler, more direct procedures, however. The challenge in developing complete seismic criteria is to provide that direct ("deterministic") analysis format while recognizing both the probabilistic nature of the seismic hazard, as reflected in the site's seismic hazard curve, and the documented variability in dynamic responses, material properties, and structural capacities. This challenge has been addressed with varying degrees of success in the various available sets of seismic criteria. Never before, however, have they been as explicitly developed as they are in this document. The criteria below address directly the following two major criteria-development difficulties: (1) the seismic hazard curve varies significantly from site-to-site, both in level and in shape, implying not only that the DBE level must be adjusted to the site, but also that any value of load factor (or strength reduction factor) will imply different levels of risk reduction at different sites; and (2) the total degree of uncertainty in the capacity variable (associated with responses, material strengths, and other factors) varies from location-tolocation (within a structure), from material-to-material, etc. 
(This degree of uncertainty is commonly measured by a coefficient of variation' or similar dimensionless quantity.)

The procedure outlined in this chapter requires the specification of two probability-related factors; together they will achieve the specified performance goal, i.e., keep below $P_{F}$, the allowable $\left(\right.$ mean $\left.^{2}\right)$ annual probability of unacceptable performance i.e., of faijure. The first factor is $P_{H}$, the (mean) hazard or annual probability of exceedance associated with a reference-level earthquake $^{3}$. The second is a risk or probability reduction factor, $R_{R}$ to be associated with the acceptance criteria. The more conservative these criteria the larger $R_{A}$. The values of $P_{H}$ and $R_{A}$ should generally be selected such that:

$$
P_{H}=\left(R_{R}\right)\left(P_{F}\right)
$$

This condition states in probabilistic terms, i.e., $P_{F}=P_{H} / R_{R}$, the obvious fact that the same safety can be achieved by many combinations of design earthquake level and acceptance criteria, provided that, when one is made less conservative, the other is made appropriately more conservative in order to compensate.

'The coefficient of variation is defined as the standard deviation divided by the mean. In seismic PRA analysis it is common to use, instead, the standard deviation of the natural $\log$ of the variable, denoted $\beta$. For $\beta$ less than about 0.3 the two coefficients are comparable in numerical value.

${ }^{2} \mathrm{As}$ is common elsewhere (e.g., in the NRC Quantitative safety Goals), we assume that the mean probability of fallure will be specified. This implies that the uncertainty in this probability induced by currently limited data and professional knowledge (i.e., "epistemic uncertainty" as distinct from natural randomness or "aleatory" uncertainty) will be addressed by averaging over that uncertainty. This uncertainty in seismic hazard curves is unusually large; it is captured in these criteria by using mean hazard curves. This mean is the average over the uncertainty in the hazard (probability) estimate. See Ref. 3.13 .

\footnotetext{
${ }^{3}$ We avoid here calling this earthquake level the Design Basis Earthquake, DBE, because, as will be seen in section 3.3, while in some cases $P_{H}$ will directly define the DBE level, in others, an alternative, somewhat larger level will be necessary for the DBE level in order to achleve the performance goal.
}

$$
3-3
$$


It is presumed here, recall, that the seismic engineering team has been given a value for $P_{F}$, the performance goal. This value may depend on the implications of the failure of the component, the redundancy of the system, the marginal cost of strengthening the component (versus another parallel component in the same system), the remaining design life, etc. This performance goal ultimately reflects the safety goals of the DOE (References 3.2 and 3.3 ).

The procedures in this document grant the flexibility of selecting one or more pairs of values of $P_{H}$ and $R_{R}$ to meet the goal, $P_{F}$. Typical values of $R_{h}$ considered are 5, 10, and 20 . One advantage of this flexibility is that the engineer can keep the same seismic input level while consistently and easily adjusting the acceptance criteria for components with different performance goals (within a factor of 4 , at least). Alternatively, one can keep the same criteria and adjust the earthquake.

Readers familiar with the DOE seismic criteria in the UCRL-15910 (Reference 3.4) will recognize this general format. In that document performance goals ( $P_{F}$ values) of $10^{-5}$ to $2 \times 10^{-4}$ are suggested for the more critical facilities. The document then defines conservative seismic acceptance criteria aimed at achieving risk reduction factors, $R_{h}$, of about $5 ; 10$, and 20 . The users are free to choose whichever set of criteria they wish. Reference 3.4 then recommends establishing the DBE by entering the seismic hazard curves at an annual probability of exceedance of $P_{H}=\left(R_{H}\right)\left(P_{F}\right)$. For example, if the specified performance goal for a structure or component is $10^{-5}$ and the selected set of acceptance criteria are associated with an $R_{R}$ of 20 , then the $D B E$ should be that with an annual probability of exceedance of $2 \times 10^{-4}$ (i.e., a mean return period of 5000 years). The criteria in this document follow this same philosophy. They supplement UCRL-15910 by providing criteria and procedures for underground high-level waste storage tanks. They also amplify UCRL-15910 by providing a more explicit, rigorous basis for the specification, of the acceptance criteria and the 
selection of the DBE; the development of this basis has demonstrated the need to make certain refinements in the UCRL-15910 process. These developments insure, for example, that the procedures are consistent over a broader range of hazard curve shapes. It is expected that these improvements will be made in a forthcoming revision of UCRL-15910.

once the values of $P_{H}$ and $R_{R}$ have been established, the design or evaluation of an existing component or structure follows straightforward procedures. Section 3.3 details the selection of the DBE earthquake consistent with $P_{H}$ (and, possibly $R_{R}$, as will be seen). The seismic acceptance process may have one of various forms. While more general processes are possible (see, sections 3.10 and 3.11), the bulk of this chapter (sections 3.4 to 3.9 ) is dedicated to a conventional process based on deterministic factors ${ }^{4}$ and pseudo-linear analysis. One of these factors depends explicitly on $R_{R}$. While the procedure in sections 3.4 and 3.9 has been chosen because of its familiarity to those experienced in seismic design and evaluation of commercial nuclear power plants ind other critical facilities, certain of the factors and details have been adjusted by the authors to better approximate the specified $R_{R}$ factors.

The primary steps in the procedure outlined in sections 3.4 to 3.9 are:

A. Perform a inear elastic seismic response analysis for the DBE ground motion to determine the elastic-computed seismic demand $D_{\text {se }}$ in accordance with sections 3.4 and 3.5 .

\footnotetext{
"By "deterministic" it is meant that for simplicity the specification of the values of the coefficients of variation and even, largely, particular percentiles is avoided. That this can be done without significant loss of generality or accuracy is one of the facts demonstrated is this document, in appendices to be cited.
} 
B. Establish the code ultimate capacities $c_{c}$ for all relevant failure modes for each component being evaluated in accordance with sections 3.6 and 3.7 .

c. For each failure mode of each component define the maximum permissible inelastic energy absorption factor $F_{\mu D}$ by which the elastic-computed seismic demand may exceed the code ultimate capacity in accordance with section 3.9 .

D. Divide the elastic-computed seismic demand $D_{\text {se }}$ by the appropriate inelastic energy absorption factor $F_{\mu D}$ and multiply by a seismic load factor $L_{s}$ to define an inelastic-factored seismic demand $D_{s i}$. This inelastic-factored seismic demand $D_{s i}$ is then combined with the "best-estimate" of the concurrent non-seismic demands $D_{n s}$ to obtain a total inelastic-factored demand $D_{t 1}$ which must be less than the code ultimate capacity $C_{c}$. This step is defined by Equation 3.4 through 3.6 of Section 3.8 .

The criteria presented are primarily based upon the judgment and experience of the authors as being appropriate to roughly achieve these seismic risk reductions. However, great rigor or quantitative accuracy in achieving these seismic risk reduction factors should not be implied. The factors merely served as target goals in developing the criteria.

The seismic criceria presented herein are considered to be sufficiently conservative to guard against damage from subsequent aftershocks with ground motion less than the DBE.

Although it is envisioned that most users will prefer to follow the deterministic pseudo-linear seismic evaluation procedure of Sections 3.4 through 3.9 as outlined in the above four steps, a more general basic seismic criterion and a general approach to demonstrate compliance are presented in section 3.10 in terms of an acceptable probability of failure capacity. This basic seismic 
criterion and alternate general approach to demonstrate compliance are presented for two reasons:

1. To enable the user to define more sophisticated alternate acceptance criteria than those presented in sections 3.4 through 3.9 when the user has a sufficient basis to develop and defend these alternate criteria.

2. To provide a basis upon which the seismic criteria of section 3.4 through 3.9 were developed.

Lastly, section 3.11, together with Appendix C, uses this basic seismic criterion of section 3.10 to benchmark the adequacy of the factors used in the deterministic pseudo-linear seismic evaluation procedure defined in sections 3.4 through 3:9.

\subsection{DESIGN BASIS EARTHQUAKE GROUND MOTION}

\subsubsection{Probabilistic Definition of Ground Motion}

Given a seismic hazard curve for the site, such as the example in Figure 3.1, it is straightforward to enter the curve at the value $P_{H}$ (which equals $R_{R} P_{F}$ ) and read off the corresponding level of the ground motion parameter [which is peak ground acceleration (PGA) in Figure 3.1]. For example, if $P_{F}$ is specified to be $10^{-5}$ and $R_{R}$ is selected to be 10 , then $P_{H}$ is $10^{-4}$, and the DBE PGA is $0.3 \mathrm{~g}$ at the sites characterized by Figure 3.1. This is the same simple procedure used in UCRL-15910.

It has been confirmed in the development of this document that this procedure is adequate provided the shape of the hazard curve is close to that in Figure 3.1. In particular, the simple procedure is adequate provided that in the range of interest, i.e., in the $10^{-4}$ to $10^{-5}$ range for high-level waste storage, the shape of the curve is such that reduction in $P_{H}$ by an order of magnitude, e.g., $10^{-4}$ to $10^{-5}$, leads to approximately a doubling of the ground motion level. 
An adjustment to the procedure is required, however, if this approximate doubling does not characterize the site's hazard curve. To make this modification a ground motion ratio, $A_{R}$, is introduced as follows:

$$
A_{R}=\frac{a_{0.1 P H}}{a_{P H}}
$$

in which $a_{P H}$ is the ground motion level at the exceedance frequency, $P_{H}$, at which the $D B E$ is to be defined, and $a_{0.1 P H}$ is the ground motion level corresponding to a factor of ten reduction in this annual exceedance frequency. For example, if it is recommended that the DBE be defined at the $2 \times 10^{-4}$ annual exceedance frequency, $A_{R}$ is the ratio of ground motion at $2 \times 10^{-5}$ to that at $2 \times 10^{-4}$. For Figure $3.1, A_{R}=0.5 \mathrm{~g} / 0.24 \mathrm{~g}=2.08$, which is close to two.

This ratio $A_{R}$ may sometimes differ significantly from two. Figure 3.2 presents two representative probabilistic seismic hazard curves expressed in terms of mean annual probability of exceedance versus peak ground acceleration. Curve A represents a hazard estimate for a western U.S. site. Curve B represents a typical hazard estimate for an eastern (lower seismicity) site. For Curve A (the western site), $A_{R}$ is 2.0 and 1.67 over the $10^{-3}$ to $10^{-4}$, and the $10^{-4}$ to $10^{-5}$ ranges, respectively. For curve $B$ (the eastern site), $A_{R}$ is 2.31 and 2.13 over these same ranges. These results are typical. For western U.S. (or higher seismicity) sites, the ratios for mean hazard curves have been seen to range from about 2.0 to as low as about 1.5 within the probability range from $10^{-3}$ to $10^{-5}$. For eastern U.S. (or lower seismicity sites), the corresponding $A_{R}$ values usually range from about 2.0 to as high as about 3.75 .

Furthermore, as seen in the examples, at any one site, $A_{R}$ is not constant over probability ranges that differ by an order of magnitude; $A_{R}$ reduces as the exceedance probability is lowered. Because of this fact adjustments may have to be made for some components whose $P_{F}$ and/or $P_{H}$ values differ.

$$
3-8
$$


As will be discussed in section 3.10, $A_{R}$ ratios ranging from 1.5 to 3.75 can be accurately and slightly conservatively accommodated by defining the DBE as the larger of $a_{P H}$ and $f_{a} a_{P F}$, in which $a_{P H}$ and $a_{P F}$ are the ground motion levels at the seismic hazard probability, $P_{H}$, and performance goal probability, $P_{F}$, respectively, and in which $f_{a}$ is an empirically derived adjustment factor defined as 0.45, 0.50, and 0.55 for $R_{R}=20,10$, and 5, respectively. symbolically,

\begin{tabular}{|c|c|}
\multicolumn{1}{c}{$D B E \geq a_{P H}$} \\
$D B E \geq f_{a} a_{P F}$ \\
\hline$R_{R}$ & $f_{a}$ \\
\hline 20 & 0.45 \\
10 & 0.50 \\
5 & 0.55 \\
\hline
\end{tabular}

It is expected that $A_{R}$ will virtually always lie within the range of 1.5 to 3.75 . However, even if $A_{R}$ lies outside this range, the larger of the results from Equations $3.3 \mathrm{a}$ and $3.3 \mathrm{~b}$ should be used to define the DBE ground motions.

Table 3.1 presents some example applications of Equations 3.3 a and $3.3 \mathrm{~b}$ for both the curve $A$ and Curve $B$ probabilistic hazard curves shown in Figure 3.2. For use in these examples, the following peak ground accelerations (PGA) can be read from Figure 3.2:

\begin{tabular}{|c|c|c|}
\hline \multirow{2}{*}{$\begin{array}{c}\text { Exceedance } \\
\text { Probability }\end{array}$} & \multicolumn{2}{|c|}{ PGA (g) } \\
\cline { 2 - 3 } & Curve A & Curve B \\
\hline \hline $1 \times 10^{-3}$ & 0.30 & 0.13 \\
$2 \times 10^{-4}$ & 0.50 & 0.24 \\
$1 \times 10^{-4}$ & 0.60 & 0.30 \\
$1 \times 10^{-5}$ & 1.00 & 0.64 \\
\hline
\end{tabular}

\subsubsection{Design Basis Earthquake Response Spectra}

The DBE ground motion at the site shall be defined in terms of smooth and broad frequency content response spectra in the 
horizontal and vertical directions defined at a specific control point. In most cases, the control point should be on the free ground surface. However, in some cases it might be preferable to define the DBE response spectra at some other locations. One such case is when a soft (shear wave velocity less than 750 feet/second), shallow (depth less than 100 feet) soil layer at the ground surface is underlain by much stiffer material. In this case, the control point should be specified at the free surface of an outcrop of this stiffer material. Wherever specified, the breadth and amplification of the DBE response spectra should be either consistent with or conservative for the site soil profile, and facility embedment conditions.

Ideally, it is desirable for the DBE response spectrum to be defined by the mean uniform hazard response spectrum (UHS) associated with the seismic hazard annual frequency of exceedance specified in section 3.2 above and Reference 3.4 over the entire natural frequency range of interest (generally 0.5 to $40 \mathrm{~Hz}$ ). Currently, however, considerable controversy exists concerning both the shape and amplitude of such mean UHS $^{5}$.

First, many existing mean UHS shapes are not consistent with response spectrum shapes derived from earthquake ground motion recordings. The DBE response spectrum should be consistent in shape with response spectrum shapes from ground motion recorded

\footnotetext{
${ }^{5}$ The UHS associated with using a specified mean hazard is not, precisely, the mean spectral velocity associated with a specified hazard. The distinction is directly analogous to the difference between the regression of $Y$ on $X$ versus that of $X$ on $Y$. See any elementary statistics text. Therefore we should perhaps use the terms "mean" UHS, "mean" PGA, etc., to denote the former values, i.e., those spectral or other values read from mean hazard curves. For simplicity, however, we shall drop the quotation marks. Incidentally, it should be emphasized that mean here refers to averaging over uncertainty in the estimation of hazard/probability. These "mean" uHs are not to be confused with the mean spectrum given a specified magnitude and distance, or the mean spectrum given a specified PGA. These two concepts, with counterparts such as median and 84 percentile spectra, are very common in earthquake engineering; the means, medians, and 84-percentiles represent in these cases distributions over repeated events or records, a variability included explicitly within the hazard analysis.
}

$$
3-10
$$


at similar sites for earthquakes with magnitudes and distances similar to those which dominate the seismic hazard at the specified annual frequency. Unless it can be demonstrated that the mean UHS shape is consistent with the response spectrum shapes obtained from appropriate ground motion records, mean UHS should not be used.

Second, even for a specified ground motion parameter such as peak ground acceleration (PGA) or peak ground velocity (PGV), the estimate for a given mean hazard or exceedance probability, $\mathrm{P}_{\mathrm{H}}$, tends to be unstable between different predictors and tends to be driven by extreme upper bound models. Mean ground motion estimates should be used only when such estimates are stable. Mean estimates outside the range of 1.3 to 1.7 times the median estimate are likely to suffer from the above problems.

Because of these issues with regard to both mean estimates and UHS, the Department of Energy has published a draft interim position on the use of probabilistic seismic hazard estimates (Reference 3.5). The following recommendations have been adapted from Reference 3.5 :

1. When a stable mean estimate of the PGA and PGV does not exist, then a surrogate mean DBE PGA and PGV set at an appropriate factor times their median estimates at the appropriate seismic hazard annual frequency of exceedance should be used. Reference 3.5 defines an approach which may be used to obtain an acceptable median estimate from existing eastern U.S. seismic hazard study results, and it defines this surrogate median-to-mean factor.

2. The DBE response spectrum is then defined by a smooth, deterministic, broad-frequency-content, median ${ }^{6}$ response

\footnotetext{
${ }^{6}$ The word median here refers to the median with respect to a suite of records. See the previous footnote.
} 
spectrum shape scaled so as to be anchored to the surrogate mean DBE PGA and PGV values defined in step 1.

Preferably, the median deterministic DBE response spectrum shape should be site-specific and consistent with the expected earthquake magnitudes, and distances, and the site soil profile and embedment depths. Reference 3.5 provides an acceptable approach for estimation of the earthquake magnitudes and distances to be used in defining this median deterministic sitespecific response spectrum shape. When a site-specific response spectrum shape is unavailable then a median standardized spectral shape such as the spectral shape defined in NUREG/CR0098 (Reference 3.6) may be used so long as such a shape is either reasonably consistent with or conservative for the site conditions.

The median site-specific response spectrum shape may be derived from any combination of the following:

a) the median response spectrum shape from a suite of actual ground motion records associated with reasonably similar magnitudes, distances, and site soil profiles.

b) regression equations defining median spectral amplifications at various natural frequencies as a function of the magnitude, distance, and soil profile.

c) band-width limited random vibration models benchmarked against response spectra from actual ground motion records associated with magnitudes, distances, and soil profiles as similar to the site as practical.

In some cases the mean DBE PGA and PGV may be associated with different controlling earthquakes in which the PGA is controlled by a lower magnitude local earthquake while the PGV is controlled by a larger magnitude more distant earthquake. In these cases it is preferable to develop separate DBE response 
spectra for each of the two controlling earthquakes in lieu of a single enveloped DBE response spectrum. This alternative is particularly appropriate when site-specific spectra shapes are used rather than a standardized spectral shape, and the sitespecific spectral shapes differ substantially for the two controlling earthquakes. In this case, the local earthquake spectral shape should be anchored to the mean DBE PGA, and the more distant earthquake spectrum shape should be anchored to the mean DBE PGV. Both spectra may then be used separately in the seismic response analysis with the largest of the separately computed responses being used to define the seismic demand. of course, alternately, the two DBE response spectra may be enveloped by a single combined DBE response spectrum which is used to define the seismic demand.

In addition, in order to define low frequency (below $1 \mathrm{~Hz}$ ) response or for the evaluation of underground piping, it may be necessary to also define a mean DBE peak ground displacement (PGD). This PGD is likely to be controlled by a larger magnitude earthquake at greater distance than the earthquake which controlled the DBE PGV.

\subsection{ANALYSIS OF SEISMIC DEMAND (RESPONSE)}

It is anticipated that the seismic demand will generally be estimated based upon linear response analyses. Sections 3.4 through 3.9 outline a set of acceptance criteria consistent with this approach. (But see also section 3.10.). DBE response spectra arrived at in accordance with section 3.3 should be used as input to such analyses. Other than for the conservatism specified in the DBE response spectra, the seismic response analyses can be median centered (no intentional conservatism), but with variation of some of the most uncertain parameters. Seismic response analyses should be conducted in accordance with the guidance contained in References 3.4 and 3.7 as amplified upon and modified herein. 
Best estimate structural models and material damping values should be used. Best estimate material damping values are provided in section 3.5. However, a variation by approximately plus/minus one standard deviation in both the natural frequency of the structure model, and soil stiffness properties should be incorporated into these analyses. In general, the structural frequency uncertainty can be accommodated by use of a $30 \%$ frequency uncertainty band either centered on the best estimate frequency or skewed to the low frequency side when such skewness is considered appropriate. Guidance on the appropriate variation of soil stiffness properties is given in section 3.3 .1 .7 of ASCE4.86 (Reference 3.7) and section 3.7 .2 of the USNRC Standard Review Plan (Reference 3.8). The seismic demand, $D_{\text {se, }}$ should be obtained from the largest computed response within these uncertainty bands. Great precision is unnecessary, and this largest response can generally be estimated by considering the following five cases:

1. Best estimate model (best estimate structural model coupled with best estimate soil properties).

2. Best estimate model frequency shifted $+15 \%$.

3. Best estimate model frequency shifted $-15 \%$

4. Best estimate structural model coupled with upper estimate soil stiffness properties.

5. Best estimate structural model coupled with lower estimate soil stiffness properties.

As noted above, it is sometimes preferable to skew the $30 \%$ frequency uncertainty to the low frequency side and for these situations, cases 2 and 3 should be adjusted accordingly. Floor spectra should be smooth (valleys filled in) envelopes from these cases. 
It is seldom necessary to analyze all five cases. When soilstructure-interaction (SSI) effects are substantial, cases 4 and 5 will lead to broader frequency shifting than will cases 2 and 3 so that cases 2 and 3 can be dropped. When SSI effects are small, Cases 4 and 5 will be enveloped by cases 2 and 3 and can then be dropped.

\subsection{DAMPING}

Damping values recommended for dynamic analyses are presented in Table 3.2 at three different response levels. These values may be used unless lower damping values are specified in the applicable construction code or standard specified by the Department of Energy for the facility design. Response Level 3 corresponds to inelastic response where the elastically computed total demand (seismic plus non-seismic) exceeds the capacity limits defined herein (i.e., credit must be taken for the inelastic energy absorption factor $F_{\mu}$ ). When evaluating the component, Response Level 3 damping may be used in elastic response analyses independent of the state of response actually reached, because such damping is expected to be reached prior to component failure. When determining the input to subcomponents mounted on a supporting structure, the damping value to be used in elastic response analyses of the supporting structure to define input to the subcomponent should be a function of the response level reached in the majority of the seismic load resisting elements of the supporting structure. Defining $D_{t}$ as the total elastic- computed demand (seismic $D_{s e}$ plus non-seismic $D_{n s}$ ) for the combined (three earthquake components) and enveloped (frequency varied) results and $c_{c}$ as the code strength capacity (see section 3.7) for the supporting structure, then the appropriate Response Level damping can be estimated from the following: 


\begin{tabular}{|c|c|}
\hline Response Level & $D_{t} / C_{c}$ \\
\hline \hline 3 & $\approx 1.0$ \\
\hline $2 *$ & $\approx 0.5$ to 1.0 \\
\hline $1 *$ & $\leqslant 0.5$ \\
\hline
\end{tabular}

*Consideration of these damping levels is required only in the generation of floor or amplified response spectra to be used as input to sub-components mounted on the supporting structure.

The damping values presented in Table 3.2 are intended to be best-estimate (median centered) damping values with no intentional conservative bias for use in elastic response analyses. Other damping values may be used when such values are properly justified as best-estimate values. For example, in the case of very high viscosity fluid, impulsive mode damping values in excess of $4 \%$ are permissible for tanks.

Response Level 3 damping values are intended for use in elastic response analyses coupled with the permissible inelastic energy absorption factors $\mathrm{F}_{\mu}$ defined later. However, when a nonlinear inelastic response analysis which explicitly incorporates the hysteretic energy dissipation is performed, no higher than Response Level 2 damping values should be used to avoid the double-counting of this hysteretic energy dissipation which would result from the use of Response Level 3 damping values.

\subsection{MATERIAL STRENGTH PROPERTIES}

For existing components, material strength properties should be established at the $95 \%$ exceedance actual strength levels associated with the time during the service life at which such strengths are minimum. If strengths are expected to increase during the service life, then the strength of an existing component should be its value at the time the evaluation is performed. If strengths are expected to degrade during the 
service life, then strengths to be used in the evaluation should be based upon estimated $95 \%$ exceedance strengths at the end of the service life. Whenever possible, material strengths should be based on $95 \%$ exceedance values estimated from tests of the actual materials used at the facility. However, when such test data are unavailable, then code minimum material strengths may be used. If degradation is anticipated during the service life, then these code minimum strengths should be further reduced to account for such degradation (for example, long term thermal effects on concrete). See section 3.7 for additional discussion on applicable code material strengths.

For new designs, material strength properties should be established at the specified minimum value defined by the applicable code or material standard. If degradation is anticipated during the service life, then these code minimum strengths should be further reduced to account for such degradation.

\subsection{CAPACITIES}

In general, for load combinations which include the DBE loading, capacities $c_{c}$ to be used should be based upon code-specific minimum ultimate or limit-state (e.g., yield or buckling) capacity approaches coupled with material strength properties specified in section 3.6. For concrete, the ACI ultimate strength approach with the appropriate capacity reduction factor, $\phi$, included as specified in either ACI318 (Reference 3.9 ) or ACI349 (Reference 3.10) should be used. For structural steel, the AISC-LRFD (Reference 3.11) limit-state strength approach with the appropriate capacity reduction factor, $\phi$, included is preferred. However, the AISC-Plastic Design (Part 2, Reference 3.12 or Chapter $N$, Reference 3.13) maximum strength approach may be used so long as the specified criteria are met. The plastic design strengths can be taken as 1.7 times the allowable stresses specified in Reference 3.12 or 3.13 unless 
another factor is defined in the specified code. For ASME Section III, Division 1 components, ASME Service Level D (Reference 3.14) capacities should be used. In some cases, functional failure modes may require lesser limits to be defined (e.g., ASME Mechanical Equipment Performance standard, Reference 3.15).

For existing facilities, in most cases, the capacity evaluation equations should be based on the most current edition of the appropriate code, particularly when the current edition is more conservative than earlier editions. However, in some cases (particularly with the ACI and ASME codes), current code capacities may be more liberal than those specified at the time the component was designed and fabricated, because fabrication and material specification requirements have become more stringent. In these later cases, current code capacities will have to be reduced to account for the more relaxed fabrication and material specifications that existed at the time of fabrication. In all cases, when material strength properties are based on code minimum material strengths, the code edition enforced at the time the component was fabricated should be used to define these code minimum material strengths.

If any material can be degraded during the service life, the degraded material size and properties should be used for estimation of the component capacity. For example, when corrosion is likely during the service life, thicknesses should be reduced by an appropriate corrosion allowance before computing the code capacity.

A capacity approach acceptable for the seismic capacity evaluation of unanchored and anchored flat-bottom liquid storage tanks at the atmospheric pressure is presented in chapter 5 . It is judged that for temperatures not exceeding $200^{\circ} \mathrm{F}$, the thermal effects need not be considered explicitly in such capacity evaluations. 


\subsection{LOAD COMBINATIONS AND ACCEPTANCE CRITERIA}

This section deals only with load combinations that include DBE loadings. In many cases, other (non-seismic) load combinations may control the design or evaluation of a component. These nonseismic load combinations should be defined by other documents.

It is assumed herein that the DBE seismic demand, $D_{\text {se, }}$ will be computed by linear elastic analyses conducted in accordance with the response criteria defined in sections 3.3 through 3.5. This elastic-computed seismic demand $D_{\text {se }}$ should be modified by the appropriate inelastic energy absorption factor $F_{\mu D}$ as defined in section 3.9 and by the appropriate seismic load factor $L_{s}$ to obtain an inelastic-factored seismic demand $D_{s 1}$ by:

$$
D_{s i}=\frac{D_{s \theta}}{F_{\mu D}} L_{s}
$$

The seismic load factor $L_{s}$ is used to accommodate varying seismic risk reduction factors $R_{R}$ and ranges as follows:

\begin{tabular}{|r|c|}
\hline$R_{R}$ & $L_{s}$ \\
\hline \hline 20 & 1.15 \\
10 & 1.00 \\
5 & 0.87 \\
\hline
\end{tabular}

Note that this is the only factor that need be adjusted to modify the acceptance criteria for different specified $R_{R}$ levels. (Recall, however, that in some circumstances the DBE level may be modified if $R_{R}$ changes; see section 3.3.).

The total inelastic-factored demand $D_{t 1}$ is then given by:

$$
D_{t 1}=D_{n s}+D_{s 1}
$$

where $D_{n s}$ represents the best-estimate of all non-seismic demands expected to occur concurrently with the DBE. Equation 3.5 represents the DBE load-combinations equation. The seismic 
capacity is adequate when the capacity $C_{c}$ determined as defined in section 3.? exceeds $D_{t 1}$, i.e.:

$$
C_{c} \geq D_{n s}+\frac{D_{s e}}{F_{\mu D}} L_{s}
$$

Equat. in 3.6 represents the seismic acceptance criterion appropriate for the DBE.

No load factors are needed on $D_{n s}$ in Equation 3.5. The nonseismic demand $D_{n s}$ should be defined at its best-estimate level as opposed to an unlikely-to-exceed or conservative level. The conservatism embodied in defining $C_{C}, F_{\mu D}$, and $D_{s e}$ are sufficient to achieve the specified $R_{R}$ values without additional sources of conservatism being required.

In some cases, such as a column under combined axial compression and moment, the code capacity $c_{c}$ is defined in terms of interaction equations. Furthermore, the $F_{\mu D P}$ for axial compression defined in section 3.9 is less than $F_{\mu D M}$ for flexure. In this case, Equations 3.4 and 3.5 are separately entered to establisir the total inelastic demands $P_{t 1}$ and $M_{t 1}$ for axial compression and moment, respectively, i.e.:

$$
P_{t i}=P_{n s}+\frac{L_{s} P_{s e}}{F_{\mu D P}}, \quad M_{t i}=M_{n s}+\frac{L_{s} M_{s \theta}}{F_{\mu D M}}
$$

The combination of $\mathrm{P}_{t i}$ and $\mathrm{M}_{t i}$ is entered into the code capacity interaction equation to determine the adequacy of the seismic design.

For ductile failure modes, non-seismic demands which are relieved by small levels of inelastic distortion (such as thermal and settlement stresses) do not have to be included in Equation 3.5 for combination with the factored seismic inertial force induced demand. However, for non-ductile failure modes,

$$
3-20
$$


these inelastic-relieved non-seismic stresses must still be included. For example, if a wall capacity is controlled by flexure, these inelastic-relieved non-seismic stresses do not have to be added to the seismic demand $D_{81}$. However, if the wall capacity is controlled by shear, they do have to be added. In addition, seismic and non-seismic displacements and strains are additive when checking displacemerit or strain criteria such as for underground pipes (see Chapter :).

As another example, many vertical cylindrical flat bottom highlevel waste storage tanks are restrained against lorgitudinal (vertical) movement at both the top and bottom of the tank walls. In many cases, the degree of longitudinal restraint is uncertain and difficult to quantity. Therefore, the longitudinal stresses set up in the tank walls are difficult to determine, but can be bounded by the cases of full longitudinal restraint and no longitudinal restraint. When fully restrained, substantial longitudinal stresses occur in the tank walls due to the following reasons:

1. Poisson's ratio induced longitudinal stresses resulting from the circumferential (hoop) stresses induced by the combination of hydrostatic and hydrodynumic fluid pressures on the tank wall (See chapter 4). For all practical problems, these Poisson's ratio induced longitudinal stresses are tensile and are a small fraction (about $30 \%$ ) of the average peak hoop stress over the height of the tank. They are easily relieved by a very small amount of longitudinal straining in the cylindrical shell or support relaxation.

2. Thermal expansion stresses. These longitudinal thermal expansion stresses are compressive and may be large at high temperatures. But, at metal temperatures not exceeding $200^{\circ} \mathrm{F}$ the corresponding longitudinal compressive strains are less than $0.15 \%$ and thus the stresses are 
easily relieved by small amounts of inelastic straining or bowing of the thin metal tank sidewalls.

In conclusion, for a ductile metal tank, both of the above two longitudinal stresses are secondary and easily relieved by a very small amount of nonlinear longitudinal straining (less than $0.15 \%)$. As such, neither of these computed elastic longitudinal stress will reduce the seismic capacity of the tank, and neither of them have to be combined with the primary seismic overturning induced longitudinal stresses when defining $D_{t 1}$ by Equation 3.5 .

\subsection{INELASTIC ENERGY ABSORPTION FACTOR}

The inelastic energy absorption factor is defined as the amount that the elastic-computed seismic demand may exceed the capacity of a component without impairing the performance of the component. Thus, the elastic-computed seismic demand $\mathrm{D}_{\text {se }}$ may be factored by an inelastic energy absorption factor $F_{\mu D}$ as shown in Equation 3.4 to obtain an inelastic factored seismic demand $D_{s i}$. In order to achieve a ratio of the seismic hazard frequency to the seismic risk frequency between 5 and 20 , this inelastic energy absorption factor $F_{\mu D}$ should be defined by:

$$
F_{\mu D}=F_{\mu 58}
$$

where $\mathrm{F}{ } 5 \%$ is the estimated inelastic energy absorption factor associated with a permissible level of inelastic distortions specified at about the $5 \%$ level, i.e., there is only a $5 \%$ chance that $F_{\mu}$ will be less than $F_{\mu 5 \%}$.

It is always preferable to perform nonlinear analysis on the structure or component being evaluated in order to estimate $F_{\mu 5 \%}$ for use in Equation 3.8 to define $F_{\mu D}$. Some guidance on estimating $F_{\mu 5 \%}$ is given in Appendix D. However, such analyses are often expensive and controversial. Therefore, a set of standard values of $F_{\mu D}$ is provided in Table 3.3 for common elements associated with underground high-level waste storage tanks, and discussed in the remainder of this section. 
Additional $F_{\mu}$ values are provided in Table 4.7 of Reference 3.4 . The $F_{\mu}$ values presented in Reference 3.4 for the Moderate Hazard category may be used for $F_{\mu D}$. The $F_{\mu D}$ values presented in Table 3.3 or from Reference 3.4 may be used in lieu of performing nonlinear analyses, so long as the following cautions are observed.

The use of $F_{\mu D}$ values listed in Table 3.3 equal to 1.5 and greater for concrete walls is conditional on extensive wall cracking but stable wall behavior constituting acceptable wall performance. If only minor wall cracking is acceptable, then $F_{\mu D}$ should be 1.0 .

The $F_{\mu D}$ values listed in Table 3.3 for ductile failure modes (i.e., greater than 1.0) assume that steel reinforcing bars, metal tank shells and anchorage will remain ductile during the component's entire service life. It is assumed that the metal will retain at least a $6 \%$ uniaxial elongation strain capability including the effects of welding. If this metal can become embrittled at some time during the service life, $F_{\mu D}$ values should be 1.0 .

In some cases reinforcement details in older facilities do not satisfy the development length requirement of current codes (References 3.9 and 3.10). In these instances the potential exists for a ductile failure mode associated with yielding of the reinforcement to become a more brittle mode associated with bond failure. Data exist (Reference 3.16), however, indicating that bond failure modes retain a reasonable amount of ductility provided that the reinforcement is suitably confined within the region of the potential bond failure. The confinement may be provided by a cover of at least 2.5 bar diameters or by ties (stirrups) spaced no further than 5 bar diameters apart. If this confinement is provided a strength of the reinforcement equal to the yield strength of the steel times the ratio of actual to required development length may be used in the 
capacity evaluations. In these cases the factor $\left(F_{\mu D}\right)$ should be limited to 1.0 . If the confinement is not provided the reinforcement should be omitted in the capacity evaluations.

The $F_{\mu D}$ values listed in Table 3.3 or from Reference 3.4 and the acceptance criteria of section 3.8 are based on the assumption that the component will be removed from service after being subject to ground motion in excess of the DBE response spectrum. If a component is to remain in service after being subjected to a DBE, particularly when stress corrosion cracking is a major concern, $F_{\mu D}$ should be 1.0 and either the seismic load factor $L_{s}$ in Equation 3.4 may have to be increased or the capacity $c_{c}$ may have to be reduced in order to maintain the seismic margin defined in section 3.10 .

For low-ductility failure modes such as axial compression or shear in concrete walls or columns and wall-to-diaphragm, wallto-column, or column-to-base connections, the $F_{\mu D}$ values listed in Table 3.3 are 1.0. In most cases, such stringent limits can be relaxed somewhat, as described below, because most components also have a ductile fajlure mode which when reached is likely to limit the demand in the low-ductility failure modes. Unless the component has a seismic capacity in the ductile failure mode significantly in excess of its required capacity, inelastic distortions in this ductile failure mode will likely limit the factored seismic $D_{s i}$ in the low-ductility failure modes to levels less than those given by Equation 3.4 with the $F_{\mu D}$ values given by Table 3.3. Since greater conservatism exists in code capacities $c_{c}$ for low-ductility failure modes than for ductile failure modes, the failure will be controlled by the ductile failure mode so long as the low-ductility failure mode code capacity is at least equal to the ductile failure mode capacity. Trus, for low-ductility failure modes, the factored seismic demand $D_{s 1}$ can be limited to the lesser of the following:

1. $D_{s 1}$ given by Equation 3.4 using $F_{\mu D}$ from Table 3.3 , or 
2. $D_{s 1}=C_{c}-D_{n s}$ computed for the ductile failure mode, where $C_{c}$ is the ductile failure mode code capacity.

Therefore, for example, connections do not have to be designed to have code capacities $c_{c}$ greater than the code capacities $c_{c}$ of the members being connected, or the total factored demand $D_{t 1}$ given by Equations 3.4 and 3.5 and Table 3.3, whichever is less. similarly, the code shear capacity of a wall does not have to exceed the total shear load which can be supported by the wall at the code flexural capacity of the wall. Finally, the horizontal seismic-induced axial force in a moment frame column can be rimited to the axial force which can be transmitted to the column when a full plastic hinge mechanism develops in the frame where the plastic hinge capacities are defined by the code ultimate flexural capàcities.

When the dominant response frequency (generally the fundamental frequency) of the component is greater than the frequency at which the input spectral acceleration is maximum, the cautions contained in section 4.2 .3 and illustrated in Figure $4-4$ of Reference 3.4 remain in effect. In this case, the factored seismic demand $D_{s 1}$ may be computed from any of the following three approaches:

1. The maximum spectral acceleration shall be used to compute the elastic response of the dominant response mode in Iieu of the lesser input spectral acceleration corresponding to the frequency of this mode. In this case, the $F_{\mu D}$ values listed in Table 3.3 or Reference 3.1 may be used.

2. The lesser spectral acceleration corresponding to the modal frequency of the dominant response mode may be used together with $F_{\mu D}$ values of 1.0 .

3. The spectral acceleration corresponding to the modal frequency of the dominant response may be used together 
with $F_{\mu D}$ values based on $F_{\mu 5 \%}$ computed from nonlinear analyses in accordance with guidance given in Appendix $D$. This approach is the most accurate and least conservative approach, but requires more effort.

The DBE response spectra defined in accordance with section 3.3 are elastic response spectra which may be directly used to compute the elastic-computed seismic demand which is then divided by $F_{\mu D}$ to obtain an inelastic-factored seismic demand. However, some engineers prefer to reverse the order of these steps by first dividing the elastic response spectra by $F_{\mu D}$ to obtain inelastic response spectra which may be directly used to compute the inelastic-factored seismic demand. This approach is also permitted so long as it is performed consistent with the use of $F_{\mu D}$ as described herein.

One way to obtain this consistency is to first multiply the elastic DBE response spectra by the seismic load factor $I_{s}$ defined by Equation 3.4a to obtain the load-factored elastic DBE response spectra. Next, at all frequencies equal or less than the frequencies at which the input spectrum is maximum, these load-factored elastic DBE response spectra are divided by $F_{\mu 5 \%}$ to obtain the inelastic-factored spectra. At all higher frequencies, the inelastic-factored spectral accelerations are defined by the lesser of either the load-factored elastic spectral acceleration at that frequency, or the maximum loadfactored elastic spectral acceleration divided by $F_{\mu 5 \%}$. Alternately, frequency dependent $F_{\mu 5 \%}$ obtained in accordance with the guidance given in Appendix D and appropriate references such as References D.1 through D.6 of Appendix D may be used at all frequencies to obtain the inelastic-factored response spectra from the load-factored elastic response spectra. This method becomes more complicated when different failure modes with differing $F_{\mu 5 \%}$ are present. 
This completes the specification of a set of seismic criteria that will satisfy the performance goal $P_{F}$ through first the introduction of $P_{H}$ and $R_{R}$, followed by the determination of the DBE and acceptance criteria, as outlined in sections 3.3 through 3.9 .

3.10 THE BASIC SEISMIC CRITERION AND THE GENERAL APPROACH TO COMPLIANCE

The basic seismic criterion and the more general approach to compliance presented in this section are needed for only the following reasons:

1. To enable the user to define more sophisticated alternate acceptance criteria than those presented in sections 3.4 through 3.9, when the user has a sufficient basis to develop and defend these alternate criteria, and

2. To provide the quantitative basis (in conjunction with Section 3.11) upon which the seismic criteria of sections 3.4 through 3.9 were developed.

The application of the deterministic, pseudo-linear seismic evaluation procedure defined in sections 3.4 through 3.9 does not require the use of any of the material presented in sections 3.10 and 3.11 .

\subsubsection{The Basic Seismic criterion}

For probabilistic seismic hazard curves such as those shown in Figures 3.1 and 3.2 , it is demonstrated in Appendix $A$ that $r i s k$ reduction factors $R_{R}$ of 20,10 and 5 are closely obtained when:

$$
C_{108} \geq 1.5 L_{s}(D B E)
$$

In this, the basic seismic criterion, $C_{10 \%}$ represents the $10 \%$ seismic input percentile level, i.e., the level at which a $10 \%$ 
probability of failure is estimated, and $I_{s}$ depends on $R_{A}$ as follows :

\begin{tabular}{|c|c|}
\hline$R_{R}$ & $I_{8}$ \\
\hline 20 & 1.15 \\
10 & 1.00 \\
5 & 0.87 \\
\hline
\end{tabular}

Notice that this single "basic" criterion (Equation 3.9) compares capacity and demand in ground motion terms, rather than in force, stress, or deformation terms, as is implied in sections 3.4 to 3.9 . The non-seismic demands are implicitly included here within $\mathrm{C}_{10 \%}$.

Appendix A demonstrates that the basic seismic criterion defined by Equation 3.9 (with Equation 3.9a) is appropriate for a wide range of hazard curves with different shapes, i.e., with a wide variation of ground motion ratios $A_{A}$ (defined by Equation 3.2 ) when the DBE ground motion is defined as the larger of the values given by Equations $3.3 \mathrm{a}$ and 3.3b. This demonstration covers the practical range of $A_{A}$ ratios from 1.5 to 3.75 . However, the basic criterion Equation 3.9 (with Equation 3.9a), coupled with the DBE defined by Equations $3.3 \mathrm{a}$ and $3.3 \mathrm{~b}$, can be extended beyond this range of $A_{R}$ values with generally increasing conservatism.

Using numerical convolution of hazard and fragility curves, Appendix B validates the applicability of Equation 3.9 (with Equatin 3.9 ) for several cases with the hazard curves given in Figure 3.2 .

\subsubsection{The General Approach to Compliance}

The most general approach to demonstrate compliance with the 
above basic seismic criterion is as follows. Given the performance criterion $P_{F}$ and the preferred $R_{h}$ :

1. Establish the DBE ground motion in accordance with the guidance of Section 3.3.

2. Define a scaled Design Basis Earthquake (SDBE) ground motion by increasing the DBE ground motion by an earthquake adjustment factor $F_{0}$ defined by:

$$
\operatorname{SDBE}=\left(F_{e}\right) \quad(D B E)
$$

in which

$$
F_{\mathrm{e}}=1.5 \mathrm{~L}_{8}
$$

where $L_{s}$ is the appropriate seismic load factor from Section 3.10 .1 for the selected seismic risk reduction factor $R_{R}$. Thus, one obtains the following values of $F_{e}$ :

\begin{tabular}{|c|c|c|}
\hline$R_{R}$ & $L_{8}$ & $F_{8}$ \\
\hline \hline 20 & 1.15 & 1.7 \\
\hline 10 & 1.00 & 1.5 \\
\hline 5 & 0.87 & 1.3 \\
\hline
\end{tabular}

3. Perform sufficient linear analyses, nonlinear analyses, testing, etc., to reasonably determine that for the combination of the SDBE with the best-estimate of the concurrent non-seismic loads there is less than about a $10 \%$ probability of unacceptable performance.

Any seismic evaluation approach which is consistent with the above three steps is acceptable.

3.11 BENCHMARKING DETERMINISTIC SEISMIC EVALUATION PROCEDURES AGAINST THE BASIC SEISMIC CRITERION

The basic criterion Equation 3.9 (with Equation 3.9a) defines the necessary overall conservatism that must be input into any seismic evaluation procedure in order to achieve the desired performance goal probability $P_{F}$. The DBE has a $P_{H}$ consistent 
with $P_{F}$ and $R_{A}$. Recall for the seismic hazard curve with the shape of Figure 3.1,

$$
R_{R}=P_{H} / P_{F}
$$

The necessary overall conservatism to satisfy Equation 3.9 could have been introduced into steps $A$ through $D$ by any of a variety of combinations of values or factors in the deterministic pseudo-linear seismic evaluation procedure described in section 3.1 and defined in detail in sections 3.4 through 3.9. The deterministic procedure defined in section 3.4 through 3.9 was chosen because it closely follows existing practices for the seismic design of critical facilities.

In this approach, very little conservatism has been introduced in the computation of the elastic-computed seismic demand (Section 3.4). Best estimate structural models and material damping are used. It has been found that introducing conservatism into the elastic-computed demand analysis introduces a highly variable factor of conservatism across the entire spectrum of natural frequencies and locations within a structure. This variation makes it difficult to achieve a specified target $r i s k$ reduction ratio, $R_{R}$. Reasonable variation in structure and soil stiffness properties are, however, considered and the maximum computed seismic demand over this uncertainty variation is used to represent the elastic-computed seismic demand. It is estimated that enveloping the effects of these stiffness variations results in less than a $25 \%$ chance of the elastic-computed response being exceeded given the occurrence of the DBE.

on the other hand, considerable conservatism has been introduced in the specified capacity by using minimum code ultimate capacities (including code specified strength reduction factors) coupled with $95 \%$ exceedance or code specified material strengths (sections 3.6 and 3.7). For ductile failure modes, it is expected that the specified capacities will have at least a $98 \%$ probability of being exceeded by the actual capacities. For 
brittle failure modes, code capacities contain even greater conservatism; the code capacity typically being about half of the median (or "best-estimate") capacity.

Also considerable conservatism is introduced in the specified maximum permissible inelastic energy absorption factor by which the elastic-computed seismic demand is divided to obtain the inelastic-factored seismic demand (section 3.9). The permissible inelastic energy absorption factor $F_{\mu D}$ is conservatively established at its value associated with inelastic distortions corresponding to about a $5 \%$ failure probability.

In addition, a seismic load factor $L_{s}$ is introduced in Equation 3.4 used to define the inelastic-factored seismic demand so as to accommodate a range of seismic risk reduction ratios ranging from 20 to 5 . The values of the seismic load factor $L_{s}$ and the required degree of conservatism for the permissible inelastic energy absorption factor $F_{\mu D}$ were based upon the benchmarking demonstration studies outlined in Appendix $C$. It is shown there that, taken together, the procedures and values in sections 3.4 to 3.9 manage to achieve the target $R_{R}$ levels for the wide range of response and capacity uncertainties that are encountered in practice.

Therefore the procedures recommended in chapter 3 have succeeded in meeting the objectives of giving flexibility, simplicity, and opportunities for adaption despite the complex and diverse nature of the seismic safety problem. 


\section{REFERENCES}

3.1 Melchers, R.E., "Structural Reliability, Analysis and Prediction," Ellis, Horwood, Ltd., Chichester, England, 1987 .

3.2 SEN-35-91, DOE Nuclear Safety Policy, September 9, 1991.

3.3 DOE order 5480.NPH, Natural Phenomena Hazards Mitigation for Department of Energy Facilities, (Draft) October 2, 1992 .

3.4 Kennedy, R.P., et al., "Design and Evaluation Guidelines for Department of Energy Facilities subjected to Natural Phenomena Hazards, UCRL-15910." Prepared for the office of Safety Appraisals, U.S. Department of Energy, June 1990 .

3.5 Interim Standard on "Use of Lawrence Livermore National Laboratory and Electric Power Research Institute probabilistic Seismic Hazard Curves," Department of Energy seismic Working Group, Issued in March 1992.

3.6 Newmark, N.M. and Hall, W.J., "Development of Criteria for Seismic Review of Selected Nuclear Power Plants," NUREG/CR-0098, U.S. Nuclear Regulatory Commission, May 1978 .

3.7 "Seismic Analysis of Safety-Related Nuclear structures and Commentary on standard for Seismic Analysis of SafetyRelated Nuclear structures," Reference 4-86, American Society of Civil Engineers (ASCE), September 1986.

3.8 "Standard Review Plan, NUREG-0800, Rev. 2," U.S. Nuclear Regulatory Commission, August 1989. 
3.9 American Concrete Institute, "Building Code Requirements for Reinforced Concrete, ACI 318-89," Detroit, Michigan, 1989 .

3.10 American concrete Institute, "Code Requirements for Nuclear Safety-Related Concrete structures (ACI 349-85) and Commentary - ACI 349R-85," Detroit, Michigan, 1985.

3.11 American Institute of Steel Construction, "Manual of steel Construction, Load \& Resistance Factor Design," LRFD, 1st Ed., Chicago, Illinois, 1986.

3.12 American National standard, "Nuclear Facilities - steel Safety-Related Structures for Design, Fabrication and Erection," ANSI/AISC N-690, 1984.

3.13 American Institute of steel Construction, "Manual of steel Construction," ASD, Ninth Ed., Chicago, Illinois, 1989.

3.14 American Society of Mechanical Engineers, "ASME 3oiler \& Pressure Vessel code - Nuclear Power Plant Components, Section III Division-I," ASME, 1989.

3.15 "ASME Mechanical Equipment Performance Standard."

3.16 Eligehausen R., Popov, E.P. and Bertero, V.V., "Local Band Stress-slip Relationships of Deformed Bars under Generalized Excitations," Report No. DCB/EERC-82/23, University of California at Berkeley, October 1983.

3.17 "Seismic Design Guidelines for Essential Buildings, A Supplement to Seismic Design for Buildings," Army TM5-80910.1, Navy NAVFAC P-355.1, Air Force ARM 88-3, Chapter 13.1, Departments of the Army, Navy arid Air Force, Washington, DC, February 1986. 
3.18 Kennedy, R.P., et al., "Subsystem Response Review, seismic Safety Margin Research Program," NUREG/CR-1706, UCRL15216, October 1980 .

3.19 "A Methodology for Assessment of Nuclear Power Plant Seismic Margin, NP-6041, Rev. 1," Electric Power Research Institute, June 1991. 
NOTATION

$A_{R} \quad$ ground motion slope ratio as defined by Equation 3.2

$\mathrm{C}_{\mathrm{c}} \quad$ capacity based on code formula or stresses

$\mathrm{C}_{\mathrm{p} \%} \quad$ seismic capacity estimated at a failure probability of $\mathrm{p} \%$

DBE design basis earthquake, defined by Equation 3.3

$D_{n s} \quad$ non-seismic demand

$D_{\text {se }}$ seismic demand based on elastic analysis

$D_{\text {si }}$ seismic demand based on inelastic analysis

$D_{t} \quad$ total demand

$D_{t 1}$ total seismic demand considering inelastic absorption factor $\left(=D_{s e} / F_{\mu D}\right)$

$\mathrm{F}_{\mathrm{e}} \quad$ earthquake adjustment factor

$F_{\mu} \quad$ inelastic energy absorption factor

$F_{\mu p}$ inelastic absorption factor specified at a failure probability level of $p$

$\mathrm{L}_{\mathrm{s}} \quad$ seismic load factor

$M_{n s} \quad$ nonseismic moment

$M_{\text {se }} \quad$ seismic moment based on elastic analysis

$\mathrm{M}_{\mathrm{s} 1} \quad$ seismic moment based on inelastic analysis

PGA peak ground acceleration

PGD peak ground displacement

PGV peak ground velocity

$\mathrm{P}_{\mathrm{F}}$ annual probability of failure or unacceptable performance ( i.e. performance goal)

$\mathrm{P}_{\mathrm{H}}$ the seismic hazard (i.e., annual frequency of exceedance) associated with a reference-level earthquake, in some cases the DBE.

$P_{n s}$ nonseismic axial load 
$P_{s e} \quad$ seismic axial load based on elastic analysis

$P_{t 1}$ total axial load based on inelastic analysis

$R_{R}$ risk reduction factor, associated with a specific set of response and capacity criteria

SDBE scaled design basis earthquake

$\beta \quad$ composite logarithmic standard deviation

$\phi \quad$ capacity reduction factor (e.g. as per ACI318) 
Table 3,1 Example DBE PGA Values Based Upon Figure 3.2 Hazard Curves

\begin{tabular}{|c|c|c|c|c|}
\hline $\begin{array}{c}\text { Example } \\
\text { Case }\end{array}$ & $\begin{array}{c}\text { Specified Seismic } \\
\text { Performance Goal, } \\
\text { Risk Reduction } \\
\text { Factor, and } \\
\text { Hazard Exceedance } \\
\text { Probability }\end{array}$ & $\begin{array}{c}\text { Hazard } \\
\text { Curve }\end{array}$ & $\begin{array}{c}\text { DBE } \\
\text { PGA } \\
\text { Level } \\
(\mathrm{g})\end{array}$ & $\begin{array}{c}\text { Governing } \\
\text { Equation }\end{array}$ \\
\hline \hline \multirow{2}{*}{$\mathrm{I}$} & $\begin{array}{l}\mathrm{P}_{\mathrm{F}}=1 \times 10^{-5} \\
\mathrm{R}_{\mathrm{R}}=20 \\
\mathrm{P}_{\mathrm{H}}=2 \times 10^{-4}\end{array}$ & $\mathrm{~A}$ (Western) & 0.50 & $3.3 \mathrm{a}$ \\
\cline { 2 - 5 } & $\begin{array}{l}\mathrm{P}_{\mathrm{F}}=1 \times 10^{-4} \\
\mathrm{R}_{\mathrm{R}}=10 \\
\mathrm{P}_{\mathrm{H}}=1 \times 10^{-3}\end{array}$ & $\mathrm{~A}$ (Wastern) & 0.29 & $3.3 \mathrm{~b}$ \\
\cline { 3 - 6 } & $\mathrm{B}$ (Eastern) & 0.30 & $3.3 \mathrm{a}$ \\
\hline
\end{tabular}


Table 3.2 Recommended Damping Values (Based on References 3.4, $3.6,3.7,3.17,3.18$ and 3.19$)$

\begin{tabular}{|c|c|c|c|}
\hline \multirow[b]{2}{*}{ Type of Component } & \multicolumn{3}{|c|}{ Damping (\% of Critical) } \\
\hline & $\begin{array}{c}\text { Response } \\
\text { Level } 1 \\
\end{array}$ & $\begin{array}{l}\text { Response } \\
\text { Level } 2 \\
\end{array}$ & $\begin{array}{c}\text { Response } \\
\text { Level } 3 \\
\end{array}$ \\
\hline $\begin{array}{l}\text { Welded and friction- } \\
\text { bolted steel structures }\end{array}$ & 2 & 4 & 7 \\
\hline $\begin{array}{l}\text { Bearing-bolted steel } \\
\text { structures }\end{array}$ & 4 & 7 & 10 \\
\hline $\begin{array}{l}\text { Prestressed concrete } \\
\text { structures (without } \\
\text { complete loss of } \\
\text { prestress) }\end{array}$ & 2 & 5 & 7 \\
\hline $\begin{array}{l}\text { Reinforced concrete } \\
\text { structures }\end{array}$ & 4 & 7 & 10 \\
\hline Piping & 3 & 5 & 5 \\
\hline $\begin{array}{l}\text { Massive, low-stressed } \\
\text { components (pumps, } \\
\text { motors, etc.) }\end{array}$ & 2 & 3 & $--\left({ }^{1}\right)$ \\
\hline $\begin{array}{l}\text { Light, welded instrument } \\
\text { racks }\end{array}$ & 2 & 3 & $--\left({ }^{1}\right)$ \\
\hline Electrical cabinets & 3 & 4 & $5\left({ }^{2}\right)$ \\
\hline $\begin{array}{l}\text { Liquid containing metal } \\
\text { tanks: }\end{array}$ & & & \\
\hline Impulsive mode & 2 & 3 & 4 \\
\hline sloshing mode & 0.50 & 0.5 & 0.5 \\
\hline
\end{tabular}

(1) Should not be stressed to response level 3 .

(2) May be used for anchorage and structural failure modes which are accompanied by at least some inelastic response. Response Level 1 damping values should be used for functional failure modes such as relay chatter or relative displacement issues which may occur at a low cabinet stress level. 
Table 3.3 Inelastic Energy Absorption Factors (Inelastic Demand/Capacity) $F_{\mu D}$

\begin{tabular}{|c|c|}
\hline Structural system & $F_{\mu D}=F_{\mu 5 \%}$ \\
\hline \hline Concrete vault & \\
\hline Walls: & \\
In-plane: & 1.75 \\
Flexure & 1.5 \\
Shear & 1.75 \\
Out-of-plane: & 1.0 \\
Flexure & \\
Shear & 1.0 \\
Columns: & 1.5 \\
Axial Compression & 1.0 \\
Flexure & 1.0 \\
Shear & 1.25 \\
Connections & \\
Metal Liquid-Storage Tanks & \\
Moment and Shear Capacity & 1.5 \\
Hoop Capacity & \\
\hline
\end{tabular}




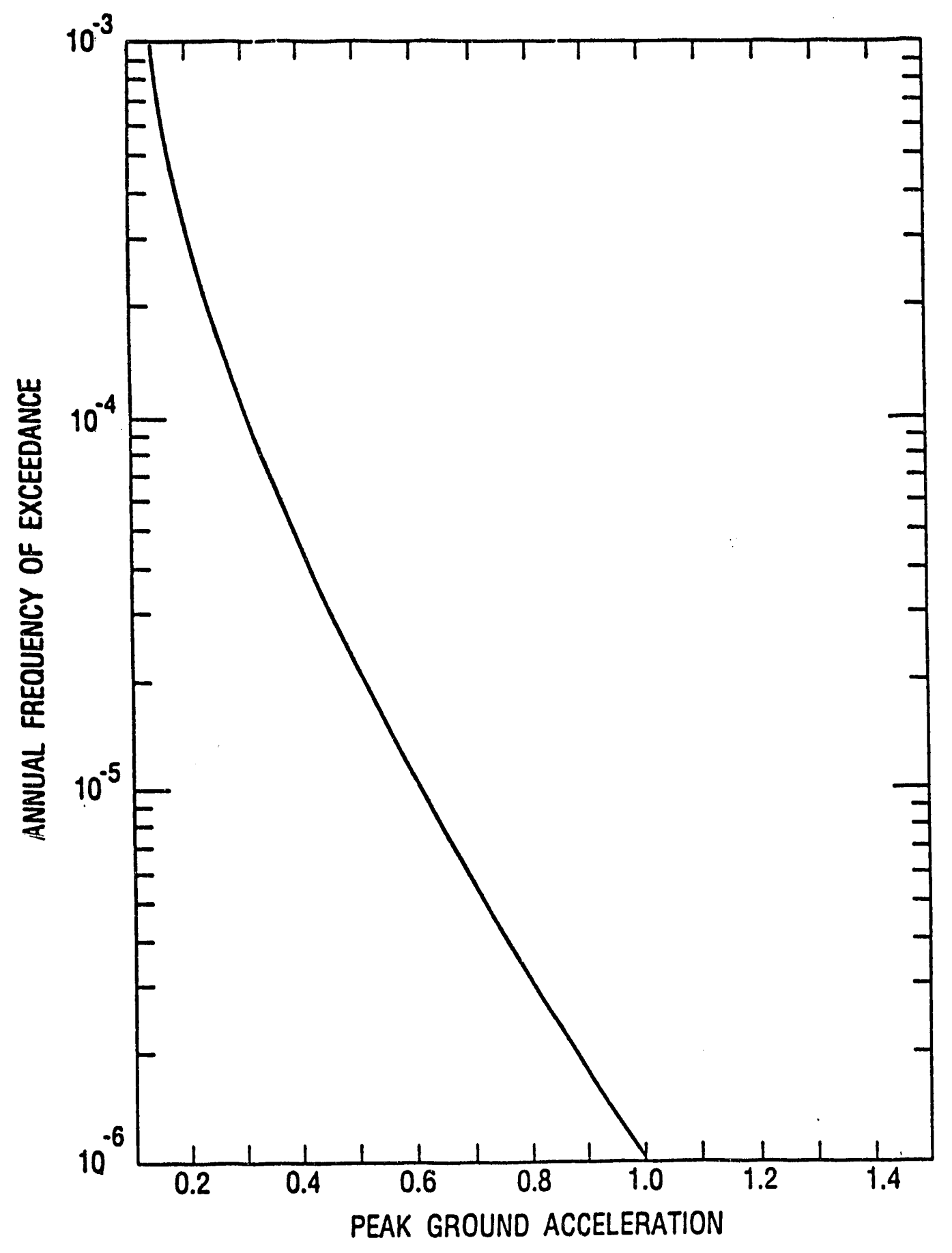

Figure 3.1 Typical Probabilistic Seismic Hazard Curve

$$
3-40
$$




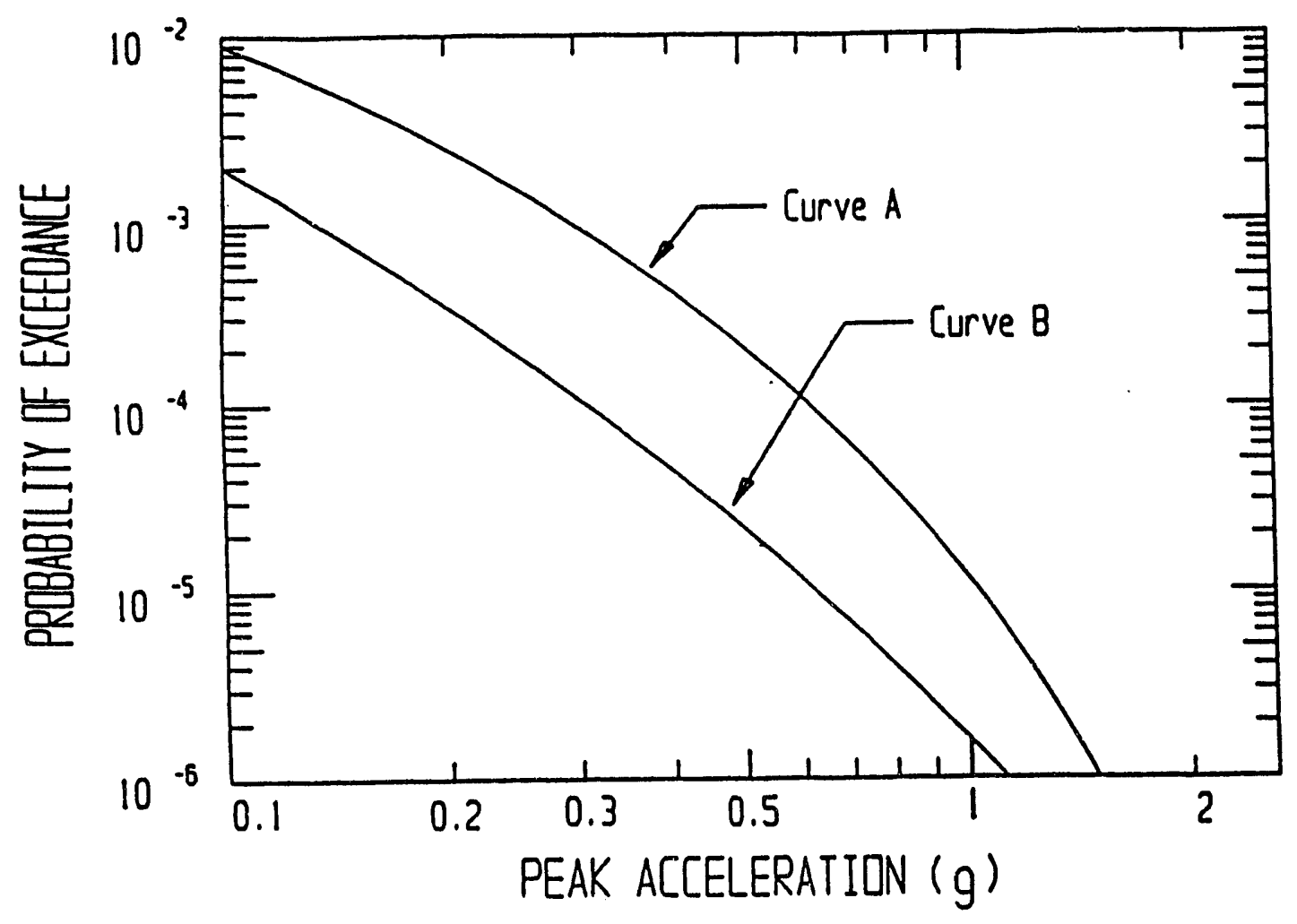

Figure 3.2 Other Representative Probabilistic Hazard Curves 3-41 
CHAPTER 4

EVALUATION OF HYDRODYNAMIC EFFECTS IN TANKS

\subsection{OBJECTIVES AND SCOPE}

The design guidelines in this chapter are for the evaluation of the hydrodynamic pressures and forces and of the associated liquid motions induced by earthquake ground motions in liquidstorage tanks. The term hydrodynamic is used in a generalized sense to represent the dynamic effects of any liquid.

The systems examined are shown in Figure 4.1. They are upright, circular cylindrical tanks of radius $R$ and height $H_{t}$ which are filled with liquid to a height $\mathrm{H}_{\ell}$. The liquid is considered to be $n$ uniform mass density and free at its upper surface. The tank wall is presumed to be clamped to a rigid moving base so that no sliding or base uplifting may occur, and to be either free or constrained at the top. The effects of both horizontal and vertical components of ground shaking are examined. Consideration also is given to the effects of a rocking component of base motion. Whereas the cantilever system is excited solely at the base, the top-constrained system is presumed to be excited simultaneously and similarly at the base and the top. Except where otherwise indicated, the liquid and tank heights may be different.

The mass densities of the tank wall and liquid are denoted by $\rho_{t}$ and $\rho_{\ell}$, and the modulus of elasticity and Poisson's ratio for the tank material are denoted by $E_{t}$ and $\nu_{t}$, respectively. Points on the tank wall are defined by the vertical distance $z$, measured positive upward from the tank base, and by the circumferential angle $\theta$, which is measured counterclockwise from the direction of the horizontal excitation. The accelerations of the horizontal, vertical and rocking components of the base motion 
at any time $t$ are denoted by $\ddot{x}(t), \ddot{z}(t)$ and, $\ddot{\psi}(t)$, respectively, and the absolute maximum values of these quantities are denoted by $\ddot{x}_{0}, \ddot{z}_{0}$ and $\ddot{\psi}_{0}$.

Two additional assumptions are embodied in the information presented herein: (1) The tank wall is of uniform thickness, $t_{t w} ;$ and (2) the liquid is incompressible and inviscid. For tanks of variable wall thickness, the non-uniform wall must be replaced by one of constant thickness, as indicated in a later section.

Exploratory studies of the hydrodynamic effects induced by viscous liquids (References 4.4 and 4.6) suggest that, for the viscosity values deemed to be appropriate for the materials found in waste-storage tanks in DOE facilities, the effects are practically the same as those induced by inviscid liquids. Pending the outcome of additional studies which are currently in progress, the information presented may, therefore, be considered to be valid for viscous liquids as well.

The evaluation of the seismic response of these systems does not warrant the use of complex, computer-based finite-difference or finite-element methods, and may be implemented reliably and cost-efficiently by the procedures described herein. More sophisticated methods and computer programs may naturally be used, provided their reliability is confirmed by comparing their predictions for representative cases with those deduced by the procedures described here.

In the form presented herein, the design provisions are applicable only to relatively broad tanks, for which the ratio of liquid-height to tank-radius, $H_{\ell} / R$, is less than unity. These proportions are representative of those of waste-storage tanks normally found in DOE facilities.

For background information on the subject matter covered in this 
chapter, and for data on the response of tanks with values of $H_{l} / R$ in excess of unity, the reader is referred to the references listed at the end of the chapter.

\subsection{RESPONSES OF INTEREST AND MATERIAL OUTLINE}

A critical element in the analysis of the seismic response of the tank-liquid system is the evaluation of the hydrodynamic pressures exerted against the tank wall and base. Once these pressures have been established, the corresponding forces and stresses in the tank may be determined with relative ease.

of special importance in the seismic design and safety evaluation of tanks are the maximum values of the following forces:

- The hoop forces in the tank wall;

- The total hydrodynamic force exerted on the tank wall, and the resulting end shears;

- The resulting bending moments across sections normal to the tank axis; these moments, in combination with the beam theory, are used to evaluate the axial forces in the tank wall; and

- The forces and moments transmitted to the tank support.

Also of importance is the maximum vertical or sloshing motion of the free liquid surface.

In the following sections, the hydrodynamic pressures and tank forces are evaluated first for a horizontal component of ground shaking, then for a possible rocking motion of the tank base, and finally for a vertical motion of the ground. The sloshing motion of the free liquid surface is examined at the end of the chapter. The effects of dynamic coupling between the tankliquid system, the supporting vault, and the surrounding soil are considered only briefly in this chapter; they are examined

$$
4-3
$$


in detail in Chapter 6 .

\subsection{EFFECTS OF HORIZONTAL COMPONENT OF SHAKING}

\subsubsection{General}

The hydrodynamic effects induced by the horizontal component of ground shaking may conveniently be expressed as the sum of two components:

- An impulsive component, which represents the effects of the part of the liquid that may be considered to move in synchronism with the tank wall as a rigidly attached mass; and

- A convective component, which represents the action of the part of the liquid near the free surface that experiences sloshing or rocking motion.

In mathematical terms, the impulsive component of the solution satisfies the actual boundary conditions along the lateral and bottom surfaces of the liquid and the condition of zero hydrostatic pressure at the mean level of the free liquid surface; accordingly, it does not account for the effects of the surface waves associated with sloshing actions. The convective component of the solution effectively corrects for the difference between the actual boundary condition at the mean liquid surface and the one considered in the development of the impulsive solution.

Because it is associated with motions of significantly lower frequencies than the natural frequencies of the tank-liquid system or the dominant frequencies of the excitation, the convective part of the solution is practically unaffected by the flexibility of the tank wall, and may be evaluated with reasonable accuracy considering the tank to be rigid. By contrast, the impulsive part of the solution is sensitive to the 
tank wall flexibility, and this factor must be, and is, provided for in the analysis.

\subsubsection{Hydrodynamic Wall Pressures}

The instantaneous value of the hydrodynamic pressure induced at an arbitrary point of the tank wall, $p=p(\eta, \theta, t)$, may be expressed as

$$
p(\eta, \theta, t)=p_{1}(\eta, \theta, t)+p_{c}(\eta, \theta, t)
$$

in which $\eta=\mathrm{z} / \mathrm{H}_{\ell}=$ the normalized vertical distance measured from the base, positive upward; and $p_{1}$ and $p_{c}$ are, respectively, the impulsive and convective components of the pressure. The impulsive component may be expressed by the product of functions of $\eta, \theta$ and $t$ as

$$
p_{i}(\eta, \theta, t)=c_{i}(\eta) \rho_{i} R A_{i}(t) \cos \theta
$$

and the convective component may be expressed by the sum of the products of such functions, as

$$
p_{c}(\eta, \theta, t)=\sum_{n=1}^{N}\left[c_{c n}(\eta) \rho, R A_{c n}(t)\right] \cos \theta
$$

in which $\mathrm{N}$ is a sufficiently large integer. In these expressions, $A_{1}(t)$ and $A_{c n}(t)$ are pseudoacceleration response functions for single-degree-of-freedom oscillators defined in greater detail later; $c_{1}(\eta)$ is a dimensionless function of $\eta$ that defines the axial or heightwise variation of the impulsive component of the wall pressure; and $c_{c n}(\eta)$ is a similar function that defines the corresponding variation of the pressure associated with the nth sloshing mode of vibration of the liquid. The latter function is given by

$$
c_{c n}(\eta)=\frac{2}{\lambda_{n}^{2}-1} \frac{\cosh \left[\lambda_{n}\left(H_{l} / R\right) \eta\right]}{\cosh \left[\lambda_{n}\left(H_{l} / R\right)\right]}
$$

in which $\lambda_{n}$ represents the nth root of the first derivative of $4-5$ 
the Bessel function of the first kind and first order. The first three of these roots are

$$
\lambda_{1}=1.841 \quad \lambda_{2}=5.331 \quad \lambda_{3}=8.536
$$

Note that, in addition to the position coordinate $\eta$, the functions $c_{c n}(\eta)$ depend on the liquid height to tank radius ratio, $\mathrm{H}_{\ell} / \mathrm{R}$. The maximum values of these functions occur at the top, $\eta=1$, are independent of $H_{\ell} / R$, and add up to unity. The first three maxima are

$$
C_{c 1}(1)=0.837 \quad C_{c 2}(1)=0.073 \quad C_{c 3}(1)=0.028
$$

With the functions $c_{c n}(\eta)$ determined, the function $c_{1}(\eta)$ for the impulsive component of wall pressure may be determined from

$$
c_{i}(\eta)=1-\sum_{n=1}^{N} c_{c n}(\eta)
$$

The values of $c_{1}(\eta)$ for tanks of different proportions are listed in Table 4.1. These values may also be determined approximately from

$$
c_{i}(\eta)=D_{i}\left[\cos \frac{\pi}{2} \eta-0.11 \cos \frac{3 \pi}{2} \eta+0.04 \cos \frac{5 \pi}{2} \eta-0.02 \cos \frac{7 \pi}{2} \eta+\ldots\right]
$$

in which $D_{1}$ is a dimensionless function of $H_{l} / R$, given in column 2 of Table 4.2 .

Equations 4.2 and 4.3 reveal that both components of the hydrodynamic wall pressure vary in the circumferential direction as $\cos \theta$. Therefore, their peak values at an arbitrary elevation and time are attained along a diametral axis in the direction of the excitation, and the zero values are attained along a normal axis. Equations 4.4 and 4.7 further reveal that, whereas the convective pressure components decrease from top to bottom, the impulsive component increases from zero at the liquid surface to a maximum at the base. 
The distribution function $c_{1}(\eta)$ for the impulsive component of the hydrodynamic wall pressure and the corresponding functions for the first two convective components are shown in Figure 4.2 for tanks with $H_{\ell} / R=0.75$. Also shown in Figure 4.3 are the radial distributions of the corresponding pressures exerted on the tank base. The latter pressures are defined by equations of the same form as Equations 4.2 and 4.3 , except that the dimensionless distribution functions $c_{1}(\eta)$ and $c_{c n}(\eta)$ in these expressions must be replaced by the functions $c_{1}(\xi)$ and $c_{c 11}(\xi)$, in which $\xi$ is the normalized radial distance $r / R$.

Note should be taken of the fact that the pressures in Equation 4.1 through 4.3 are expressed in terms of the tank radius, $R$, rather than the liquid height, $\mathrm{H}_{\ell}$. Accordingly, in comparing tanks of different proportions, their radii rather than their heights must be considered to be the same.

Implicit in Equation 4.2 is the assumption that the distribition (but not magnitude) of the impulsive component of the wall pressure is independent of the tank wall flexibility and identical to the distribution of the corresponding pressure in a rigid tank of the same proportions. More precise analyses of flexible tanks with both free and coristrained top boundaries (References $4.3,4.5,4.11$ and 4.12 ) reveal that this is indeed a valid approximation for the relatively broad tanks with values of $H_{l} / R \leq 1$ considered herein. While Equation 4.2 for the impulsive effects is limited to such broad tanks, Equations 4.3 and 4.4 for the convective effects may be used for tanks of arbitrary proportions.

The functions $A_{1}(t)$ and $A_{c n}(t)$ in Equations 4.2 and 4.3 represent the instantaneous pseudoaccelerations induced by the prescribed base motion in viscously damped single-degree-of-freedom linear systems of specjified damping and natural frequencie:. Specifically, $\lambda_{1}(t)$ refers to a system the natural frequency of which is ecual to the fundamental frequency of the tank 
vibrating along with the impulsive component of the liquid mass, and $A_{c n}(t)$ refers to a system with a natural frequency equal to the nth sloshing frequency of vibration of the contained liquid. These frequencies are defined further in the next two sections. The damping value used in the computation of the impulsive effects should correspond to that deemed to be appropriate for the tank wall material, whereas that for the convective effects should be taken as 0.5 percent of the critical value, unless higher values can be justified. These issues are addressed further in chapter 5 .

For a single-degree-of-freedom system with a circular natural frequency $\omega$ and percentage of critical damping $\zeta$, the pseudoacceleration $A(t)$ is given by

$$
A(t)=\frac{\omega}{\sqrt{1-\zeta^{2}}} \int_{0}^{t} \ddot{x}(\tau) \exp [-\zeta \omega(t-\tau)] \sin \left[\omega \sqrt{1-\zeta^{2}}(t-\tau)\right] d \tau
$$

and it is related to the instantaneous deformation of the system, $u(t)$, by

$$
A(t)=\omega^{2} u(t)
$$

The absolute maximum values of $u(t)$ and $A(t)$ are the quantities displayed in deformation and pseudoacceleration response spectra, respectively. The spectral pseudoacicelerations will be denoted by $S_{A}$, and appropriate subscripts will be used to identify the values corresponding to the impulsive and convective components of response.

\subsubsection{Natural Sloshing Frequencies}

The natural frequency in cycles per second of the nth convective or sloshing mode of vibration of the liquid, $f_{c n}$, is given by

$$
f_{c n}=\frac{1}{2 \pi} \sqrt{\lambda_{n} \frac{g}{R} \tanh \left[\lambda_{n}\left(H_{\ell} / R\right)\right]}
$$

$$
4-8
$$


in which $g$ represents the acceleration of gravity, and $\lambda_{n}$ has the values given in Equation 4.5 .

As a measure of the values of $f_{c n}$ that may be encountered in practice, it is noted that, for tanks with $\mathrm{H}_{\ell} / \mathrm{R}=0.5$, Equation 4.11 leads to the following expressions for the first three sloshing periods of vibration

$$
T_{c 1}=0.958 \sqrt{R} \quad T_{c 2}=0.482 \sqrt{R} \quad T_{c 3}=0.379 \sqrt{R} \quad(4.12)
$$

in which $T_{c n}=1 / f_{c n}$ is expressed in seconds, and $R$ is expressed in feet. Observe that the sloshing periods can be quite long for tanks of large radii.

\subsubsection{Fundamental Natural Frequency of Tank-Liquid System}

The fundamental natural requency of the impulsive mode of vibration of the tank-liquid system, in cycles per second or $\mathrm{Hz}$, is given by

$$
f_{i}=\frac{1}{2 \pi} \frac{C_{i}}{H_{l}} \sqrt{\frac{E_{t}}{\rho_{t}}}
$$

where $C_{1}$ is a dimensionless coefficient which, in addition to the ratio of liquid height to tank radius, $H_{\ell} / R$, depends on

- The wall thickness to tank radius ratio, $t_{t w} / R$;

- The ratio of the mass densities for the liquid and tank material, $\rho_{\ell} / \rho_{\mathrm{t}}$;

- Poisson's ratio for the tank material, $\nu_{t}$; and

- The conditions of tank support at the top.

For water-filled steel tanks for which $E_{t}=30,000 \mathrm{ksi}$ and $\gamma_{t}=\rho_{t} g=490 \mathrm{lb} / \mathrm{ft}^{3}$, Equation 4.13 may be written as 


$$
f_{i}=\frac{2,680 C_{i}}{H_{l}}
$$

in which $\mathrm{H}_{\ell}$ is expressed in feet.

The values of $C_{1}$ for a representative group of roofless steel tanks that are filled with water are listed in the left part of Table 4.3. For these solutions, $t_{t w} / R=0.001, \nu_{t}=0.3$ and $\rho_{\ell} / \rho_{t}$ $=0.127$. Three conditions of support are considered for the top boundary of the shell:

- A completely free condition, for which the axial, circumferential and radial displacements are unconstrained;

- A roller support, for which only the axial displacements are unconstrained and the others vanish; and

- A hinge support, for which all three displacement components vanish.

For a clamped top boundary, for which the rotation of the tank wall vanishes in addition to all linear displacement components, the results may be taken equal to those for the hinged boundary.

If the values of $C_{1}$ for the reference values of $t_{t w} / R=0.001$ and $\rho_{\ell} / \rho_{t}=0.127$ considered in Table 4.3 are denoted by $\left(C_{1}\right)_{r}$, the corresponding values for tanks of arbitrary $t_{t w} / R$ and $\rho_{\ell} / \rho_{t}$ may be determined from

$$
C_{i}=\left(C_{i}\right)_{r} \sqrt{127\left(t_{t w} / R\right) /\left(\rho_{d} / \rho_{t}\right)}
$$

This expression is based on the assumption that the inertia effects of the tank itself are negligible compared to those of the contained liquid, a condition normally satisfied in practice. 
Effects of Nonuniform Wall Thickness. Note has already been taken of the fact that, for the tank proportions considered herein, the distribution function $c_{1}(\eta)$ in Equation 4.2 may be considered to be independent of the thickness of the tank wall and, hence, of its possible variation with height. By contrast, the pseudoacceleration $A_{1}(t)$ in this equation, being a function of the natural frequency $f_{1}$, does depend on the tank wall thickness and its heightwise variation.

For tanks of nonuniform wall thickness, the natural frequency $f_{1}$ may be determined from the information presented in the preceding section by replacing the variable thickness of the tank wall with an average value. The averaging should be done so as to emphasize the section of the tank for which the associated modal displacements are the largest. Inasmuch as the maximum displacements for the fundamental mode of vibration occur within the lower rather than the upper parts of the tank, the wall thickness should be averaged over the lower two-thirds of the liquid height.

Effect of Roof Mass. For tanks for which the top cannot deflect relative to its base, the roof mass will have no effect on the natural frequency of the tank-liquid system. Even for cantilever tanks, this mass is likely to be inconsequential, unless its magnitude is a sizable fraction of the liquid mass.

For systems for which the roof mass is sufficiently large to warrant consideration, the fundamental impulsive natural period, $\overline{\mathrm{T}}_{1}$, may be determined from

$$
\overline{T_{i}^{2}}=T_{i}^{2}+T_{f}^{2}+T_{s}^{2}
$$

in which $T_{1}=1 / f_{1}=$ the natural period determined from Equation 4.13 or 4.14 for the roofless tank-liquid system, and $T_{f}$ and $T_{s}$ are the natural periods of the empty tank computed on the assumption that the roof mass is the only structural mass.

$$
4-11
$$


Specifically, $T_{f}$ represents the natural period computed on the assumption that the empty tank responds as a cantilever flexural beam, and $T_{s}$ is the corresponding period computed on the assumption that the tank behaves as a cantilever shear beam. These periods are given by

$$
T_{f}=2 \pi \sqrt{\frac{m_{r}}{k_{f}}}
$$

and

$$
T_{s}=2 \pi \sqrt{\frac{m_{x}}{k_{s}}}
$$

in which $k_{f}=$ the flexural stiffness of the substitute beam, and $k_{s}$ = the corresponding shearing stiffness. For a tank of uniform wall thickness, these stiffnesses are given by

$$
k_{t}=3 \frac{E_{t} I_{t}}{H_{t}^{3}}=3 \pi\left(\frac{R}{H_{t}}\right)^{3} E_{t} t_{t w}
$$

and

$$
k_{s}=\frac{1}{2} \frac{G_{t} A_{t w}}{H_{t}}=\frac{\pi}{2\left(1+v_{t}\right)} \frac{R}{H_{t}} E_{t} t_{t w}
$$

In these expressions, $G_{t}=E_{t} /\left[2\left(1+\nu_{t}\right)\right]=$ the shear modulus of elasticity of the tank material; $A_{t w}=2 \pi R t_{t w}=$ the crosssectional area of the tank wall; and $I_{t}=\pi R^{3} t_{t w}=$ the moment of inertia of the tank cross section about a horizontal centroidal axis.

\subsubsection{Maximum Values of Wall Pressures}

The maximum values of the impulsive and convective components of the hydrodynamic wall pressures may be determined from Equa ions 4.2 and 4.3 by replacing the pseudoacceleration functions $A_{1}(t)$ and $A_{c n}(t)$ by their maximum or spectral values, $\left(S_{A}\right)_{1}$ and $\left(S_{A}\right)_{c n}$, 
respectively. The maximum values of the total hydrodynamic wall pressures, $p_{\max }(\eta, \theta)$, may then be determined from Equation 4.1 by combining the component maxima by the square-root-of-the-sum-ofthe-squares rule as

$$
p_{\max }(\eta, \theta)=\left[\sqrt{\left.\left[c_{i}(\eta)\left(S_{A}\right)_{i}\right]^{2}+\left[c_{c 1}(\eta)\left(S_{A}\right)_{c 1}\right]^{2}+\left[c_{c 2}(\eta)\left(S_{A}\right)_{c 2}\right]^{2}+\ldots\right]}\right]
$$

A more conservative approach would be to add to the maximum numerical value of the impulsive pressure the root-mean-square value of the maximum values of the convective pressure components, i.e., express $p_{\max }(\eta, \theta)$ as

$$
p_{\max }(\eta, \theta)=\left[c_{i}(\eta)\left(S_{A}\right)_{i}+\sqrt{\sum_{n}\left[C_{C n}(\eta)\left(S_{A}\right)_{c n}\right]^{2}}\right] \rho_{\ell} R \cos \theta
$$

When the contribution of only the fundamental sloshing mode is considered, which would be adequate in most cases, Equation 4.22 reduces to

$$
p_{\max }(\eta, \theta)=\left[C_{i}(\eta)\left(S_{A}\right)_{i}+C_{c 1}(\eta)\left(S_{A}\right)_{c 1}\right] \rho_{\ell} R \cos \theta
$$

For the terms retained, Equation 4.23 is, of course, the same as that obtained by taking the numerical sum of the component maxima.

The hydrodynamic pressures referred to above are in excess of the hydrostatic, and must be added to the latter to obtain the total wall pressures exerted by the liquid.

\subsubsection{Relative Magnitudes of Impulsive and Convective Pressures}

For the tank proportions normally encountered in practice, the hydrodynamic effects are dominated by the impulsive component of response. This is due mainly to the fact that the fundamental impulsive frequency of the tank-liquid system, $f_{1}$, normally falls 
in the amplified, nearly constant region of the pseudoacceleration response spectrum, for which the value $\left(S_{A}\right)_{1}$ is quite high. By comparison, the fundamental sloshing frequency, $f_{c 1}$, is significantly lower and is associated with correspondingly smaller values of $\left(S_{A}\right)_{c 1}$. While the spectral pseudoaccelerations corresponding to the higher sloshing frequencies may be substantial, they are associated with values of $c_{c n}(\eta)$ which are so much smaller than those for the fundamental sloshing mode (see, for example, Figure 4.2) that their contributions are generally unimportant. In fact, excellent approximations to the total hydrodynamic effects may generally be obtained by superposing on the impulsive effects those of the fundamental convective mode only; this approximation is adopted for several of the expressions presented in the following sections.

\subsubsection{Response of Partially Filled Tanks}

The information in the preceding sections is deduced from analyses in which the height of the liquid in the tank, $\mathrm{H}_{\ell}$, was considered to be equal to the tank height, $\mathrm{H}_{\mathrm{t}}$. To a reasonable degree of approximation, the results can also be used for partially filled tanks, provided the height $\mathrm{H}_{\ell}$ in all of the expressions that have been presented is interpreted properly as the liquid height and not as the tank height. Note, in particular, that $\mathrm{H}_{\ell}$ affects Equation 4.13 both directly through its presence in the denominator of that expression and indirectly through the dimensionless coefficient $C_{1}$, which is a function of $H_{\ell} / R$. Being functions of the natural frequencies $f_{1}$ and $f_{c n}$, the pseudoaccelerations $A_{1}(t)$ and $A_{c n}(t)$ also depend on $H_{\ell}$. It should be realized, however, that the maximum or critical hydrodynamic effects are likely to occur when the tank is completely, rather than only partially, filled.

\subsubsection{Evaluation of Critical Effects}

With the maximum values of the hydrodynamic wall pressures 
established, the corresponding values of the tank forces may be computed by means of a static analysis, making use of an appropriate shell theory or any one of a number of available computer programs. However, a detailed evaluation of the state of stress throughout the shell is generally not necessary, and it is sufficient to evaluate the effects across certain critical sections by simpler approaches. In particular, circumferential hoop stresses in the tank wall may be determined from the wall pressures considering the shell to behave as a series of isolated rings, and shearing and axial stresses across normal sections may be computed from the corresponding shearing forces and bendina moments by application of the beam theory.

If $\bar{p}_{\max }$ represents the maximum value of the combination of the hydrostatic and hydrodynamic wall pressure at an arbitrary level, the maximum value of the circumferential hoop stress in the tank wall at that level, $\left(\sigma_{\theta}\right)_{\max }$ is given by

$$
\left(\sigma_{\theta}\right)_{\max }=\frac{\bar{p}_{\max } R}{t_{t w}}
$$

in which $t_{t w}$ should be taken as the actual wall thickness at the level under consideration. The stress evaluated in this manner should be compared to the allowable stress for a normal section one foot above the base as well as for each section where $t_{t w}$ changes.

Similarly, if $V_{\max }$ and $\mathrm{M}_{\max }$ represent the maximum values of the shearing force and bending moment across a normal section, the maximum value of the corresponding shearing stress in the tank wall, $\tau_{\max }$ is given by

$$
\tau_{\max }=2 \frac{V_{\max }}{A_{t w}}=\frac{1}{\pi} \frac{V_{\max }}{R t_{t w}}
$$

and the corresponding value of the axial force per unit of circumferential length, $\left(\mathrm{N}_{\mathrm{z}}\right)_{\max }$, is given by

$$
4-15
$$




$$
\left(N_{z}\right)_{\max }=\frac{M_{\max }}{\pi R^{2}}
$$

Finally, the maximum axial stress, $\left(\sigma_{z}\right)_{\max }$ is given by

$$
\left(\sigma_{z}\right)_{\max }=\frac{\left(N_{z}\right)_{\max }}{t_{t W}}
$$

in which $t_{\text {tw }}$ should again be taken as the thickness of the tank wall for the section under consideration. The critical sections and the evaluation of the maximum shear and bending moment are discussed in the following sections.

\subsubsection{Total Hydrodynamic Force}

The instantaneous value of the total hydrodynamic force induced against the tank wall, $P(t)$, may be expressed, in a form analogous to Equation 4.1 , by the sum of an impulsive component and a series of convective components as

$$
P(t)=m_{i} A_{i}(t)+\sum_{n=1}^{N} m_{c n} A_{c n}(t)
$$

in which $\mathrm{m}_{1}=$ the component of the liquid mass which may be considered to move in unison with the tank wall, and $m_{c n}=$ the mass associated with the nth sloshing mode of vibration of the liquid. Obtained by integration of the appropriate components of the hydrodynamic wall pressures, these masses are given by

$$
{ }^{*} m_{c n}=\left\{\frac{2}{\lambda_{n}\left(\lambda_{n}^{2}-1\right)\left(H_{\ell} / R\right)} \tanh \left[\lambda_{n}\left(H_{\mathrm{l}} / R\right)\right]\right\} m_{\mathrm{l}}
$$

and

$$
m_{i}=m_{\ell}-\sum_{n=1}^{N} m_{c n}
$$

in which $\mathrm{m}_{\ell}=\pi \mathrm{R}^{2} \mathrm{H}_{\ell} \rho_{\ell}=$ the total liquid mass. The values of $\mathrm{m}_{1}$, $4-16$ 
$m_{c 1}$ and $m_{c 2}$, normalized with respect to the total liquid mass, $m_{l}$, are listed in columns 3,7 and 8 of Table 4.2. In view of the smallness of the values of $m_{o n}$ for $n \geq 2$, it is normally sufficient to consider only the first term of the summation in Equation 4.28 .

\subsubsection{Critical Tank Forces}

\subsubsection{Base Shear}

For cantilever tanks with a free top, the base shear is clearly equal to the total hydrodynamic wall force defined by Equation 4.28

For top-constrained tanks of the proportions considered herein, the instantaneous value of the base shear, $v(0, t)=v_{b}(t)$, may be expressed approximately in a form analogous to Equation 4.28 as

$$
V_{b}(t)=0.60 m_{i} A_{i}(t)+\alpha_{c 1} m_{c 1} A_{c 1}(t)
$$

in which $\alpha_{c 1}$ is a dimensionless factor representing the contribution of the fundamental convective mode. The effects of the higher convective modes are generally quite small, and are not provided for in this expression. The values of $\alpha_{c 1}$ for tanks constrained at the top either by rolier or hinge supports are listed in Table 4.4. These values as well as the factor 0.60 in Equation 4.31 are for fully filled systems, for which the resulting forces are greater than for partially filled systems.

The factor 0.60 in Equation 4.31 indicates that, for both conditions of top support considered, the impulsive component of the base shear is 60 percent of the corresponding component of the total force exerted on the tank wall. similarly, the values in Table 4.4 indicate that the convective component of the base shear may range from 37 percent to 50 percent of the corresponding component of the total force. The shear at the 
top is clearly equal to the difference between the total hydrodynamic wall force and the base shear.

With the instantaneous values of the end shears established, their maximum values may be obtained by appropriate combinations of the peak values of their impulsive and convective components, as previously indicated for the corresponding wall pressures.

\subsubsection{Bending Moments Across Normal Tank Sections}

Moments for Cantilever Tanks. For a cantilever tank with a totally free top boundary, the absolute maximum bending moment occurs across a normal section immediately above thie tank base, and its instantaneous value, $M(0, t)=M_{b}(t)$, is given by.

$$
M_{b}(t)=0.40 m_{i} H_{\ell} A_{i}(t)+\sum_{n=1}^{N} m_{c n} h_{c n} A_{c n}(t)
$$

in which the first term represents the impulsive component and the summation represents the convective components. The quantity $h_{c n}$ in this equation represents the height at which the nth sloshing mass may be considered to be concentrated, and it is defined by

$$
h_{c n}=\left\{1-\frac{1}{\lambda_{n}\left(H_{l} / R\right)} \tanh \left[\frac{\lambda_{n}}{2}\left(H_{l} / R\right)\right]\right\} H_{l}
$$

The values of $h_{c 1}$ and $h_{c 2}$ are listed in columns 9 and 10 of Table 4.2. Equation 4.32 reveals that the impulsive mass, $m_{1}$, is effectively concentrated at a distance of $0.40 \mathrm{H}_{2}$ from the base.

For cantilever tanks for which the thickness of the tank wall decreases with height, the bending moment inducing the largest axial wall stress may well occur at some distance away from the base. It is desirable, therefore, to evaluate the heightwise variation of the moment as well.

On a normal section defined by the dimensionless distance $\eta_{0}$ the $4-18$ 
instantaneous value of the impulsive component of the bending moment, $M_{1}(\eta, t)$, can most conveniently be expressed in terms of the total mass of the liquid, $m_{\ell}$, and the liquid height, $H_{\ell}$, as

$$
M_{i}(\eta, t)=d_{1}(\eta) m_{l} H_{l} A_{1}(t)
$$

and the corresponding convective component, $M_{0}(\eta, t)$, may be expressed by the series

$$
M_{c}(\eta, t)=\sum_{n=1}^{N} d_{c n}(\eta) m_{1} H_{1} A_{c n}(t)
$$

in which $d_{1}(\eta)$ and $d_{o n}(\eta)$ are dimensionless functions. The values of $d_{1}(\eta)$ and $d_{c n}(\eta)$ for cantilever tanks of different proportions are listed in Tables 4.5 and 4.6 .

For a section immediately above the base, the values of $d_{1}$ and $d_{c n}$ are related to the quantities $0.40 m_{1}$ and $m_{c n} h_{c n}$ in Equation 4.32 as follows:

$$
d_{i}=0.40 \frac{m_{i}}{m_{l}}
$$

and

$$
d_{c n}=\frac{h_{c n}}{H_{l}} \frac{m_{c n}}{m_{l}}
$$

However, because the two sets of quantities were evaluated by procedures of somewhat different accuracy, the values obtained from Equations 4.36 and 4.37 do not always agree with those listed in Tables 4.5 and 4.6 to the number of significant figures reported.

Moments for Top-Constrained Tanks. The values of $d_{1}(\eta)$ and $d_{c 1}(\eta)$ in Equations 4.34 and 4.35 for tanks with a roller support $7 t$ the top are listed in Tables 4.7 and 4.8 , respectively, and the corresponding values for tanks hinged at the top are given in 
Tables 4.9 and 4.10. In addition, the functions $d_{1}(\eta)$ and $d_{c 1}(\eta)$ for cantilever and top-constrained tanks with $H_{\ell} / R=0.75$ are compared in Figure 4.4 .

The values in this figure and the tables referred to, like those presented in Tables 4.5 and 4.6 , are strictly valid for steel tanks with $t_{t w} / R=0.001$ that are fully filled with water. The ratio of the mass densities for the liquid and tank material in this case is $\rho_{l} / \rho_{t}=0.127$, and Poisson's ratio of the tank material is $\nu_{t}=0.3$. However, provided the tanks are fully filled, the results may be used with good accuracy for all combinations of the parameters that are likely to be encountered in the type of applications envisioned herein.

Examination of the data in Tables 4.5 through 4.10 reveals the following:

1. The maximum values of the bending moment coefficients for tanks with a roller support at the top are, as might be expected, smaller than those for similarly excited cantilever tanks of the same proportions. By contrast, the corresponding values for tanks with the hinged boundary are either of the same order of magnitude or significantly larger than those for cantilever tanks.

2. The heightwise distributions of both the impulsive and convective components of the bending moments for the top-constrained tanks are more nearly uniform than for the corresponding cantilever tanks. Furthermore, whereas the absolute maximum values of the moment for the cantilever tanks occur at the base, those for the top-constrained tanks occur at or close to midheight.

3. For a prescribed direction of the hydrodynamic wall pressure, the bending moments in top-constrained tanks act in a direction opposite to that for the corresponding 
cantiiever tanks. This fact is indicated by the opposite signs of the data presented in Tables 4.5 and 4.6 and in Tables 4.7 through 4.10 .

The trends referred to above are Poisson's ratio-related, and may be explained as follows. Because of the Poisson's ratio effect, a tensile circumferential (hoop) force in the tank wall tends to induce axial shortening of the wall, whereas a compressive circumferential force tends to induce axial extension. For a tank that is fully constrained against axial movements, these displacements naturally cannot occur. As a result, the circumferential tensile forces caused by the hydrodynamic wall pressures over half of the tank induce tensile axial forces over that half, and the circumferential compressive forces over the opposite half induce compressive axial forces in that half. The net effect of these axial forces is a bending moment over sections normal to the tank axis. Furthermore, the direction of this moment is opposite to that of the moment induced in a similarly excited cantilever tank.

The axial force per unit of circumferential length, $\mathrm{N}_{z}$, corresponding to the moments referred to above may be determined from Equation 4.26. For tanks that are totally constrained in the axial direction, the value of $\mathrm{N}_{z}$ due to this Poisson's ratio-related effect is approximately $\nu_{t}$ times (for steel tanks, 30 percent of) the corresponding average hoop force over the tank height. The latter force is given roughly by

$$
\left(N_{\theta}\right)_{a v}=\left[\frac{m_{i}}{m_{l}}\left(S_{A}\right)_{i}+\frac{m_{c 1}}{m_{l}}\left(S_{A}\right)_{c 1}\right] \rho_{l} R^{2}
$$

It should be realized that, for axially constrained tanks, Poisson's ratio-related axial forces also develop under hydrostatic loads, and that these forces must be considered in assessing the consequences of the corresponding forces induced by the hydrodynamic actions. For the tank proportions and 
intensities of ground shaking normally encountered in practice, the uniform axial tensile forces induced by the hydrostatic wall pressures are generally larger than the corresponding tensile and compressive forces induced by the hydrodynamic pressures. The net effect under these conditions would be a reduction in the magnitudes of the compressive axial forces compared to those developed in a free-standing cantilever tank, and a consequent reduction in the tendency for wall buckling.

The Poisson's ratio-related axial forces may easily be relieved by slight movements of the supports or slight bending of the tank wall. since such movements are almost certain to occur in practice, the roller condition of top support is believed to be a more realistic representation of actual conditions than the hinged condition.

The effect of Poisson's ratio $\nu_{t}$ on the bending moments induced across normal sections of tanks with a roller support at the top is illustrated in Table 4.11. Listed are the values of the moment coefficients $d_{1}(\eta)$ and $d_{c 1}(\eta)$ for tanks with $H_{\ell} / R=0.75$ and values of $\nu_{t}=0$ and 0.3 . It is observed that increasing $\nu_{t}$ increases the positive moments and decreases the negative moments. Note, in particular, that whereas the base moments are negative for $\nu_{\mathrm{t}}=0$, they are positive for $\nu_{\mathrm{t}}=0.3$.

Further insights into the magnitude and distribution of the axial forces induced in top-constrained tanks may be gained from the membrane solutions presented in Appendix E.

\subsubsection{Effects of Tank Inertia}

To the hydrodynamic effects considered in the preceding sections must also be added the inertia effects of the tank itself. However, unless the mass of the roof is substantial compared to that of the contained liquid and unless the roof is free to move laterally, these effects are likely to be negligible. When 
their consideration is warranted, they may be evaluated conservatively by considering the tank to behave as a rigid body but taking the pseudo-acceleration of the sys'cem $\left(S_{A}\right)_{1}$ as the maximum response acceleration.

In particular, for a cantilever system, the maximum value of the base shear induced by the tank inertia is given by

$$
V_{\max }=\left(m_{w}+m_{r}\right)\left(S_{A}\right)_{i}
$$

in which $m_{w}$ and $m_{r}$ are the total masses of the tank wall and roof, respectively. similarly, the maximum base moment is given by

$$
M_{\max }=\left(m_{w} H_{w}+m_{r} H_{r}\right)\left(S_{A}\right)_{i}
$$

in which $\mathrm{H}_{\mathrm{r}}$ is the distance from the base to the centroid of the roof mass, and $\mathrm{H}_{\mathrm{w}}$ is the corresponding distance to the center of gravity of the inertia forces of the tank wall.

\subsubsection{Hydrodynamic Forces Transmitted to Tank Support}

The horizontal shear transmitted through the base plate of the tank to its support is clearly equal to the shear $v_{b}(t)$ induced across a section immediately above the plate. By contrast, the bending moments across sections just above and below the base plate are different; the moment beneath the plate also includes the effect of the radially varying hydrodynamic pressures exerted on the plate itself (see Figure 4.3).

The instantaneous value of the moment increment $\Delta M_{b}(t)$ due to the hydrodynamic base pressures may be expressed in a form analogous to Equations 4.34 and 4.35 s

$$
\Delta M_{b}(t)=e_{i} m_{l} H_{l} A_{i}(t)+e_{c 1} m_{l} H_{l} A_{c 1}(t)
$$

in which the first term represents the contribution of the impulsive component, and the second term represents the contribution of the fundamental convective component. The 
values of $e_{1}$ for tanks of different proportions are listed in Column 4 of Table 4.2 , whereas those of $e_{c 1}$ are defined by

$$
e_{c 1}=\frac{2\left(R / H_{\ell}\right)^{2}}{\lambda_{1}^{2}\left(\lambda_{1}^{2}-1\right) \cosh \left[\lambda_{1}\left(H_{\ell} / R\right)\right]}
$$

and they are listed in column 11 of the table. The contributions to $\Delta \mathrm{M}_{b}(t)$ of the higher convective modes of vibration are negligible and are not provided for in Equation 4.41. For tanks with the values of $\mathrm{H}_{\ell} / \mathrm{R} \leq 1$ considered herein, Equation 4.41 may be used for both cantilever and top-constrained systems that are either fully or partially filled. The functions $A_{1}(t)$ and $A_{c l}(t)$ in this equation are naturally different for the different conditions.

The total moment transmitted through the base plate of the tank to its support is obtained by adding Equation 4.41 to the base values of the moments defined by Equations 4.34 and 4.35 . The absolute maximum value of this moment is then obtained by combining the peak values of its impulsive and convective components in the manner indicated previously for other effects. In the implementation of these steps for top-constrained tanks, care should be exercised to ensure that the correct signs are used for the component effects.

For tanks that are supported within vaults, the hydrodynamic forces and moments transmitted to the vaults are as shown in Figure 4.5. Part (a) of the figure refers to a free-standing, cantilever tank, whereas parts (b) and (c) refer to topconstrained tanks with roller and hinge supports, respectively. The forces induced by the cantilever system are merely the shear $V_{b}(t)$ and the bending moment $M_{b}(t)+\Delta M_{b}(t)$ transmitted through the base plate of the tank, whereas those for the top-constrained systems, also include the reactions of the tank at the top. The instantaneous value of the horizontal top reaction is clearly equal to the difference between the total 
hydrodynamic wall force $P(t)$ defined by Equation 4.28 and the base shear $v_{b}(t)$. Similarly, the intensity of the vertical top reaction for the tank with the hinge support may be determined from the top values of the bending moments defined by Equations 4.34 and 4.35 , by making use of Equation 4.26 and the top values of $d_{1}(\eta)$ and $d_{c 1}(\eta)$ listed in Tables 4.9 and 4.10 .

For the evaluation of the soil-structure interaction effects considered in chapter 6 , one needs to know the total horizontal force, $P(t)$, and the total overturning moment transmitted to the vault. Denoted by $M_{b}^{\prime}(t)$, this moment is normally referred to a centroidal axis at the interface of the tank base and the supporting vault which is normal to the plane of the tank motion. The relevant axis is identified on the diagrams of Figure 4.5 by a heavy dot.

For a cantilever tank, the total overturning moment for the vault is merely equal to the moment $M_{b}(t)+\Delta M_{b}(t)$ transmitted through the base plate of the tank, whereas for the topconstrained tanks, it also includes the effects of the tank reactions at the top. While the additional moments due to the latter forces may be evaluated from information already presented, the total moment for both the top-constrained and cantilever tanks can more simply be expressed in a form analogous tor Equation 4.32 as

$$
M_{b}^{\prime}(t)=m_{i} h_{i}^{\prime} A_{i}(t)+m_{c 1} h_{c 1}^{\prime} A_{c 1}(t)
$$

in which the first term represents the impulsive component, and the second term represents the fundamental convective component. The contributions of the higher convective masses are negligible and are not considered. The quantity $h_{i}^{\prime}(t)$ in this equation represents the height at which $m_{1}$ must be concentrated to yield the correct impulsive component of the overturning moment for the vault, and $h_{c 1}^{\prime}$ represents the corresponding height for the fundamental convective mass. These heights are defined by 


$$
h_{i}^{\prime}=\left[0.40+e_{i} \frac{m_{l}}{m_{i}}\right] H_{\ell}
$$

and

$$
h_{c 1}^{\prime}=\left[\frac{h_{c 1}}{H_{l}}+e_{c 1} \frac{m_{l}}{m_{c 1}}\right] H_{l}
$$

and their values for tanks of different proportions are listed in Columns 5 and 12 of Table 4.2 .

Equations 4.43 through 4.45 follow from the fact that the total overturning moment for the vault also equals the sum of the base moments due to the hydrodynamic pressures exerted on the wall and the base plate of the tank. These equations may be used for both cantilever and top-constrained tanks, and for both full and partially filled systems. As already intimated, the pseudoacceleration functions in these equations are, of course, different for different systems.

\subsubsection{Modeling of Tank-Liquid System}

For the purpose of evaluating the total hydrodynamic force and the total overturning moment exerted by the tank on the supporting vault, the tank-liquid system may be modeled by two cantilever sticks with masses $m_{1}$ and $m_{c 1}$ concentrated at heights $h_{i}^{\prime}$ and $h_{c 1}^{\prime}$ from the base, as shown in Figure 4.6. These masses and heights may be determined from columns $3,5,7$ and 12 of Table 4.2. The cantilever with mass $m_{1}$ in this model simulates the effects of the impulsive mass of the liquid, whereas the one with mass $m_{c 1}$ simulates the effects of the fundamental convective portion of the liquid mass. The stiffness. of the cantilever with the mass $m_{1}$ must be such that its natural frequency is equal to the fundamental natural frequency of the tank-liquid system defined by Equation 4.13. Similarly, the stiffness of the cantilever with the mass $m_{c 1}$ must be such that its natural

$$
\text { 4-26 }
$$


frequency is equal to the fundamental sloshing frequency of the liquid defined by Equation 4.11. Being negligible, the effects of the higher convective masses are not provided for in the model.

This model may be used with good accuracy for both cantilever and top-constrained tanks, whether fully or only partially filled with liquid. The natural frequency of the model will naturally be different in the different cases. However, in the form presented so far, the model is valid only for rigidly supported systems, for which the base is subjected to a purely horizontal, translational motion. For flexibly supported systems, for which the base motion also includes a rocking component, the base of the model should be considered to possess a mass moment of inertia, $I_{b}$, about a horizontal centroidal axis. This adjustment is needed to provide for the moment of the additional hydrodynamic base pressures induced by the rocking component of the excitation. The values of $I_{b}$ for tanks of different proportions are listed in Column 6 of Table 4.2 ; these are normalized with respect to $m_{l} R^{2}$.

The modeling of the tank-liquid system for the vertical component of ground shaking is considered in section 4.5 .4 .

\subsection{EFFECTS OF ROCKING COMPONENT OF BASE MOTION}

For the responses defined so far, the tank base has been presumed to experience a purely translational, horizontal motion. The magnitudes of the rocking components of foundation motion that may realistically be expected in practice are generally small and have a negligible effect on the convective components of response.

The impulsive effects induced by the combination of the horizontal and rocking components of base motion may be determined from the expressions presented in the preceding 
sections merely by redefining the response pseudoacceleration $A_{1}(t)$ in these expressions to correspond to an effective, horizontal base acceleration

$$
\tilde{x}_{\theta}(t)=\ddot{x}(t)+h_{i}^{\prime} \psi(t)
$$

This is tantamount to replacing $\ddot{x}(\tau)$ in Equation 4.9 by $\ddot{x}_{e}(\tau)$. The function $\psi(t)$ in Equation 4.46 represents the instantaneous rocking acceleration of the tank base, and $h_{i}^{\prime}$ represents the height defined by Equation 4.44 .

Because of phase differences between $\ddot{x}(t)$ and $\psi(t)$, the maximum values of $\ddot{x}_{e}(t)$ and of the associated response pseudoacceleration are likely to be smaller than those corresponding to $\ddot{x}(t)$. As a result, the maximum response due to $\ddot{x}_{e}(t)$ is likely to be smaller than that due to $\ddot{x}(t)$. In the absence of the correct phase relationship between $\ddot{x}(t)$ and $\psi(t)$, the maximum effects of the component motions may be combined by the square-root-of-thesum-of-squares rule, leading to a conservative estimate of the response.

\subsection{EFFECTS OF VERTICAL COMPONENT OF BASE MOTION}

\subsubsection{Hydrodynamic Effects}

The hydrodynamic wall pressure induced by the vertical component of ground shaking is uniformly distributed in the circumferential direction and may be considered to increase from top to bottom as a half-sine wave. The maximum value of this pressure at a level defined by the dimensionless distance $\eta$ is given by

$$
p_{v}(\eta)=0.8\left[\cos \frac{\pi}{2} \eta\right] \rho_{l} H_{l}\left(S_{A}\right)_{v}
$$

in which $\left(S_{A}\right)_{v}$ represents the spectral pseudoacceleration of a similarly excited single-degree-of-freedom system, the natural frequency and damping of which are equal to those of the fundamental, axisymmetric, breathing mode of vibration of the 
tank-liquid system. For roofless tanks, the latter frequency, $f_{v}$, may be expressed in forms similar to those of Equations 4.13 and 4.14 as

$$
f_{v}=\frac{1}{2 \pi} \frac{C_{v}}{H_{\ell}} \sqrt{\frac{E_{t}}{\rho_{t}}}
$$

or

$$
f_{v}=\frac{2,680 C_{v}}{H_{l}}
$$

in which $C_{v}$ is a dimensionless coefficient that depends on $H_{\ell} / R$, $t_{\mathrm{tw}} / \mathrm{R}, \rho_{\ell} / \rho_{\mathrm{t}}$ and $\nu_{\mathrm{t}} ; \mathrm{f}_{\mathrm{v}}$ is expressed in cycles per second; and $\mathrm{H}_{\ell}$ in Equation 4.49 is expressed in feet. Identified with the subscript $r$, the values of $c_{v}$ for the reference steel tanks with $t_{t w} / R=0.001$ and $\rho_{\ell} / \rho_{t}=0.127$ are given in the extreme right column of Table 4.3 . These results may be used irrespective of the condition of tank support at the top. The results for other values of $t_{t w} / R$ and $\rho_{\ell} / \rho_{t}$ may be determined from an expression analogous to Equation 4.15. With the hydrodynamic pressures $p_{v}(\eta)$ determined from Equation 4.47 , the corresponding forces in the tank wall may be determined by static analysis.

For tanks that are constrained in the axial direction, in addition to the circumferential hoop forces, there develop poisson's-ratio related axial forces analogous to those considered in section 4.3.5.2. These forces are uniformly distributed in the axial direction, and their maximum intensity is equal to the product of Poisson's ratio $\nu$ and the average intensity of the maximum hoop forces over the tank height.

\subsubsection{Effects of Tank Inertia}

For the vertical component of shaking considered in this section, the inertia of the tank wall and roof lead to oscillatory axial forces which are uniformly distributed in the circumfer- 
ential airection and attain their maximum values at the base. These forces are normally small and may be neglected. However, they may be evaluated simply by considering the tank wall to be rigid. This approach is justified by the fact that the fundamental natural frequency of the tank-roof system in the axial, column-like mode of vibration is generally much higher than the dominant frequencies of the oscillations in the base motion.

For cantilever tanks and for tanks with a roller support at the top, the maximum axial force per unit of circumferential length, $\left(\mathrm{N}_{\mathrm{z}}\right)_{\max }$, may be determined from

$$
\left(N_{z}\right)_{\max }=\frac{1}{2 \pi R}\left(m_{w}+m_{r}\right) \ddot{z}_{0}
$$

in which $\ddot{z}_{0}$ is the maximum value of the vertical component of the base acceleration.

For tanks that are hinged at the top, the inertia force of the roof will be resisted by the top support, and the maximum axial force at the base will be one-half of the force defined by the first term of Equation 4.50 .

\subsubsection{Combination with other Effects}

The effects of the vertical component of base shaking should be combined with those of the horizontal and rocking components by the square-root-of-the sum-of-squares rule.

For axially constrained tanks, it should be recalled that Poisson's ratio related axial forces are induced under both hydrodynamic and hydrostatic conditions of loading. As a matter of fact, for realistic intensities of ground shaking, the maximum compressive axial forces due to the hydrodynamic effects will normally be counter-balanced by the axial tensile forces due to the hydrostatic effects. 


\subsubsection{Modeling of Tank-Liquid System}

For the purpose of evaluating the total vertical hydrodynamic force transmited through the tank base to the supporting vault, the tank-liquid system may be modeled as a single-degree-offreedom system with a mass equal to 80 percent of the total liquid mass and a natural frequency and damping factor equal to those of the tank-liquid system in its fundamental axisymmetric mode of vibration.

\subsection{EFFECTS OF SOIL-STRUCTURE INTERACTION}

In the approach outlined herein, the effects of soil-structure interaction are provided for in the evaluation of the acceleration histories $\ddot{x}(t), \ddot{\psi}(t)$ and $\ddot{z}(t)$, and need not be reconsidered. It should be noted that these accelerations are of the motions actually experienced by the tank base and not those experienced by the ground under free-field conditions. Similarly, the pseudoaccelerations $A_{1}(t)$ and $A_{c n}(t)$ and $A_{v}(t)$ are for the actual motions of the tank base. These input and response quantities may be determined directly from the analysis of the tank-vault-soil system considered in Chapter 6, and need not be evaluated independently. The effects of potential variations in the free-field ground motions between the top and bottom of the vault are accounted for in the analysis of the vault-soil system.

If the tank-liquid system is analyzed for the free-field ground motion, the effects of soil-structure interaction on the tank response may be approximated by the procedures of References $4.7,4.8$ and 4.10 by appropriately reducing the fundamental natural frequency of the tank-liquid system and increasing its damping. These effects need be considered only for the impulsive components of response, as the effects on the convective components are negligible. 


\subsection{SURFACE DISPLACEMENTS OF LIQUID}

The maximum vertical displacement of the liquid suriace, the socalled slosh height $h_{s}$, is needed to define the freeboard that must be provided to prevent the liquid from impacting the roof. This displacement may be determined from

$$
h_{s}=R \sqrt{\left(0.837 \frac{\left(S_{A}\right)_{C 1}}{g}\right)^{2}+\left(0.073 \frac{\left(S_{A}\right)_{C 2}}{g}\right)^{2}+\left(0.028 \frac{\left(S_{A}\right)_{C 3}}{g}\right)^{2}+\cdots}
$$

Equation 4.51 accounts for the effect of the horizontal component of base shaking only. The magnitude and frequency characteristics of the rocking component of base motion for the tanks examined herein are normally such that the contribution of this component to the surface displacement of the liquid is negligible (Reference 4.10). When both components of base motion are sufficiently important to warrant their consideration, the combined effect may be evaluated from Equation 4.51 by interpreting the pseudoaccelerations $\left(S_{A}\right)_{\mathrm{cn}}$ to correspond to the effective horizontal base acceleration defined by

$$
\left[\ddot{x}_{\theta}(t)\right]_{c n}=\ddot{x}(t)+h_{c n}^{\prime} \ddot{\psi}(t)
$$

in which $h_{c n}^{\prime}$ represents the height of the nth convective liquid mass (see Reference 4.9). The values of $h_{c_{1}}^{\prime}$ for tanks of different proportions are listed in Table 4.2, and those of $h_{c}^{\prime}$ and $h_{c 3}^{\prime}$ may, if needed, be determined from generalized versions of Equations 4.42 and 4.45 by replacing $\lambda_{1}$ by $\lambda_{n}$ and $\left(S_{A}\right)_{c 1}$ by $\left(S_{A}\right)_{c n}$.

If the available freeboard is not adequate for the computed sloshing height, either the liquid level must be lowered or the tank head and wall must be designed to withstand the impact of the sloshing liquid. These issues are addressed further in Chapter 6 , and more detailed guidance will be provided in a future edition of this publication. 
In assessing the capacity of the tank wall near its junction to the roof, the maximum hydrodynamic pressure computed from Equation 4.3 for $\eta=1$ must be applied at the highest elevation of the water surface, i.e., at $z=H_{l}+h_{s}$, not at the elevation of the liquid surface at rest. 


\section{REFERENCES}

4.1 Haroun, M.A., and Abdel-Hafiz, E.A., "A Simplified Seismic Analysis of Rigid Base Liquid storage Tanks Under Vertical Excitation with soil-structure Interaction", Soil Dynamics Earthquake Engineering, Vol. 5, 1986, pp. 217-225.

4.2 Haroun, M.A., and Housner, G.W., "Seismic Design of Liquid storage Tanks", Journal of Technical Councils, ASCE, Vol. 107, No. 1, 1981, pp. 191-207.

4.3 Haroun, M.A., and Housner, G.W., "Dynamic Characteristics of Liquid Storage Tanks", Journal of the Engineering Mechanics Division, ASCE, Vol. 108, No. EM5, 1982, pp. $783-800$.

4.4 Tang, Y., Uras, R.A., and Chang, Y.W., "Effect of Viscosity on Seismic Response of Waste storage Tanks", Argonne National Laboratory, Reactor Engineering Division, March 1992 .

4.5 Veletsos, A.S., "Seismic Response and Design of Liquid Storage Tanks", Guidelines for the Seismic Design of oil and Gas Pipeline systems, Technical Council on Lifeline Earthquake Engineering, ASCE, New York, 1984, pp. 255-370 and 443-461.

4.6 Veletsos, A.S., "On Influence of Liquid Viscosity on Dynamic Response of Tanks", Report presented to BNL/DOE Seismic Experts Panel, Rockville, Maryland, April 10, 1992.

4.7 Veletsos, A.S., and Tang, Y., "Dynamics of Vertically Excited Liquid storage Tanks", Journal of structural Division, ASCE, Vol. 112, 1986, pp. 1228-1246. 
4.8 Veletsos, A.S., and Tang, Y., "Interaction Effects in Vertically Excited steel Tanks", Dynamic Response of Structures (Eds. G.C. Hart and R.B. Nelson), ASCE, 1986, pp. 636-643.

4.9 Veletsos, A.S., and Tang, Y., "Rocking Response of Liquid Storage Tanks", Journal of Engineering Mechanics, ASCE, Vol. 113, Nov. 1987, pp. 1774-1792.

4.10 Veletsos, A.S., and Tang, Y., "Soil-structure Interaction Effects for Laterally Excited Liquid storage Tanks," Journal of Earthquake Engineering and Structural Dynamics, Vol. 19, 1989, pp. 473-496.

4.11 Veletsos, A.S., and Shivakumar, P., "Hydrodynamic Effects in Tanks with Different Conditions of Support", Preceedings, Third DOE Natural Phenomena Hazards Mitigation Conference, st. Louis, MI, October, 1991, pp. 578-587.

4.12 Veletsos, A.S., Shivakumar, P., Tang, Y. and Tang, H.T., "Seismic Response of Anchored Steel Tanks", Proceedings, Third symposium on Current Issues Related to Nuclear Plant Structures, Equipment and Piping, A. J. Gupta, Editor, North Carolina state University, Raleigh, NC, 1990, pp. $x / 2-2$ to $x / 2-15$.

4.13 Veletsos, A.S., and Yang, J.Y., "Earthquake Response of Liquid storage Tanks", Advances in Civil Engineering Through Engineering Mechanics, Proceedings ASCE/EMD Specialty Conference, Raleigh, North Carolina, 1977, pp. 1-24. 
NOTATION

$A(t)$ instantaneous pseudoacceleration for a simple oscillator

$A_{c n}(t)$ instantaneous pseudoacceleration for nth convective or sloshing mode of response

$A_{1}(t)$ instantaneous pseudoacceleraton for impulsive component of response

$A_{v}(t)$ instanteous pseudoacceleration for response to vertical component of ground shaking

$c_{c n}(\eta)$ dimensionless function defining axial variation of wall pressure associated with the nth convective or sloshing mode of vibration of liquid

$c_{1}(\eta)$ dimensionless function defining axial variation of impulsive component of wall pressure

$C_{1}$ dimensionless coefficient in expression for $f_{1}$

$\left(C_{1}\right)_{r}$ value of $C_{f}$ for reference values of tank parameters considered in Table 4.3

$c_{v}$ dimensionless coefficient in expression for $f_{v}$

$d_{c n}(\eta)$ dimensionless function of $\eta$ in expression for $n$th convective component of overturning bending moment $M_{c n}$.

$d_{c n} \quad$ value of $d_{c n}(\eta)$ for $\eta=0$

$\mathrm{d}_{1}$ value of $\mathrm{d}_{1}(\eta)$ for $\eta=0$

$d_{1}(\eta)$ dimensionless function of $\eta$ in expression for impulsive component of overturning kending moment $M_{i}$

$D_{1}$ dimensionless function of $H / R$ in approximate expression for $c_{1}(\eta)$

$e_{c n}$ dimensionless factor in expression for $n$th convective component of base moment increment $\Delta \mathrm{M}_{\mathrm{b}}$

$e_{1}$ dimensionless factor in expression for impulsive component of base moment increment $\Delta \mathrm{M}_{\mathrm{b}}$

$E_{t} \quad$ modulus of elasticity of tank material

$f_{c n}$ natural frequency, in cycles per unit of time, of nth convective or sloshing mode of vibration of liquid in tank 
$f_{1}$ fundamental natural frequency of impulsive mode of vibration of tank-liquid system

$f_{v} \quad$ fundamental natural frequency for axisymmetric, breathing mode of vibration of tank-liquid system

g acceleration due to gravity

$G_{t} \quad$ shear modulus of elasticity of tank material

$h_{c n}$ height at which $m_{c n}$ must be concentrated to yield the correct base moment for nth convective component of response

$h_{c n}^{\prime}$ height at which $m_{c n}$ must be concentrated to yield the correct nth convective component of the overturning moment transmitted by the tank-liquid system to the supporting vault

$h_{i}^{\prime}$ height at which $m_{i}$ must be concentrated to yield the correct impulsive component of the overturning moment transmitted by the tank-liquid system to the supporting vault.

$h_{\text {s }}$ maximum vertical displacement or 'slosh height' of liquid surface

$\mathrm{H}_{\ell} \quad$ height of liquid

$\mathrm{H}_{\mathrm{r}} \quad$ distance from tank base to centroid of roof mass

$\mathrm{H}_{\mathrm{t}} \quad$ height of tank

$\mathrm{H}_{w}$ distance from tank base to point of application of resultant of lateral inertia forces for tank wall.

$k_{f}, k_{s}$ stiffness of tank when assumed to behave as a flexural beam and a shear-beam, respectively

$m_{c n} \quad$ liquid mass participating in $n t h$ convective mode of vibration

$m_{1} \quad$ impulsive component of liquid mass, i.e., portion of $m_{l}$ which may be considered to act in synchronism with tank wall

$m_{l} \quad$ total liquid mass

$m_{r} \quad$ total mass of tank roof

$m_{w} \quad$ total mass of tank wall 
M overturning bending moment across a section normal to tank axis

$M_{b}$ value of $M$ for a section immediately above tank base

$M_{b}^{\prime} \quad$ total overturning bending moment transmitted from tank to supporting vault

$\Delta \mathrm{M}_{\mathrm{b}} \quad$ base moment increment induced by hydrodynamic pressures exerted on tank base

$M_{c} \quad$ convective component of $M$

$M_{1} \quad$ impulsive component of $M$

$\mathrm{N}_{z}$ axial force per unit circumferential length of tank wall

$\mathrm{N}_{\theta} \quad$ circumferential or hoop force in tank wall per unit of tank height

$\left(\mathrm{N}_{\theta}\right)_{\text {av }}$ average value of $\mathrm{N}_{\theta}$ over liquid height, $\mathrm{H}_{\ell}$

$\mathrm{p}$ hydrodynamic pressure exerted at an abitrary point of tank wall

$p_{c} \quad$ convective or sloshng component of $p$

$p_{1} \quad$ impulsive component of $p$

$\overline{\mathrm{p}}_{\max }$ maximum value of combination of hydrostatic and hydrodynamic wall pressure at an arbitrary level

$\mathrm{p}_{\max } \quad$ absolute maximum value of $\mathrm{p}$ at an arbitrary point of tank wall

$p_{v} \quad$ hydrodynamic wall pressure induced by vertical component of ground motion

$P(t) \quad$ instantaneous value of total hydrodynamic force exerted on tank wall

$\mathrm{R}$ radius of tank

$\left(S_{A}\right)_{c n}$ absolute maximum or spectral value of $A_{c n}(t)$

$\left(S_{A}\right)_{i}$ absolute maximum or spectral value of $A_{1}(t)$

$\left(S_{A}\right)_{v}$ absolute maximum or spectral value of $A_{v}(t)$

$t$ time

$t_{\text {tw }} \quad$ thickness of tank wall 


\begin{tabular}{|c|c|}
\hline $\mathrm{T}_{\mathrm{cn}}$ & $\begin{array}{l}1 / f_{c n}=\text { natural period of nth convective or sloshing mode } \\
\text { of vibration of liquid in tank }\end{array}$ \\
\hline $\mathrm{T}_{\mathrm{f}}$ & $\begin{array}{l}\text { natural period of vibration of empty tank computed on } \\
\text { assumption that roof mass is the only mass and that tank } \\
\text { behaves as a flexural beam }\end{array}$ \\
\hline $\mathrm{T}_{1}$ & $\begin{array}{l}1 / f_{1}=\text { fundamental natural period of impulsive mode of } \\
\text { vibration }\end{array}$ \\
\hline $\mathrm{T}_{\mathrm{s}}$ & $\begin{array}{l}\text { natural period of vibration of empty tank computed on } \\
\text { assumption that roof mass is the only mass and that tank } \\
\text { behaves as a shear-beam }\end{array}$ \\
\hline $\mathrm{V}$ & horizontal shearing force \\
\hline $\mathrm{V}_{\mathrm{b}}$ & value of $V$ at tank base \\
\hline$\ddot{x}$ & acceleration of horizontal component of base motion \\
\hline$\ddot{x}_{\mathrm{e}}$ & $\begin{array}{l}\text { effective horizontal acceleration of base motion defined } \\
\text { by Equation } 4.46\end{array}$ \\
\hline$\left(\ddot{x}_{e}\right)_{c n}$ & $\begin{array}{l}\text { effective horizontal acceleration of base motion defined } \\
\text { by Equation } 4.52\end{array}$ \\
\hline$z$ & vertical distance measured upward from tank base \\
\hline$\ddot{z}(t)$ & $\begin{array}{l}\text { instantaneous value of acceleration for } \\
\text { component of base motion }\end{array}$ \\
\hline$\ddot{z}_{0}$ & absolute maximum value of $\ddot{z}(t)$ \\
\hline$\alpha_{\mathrm{c} 1}$ & $\begin{array}{l}\text { dimensionless factor in expression for base shear induced } \\
\text { by fundamental convective component of response }\end{array}$ \\
\hline$\zeta$ & percentage of critical damping \\
\hline$\eta$ & $\mathrm{z} / \mathrm{H}_{\ell}=$ dimensionless vertical position coordinate \\
\hline$\theta$ & circumferential angle \\
\hline$\lambda_{n}$ & $\begin{array}{l}\text { nth root of first derivative of Bessel function of first } \\
\text { kind and first order }\end{array}$ \\
\hline$\nu_{\mathrm{t}}$ & Poisson's ratio of tank material \\
\hline$\xi$ & $r / \mathrm{H}_{\ell}=$ dimensionless horizontal position coordinate \\
\hline & ss density of liquid \\
\hline
\end{tabular}


$\rho_{t} \quad$ mass density of tank material

$\sigma_{\theta} \quad$ circumferential or hoop stress in tank wall

$\sigma_{2} \quad$ axial stress in tank wall

$\tau \quad$ shearing stress in tank wall

$\ddot{\psi}(t)$ acceleration of rocking component of base motion

$\omega \quad$ circular natural frequency 


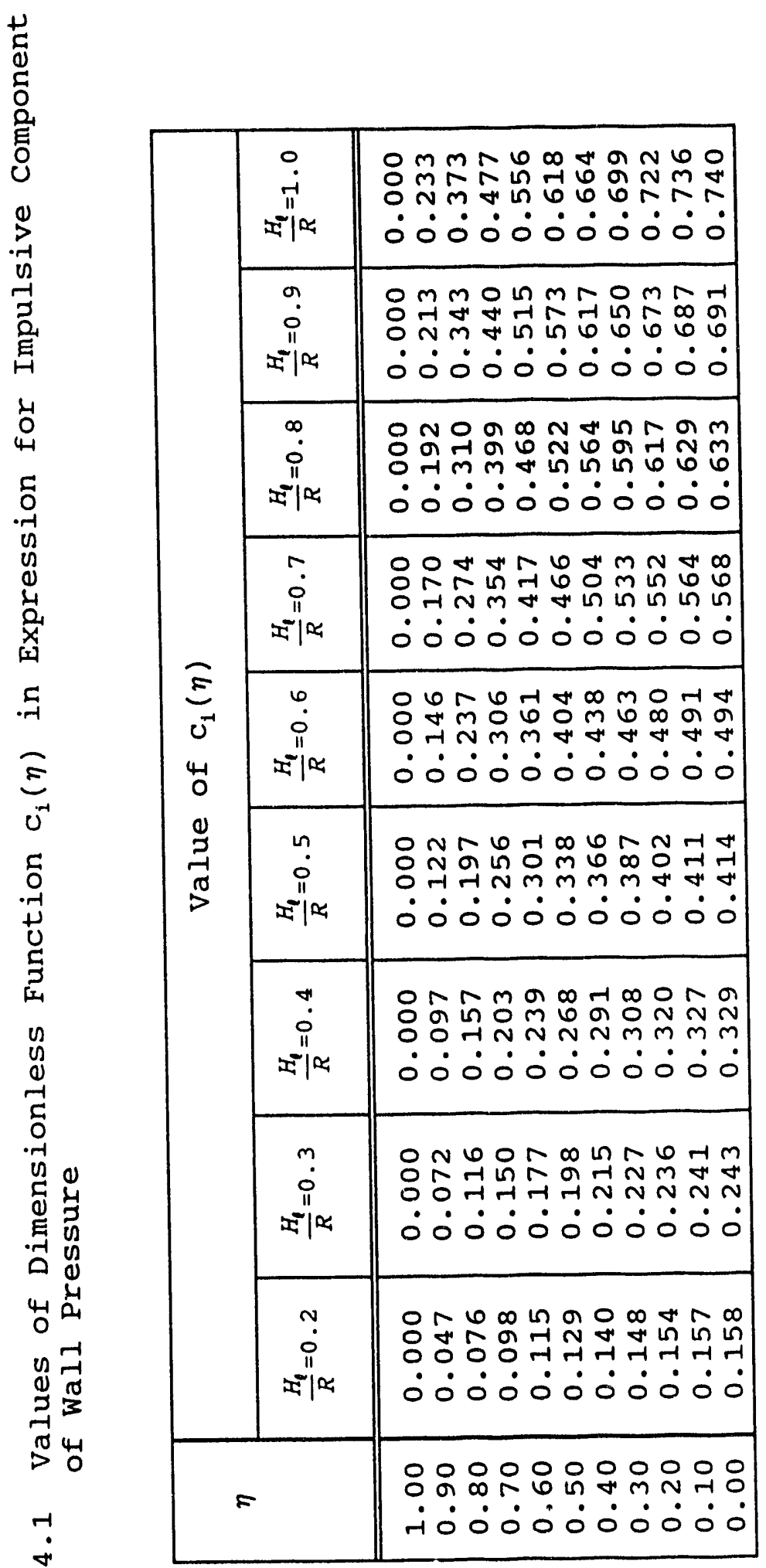

崩 


\begin{tabular}{|c|c|c|c|}
\hline \multirow{6}{*}{ 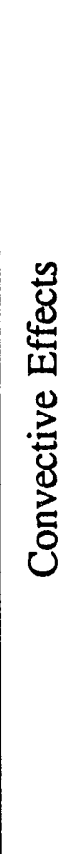 } & $-\bar{y} \mid x$ & $\widetilde{\Xi}$ & 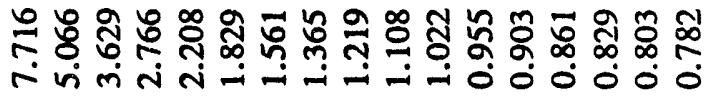 \\
\hline & $\vec{\omega}$ & $\Xi$ & 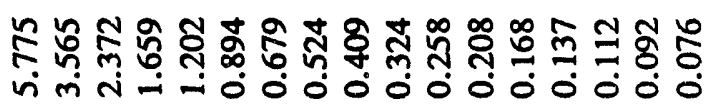 \\
\hline & בُ & $\stackrel{0}{\varrho}$ & 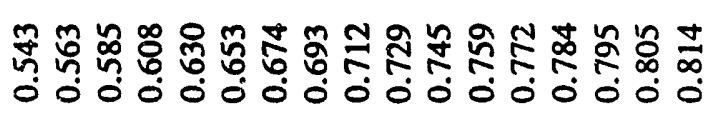 \\
\hline & $c^{y} \mid x^{-5}$ & $\widehat{a}$ & 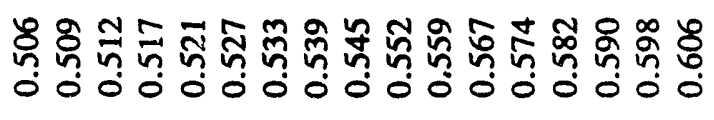 \\
\hline & $\varepsilon^{\tilde{v}} \mid E^{-}$ & 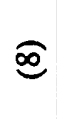 & 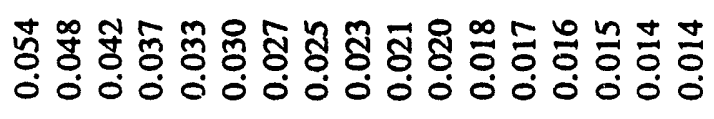 \\
\hline & 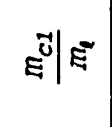 & $E$ & 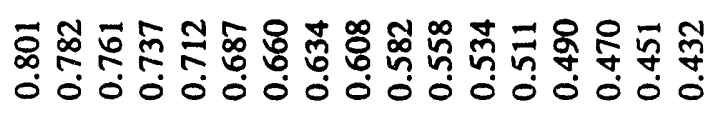 \\
\hline \multirow{5}{*}{ 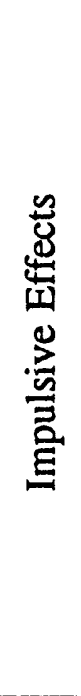 } & $-\left.1\right|^{n}$ & e & 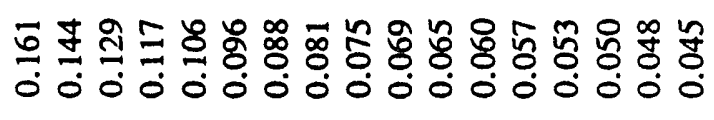 \\
\hline & $-x^{-1} \mid x^{-2}$ & $\sqrt{5}$ & 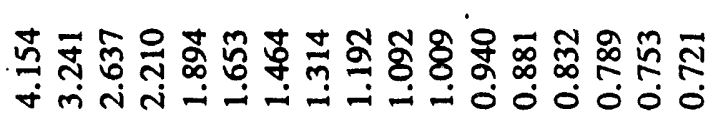 \\
\hline & $\sqrt{\omega}$ & $\mathbb{E}$ & 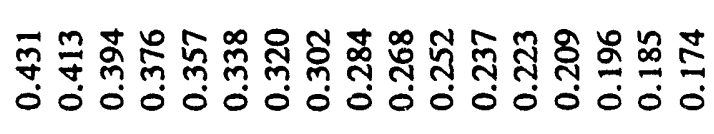 \\
\hline & $\dot{E}^{-1} \mid E$ & (2) & 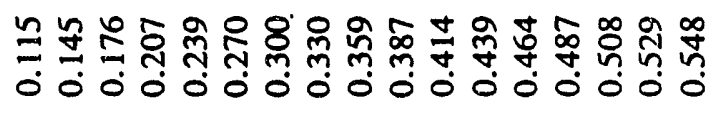 \\
\hline & 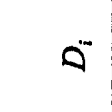 & $\widehat{\imath}$ & 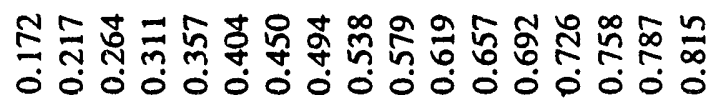 \\
\hline \multicolumn{2}{|c|}{$\frac{2}{x}$} & $\Xi$ & 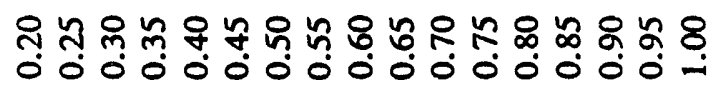 \\
\hline
\end{tabular}

$\stackrel{\sim}{\square}$

章 
Table 4.3 Values of Coefficients in Expressions for Fundamental Impulsive Frequencies of Lateral and Vertical Modes of Vibration of Roofless Steel Tanks Filled with Water; $t_{t w} / R=0.001$, $\rho_{\mathrm{l}} / \rho_{\mathrm{t}}=0.127, \nu_{\mathrm{t}}=0.3$

\begin{tabular}{|c|c|c|c|c|}
\hline \multirow{3}{*}{$\mathrm{H}_{\ell} / \mathrm{R}$} & \multicolumn{3}{|c|}{$\begin{array}{c}\text { Values of }\left(C_{1}\right) \text { for } \\
\text { Lateral Motion }\end{array}$} & \multirow{3}{*}{$\begin{array}{c}\text { Values } \\
\text { of } \\
\left(C_{v}\right)_{r} \\
\text { for } \\
\text { Vextical } \\
\text { Motion }\end{array}$} \\
\hline & \multicolumn{3}{|c|}{ Top Support Condition } & \\
\hline & Free & Roller & Hinged & \\
\hline 0.20 & 0.0516 & 0.0521 & 0.0539 & 0.0523 \\
\hline 0.25 & 0.0561 & 0.0569 & 0.0589 & 0.0570 \\
\hline 0.30 & 0.0600 & 0.0613 & 0.0634 & 0.0611 \\
\hline 0.35 & 0.0635 & 0.0653 & 0.0675 & 0.0649 \\
\hline 0.40 & 0.0666 & 0.0690 & 0.0712 & 0.0682 \\
\hline 0.45 & 0.0694 & 0.0724 & 0.0747 & 0.0712 \\
\hline 0.50 & 0.0719 & 0.0758 & 0.0781 & 0.0738 \\
\hline 0.55 & 0.0742 & 0.0789 & 0.0812 & 0.0762 \\
\hline 0.60 & 0.0762 & 0.0820 & 0.0843 & 0.0783 \\
\hline 0.65 & 0.0781 & 0.0850 & 0.0873 & 0.0802 \\
\hline 0.70 & 0.0799 & 0.0880 & c.0901 & 0.0819 \\
\hline 0.75 & 0.0815 & 0.0909 & 0.0930 & 0.0834 \\
\hline 0.80 & 0.0829 & 0.0937 & 0.0957 & 0.0848 \\
\hline 0.85 & 0.0843 & 0.0966 & 0.0984 & 0.0860 \\
\hline 0.90 & 0.0855 & 0.0993 & 0.1011 & 0.0870 \\
\hline 0.95 & 0.0865 & 0.1020 & 0.1037 & 0.0880 \\
\hline 1.00 & 0.0875 & 0.1047 & 0.1062 & 0.0889 \\
\hline
\end{tabular}


Table 4.4 Values of Coefficient $\alpha_{c 1}$ in Expression for Convective Component of Base Shear in TopConstrained Tanks

\begin{tabular}{|c|c|c|}
\hline \multirow{2}{*}{$H_{\ell} / R$} & \multicolumn{2}{|c|}{ Top Support Condition } \\
\cline { 2 - 3 } & Roller & Hinged \\
\hline \hline 0.20 & 0.462 & 0.509 \\
0.25 & 0.454 & 0.504 \\
0.30 & 0.448 & 0.498 \\
0.35 & 0.443 & 0.493 \\
0.40 & 0.438 & 0.488 \\
0.45 & 0.432 & 0.463 \\
0.50 & 0.429 & 0.477 \\
0.55 & 0.423 & 0.472 \\
0.60 & 0.418 & 0.464 \\
0.65 & 0.412 & 0.459 \\
0.70 & 0.407 & 0.452 \\
0.75 & 0.401 & 0.444 \\
0.80 & 0.395 & 0.438 \\
0.85 & 0.390 & 0.431 \\
0.90 & 0.383 & 0.421 \\
0.95 & 0.377 & 0.415 \\
1.00 & 0.372 & 0.406 \\
\hline
\end{tabular}




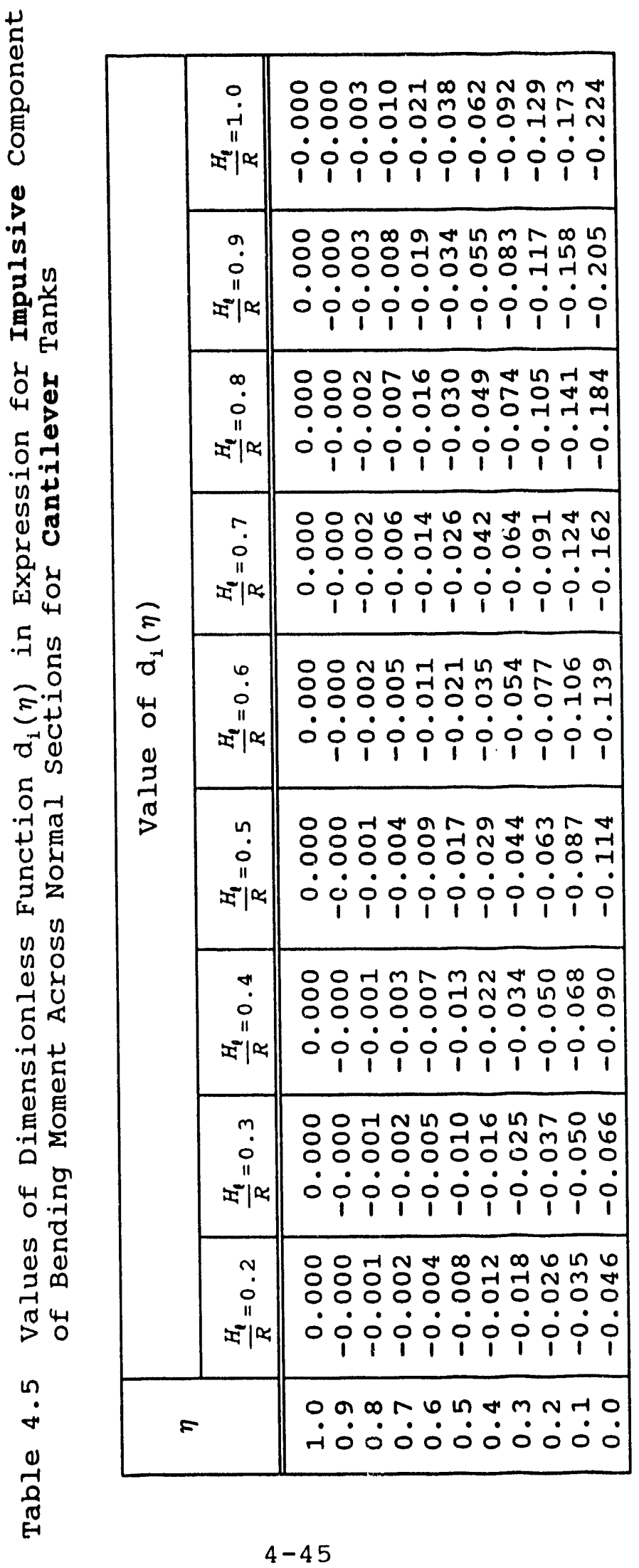




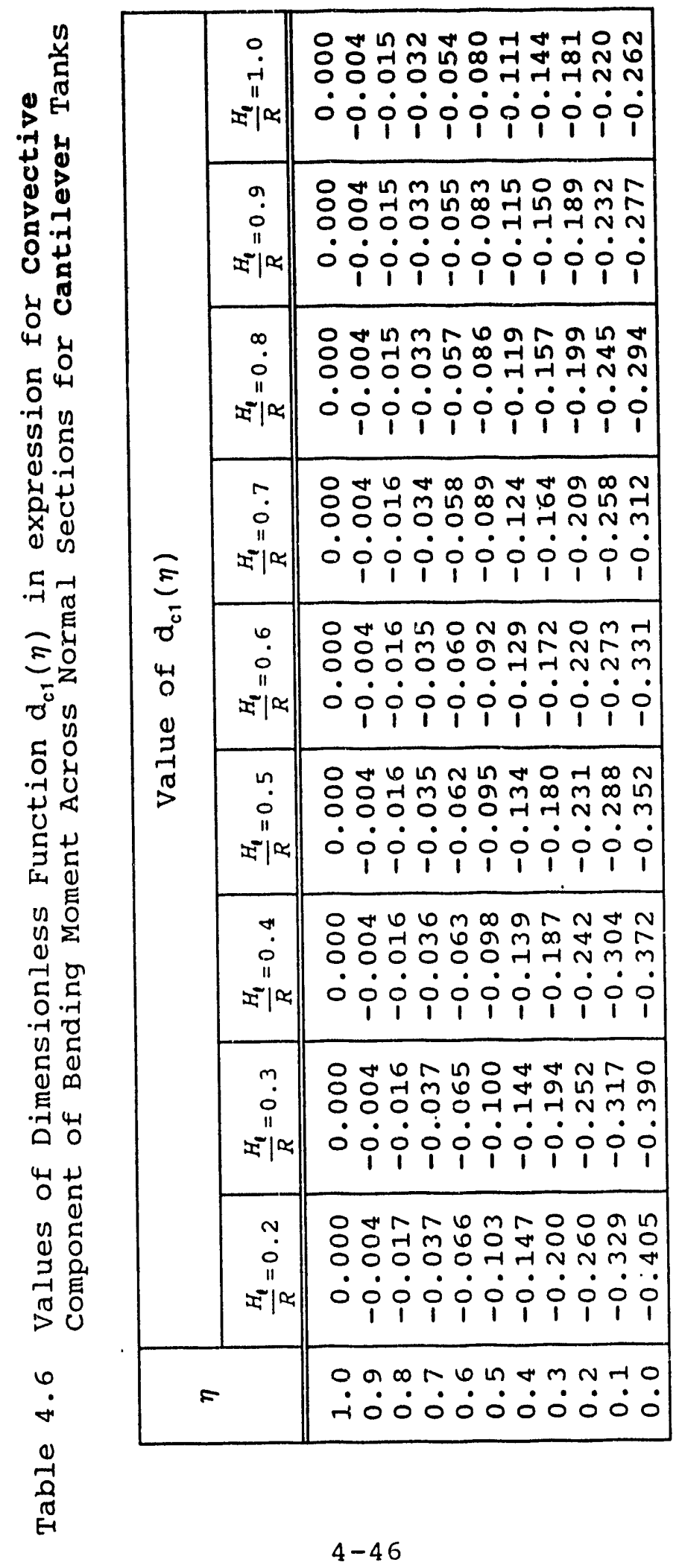




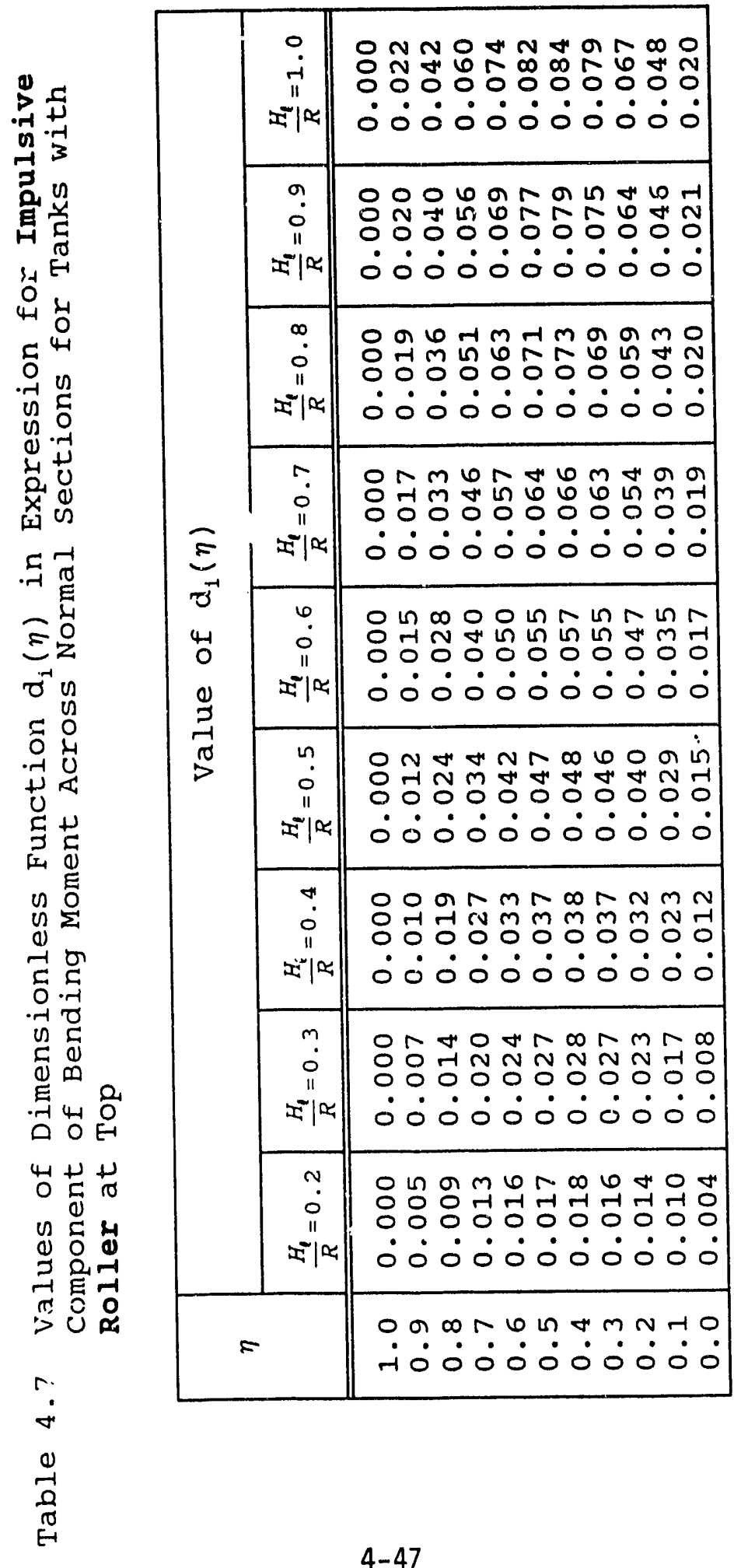




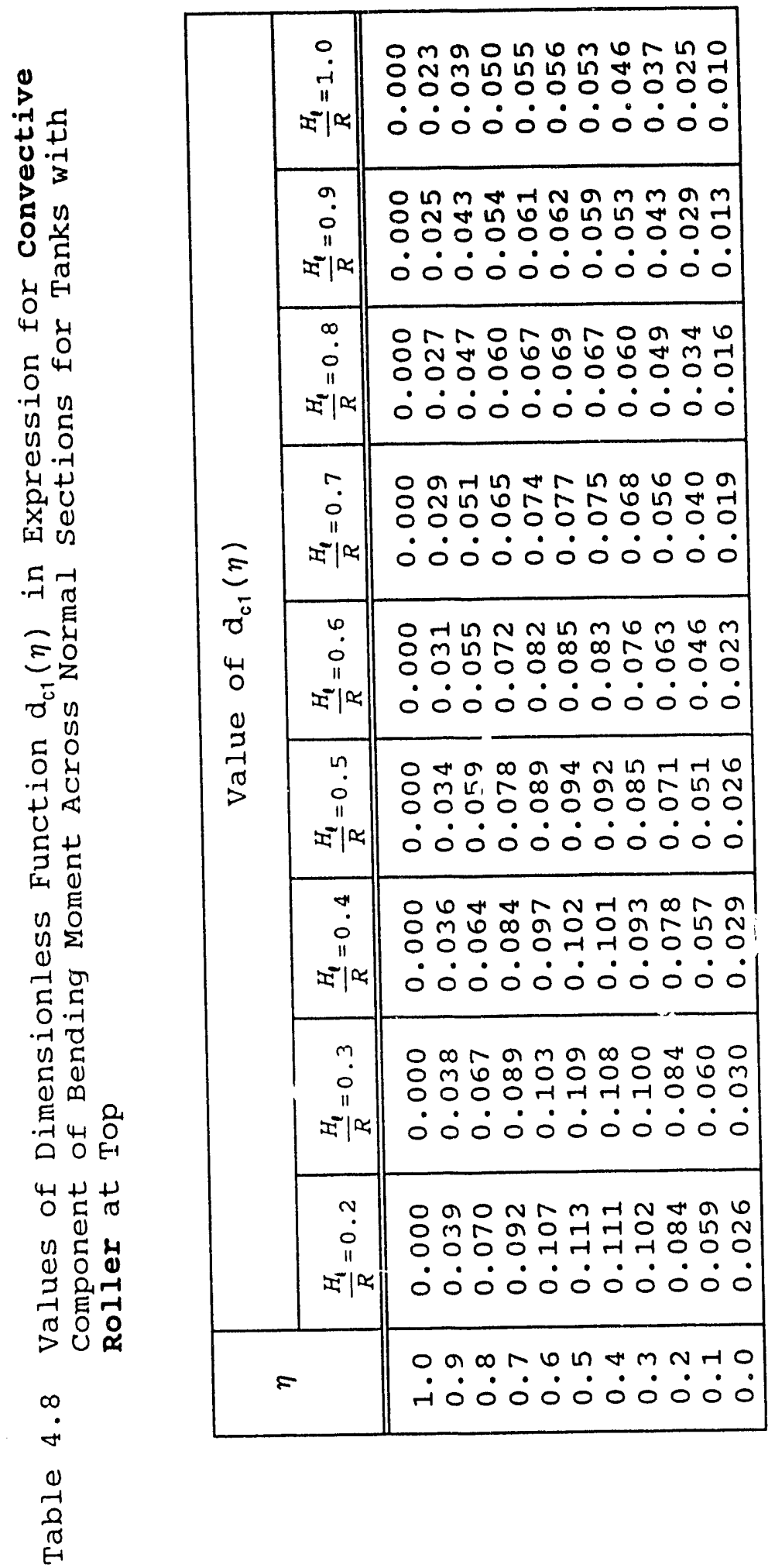




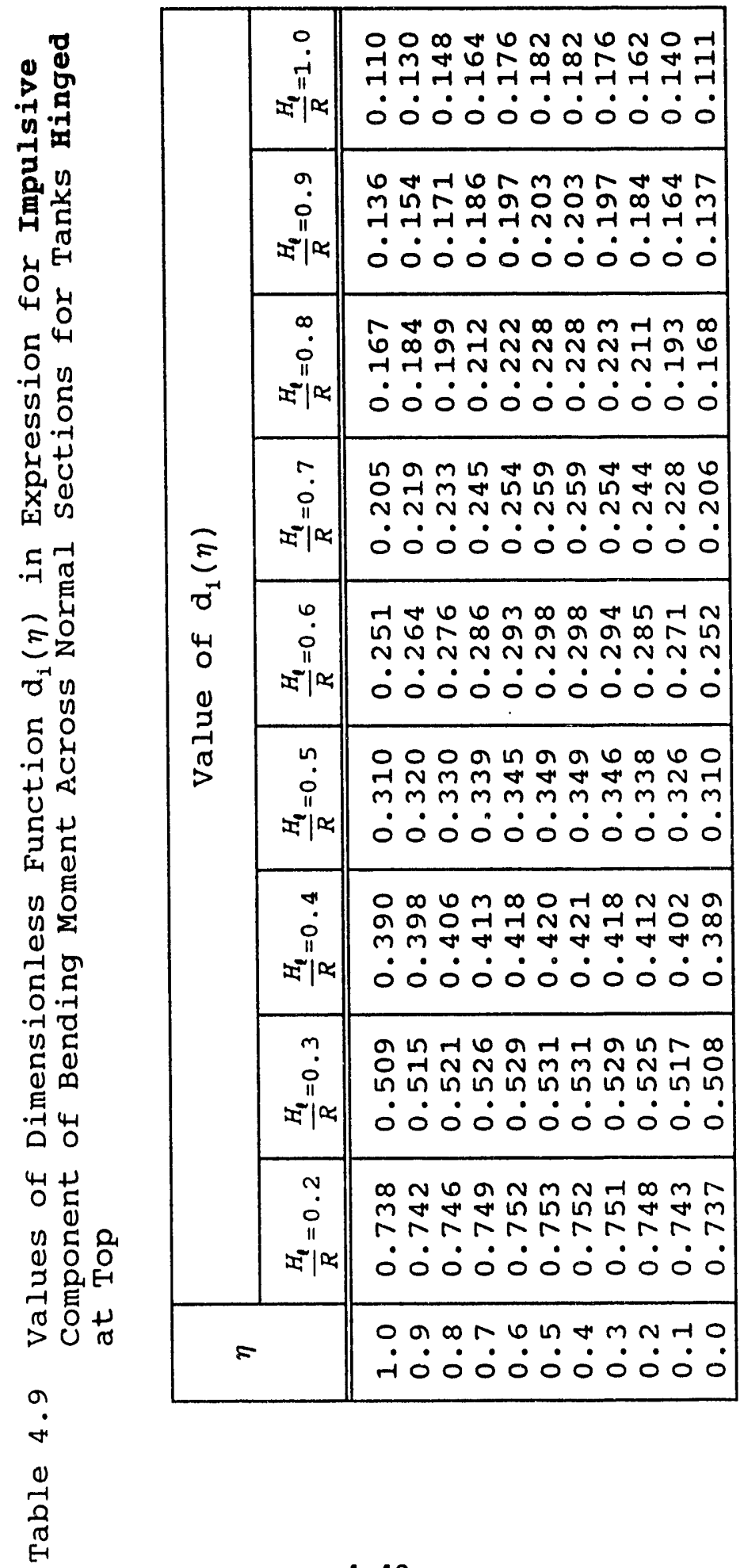




\begin{tabular}{|c|c|c|c|}
\hline & & 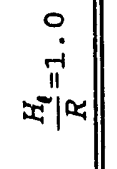 & 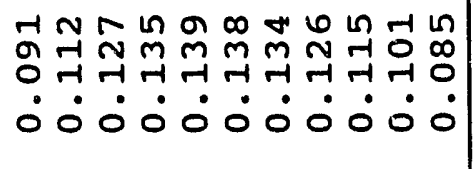 \\
\hline 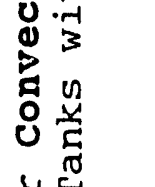 & & \begin{tabular}{c|c||}
9 \\
0 \\
11 \\
$x=0$
\end{tabular} & 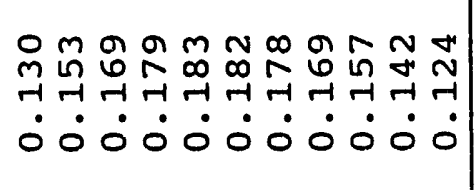 \\
\hline 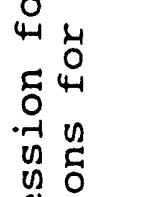 & & \begin{tabular}{c||}
$\infty$ \\
$\dot{0}$ \\
11 \\
$x^{\prime \prime} \mid$
\end{tabular} & 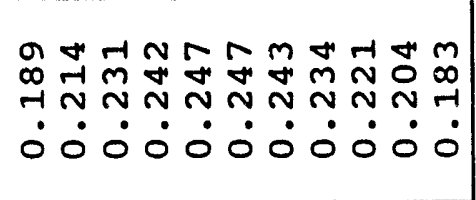 \\
\hline 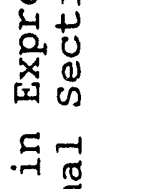 & E & $\begin{array}{c}\because \\
0 \\
11 \\
20\end{array}$ & 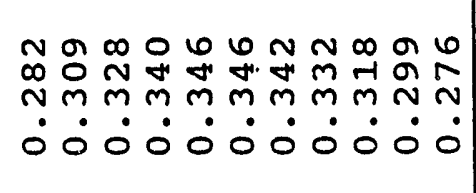 \\
\hline 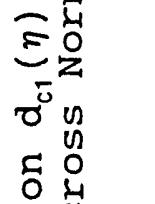 & $\begin{array}{l}0 \\
4 \\
0 \\
0 \\
\beth\end{array}$ & $\begin{array}{c}0 \\
\dot{0} \\
\ddot{1} \\
x^{\prime}|\times|\end{array}$ & 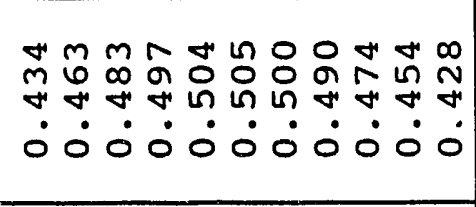 \\
\hline 茫 & $\stackrel{\pi}{>}$ & $\begin{array}{c}n \\
0 \\
11 \\
x=1\end{array}$ & 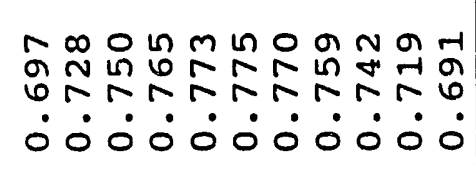 \\
\hline 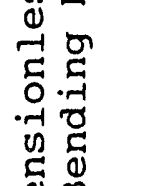 & & 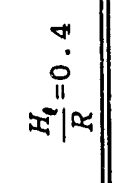 & 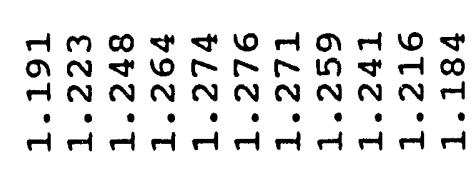 \\
\hline 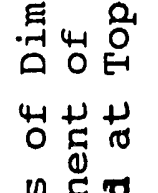 & & \begin{tabular}{c||}
$m$ \\
0 \\
$i=\mid$ \\
$x \mid 104$
\end{tabular} & 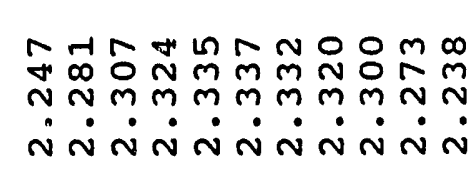 \\
\hline 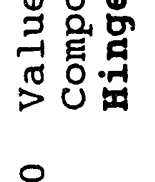 & & 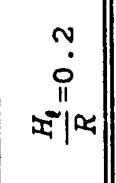 & 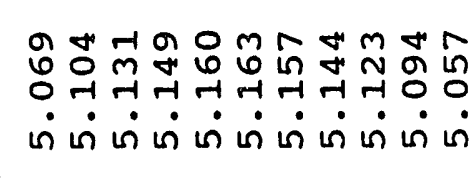 \\
\hline$\dot{\nabla}$ & \multicolumn{2}{|c|}{$F$} & 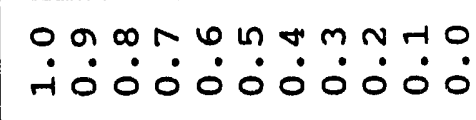 \\
\hline
\end{tabular}


Table 4.11 Effect of Poisson's Ratio of Tank Material on Values of Dimensionless Functions in Expression for Impulsive and Convective Components of Moment Across Normal Sections for Tanks with $H_{\ell} / R=0.75$ and Roller support at Top

\begin{tabular}{|c|c|c|c|c|}
\hline \multirow{2}{*}{$\eta$} & \multicolumn{2}{|c|}{ Value of $\mathrm{d}_{1}(\eta)$} & \multicolumn{2}{c|}{ Value of $\mathrm{d}_{\mathrm{c} 1}(\eta)$} \\
\cline { 2 - 5 } & $\nu_{\mathrm{t}}=0.0$ & $\nu_{\mathrm{t}}=0.3$ & $\nu_{\mathrm{t}}=0.0$ & $\nu_{\mathrm{t}}=0.3$ \\
\hline \hline 1.0 & 0.000 & 0.000 & 0.000 & 0.000 \\
0.9 & 0.016 & 0.019 & 0.026 & 0.028 \\
0.8 & 0.031 & 0.037 & 0.044 & 0.049 \\
0.7 & 0.043 & 0.051 & 0.055 & 0.062 \\
0.6 & 0.051 & 0.062 & 0.061 & 0.070 \\
0.5 & 0.055 & 0.068 & 0.061 & 0.073 \\
0.4 & 0.053 & 0.070 & 0.056 & 0.071 \\
0.3 & 0.047 & 0.066 & 0.046 & 0.064 \\
0.2 & 0.034 & 0.056 & 0.032 & 0.052 \\
0.1 & 0.016 & 0.041 & 0.015 & 0.037 \\
0.0 & -0.008 & 0.020 & -0.007 & 0.017 \\
\hline
\end{tabular}



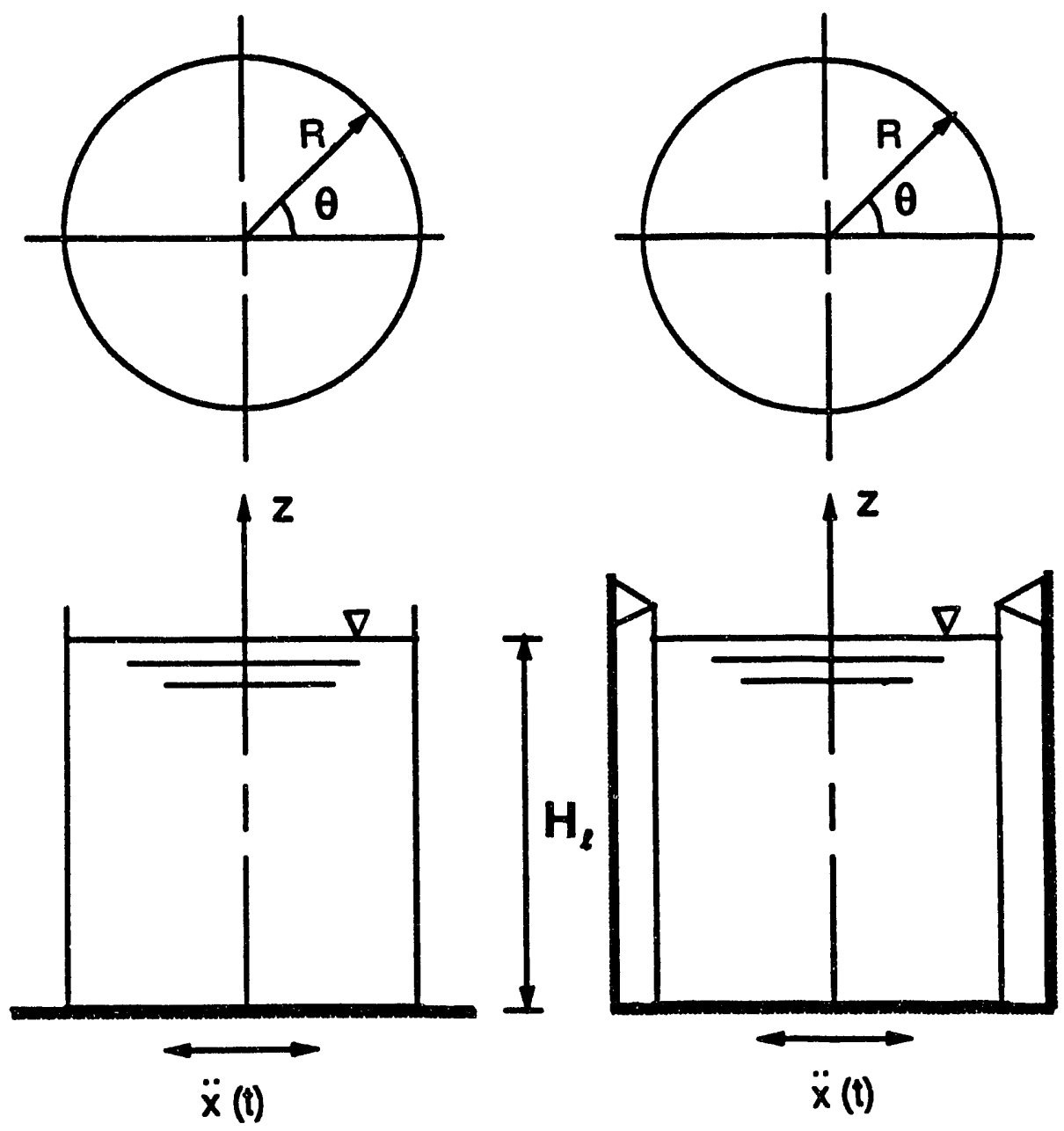

Figure 4.1 Systems Considered

$4-52$ 


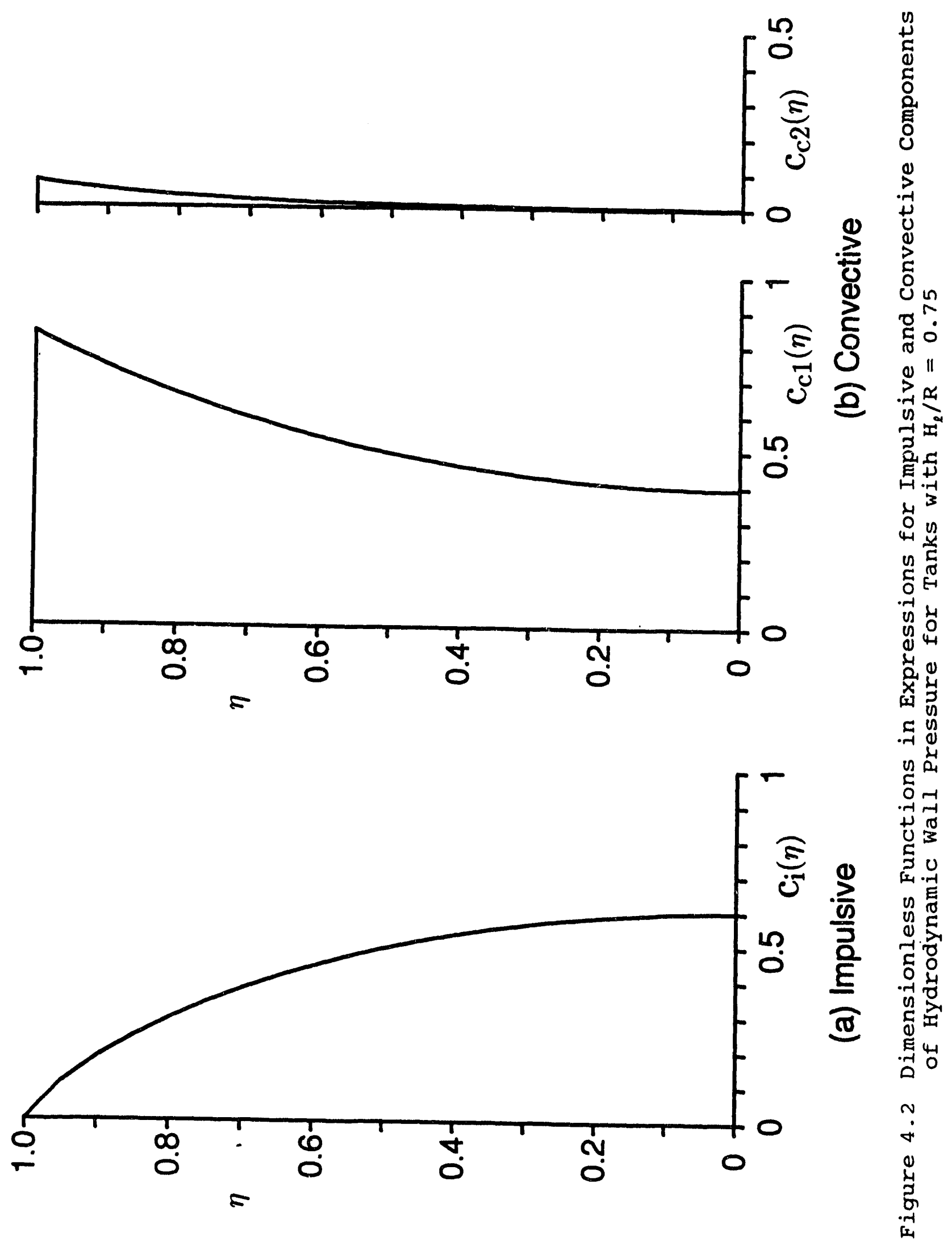

4-53 


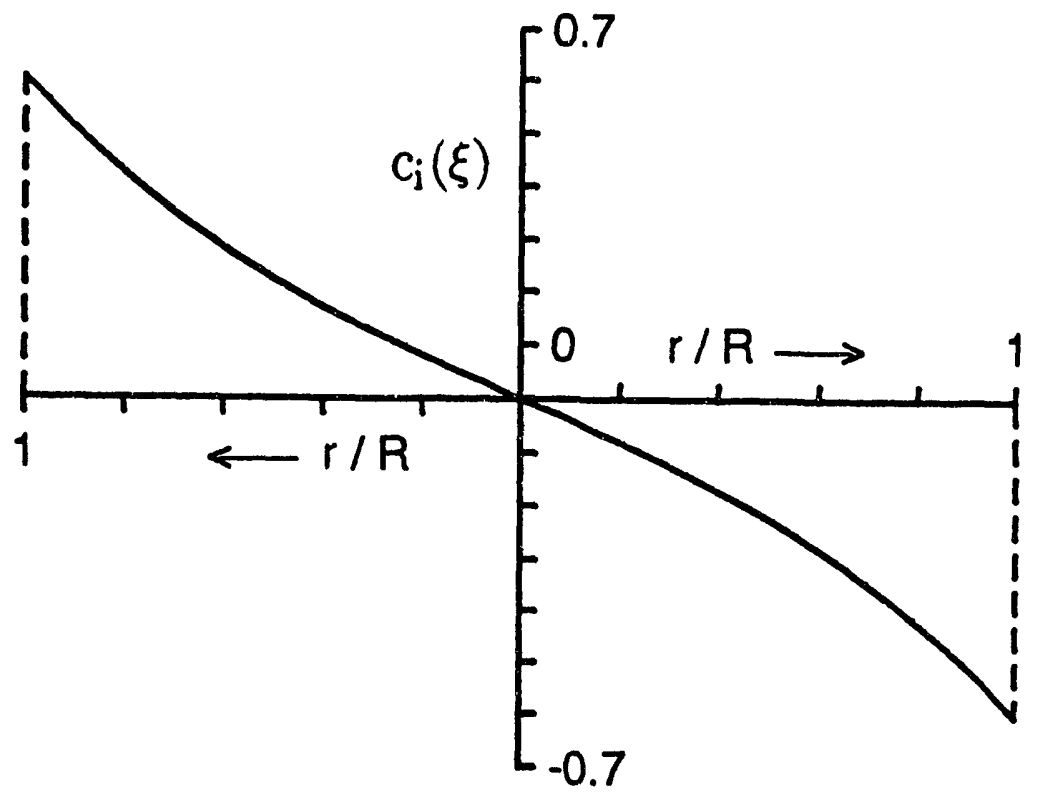

(a) Impulsive

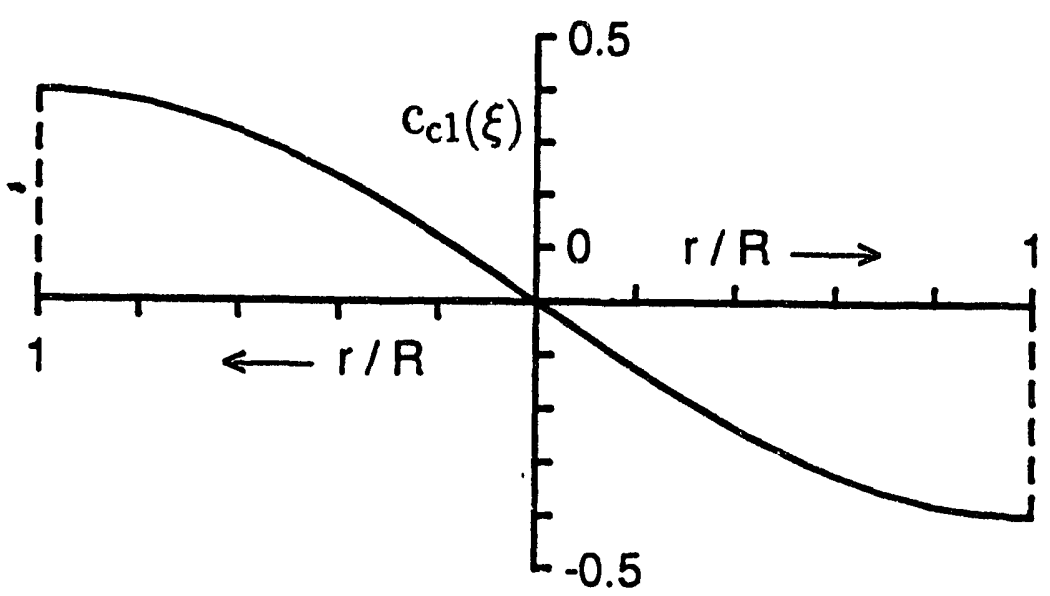

(b) Convective

Figure 4.3 Dimensionless Functions in Expressions for Impulsive and Fundamental Convective components of Hydrodyanmic Base Pressure for Tanks with $H_{\ell} / R=0.75$ 


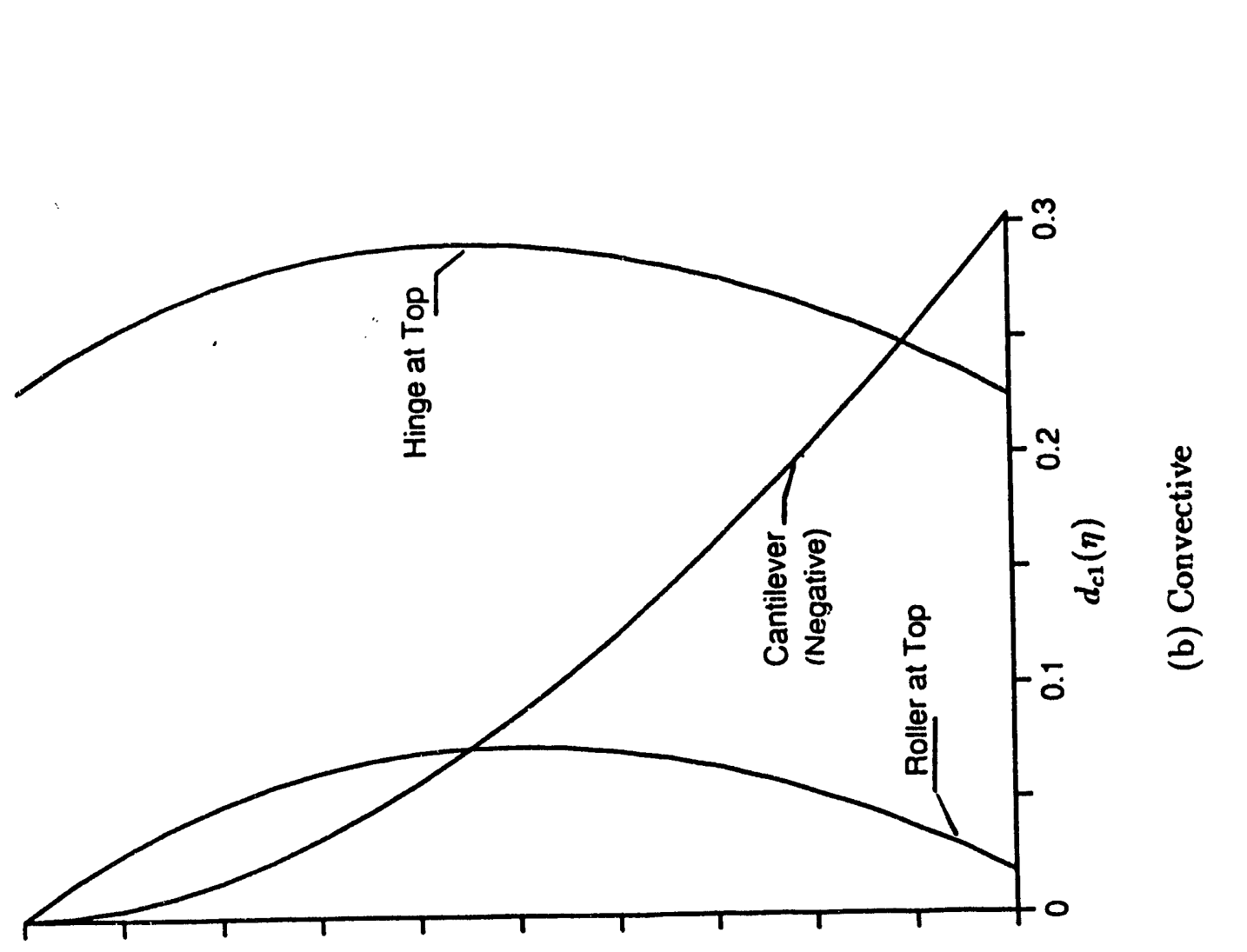

$n$

年

晃 品

z

n

ชั :

प्रु

\&

on

步

党

号

бूू.

कु

है

in

40

$4 .-1$

in:

茊

- 0

.

45

0

84

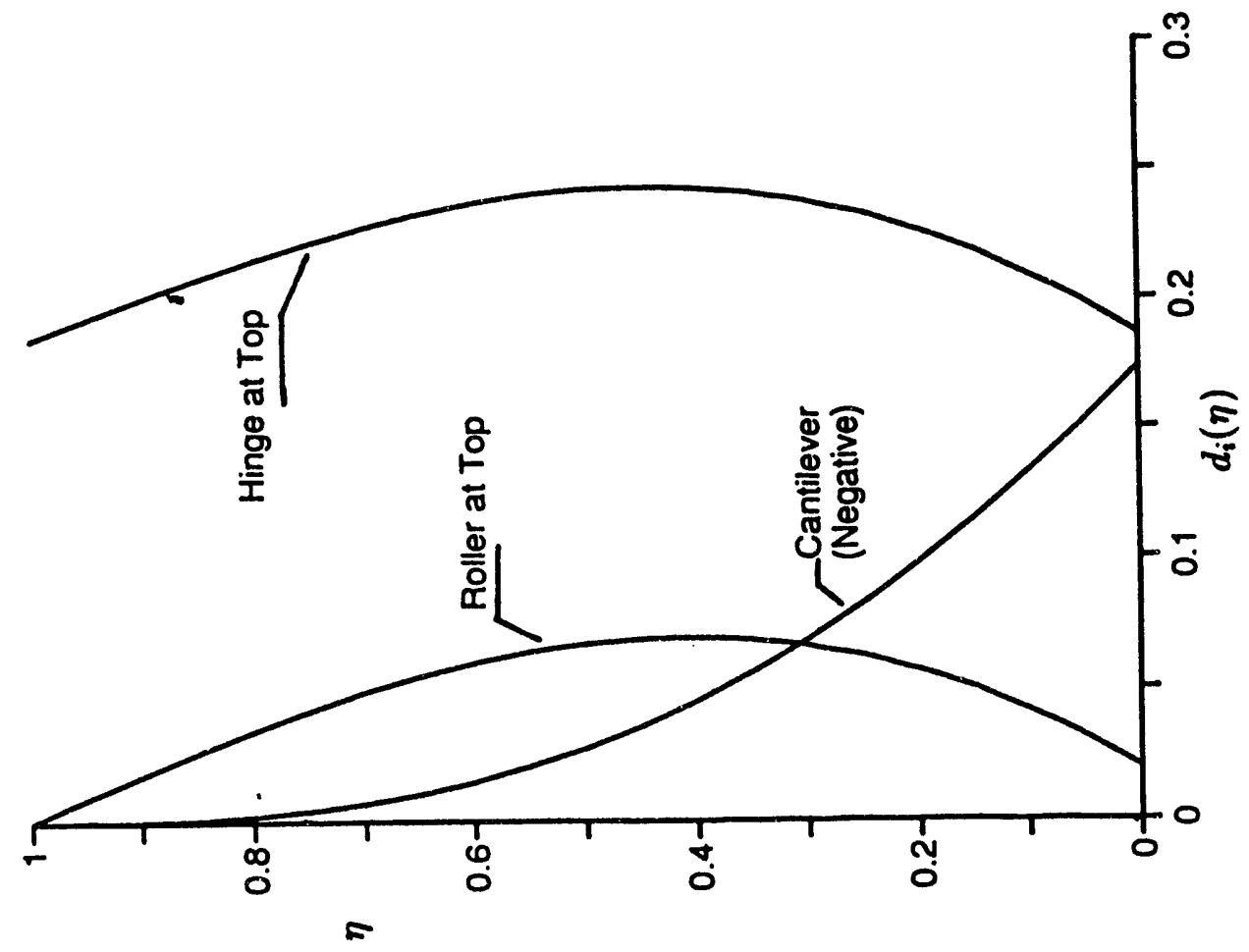

4

놈

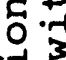

出

o

至光

总

${ }^{\infty} \mathrm{H}$

o 4

is

30

$+0$

जै

- 0

工

$\dot{*}$

㟧

4-55 


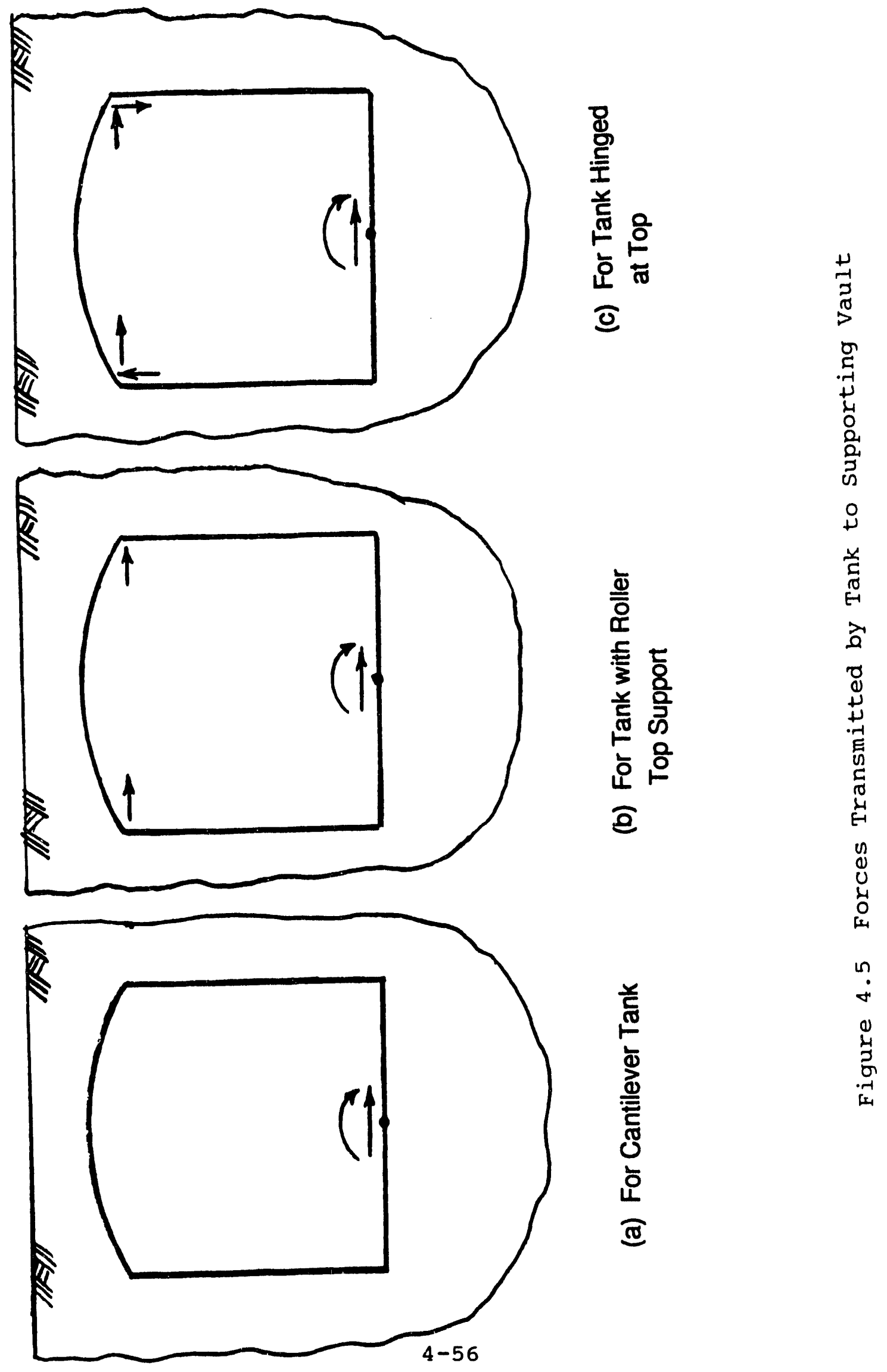




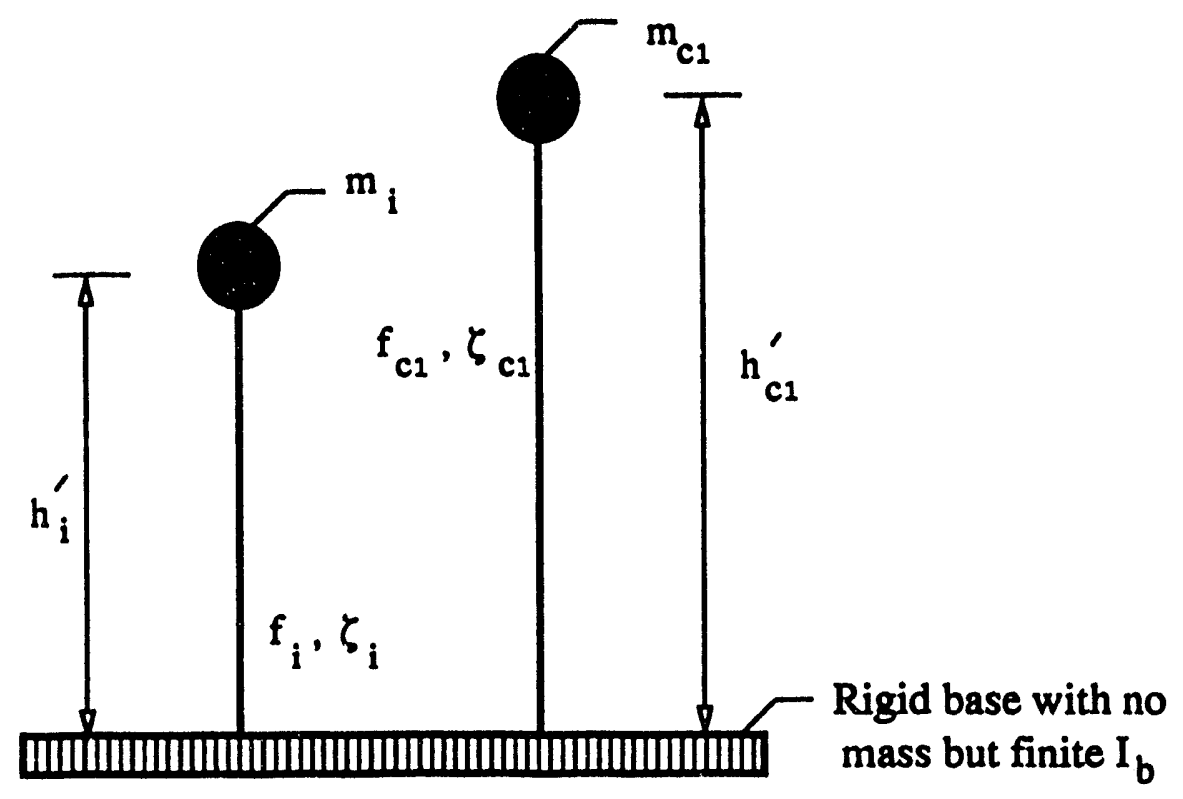

Figure 4.6 Modeling of Tank-Liquid System for Explicit Purpose of Evaluating Total Hydrodynamic Forces Transmitted to supporting Vault 
CHAPTER 5

\section{SEISMIC CAPACITY OF METAL FLAT-BOTTOM VERTICAL LIQUID STORAGE TANKS}

\subsection{INTRODUCTION}

This chapter provides an approach for the evaluation of the seismic capacity of either anchored or unanchored metal flatbottom vertical liquid storage tanks. The approach has been adapted from References 5.1 and 5.2. The approach is to first develop a nominal minimum ultimate strength capacity and then apply appropriate strength reduction factors to obtain capacity factors of safety consistent with those defined for other components in section 3.7 and Appendix C. Figure 5.1 shows an example flat-bottom vertical liquid storage tank for which this approach is considered applicable.

Flat bottom vertical fluid storage tanks have sometimes failed with loss of contents during strong earthquake shaking. For tanks with radius-to-wall thickness ratios greater than about 600 or tanks with minimal or no anchorage, failure has often been associated with rupture of the tank wall near its connection to the base, due either to excessive tank wall buckling or bolt stretching and excessive base-plate uplift. Both failure modes are primarily due to dynamic overturning moment at the tank base due to impulsive mode fluid pressure on the tank side walls. Another common failure mode has been breakage of piping connected to a tank which has occurred in a number of cases as a result of relative movement. When the pipe enters the tank below the fluid level, then breakage of a pipe section between the tank wall and shutoff valve is one of the most prevalent causes of loss of fluid from a storage tank. Breakage of a pipe beyond the shutoff valve is less serious. Another common cause of tank failure has been severe distortion of the tank bottom at or near the tank side wall due to a soil 
failure (soil liquefaction, slope instability, or excessive differential settlement). For new tanks these soil-induced failures are best prevented by proper soil compaction prior to placement of the tank and through the use of reinforced mat foundations under tanks. For existing tanks either founded on ring foundation or directly founded on the soil (i.e., no reinforced mat foundation), these soil-induced potential failure modes should also be investigated. Seismic design of flatbottom tanks should emphasize adequate overturning moment capacity, piping flexibility, and prevention of foundation failures under the tank.

Other failure modes which are of much lesser importance either because of their general lack of occurrence or less severe consequences, but which deserve some attention, are tank sliding, excessive hoop tensile stresses due to hydrodynamic pressures on the tank side walls, and damage to roofs and internal attachments. Sliding is a concern for unanchored smaller diameter tanks. However, sliding of an unanchored tank with greater than a 30-foot diameter and fluid height less than the diameter is extremely unlikely. Simple calculations indicates that there is sufficient friction between the tank bottom and foundation to prevent sliding for these tanks. Tensile hoop stresses due to shaking-induced pressures between the fluid and tank wall can become large and lead to splitting and leakage. This phenomenon has occurred in riveted tanks where leakage at the riveted joints has resulted from seismic pressure-induced hoop yielding. This occurrence is more common in the upper tank wall because the ratio of seismic induced pressures to hydrostatic pressure is greater in the upper portions. However, there does not appear to be any case where a welded steel tank has actually ruptured due to seismically induced hoop strains. Tank ductility appears to be sufficient to accommodate these hoop strains. However, large tensile hoop stresses combined with compressive longitudinal stresses do 
contribute to the likelihood of "elephant foot" buckling near the tank base due to overturning moment, and must therefore be considered. Lastly, there have been a number of instances of roof damage when insufficient freeboard exists to accommodate fluid sloshing. In addition, lateral movement and torsional rotations of the fluid which develop during ground shaking have broken guides, ladders, and other internal appurtenances attached between the roof and bottom plate. However, roof damage or broken appurtenances, although expensive to repair, do not lead to substantial fluid loss and so are of lesser consequences.

Neither the seismic response nor seismic capacity of internal appurtenances have been explicity addressed in this document. However, they must be evaluated in a manner consistent with this document. Guidance on their seismic response evaluation is given in ASCE 4-86 (Reference 5.10) and capacities should be determined in accordance with the requirements of sections 3.6 and 3.7 .

Each of the potential failure modes described above should be considered in the seismic evaluation of a metal flat-bottom vertical liquid storage tanks. The seismic evaluation of these tanks consists of two parts: a seismic response evaluation, and a seismic capacity assessment. The topic of response evaluation has been extensively described in the literature during the last ten years (References 5.3 through 5.10), and is covered in Chapter 4 and Appendix D.

The seismic response evaluation should provide estimates of each of the following:

1. The overturning moment in the tank shell immediately above the base plate of the tank. This moment should be compared with the base moment capacity which is governed by a combination of shell buckling and anchor bolt yielding or 
failure and generally governs the seismic capacity of the tank.

2. The overturning moment applied to the tank foundation through a combination of the tank shell and the base plate. This moment is only needed for tanks founded on soil sites where a foundation failure mode should be investigated and is generally obtained as part of the SSI evaluation. It seldom governs the seismic capacity.

3. The base shear beneath the tank base plate. This base shear is compared to the horizontal sliding capacity of the tank. For atmospheric tanks with a radius greater than 15 feet it seldorn controls the seismic capacity.

4. The moment in the tank shell at locations where the tank shell is thinner than at the base (such as occurs at 9 feet above the base in the Figure D.1 example tank), and at the location of maximum moment if such a location is away from the base as would be the case for a tank laterally supported at the top of the side wall as well as the base.

5. The hydrostatic pressure $p_{\text {st }} i$ the seismic-induced hydrodynamic pressures due to the horizontal input component (combination of impulsive and convective modes) $p_{\mathrm{dh}}$; and the hydrodynamic pressures due to the vertical input component $p_{\mathrm{dv}}$. It is common design practice to compare these combined pressures with the membrane hoop capacity of the tank side walls at one-foot above the base and each location where thickness changes. In addition, the pressure at the base is needed for the base moment and shear capacity calculations. Thus, for the example tank, these combined pressures are needed at 0,1 , and 10 feet above the base of the tank. These combined pressures essentially never govern the seismic capacity of a properly designed tank. 
6. The fluid slosh height. This slosh height is compared with the freeboard above the top of the fluid to estimate whether roof damage is likely.

For each of the computed tank responses and failure modes described above, capacity criteria are presented in the following sections.

\subsection{SLOSH HEIGHT CAPACITY}

The approach given in chapter 4 for computing the dynamic response of liquid storage tanks is conditional on the liquid surface being free to move vertically unconstrained by the tank roof. If the liquid sloshes against a substantial portion of the tank roof due to inadequate freeboard between the liquid surface and the tank roof, then the following phenomena occur:

1. The hydrodynamic pressure against the tank wall increases due to the vertical constraint of the liquid surface. The hydrodynamic pressure may conservatively be assumed to increase to the level imposed if $100 \%$ of the liquid responded in the impulsive mode.

2. The shear force and bending moment throughout the tank height also increase in a manner corresponding to the increase in the hydrodynamic pressure.

3. The liquid pressure acting against the tank roof will change the longitudinal force in the cylindrical walls of the tank and also could damage the roof. The performance of the tank at its base might be adversely influenced by the changed longitudinal force.

Each of these adverse consequences would have to be investigated if inadequate freeboard is provided. In most cases, it is preferable to provide an adequate factor of safety against the computed slosh height in order to avoid these added 
complications.

In order to provide an adequate factor of safety above the computed slosh height response $h_{s r}$, the slosh height capacity $h_{s c}$ should be determined as follows:

$$
h_{s c} \geq 1.6 L_{s} h_{s r}
$$

where $L_{s}$ is the appropriate seismic load factor from Equation 3.9a. The factor 1.6 in Equation 5.1 has been made slightly larger than the factor of 1.5 in Equation 3.9 to provide for increased slosh heights due to nonlinear surface effects.

For a spherical domed roof such as that shown in Figure 5.1 or a domed roof that can be approximated by a combination of cylindrical and spherical segments (such as a torispherical roof), the available slosh height capacity $h_{s c}$, before excessive forces result on the dome, is approximately:

$$
h_{s c} \approx h_{c}+\frac{h_{d}}{4}
$$

where $h_{c}$ is the cylindrical wall height above the liquid and $h_{d}$ is the dome height above the cylindrical wall. When $h_{s c}$ defined by Equation 5.2 satisfies Equation 5.1 , the above defined adverse consequences are considered to be negligible and do not have to be addressed.

\subsection{HOOP TENSION CAPACITY}

For seismic loads, the hoop membrane stress capacity, $\sigma_{c}$, of the tank sheli should be taken as the ASME Code (Reference 5.15) Service Level D limit for a primary stress of 2.0S. For example, $\sigma_{c}=37.5 \mathrm{ksi}$ for SA240-Type 304 stainless steel. Thus, the pressure capacity $p_{c}$ is:

$$
p_{c}=\frac{\sigma_{c} t_{t w}}{R}
$$

$$
5-6
$$


where $t_{t w}$ is the tank wall thickness, and $R$ is the tank radius. This capacity is then compared with the total inelastic factored demand given by:

$$
p_{t i}=p_{s t}+\frac{L_{S}\left[p_{d h}^{2}+p_{d v}^{2}\right]^{1 / 2}}{F_{\mu D}}
$$

where hydrodynamic pressures from the horizontal component ( $p_{d h}$ ) and from the vertical component $\left(p_{d v}\right)$ are combined probabilistically by the square-root-sum-of-squares method, $F_{\mu D}$ $=1.5$ from Table 3.3 and $L_{s}$ is the appropriate seismic load factor from Equation $3.4 \mathrm{a}$ (e.g., $L_{\mathrm{s}}=1.15$ for $R_{\mathrm{R}}=20$ ).

\subsection{MAXIMUM PERMISSIBLE AXIAL COMPRESSION OF TANK SHELL}

The cylindrical tank shell is subjected to an axial compression force on one side and an axial tensile force on the other side due to the seismic-induced overturning moment. At the base of the fully-anchored tank and away from the base for all tanks, the moment capacity is controlled by the maximum permissible axial compression of the tank shell. In turn, this permissible axial compression capacity must be set sufficiently low to avoid either "elephant-foot" or "diamond" buckling of the tank shell.

One possible way for tank shells to buckle is in "elephant foot" buckling near the base of the tank shell. The tank shell is subjected to a biaxial stress state consisting of hoop tension and vertical (axial) compression. In addition, radial deformations under internal pressure which are prevented at the base due to membrane tension in the base plate introduce eccentricity and bending stresses in the axial plane which further induce the tendency to "elephant foot" buckle. The onset of such "elephant foot" buckles can be estimated using elastic-plastic collapse theory (References 5.12 through 5.14). However, it should be noted that the initiation of an "elephant foot" buckle does not directly correspond to a failure of a 
tank. Many tanks have continued to perform their function of containing fluid even after developing substantial "elephant foot" buckles. However, no simple method to predict tank performance after the development of "elephant foot" buckling exists. Therefore, the onset of "elephant foot" buckling will be judged to represent the limit to the compressive buckling capacity of the tank shell.

The "elephant-foot" buckling axial stress capacity, $\sigma_{\text {be }}$ of the tank shell can be estimated by (References 5.12 through 5.14):

$$
\sigma_{b e}=\frac{0.6 E_{t}}{\left(R / t_{t w}\right)}\left[1-\left(\frac{p_{m \dot{x}} R}{\sigma_{y e} t_{t w}}\right)^{2}\right]\left[1-\frac{1}{1.12+S_{1}^{1.5}}\right]\left[\frac{S_{1}+\left(\sigma_{y e} / 36 k s i\right)}{S_{1}+1}\right]
$$

where $s_{1}=R /\left(400 t_{t w}\right), t_{t w}$ is the tank wall thickness near the shell base, $p_{m x}$ is the maximum tank internal pressure, and $\sigma_{y e}$ is the effective yield stress of the tank material. The axial capacity $\sigma_{b e}$ should always be limited to the minimum yield stress $\sigma_{y}$. In Equation 5.5, $p_{m x}$ should be taken as:

$$
p_{m x}=p_{s t}+p_{d h}+0.4 p_{d v}
$$

which represents the maximum probabilistically combined pressure against the tank wall at the location of the maximum longitudinal compressive stress and the time of occurrence of the maximum moment. For a material with a well defined yield point such as A36 carbon steel, $\sigma_{y e}$ should correspond to this yield stress. For a tank shell material with no specific yield point, $\sigma_{y e}$ should be set at the ASME Code (Reference 5.15) Service Level (D) limit for primary membrane which is $2 S^{1}$. For example, for SA240-Type 304 stainless steel, $\sigma_{\text {ye }}=37.5 \mathrm{ksi}$.

The diamond buckling capacity of the cylindrical shell, $\sigma_{b d}$

's depends on temperature and should be determined for the expected temperature of the tank. 
under combined axial bending and internal pressure can be essentially lower bound estimated from:

$$
\begin{aligned}
& \sigma_{b d}=\alpha \eta \sigma_{c} \\
& \sigma_{c}=\frac{0.6 E_{t}}{R / t_{t w}}
\end{aligned}
$$

where $\sigma_{c}$ is the "classical" shell buckling capacity, $\alpha$ is a capacity reduction factor due to imperfection and $\eta$ is a plasticity reduction factor. For cylindrical shells subjected to axial compression with $600 \leq R / t_{t w} \leq 1000$, ASME Code Case $N-$ 284 (Reference 5.22) defines:

$$
\begin{aligned}
\alpha_{A S M E}=0.207 \\
\eta=1.0, \text { if } \Delta \leq 0.55 \\
\eta=\frac{0.45}{\Delta}+0.18, \text { if } 0.55<\Delta \leq 1.6 \\
\text { where: } \Delta=\alpha \sigma_{c} / \sigma_{y}
\end{aligned}
$$

On the other hand, NASA SP-8007 (Reference 5.16) defines different values for $\alpha$ depending upon whether the overall loading on the cyclindrical shell is uniform axial compression or bending, and also incorporates an influence for internal pressure. From NASA SP-8007:

$$
\begin{aligned}
\alpha_{\text {NASA }} & =\gamma+\frac{\Delta \gamma}{0.6} \\
\gamma_{\text {axial }} & =1-0.901\left(1-e^{-\phi}\right) \\
\gamma_{\text {bend }} & =1-0.731\left(1-e^{-\phi}\right) \\
\phi & =\frac{1}{16} \sqrt{\frac{R}{t_{t W}}}
\end{aligned}
$$


where $\Delta \gamma$ is an increase factor for internal pressure as given by Figure 5.2 (Reference 5.16). In Figure 5.2, $\mathrm{p}_{\mathrm{m}}$ should be taken as:

$$
p_{m n}=p_{s t}+p_{d h}-0.4 p_{d v}
$$

which represents the minimum probabilistic combined pressure against the tank side wall at the location of the maximum longitudinal compressive stress and the time of occurrence of the maximum moment.

In the judgment of the authors, the ASME Code Case $\mathrm{N}-284$ value for $\alpha$ (Equation $57 \mathrm{~b}$ ) is too conservative for bending-induced axial stress which varies both circumferentially and longitudinally, and also provides no credit for the beneficial effect of internal pressure. However, the NASA SP-8007 value for $\alpha$ (Equation $5.7 d$ ) is based on model tests which may not have as severe of imperfections as actual tanks, and may not be adequately conservative. These issues are being further investigated. In the meantime, for $200 \leq\left(R / t_{t w}\right) \leq 1500$, it is recommended that:

$$
\alpha=0.8 \alpha_{\text {NASA }} \leq 0.48
$$

where $\gamma$ in Equation $5.7 \mathrm{~d}$ is based on $\gamma_{\text {bend }}$ from Equation $5.7 \mathrm{f}$.

The value of $\alpha_{A S M E} / \gamma_{\text {axial }}$ ranges, from 0.7 to 0.9 and averages 0.8 for $\left(R / t_{t w}\right)$ from 600 to 1000 where Equation $5.7 \mathrm{~b}$ applies. Therefore, the use of a factor of 0.8 in Equation 5.8 is intended to provide about the same degree of conservatism for the case of bending plus internal pressure as is contained in Equation $5.7 \mathrm{~b}$ for pure axial compression. The limit on $\alpha$ of 0.48 is intended to guard against excessively high values of $\alpha$ due to the benefit of the internal pressure obtained from Figure 5.2 .

The nominal buckling stress $\sigma_{b}$ should be taken as the lesser of $\sigma_{\text {be }}$ (Equation 5.5), or $\sigma_{b d}$ (Equation 5.7). Then the maximum $5-10$ 
permissible axial compression force per unit of circumferential length is given by:

$$
\begin{aligned}
C_{b} & =\sigma_{b} t_{t w} / F S \\
\text { where, } F S & =1.34
\end{aligned}
$$

In this equation, $F S$ is the factor of safety required for ASME Service Level D necessary to provide high confidence of avoiding a buckling failure.

\subsection{MOMENT CAPACITY AWAY FROM TANK BASE}

At locations along the cylindrical shell away from the base, the moment capacity is given by:

$$
M_{C}=C_{b} \pi R^{2}-\frac{P_{a} R}{2}
$$

where $P_{a}$ is any concurrent axial compressive force on the cylindrical shell (generally negligible).

\subsection{ANCHORAGE CAPACITY AT TANK BASE}

The base anchorage bolt hold-down capacity, $\mathrm{T}_{\mathrm{cb}}$, is governed by the weakest of the following elements:

1. Bolt tensile capacity

2. Anchorage of bolt into concrete foundation

3. Capacity of the top plate of bolt chairs to transfer bolt loads to the vertical chair gussets

4. Attachment of the top plate and vertical chair gussets to the tank wall.

5. Capability of tank wall to withstand concentrated loads imposed on it by chairs

Each of these capacities should be based on code minimum

$$
5-11
$$


ultimate strength or limit state capacities with the appropriate code-imposed strength reduction factor $(\phi)$.

\subsection{BASE MOMENT CAPACITY OF FULLY ANCHORED TANKS}

A tank is considered fully anchored only when the hold-down capacity $T_{c b}$ per bolt satisfies the following condition:

$$
T_{c b} \geq 2 \pi R C_{b}\left(\frac{\theta_{b}}{360^{\circ}}\right)
$$

where $\theta_{b}$ is the circumferential angle between bolts. In this case, the neutral axial remains through the centerline of the tank at maximum capacity and the base moment capacity is also given by Equation 5.10.

However, satisfying Equation 5.11 will require very closely spaced anchor bolts and is seldom practical. In most cases, Equation 5.11 is not satisfied and the tank is treated as either partially anchored or unanchored. In either case, the neutral axis will shift toward the compression side of the tank (see Figure 5.3) resulting in an increase in the peak compressive force for a given overturning moment. The base moment capacity of the partially anchored or unanchored tank will be substantially less than that given by Equation 5.10 .

5.8 BASE MOMENT CAPACITY OF PARTIALLY ANCHORED OR UNANCHORED TANKS

A reasonable approximation of the loading that exists at the base of the tank shell can be estimated based upon the following approximations:

1. Compressive stresses vary linearly from zero at the neutral axis to $C$, at the outer compression side of the tank wall (i.e., at $\theta=180^{\circ}$ ). 
2. Uplift heights $\delta_{\theta}$ vary linearly from zero at the neutral axis to $\delta_{0}$ at the outer tension side of the tank wall (i.e., at $\left.\theta=0^{\circ}\right)$.

3. For simplicity, fluid hold-down forces are also assumed to vary linearly from $T_{f n}$ at the neutral axis to $T_{f 0}$ at $\theta=0$.

Figure 5.3 illustrates the loading that exists at the base of the tank wall based on the above approximation. Also shown is the uplift of the tank wall due to an assumed rigid rotation of the base. In Figure 5.3, $C_{n}^{\prime}$ is the maximum compressive stress in the tank wall, $T_{f n}$ is the effective fluid hold-down force at the neutral axis, $\Delta T_{f}$ is the increase in fluid-hold down force at $\theta=0, T_{b 1}$ are anchor bolt hold-down forces if the tank is anchored, $w_{t}$ is the tank weight, and $M_{c}$ is the moment capacity which results from this loading distribution.

For any given angle $\theta_{n}$ to the neutral axis:

$$
\begin{gathered}
C_{m}^{\prime}=\left[\frac{W_{t}+\sum_{i=1}^{n} T_{b i}}{2 R}+T_{t n} \theta_{n}\right] C_{1}+\Delta T_{f} C_{3} \\
M_{C}=C_{m}^{\prime} C_{2} R^{2}+\sum_{i=1}^{n}\left(T_{b i} R \cos \theta_{i}\right\rangle+T_{f n} R^{2}\left(2 \sin \theta_{n}\right)+\Delta T_{t} C_{4} R^{2}
\end{gathered}
$$

where:

$$
\begin{aligned}
& C_{1}=\frac{1+\cos \theta_{n}}{\sin \theta_{n}+\left(\pi-\theta_{n}\right) \cos \theta_{n}} \\
& C_{2}=\frac{\sin \theta_{n} \cos \theta_{n}+\pi-\theta_{n}}{1+\cos \theta_{n}} \\
& C_{3}=\frac{\sin \theta_{n}-\theta_{n} \cos \theta_{n}}{\sin \theta_{n}+\left(\pi-\theta_{n}\right) \cos \theta_{n}}\left[\frac{1+\cos \theta_{n}}{1-\cos \theta_{n}}\right] \\
& C_{4}=\frac{\theta_{n}-\sin \theta_{n} \cos \theta_{n}}{1-\cos \theta_{n}}
\end{aligned}
$$


Numberical values for $c_{1}, c_{2}, c_{3}$, and $c_{4}$ as functions of $\theta_{n}$ are tabulated in Table 5.1 .

The moment capacity depends upon the axial compressive buckling capacity of the tank wall $\left(C_{b}\right)$ from section 5.4, the tensile hold-down capacity of the anchor bolts including their anchorage and attachment to the tank $\left(T_{c b}\right)$ from section 5.6, the permissible uplift height $\left(\delta_{0}\right)$ from section 5.9 , and the holddown force of fluid pressure acting on the tank base plate $\left(T_{f}\right)$ from section 5.10. Thus, each of these quantities must be estimated prior to estimating the overturning moment capacity.

The steps in solving for the moment capacity are as follows:

1. Establish the maximum permissible uplift height $\delta_{0}$ (see Section 5.9).

2. Compute the fluid hold-down force $T_{f o}$ corresponding to the uplift height $\delta_{0}$ and the fluid hold-down force $T_{\text {in }}$ at the neutral axis (see section 5.10) and then:

$$
\Delta T_{f}=T_{\text {fo }}-T_{\text {fn }}
$$

3. Assume an initial value of the angle $\theta_{n}$ to the neutral axis and estimate the anchor bolt tension $T_{b 1}$ in anchor bolt "i" from:

$$
T_{b i}=T_{b p}+K_{b}\left(\frac{\cos \theta_{i}-\cos \theta_{n}}{1-\cos \theta_{n}}\right) \leq T_{c b}
$$

where

$$
K_{b}=\frac{\delta_{0} A_{b} E_{b}}{h_{\theta}}
$$

and $\theta_{1}$ is the angle $\theta$ at bolt "i," $T_{b p}$ is any bolt pretension (generally should be taken as zero since it is likely to be lost over time), $T_{c b}$ is the bolt capacity (see 
Section 5.6), $A_{b}$ is the bolt area, $E_{b}$ is the bolt modulus of elasticity and $h$, is the effective bolt length from its attachment to the tank to its effective anchor depth in the concrete.

4. Compute $C_{\text {. }}^{\prime}$ from Equation 5.12 and compare it to the shell buckling capacity $c_{b}$. Vary $\theta_{n}$ and repeat steps 3 and 4 until $c_{a}^{\prime}=C_{b}$.

5. Determine the moment capacity $M_{0}$ from Equation 5.13.

As will be shown in the solution for capacity of the example tank in Appendix $F$, it is unnecessary to converge to a refined estimate of the angle $\theta_{n}$ to the neutral axis in step 4 in order to estimate the moment capacity $M_{c}$. Although $C_{n}^{\prime}$ is sensitive to changes in the angle $\theta_{n}, M_{c}$ is not sensitive to small changes in $\theta_{n}$.

Also, as will be shown in Appendix F, the base moment capacity of even a minimally anchored tank is substantially greater than that of an unanchored tank. Therefore, for new designs it is recommended that the tank should be either laterally supported near its top (thus greatly reducing the applied base moment) or should be anchored at its base.

\subsection{PERMISSIBLE UPLIFT DISPLACEMENT}

In order to prevent anchorage failure, the maximum uplift displacements $\delta_{0}$ of anchored tanks should be limited to a small value. For anchored tanks in which the bolt tensile capacity controls $\mathrm{T}_{\mathrm{cb}}$, $\delta_{0}$ should be limited as follows:

$$
\delta_{0} \leq 0.01 h_{\theta}
$$

where $h_{e}$ is the effective bolt length. When other failure modes control, $\delta_{0}$ should be limited to the lesser of Equation 5.18 or $1 / 4$ inch. 
For unanchored tanks much greater uplift heights are permissible. To avoid failure at the junction of the base plate and wall, it is suggested that uplift heights be limited to:

$$
\delta_{0}=0.1 L
$$

where $L$ is the computed uplift length of the base plate (see Figure 5.5 and section 5.10.2). Equation 5.19 will typically produce uplift heights of several inches. However, if piping or other components are attached to the tank wall or uplifted region of the base plate, $\delta_{0}$ must also be limited to tolerable displacements for such piping or other components.

\subsection{FLUID HOLD-DOWN FORCE}

\subsubsection{Anchored Tanks}

Following the small displacement theory, the situation in the region of axial tension in the tank wall is illustrated in Figure 5.4 for a small uplift, $\delta$. At point "o" away from the tank wall, the tank bottom is in full contact with the foundation and the displacements, rotation, and moment in the tank bottom are zero. However, at the intersection of the tank bottom and wall at point " 1 ," the tank bottom has uplifted $\delta$ and rotated $\alpha$. The length of the uplift zone is $L$, and the fluid pressure, $p_{e}$, on the tank bottom and wall resists this uplift. This uplift is accompanied by the development of tension, $T_{f}$, and moment, $M_{f}$, in the tank wall at the intersection with the tank bottom. This tension, $T_{f}$, acts as a fluid hold-down force on the tank wall. For a given uplift height, $\delta$, the hold-down tension, $\mathrm{T}_{\mathrm{f}}$, that develops is both a function of the bending stiffness of the tank wall which is a function of its thickness, $t_{t w}$, and radius, $R$, and the bending stiffness of the base plate which is a function of its thickness, $t_{t b}$.

For a tank wall restrained against radial displacement at point " 1 " by the base plate, the relationship between $M_{f}$ and $\alpha$ can be 
obtained from pages 276 through 278 of Flugge (Reference 5.18) for axisymmetric loading as follows:

$$
M_{f}=K_{s} \alpha+M_{f x}
$$

where $M_{f x}$ represents the fixed end moment, and

$$
\begin{gathered}
K_{s}=\frac{2 K \kappa}{R} \\
\frac{M_{f x}}{p_{\theta}}=\frac{R t_{t w}}{\sqrt{12\left(1-v_{t}^{2}\right)}}\left[1-\frac{R}{H_{l} K}\right] \\
K=\frac{E_{t} t_{t w}^{3}}{12\left(1-v_{t}^{2}\right)} \\
\kappa=\left[\left(R / t_{t w}\right) \sqrt{3\left(1-v_{t}^{2}\right)}\right]^{1 / 2}
\end{gathered}
$$

Even though the actual loading around the circumference is not axisymmetic, Equation 5.20 is considered to be reasonably appropriate for the actual loading condition.

Since $L$ is a very small fraction of $R$, over the length $L$, the base plate may be approximated as a radial beam. Thus, from the boundary conditions at point "o":

$$
\begin{aligned}
\alpha & =\frac{p L^{3}}{12 E_{t} I_{t b}}-\frac{M_{f} L}{2 E_{t} I_{t b}} \\
\delta & =\frac{p L^{4}}{24 E_{t} I_{t b}}-\frac{M_{f} L^{2}}{6 E_{t} I_{t b}} \\
T_{f} & =\frac{p L}{2}+\frac{M_{f}}{L}
\end{aligned}
$$

where

$$
I_{t b}=\frac{t_{t b}^{3}}{12\left(1-v_{t}^{2}\right)}
$$

Combining Equations (5.20) and (5.21), one obtains:

$$
5-17
$$




$$
\begin{gathered}
\frac{E_{t} I_{t b} \delta}{p_{\theta}}=\left[\frac{L^{4}}{24}-\left(\frac{1}{F}\right)\left(\frac{K_{s} L^{5}}{72 E_{t} I_{t b}}+\frac{M_{f x}}{p} \frac{L^{2}}{6}\right)\right] . \\
\frac{T_{e}}{p_{\theta}}=\left[\frac{L}{2}+\left(\frac{1}{F}\right)\left(\frac{K_{s} L^{2}}{12 E_{\varepsilon} I_{t b}}+\frac{M_{f x}}{p L}\right)\right] \\
\frac{M_{f}}{p_{\theta}}=\left(\frac{1}{F}\right)\left(\frac{K_{s} L^{3}}{12 E_{s} I_{b}}+\frac{M_{f x}}{p}\right) \\
\frac{M_{+}}{p_{\theta}}=\frac{L^{2}}{8}-\frac{\left(M_{f} / p\right)}{2}+\frac{\left(M_{f} / p\right)^{2}}{2 L^{2}}
\end{gathered}
$$

where

$$
F=\left[1+\frac{K_{s} L}{2 E_{t} I_{t b}}\right]
$$

Using Equations 5.22 through 5.25, one can determine the uplift height $(\delta)$, tank wall hold-down tension $\left(T_{f}\right)$, and moment $\left(M_{f}\right)$, and maximum positive moment $\left(M_{+}\right)$in the base plate as a function of the uplift length, $L$, and fluid pressure, $p_{e}$. From this information the relationship between $\delta$ and $\mathrm{T}_{f}$ is obtained. This solution based on the small displacement theory is strictly applicable under the following conditions:

1. $(L / R) \leq 0.15$. The solution ignores the stiffening of the base plate from hoop behavior and thus conservatively overpredicts the displacement $\delta$ corresponding to a given $\mathrm{T}_{\mathrm{f}}$ as the ratio ( $L / R)$ becomes larger.

2. $\left(\delta / t_{t b}\right) \leq 0.6$. This solution being based upon the small displacement theory conservatively ignores the beneficial effect that could be obtained by use of the large displacement membrane theory together with membrane tensions in the base place to reduce $\delta$ corresponding to a 
given $T_{f}$. For unanchored tanks, it has been shown (References 5.19 and 5.20) that the large displacement membrane theory greatly increases the fluid hold-down forces, $T_{f}$. Thus, for unanchored tanks, ignoring the large displacement membrane theory is likely to lead to excessive conservatism. For anchored tanks, the uplift heights $(\delta)$ are not expected to be so great and only moderate conservatism is expected to result from ignoring large displacement membrane effects. Unfortunately, no simple solution exists for considering such membrane effects and, therefore, currently one must either accept this source of conservatism for anchored tanks or make judgmental corrections to the computed fluid hold-down forces following guidance from References 5.19 and 5.20 .

3. $\left(M_{f} / M_{p b}\right) \leq 0.9 ;\left(M_{f} / M_{p w}\right) \leq 0.9 ;$ and $\left(M_{+} / M_{p b}\right) \leq 0.9$ where $M_{p b}$ and $M_{p w}$ are the plastic moment capacity of the base plate and tark wall, respectively. The previous solution is an elastic solution and becomes nonconservative if these conditions are not met. An alternate solution with plastic hinges at locations where these conditions are not met is easily formulated following the same approach as was used herein but is judged to be unwarranted because violation of these conditions is highly unlikely for $\delta$ levels associated with anchored tanks.

only violation of the third condition leads to a nonconservative estimate of the hold-down force $T_{f}$ corresponding to a given uplift displacement $\delta$. The first two conditions can be violated so long as one is willing to accept the resulting conservative underestimation of the fiuid hold-down force.

For anchored tanks, it is recommended that the small displacement theory be used to compute the fluid hold-down forces. It is further recommended that the following pressures 
be used to compute the fluid hold-down forces at locations $\theta=$ 0 and $\theta=\theta_{\mathrm{n}}$ as defined in Figure 5.3:

$$
\begin{array}{ll}
p_{e}=p_{s t}-p_{d h}-0.4 p_{d v} & \text { at }(\theta=0) \\
p_{\theta} \geq p_{s t}-0.4 p_{d v} & \text { at }\left(\theta=\theta_{n}\right)
\end{array}
$$

The pressure defined at $\theta=0$ represents the probable minimum pressure at this location at the time the maximum moment occurs. The pressure defined above at $\theta=\theta_{n}$ represents the probable minimum pressure at $\theta=90^{\circ}$ at the time the maximum moment occurs, and is thus conservative for the location $\theta=\theta_{n}$ since $\theta_{\mathrm{n}}$ will always exceed $90^{\circ}$ for partially anchored or unanchored tanks.

\subsubsection{Unanchored Tanks}

The small displacement theory of the previous subsection is excessively conservative for unanchored tanks. An upper bound theory is considered more appropriate and is used in the following analyses.

The uplift length, $L$, illustrated in Figure 5.5, is assumed to be a very small fraction of $R$, and, therefore, over the length $\mathcal{L}$, the base plate may be approximated as a radial beam. An upper bound solution results after a full plastic hinge develops at point "2" (location of maximum positive bending moment $\mathrm{M}_{\mathrm{pb}}$ ) and at point "1" (base plate to wall junction and location of maximum negative moment $\mathrm{M}_{\mathrm{pw}}$ ). Since no shear may cross point "2", the following relations hold:

$$
\frac{p_{e} L^{2}}{2}=\left[M_{p b}+M_{p w}\right]+F_{h} \delta
$$

and

$$
T_{f}=p_{\theta} L
$$

where $F_{h}$ is the horizontal component of the membrane tension in the base plate at its junction with the cylindrical shell. 
Combining equations 5.27 and 5.28 one obtains:

$$
T_{f}=\left[2 p_{\theta}\left(M_{p b}+M_{p w}+F_{h} \delta\right)\right]^{1 / 2}
$$

with

$$
M_{p b}=\frac{\sigma_{y e} t_{t b}^{2}}{4}
$$

In Equation 5.29, $\mathrm{M}_{\mathrm{pw}}$ is the smallest of the plastic moment capacities of the following: (1) the base plate from Equation 5.30 , (2) the tank wall with $t_{t w}$ substituted for $t_{t b}$ in Equation 5.30 , and (3) the welded connection between the base plate and wall. In Equation 5.30, $\sigma_{y e}$ should be as defined in section 5.4 .

An upper bound on the horizontal component of the membrane tension in the base plate, $F_{h}$, is governed by the maximum local hoop compression capacity of the tank wall. For an axisymmetric application of $F_{h}$ and $M_{p w}$ at the base of the wall, the maximum hoop compression in the tank wall occurs at the intersection of the wall and base plate and is given by:

$$
N_{\theta m}=2 \kappa\left[F_{h}-\frac{M_{p w} \kappa}{R}\right]
$$

so long as

$$
F_{h} \geq\left[\frac{2 M_{p b} \kappa}{R}\right]
$$

Conservatively $\mathrm{N}_{\theta \mathrm{m}}$ should be limited to $\left(\sigma_{\mathrm{ye}} t_{\mathrm{tw}}\right)$. With this limit:

$$
F_{h} \leq \frac{\sigma_{y e} t_{t w}}{2 \kappa}+\frac{M_{p w} \kappa}{R}
$$

Local plastic hoop yielding might allow some increase in $F_{h}$ but it is recommended that no credit be taken for such an increase.

For conservatism, it is recommended that the probable minimum pressure from Equation 5.26 be used for $p_{e}$. Then $T_{f n}$ is computed $5-21$ 
from Equation 5.29 with $\delta=0$, and $\mathrm{T}_{\text {fo }}$ is computed with $\delta=\delta_{0}$. The $\Delta \mathrm{T}_{f}$ is computed from equation 5.15 .

\subsection{BASE SHEAR CAPACITY}

For large diameter (greater than about 30 feet) flat bottom tanks with fluid heights less than the diameter, it is common and acceptable practice to rely on friction between the tank bottom and its foundation to provide the base shear capacity. since the base shear response, $v_{r}$ and the base overturning moment response, $M_{r}$ are primarily due to the fluid horizontal impulsive mode of response, they both are maximum at the same time. Thus, the nominal sliding shear capacity is:

$$
V_{c s}=(C O F)\left[W_{\theta}+\left(\sum T_{b 1}\right)\right]
$$

where

$$
W_{e}=W_{t}+p_{a}\left(\pi R^{2}\right)
$$

$\Sigma \mathrm{T}_{\mathrm{b} 1}$ is the sum of anchor bolt tensions from the overturning moment analysis, (COF) is the coefficient of friction between the tank base and its foundation, $p_{a}$ is the probable average fluid pressure on the base given by $\left(p_{s t}-0.4 P_{d v}\right)$, and $w_{t}$ is the tank wall and roof weight. The equivalent code capacity $V_{C}$ is obtained by applying a strength reduction factor $(\phi)$ of 0.75 to the nominal shear capacity $\mathrm{v}_{\mathrm{cs}}$, i.e., :

$$
V_{c}=0.75 V_{c s}
$$

Such a low factor $(\phi)$ is used because of the uncertainty associated with the coefficient of friction.

For small diameter (less than about 10 feet) tanks, or tanks with fluid heights substantially greater than the tank diameter, it is unlikely that the friction-based shear capacity given by Equation 5.35 will exceed the base shear demand from the DBE. In this case, the shear capacity should be provided by anchor bolts. It is not acceptable to credit friction for a portion of

$$
5-22
$$


the shear capacity and provide the remainder by anchor bolts. Either $100 \%$ of the reported shear capacity is to be provided by friction, or $100 \%$ must be provided by anchor bolts or other means of positive anchorage.

Some large diameter flat bottomed tanks such as the example tank have a slight cone to their bottom plate so that contained fluid will always drain away from the center toward the drain pipe at the edge. This cone is generally created by a variable thickness sand cushion between the tank bottom plate and its foundation. Furthermore, the tank bottom is generally made up of slightly overlapped fillet welded individual plates. Thus, the surface between the bottom plate and the sand cushion contains a series of rough steps. Under these conditions, it is reasonably conservative to estimate

$$
(\mathrm{COF}) \geq 0.7^{*}
$$

For flat bottom steel tanks on concrete the coF is estimated as 0.55 .

\subsection{OTHER CAPACITY CHECKS}

For tanks on soil sites, one should also check the capacity of the tank foundation and this capacity sometimes governs.

Lastly, the possibility of piping failure or the failure of nozzles/penetrations where such piping is attached to the tank should be checked. Such failure will likely lead to loss of tank contents. In fact, a significant fraction of the cases of seismic induced loss of tank contents have been due to such failures when the piping contained poor seismic details. The issues to be checked are as follows:

1. Are heavy valves or long piping runs being supported through the piping nozzles off either the tank walls or the

"Applicable for large diameter tanks with coned and uneven base. $5-23$ 
bottom plate, or are they independently supported? If heavy valves or long piping runs are being supported of $f$ the tank, then the ability of the nozzles and the tank wall or bottom plate to withstand the iniposed seismic-induced inertial forces should be checked. Methods outlined in Welding Research Bulletin 107 (Reference 5.21) may be used to compute local stresses in the tank wall, and the strength acceptance criteria for vessels contained in Chapter 3 can be used for the stress capacity.

2. Is there sufficient piping flexibility to accommodate relative seismic anchor movements (SAM) between the locations where the piping is supported from the tank wall and where it is independently supported? Particularly for unanchored tanks, the piping nozzle and tank shell should be evaluated for their ability to withstand the expected relative SAM.

\subsection{TOP SUPPORTED TANKS}

Many of the DOE underground waste storage tanks are laterally supported by the surrounding concrete vault near the top of the cyclindrical tank wall. As shown in chapter 4 , the presence of this top lateral support will greatly reduce the overturning moment applied at the base and will also reduce the base shear. In this case, the base moment capacity (section 5.8) and base shear capacity (Section 5.11) are not likely to control the seismic capability of such tanks, but should still be checked. In addition, the lateral force (shear) capacity of the top anchorage must be checked in accordance with the capacity requirements of section 3.7. Furthermore, these lateral forces must be applied to the concrete vault when checking the seismic capacity of the vault. Tanks with lateral support near the top of the cyclindrical tank wall are likely to have substantially greater seismic capacity than a similar tank without this top support. 


\section{REFERENCES}

5.1 Kennedy, R.P. and Kassawara, R.P., "Seismic Evaluation of Large Flat-Bottomed Tanks", Second symposium of current Issues Related to Nuclear Power Plant structures, Equipment, and Piping with Emphasis on Resolution of Seismic Issues in Low-Seismicity Regions, EPRI NP-6437-D, Electric Power Research Institute, May 1989.

5.2 "A Methodology for Assessment of Nuclear Power Plant Seismic Margin," NP-6041, Rev. 1, Electric Power Research Institute, June 1991.

5.3 Veletsos, A.S. and Yang, J.Y., "Dynamics of Fixed-Base Liquid Storage Tanks," Presented at the U.S.-Japan Seminar for Earthquake Engineering Research with Emphasis on Lifeline systems, Tokyo, Japan, pp. 314-341, November 1976.

5.4 Veletsos, A.S. and Yang, J.Y., "Earthquake Response of Liquid Storage Tanks," Advances in Civil Engineering Through Engineering Mechanics, Proceedings of the Engineering Mechanics Division Specialty Conference, ASCE, Raleigh, NC, pp. 1-24, 1977 .

5.5 Veletsos, A.S., "Seismic Response and Design of Liquid Storage Tanks," Guidelines for the Seismic Design of oil and Gas Pipeline Systems, ASCE, Chapter 7, 1984.

5.6 Veletsos, A.S. and Tang, Yu, "Interaction Effects in Vertically Excited steel Tanks", Dynamic Response of structures, ASCI, pp. 636-643, March 1986.

5.7 Veletsos, A.S. and Tang, Yu, "Dynamic of Vertically Excited Liquid Storage Tanks," Journal of Structural Engineering, Vol. 112, No. 6, ASCE, pp. 1228-1246, June 1986. 
5.8 Haroun, M.A. and Housner, G.W., "Seismic Design of Liquid Storage Tanks," Vol. 107, No. TC1, pp. 191-207, 1981.

5.9 Haroun, M.A. and Housner, G.W., "Complications in Free Vibration Analysis of Tanks," Journal of the Engineering Mechanics Division, Vol. 108, No. EM5, ASCE, pp. 801-818, 1982 .

5.10 "ASCE Standard and Commentary--Seismic Analysis of SafetyRelated Nuclear Structures", ASCE 4-86, September 1986.

5.11 Newmark, N.M and Hall, W.J., "Development of Criteria for Seismic Review of Selected Nuclear Power Plants", NUREG/CR0098, Nuclear Regulatory Commission, May 1978.

5.12 Priestly, M.J.N. et al., "Seismic Design of storage Tanks," Bulletin of the New Zealand National Society for Earthquake Engineering, Vol. 19, No. 4, December 1986.

5.13 Priestly, M.J.N., "Seismic Design of storage Tanks, Recommendations of a study Group of the New zealand National Society for Earthquake Engineering", December 1986 .

5.14 Rotter, J.M., "Local Inelastic Collapse of Pressurized Thin Cylindrical Steel Shells Under Axial Compression", Research Report, School of Civil and Mining Engineering, University of Sydney, Australia, 1985.

5.15 "ASME Boiler \& Pressure Vessel Code section III", Subsection NC3800, Division 1, 1989.

5.16 "Buckling of Thin-Walled Circular Cylinders", NASA SP-8007, National Aeronautics and Space Administration, August 1968.

5.17 American Institute of steel Construction, "Manual of Steel Construction, Load \& Resistance Factor Design", LRFD, First Ed., Chicago, Illinois, 1986

$$
5-26
$$


5.18 Flugge, W., "stresses in Shells", Springer-Verlag, 1960.

5.19 Manos, G.C., "Earthquake Tank-Wall stability of Unanchored Tanks," Journal of structural Engineering, Vol. 112, No. 8, ASCE, pp. 1863-1880, August 1986 .

5.20 Haroun, M.A. and Badawi, H.S., "Nonlinear Axisymmetric Uplift of Circular Lates," Dynamics of structures, ASCE, pp. 77-89, August 1987.

5.21 K.R. Wickman, Hooper, A.G. and Mershon, J.L., "Local Stresses in spherical and Cylindrical shells due to External Loadings," Welding Research Bulletin 107, August 1965 .

5.22 Miller, C.D., "Metal Containment Shell Buckling Design Methods", ASME Code Case N-284, Rev. 1, May 1991. 
$C_{b} \quad$ maximum permissible axial compressive force per unit length

C'. compressive force per unit length at the outer compression side of tank wall

$\mathbf{E}_{\mathbf{t}}$ modulus of elasticity of tank material

$\mathrm{h}_{\mathrm{c}}$ height of cylindrical tank wall above the liquid

$\mathrm{h}_{\mathrm{d}}$ dome height above cylindrical wall

$h_{0}$ effective length of anchor bolt

$\mathrm{h}_{\mathbf{s c}}$ slosh height capacity

$h_{8 r}$ slosh height response $I_{\text {tb }}$ moment of inertia of base plate

L length of uplifted portion of base plate seismic load factor

M moment in tank wall at intersection with base plate $M_{+}$ maximum positive moment

$M_{b}$ base overturning moment response

$M_{c}$ moment capacity of tank

M moment in tank due to fluid hold-down

$M_{f x}$ fixed end moment plastic moment capacity of base plate plastic moment capacity of wall

$\mathrm{N}_{\mathrm{h}}$ $N_{\theta m}$ horizontal component of membrane tension in base plate maximum hoop compression

$p$ liquid pressure

$p_{c}$ pressure capacity 
$\mathrm{p}_{\mathrm{dh}} \quad$ hydrodynamic pressure due to horizontal component of seismic motion

$p_{d v}$

$p_{\theta}$

$p_{m n}$

$P_{m x}$

$p_{\text {st }}$

$p_{t 1}$

$\mathrm{P}_{\mathrm{a}}$

R

$t_{t b}$

$t_{t w}$

$\mathrm{T}_{\mathrm{b} 1}$

$\mathrm{T}_{\mathrm{bp}}$

$\mathrm{T}_{c b}$

$T_{f}()$

$T_{f o}$

$T_{\text {fn }}$

$\mathrm{V}_{\mathrm{b}}$

$\mathrm{V}_{\mathrm{c}}$

$\mathrm{V}_{\mathrm{cs}}$

$w_{e}$

$w_{t}$

$\delta_{0}$

hydrodynamic pressure due to vericical component of seismic motion

effective pressure defined by Equation 5.26

total minimum internal pressure on tank wall at location of maximum longitudinal compressive stress

total maximum internal pressure on tank wall at location of maximum longitudinal compressive stress

hydrostatic pressure

total inelastic factored demand pressure

axial compressive force on tank wall

radius of the tank

thickness of base plate

thickness of tank wall

tensile force on anchored bolt "i"

anchor bolt pretension

tensile capacity of anchor bolt

fluid hold-down tensile force (tension)

fluid hold-down tensile force at the outer tension side of the tank wall

fluid hold-down tensile force at the neutral axis

base shear response

base sliding shear capacity using code coefficient

nominal base sliding shear capacity

effective weight for determination of base shear capacity

tank weight

uplift height at outer tension side of tank wall 


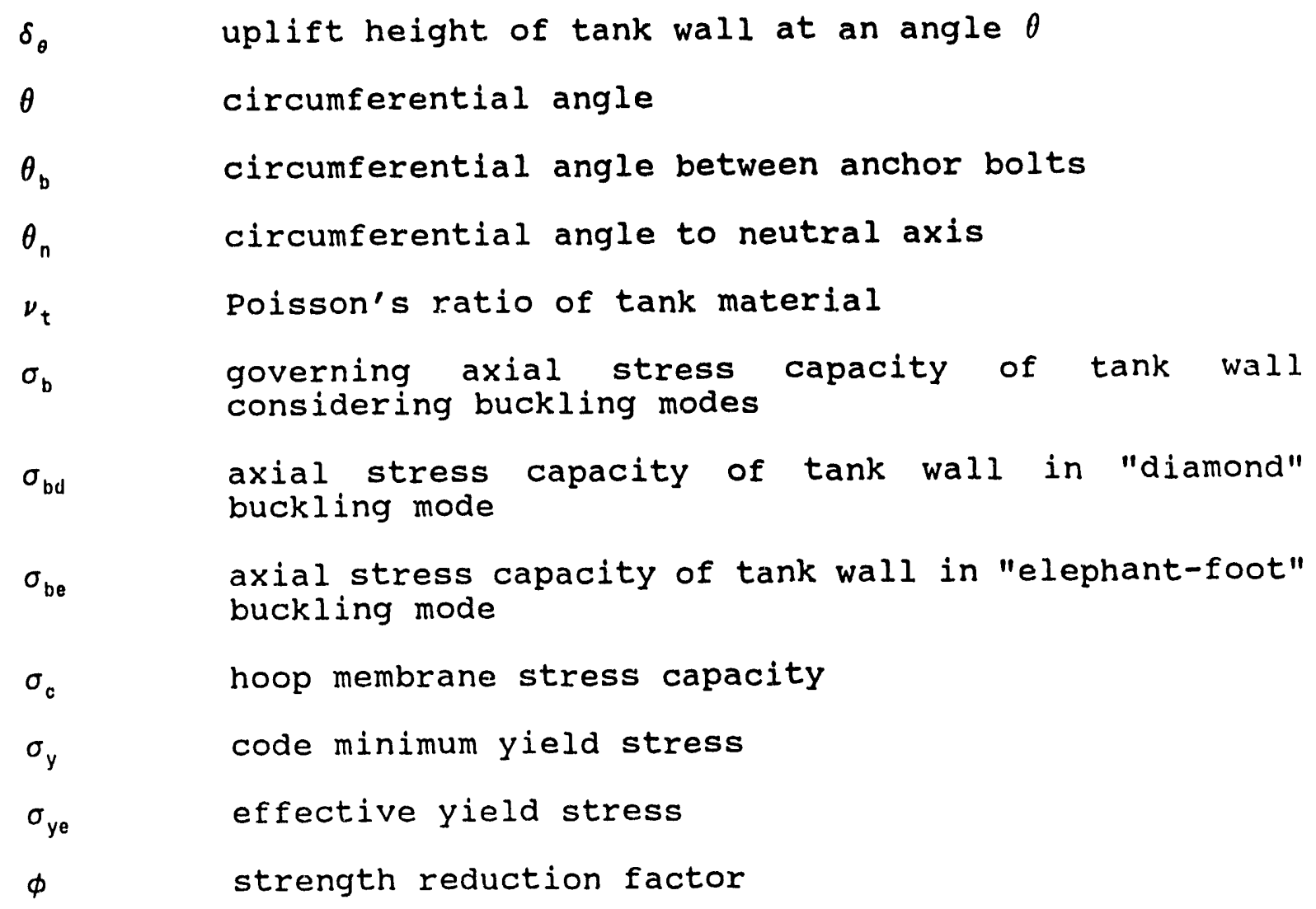


Table 5.1 Tank Parameters

\begin{tabular}{|c|c|c|c|c|}
\hline$\theta_{n}$ & $c_{1}$ & $\mathrm{C}_{2}$ & $\mathrm{C}_{3}$ & $\mathrm{C}_{4}$ \\
\hline 1.60 & 1.017 & 1.558 & 1.034 & 1.583 \\
\hline 1.65 & 1.048 & 1.534 & 1.095 & 1.602 \\
\hline 1.70 & 1.081 & 1.508 & 1.159 & 1.619 \\
\hline 1.75 & 1.117 & 1.480 & 1.228 & 1.634 \\
\hline 1.80 & 1.155 & 1.450 & 1.302 & 1.647 \\
\hline 1.85 & 1.197 & 1.417 & 1.380 & 1.658 \\
\hline 1.90 & 1.242 & 1.383 & 1.465 & 1.667 \\
\hline 1.95 & 1.291 & 1.346 & 1.555 & 1.674 \\
\hline 2.00 & 1.345 & 1.307 & 1.654 & 1.679 \\
\hline 2.05 & 1.403 & 1.266 & 1.760 & 1.683 \\
\hline 2.10 & 1.468 & 1.223 & 1.876 & 1.685 \\
\hline 2.15 & 1.539 & 1.179 & 2.003 & 1.680 \\
\hline 2.20 & 1.618 & 1.132 & 2.142 & 1.684 \\
\hline 2.25 & 1.706 & 1.083 & 2.296 & 1.682 \\
\hline 2.30 & 1.804 & 1.033 & 2.467 & 1.679 \\
\hline 2.35 & 1.915 & 0.981 & 2.658 & 1.674 \\
\hline 2.40 & 2.042 & 0.927 & 2.874 & 1.668 \\
\hline 2.45 & 2.187 & 0.872 & 3.119 & 1.661 \\
\hline 2.50 & 2.354 & 0.815 & 3.400 & 1.654 \\
\hline 2.55 & 2.551 & 0.757 & 3.727 & 1.646 \\
\hline 2.60 & 2.783 & 0.698 & 4.112 & 1.638 \\
\hline 2.65 & 3.064 & 0.637 & 4.573 & 1.630 \\
\hline 2.70 & 3.408 & 0.576 & 5.134 & 1.621 \\
\hline 2.75 & 3.840 & 0.513 & 5.834 & 1.612 \\
\hline 2.80 & 4.400 & 0.449 & 6.735 & 1.604 \\
\hline 2.85 & 5.151 & 0.385 & 7.939 & 1.596 \\
\hline 2.90 & 6.215 & 0.320 & 9.633 & 1.589 \\
\hline 2.95 & 7.834 & 0.254 & 12.20 & 1.583 \\
\hline 3.00 & 10.60 & 0.188 & 16.57 & 1.578 \\
\hline 3.05 & 16.38 & 0.122 & 25.68 & 1.574 \\
\hline 3.10 & 36.07 & 0.055 & 56.63 & 1.571 \\
\hline
\end{tabular}




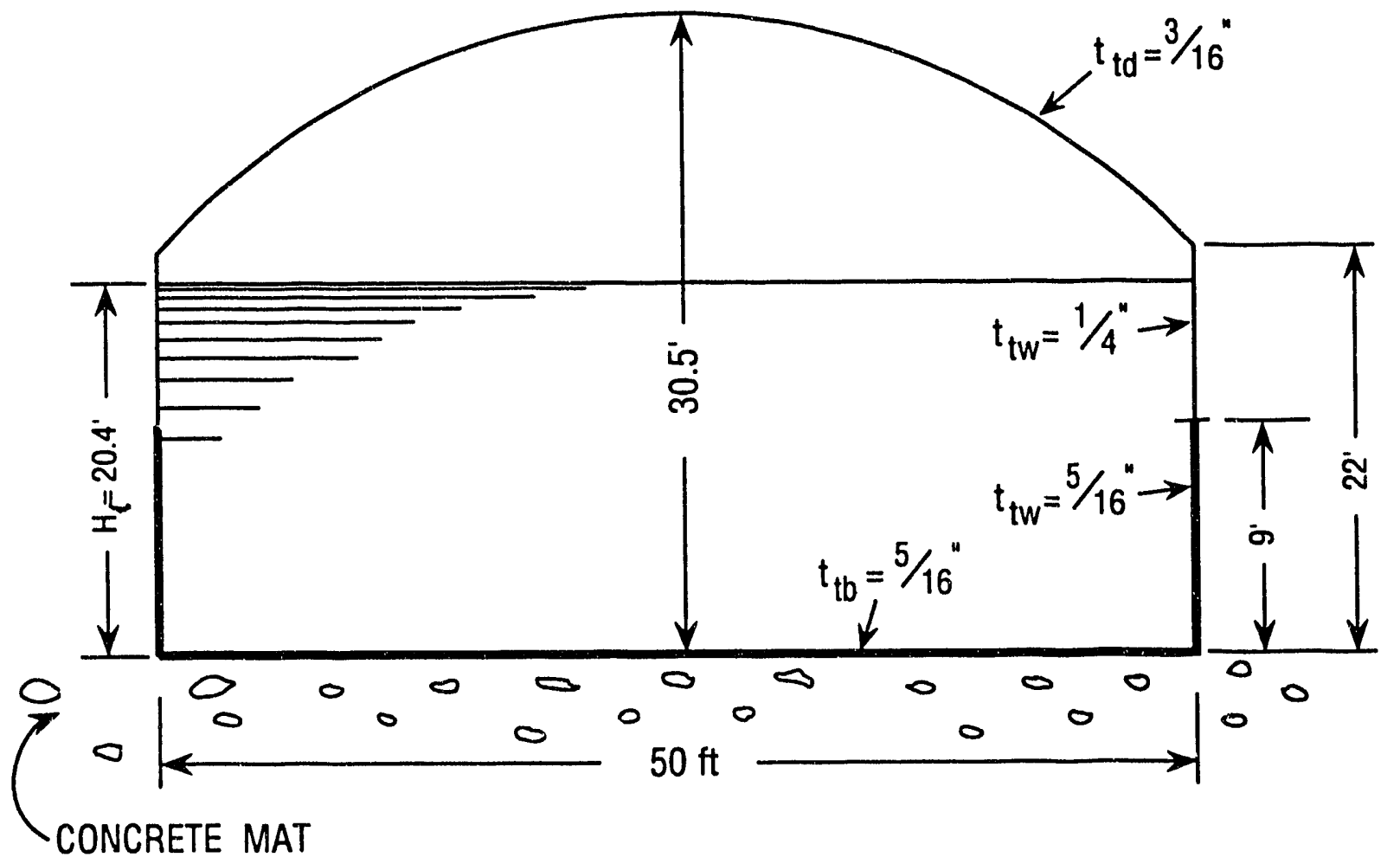

Figure 5.1 Example Tank 


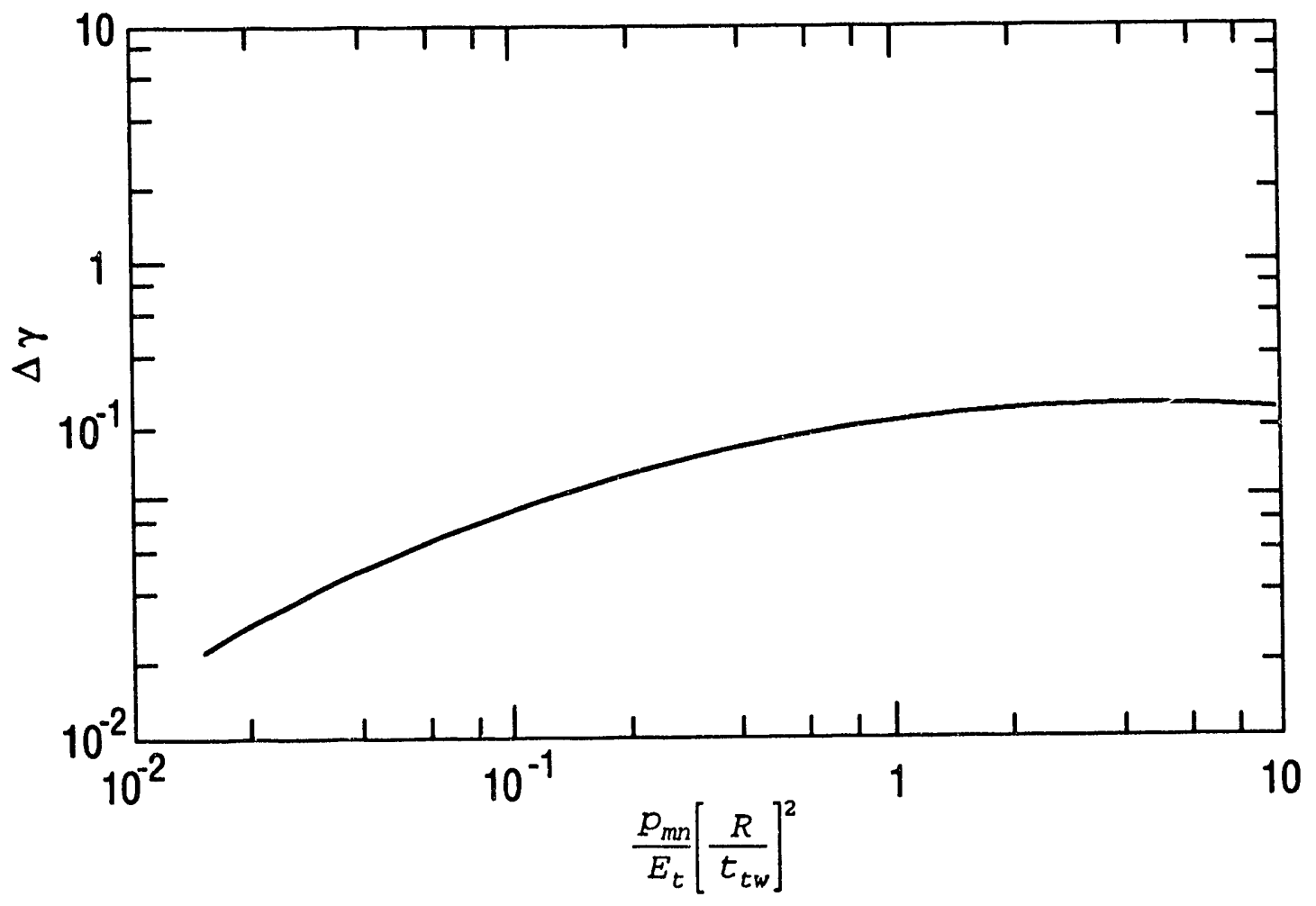

Figure 5.2 Increase in Axial Compressive Buckling Stress Coefficient of Cylinders Due to Internal Pressure (Reference 5.16)

$$
5-33
$$




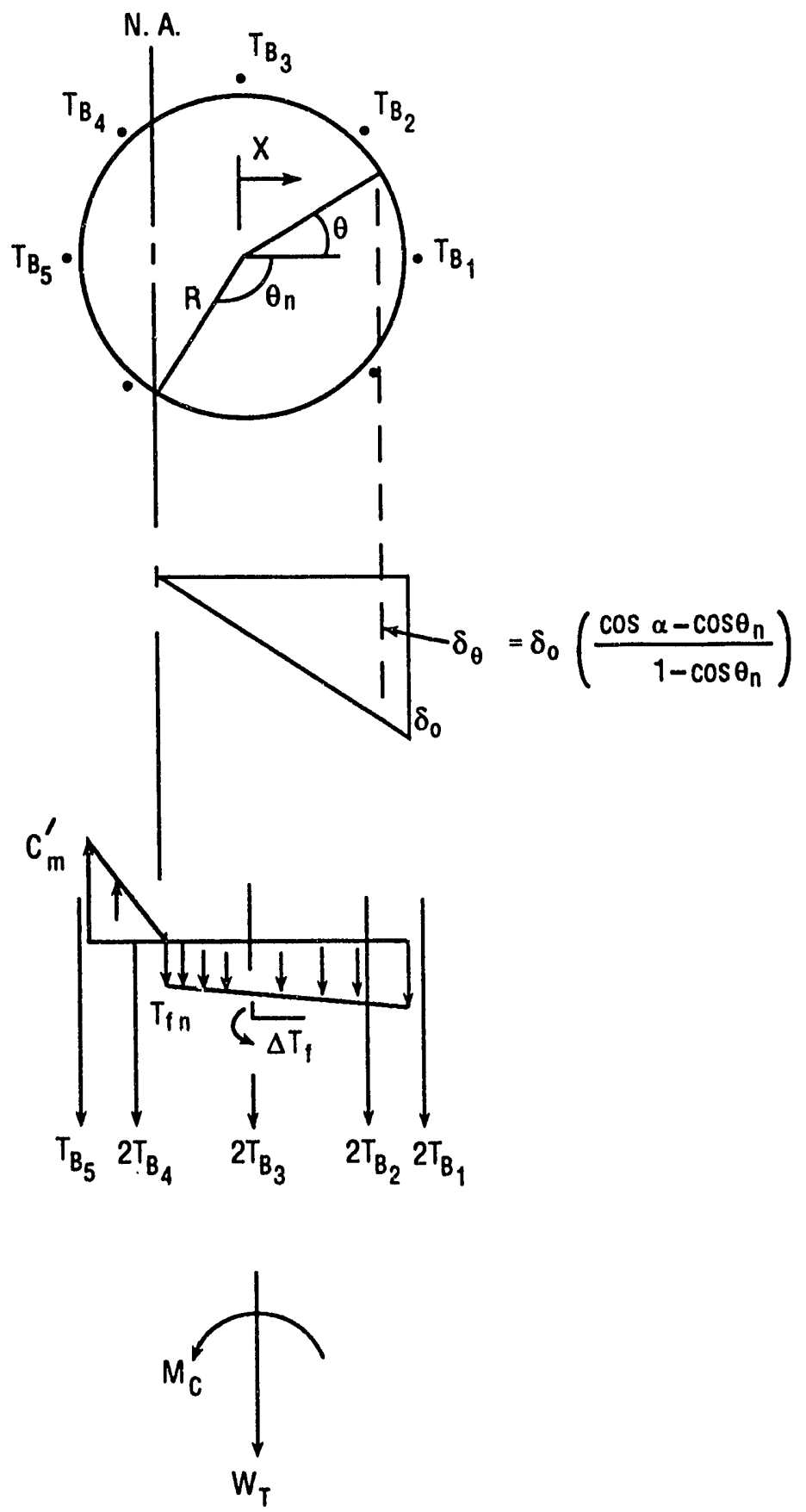

Figure 5.3 Vertical Loading on Tank Wall at Base $5-34$ 


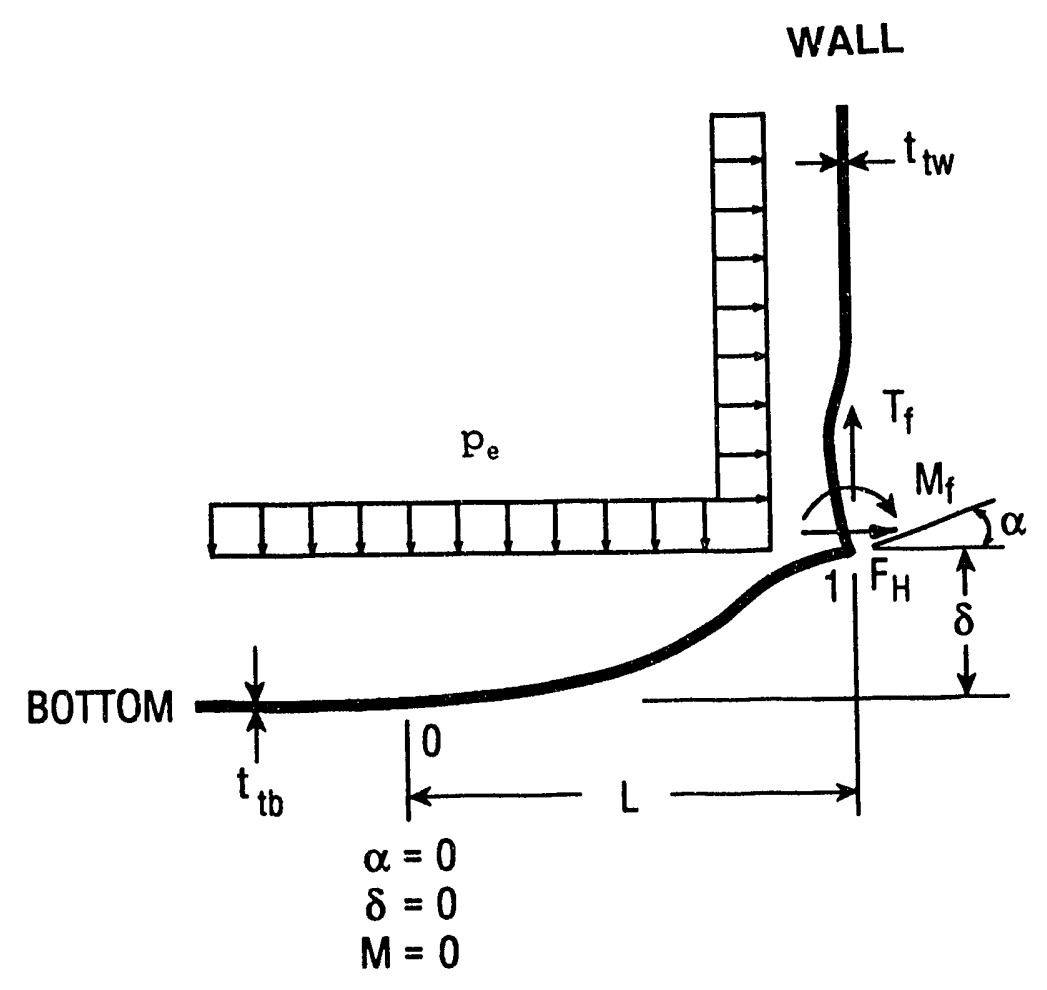

Figure 5.4 Schematic Illustration of Anchored Tank Bottom Behavior at Tensile Region of Tank Wall

$$
5-35
$$




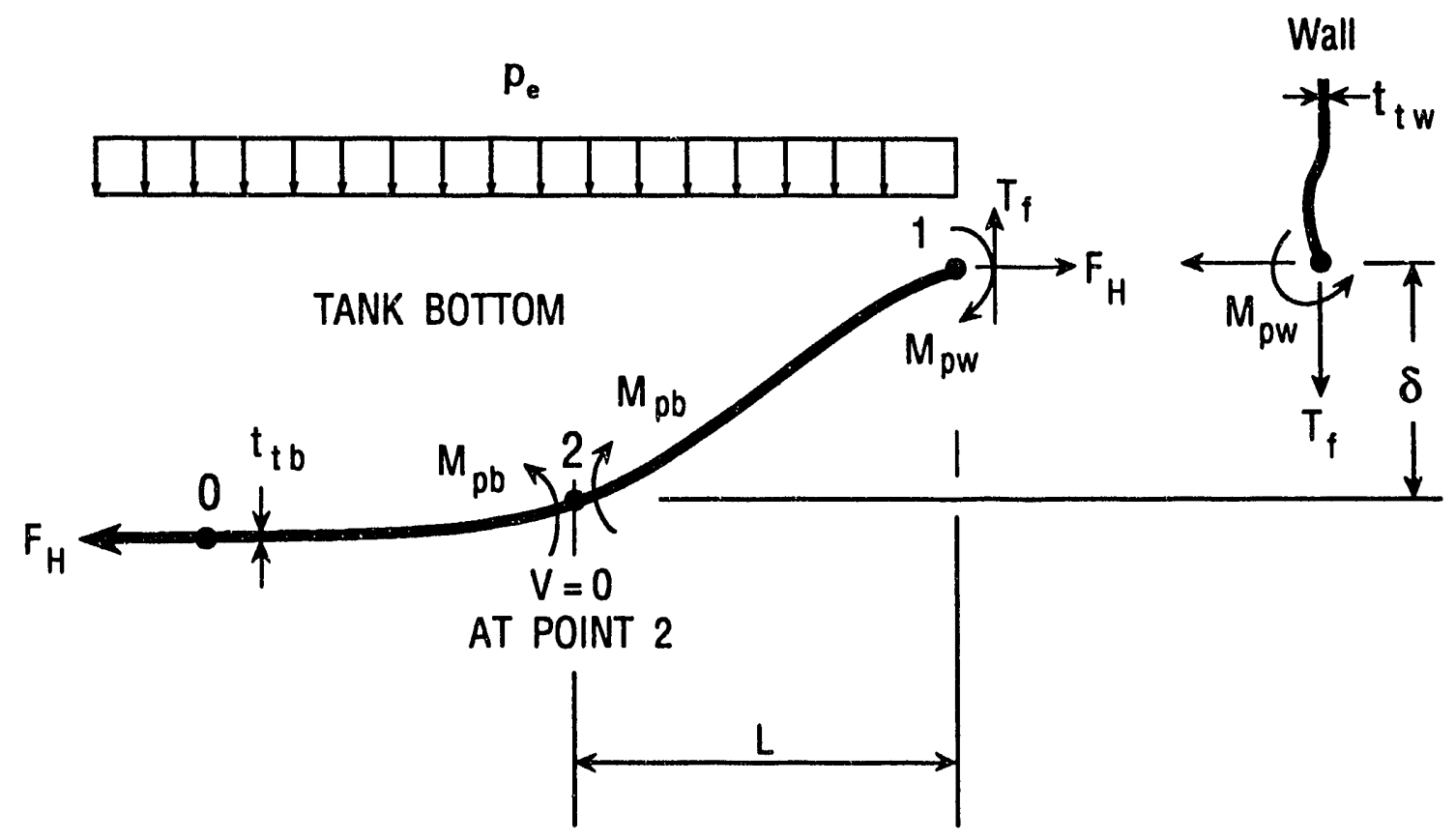

Figure 5.5 Schematic Illustration of Unanchored Tank Bottom Behavior at Tensile Region of Tank Wall 
CHAPTER 6

EVALUATION OF SOIL-VAULT INTERACTION

\subsection{INTRODUCTION}

This chapter contains provisions for evaluation of the seismic motion input to the support points of the tank and the seismic induced pressures acting on the walls of the vault. The first result is to be used in the seismic evaluation of the tank (Chapter 4), and the second result is to be used in the stress analysis of the vault structure (Chapter 3). The free field criteria motion (defined in terms of a response spectrum) to be used as input to this evaluation is discussed in chapter 3 . The tank model used in the combined vault/tank system is discussed in chapter 4 and further amplified in this chapter.

There are two important considerations associated with an evaluation of soil-vault interaction effects. The first consideration relates to the evaluation of the vertical spatial variation of the free field ground motion. A free-field motion is defined at a control point and motions compatible with the soil properties are computed at other locations in the free field. This evaluation is performed using standard convolution methods assuming vertically propagating, horizontally polarized shear waves in the free field. The soil properties affecting the vault response at many of the HLW sites are relatively uniform over depths. At these sites it is reasonable to assume that the free field motion is uniform with depth so that convolution studies are not required to define the vertical spatial variation of the ground motion.

The second consideration requires an evaluation of the soil-vault interaction effects since the vault motion may differ from the free field motion. Soil pressures acting on the vault 
can be determined from this evaluation. There are two approaches that have been used in the literature to evaluate these effects. One approach is based on finite element models of the free field and vault with continuity conditions at the soil-vault interface used to connect the two models. A second approach utilizes spring/damper models, connecting the vault model to the free field, to represent soil-vault interaction effects. Both approaches are recommended in References 6.1 and 6.2 and they have both been used extensively and successfully in seismic analyses of nuclear power plant facilities. The first approach is theoretically rigorous and leads to excellent results provided that the numerical details (element size, frequency or time increments, and boundary conditions) are properly treated. However, this approach is difficult and costly to implement. The second approach is simpler and more cost-effective, but the degree of its applicability to vaults of the relatively small height-to-radius ratios encountered in $\mathrm{HLW}$ storage facilities has not yet adequately been assessed. studies are currently underway to make this assessment and, if necessary, improve the approach. Pending the outcome of these studies, the simple approach may be used in the form described herein, which is essentially the same as that given in References 6.1 and 6.2 .

An evaluation of the mass and stiffness characteristics of typical vault-tank systems indicates that soil-vault interaction effects are of minor significance for many vaults. Therefore, the additional effort required to apply the first approach may not be warranted for underground concrete vaults. Conditions under which the soil-vault interaction effects can be neglected are also discussed in this chapter.

This chapter includes discussions of the definition of the required soil properties, free field motion, response to vertical seismic motions, response to horizontal seismic 
motions, and vault-vault interaction effects. The provisions of this chapter are applicable to vaults which are circular in cross section. The results may be applied, however, to noncircular cross sections provided that the longer plan dimension is no larger than 1.5 times the shorter plan dimension. In these cases the vault shall be assumed to be circular in cross section with a plan area equal to the actual plan area.

\subsection{SOIL PROPERTIES}

Soil properties (shear modulus, density, Poisson's ratio and damping) are required to perform both the free field convolution studies and the soil-structure interaction (SSI) analyses. These analyses should account for the dependence of these soil properties on strain levels in the soil during the DBE. sufficient in-situ data should be obtained to find mean values for the properties and to statistically define the variation of the properties.

A soils exploration program should be implemented to evaluate the soil properties to be used in the seismic analyses. The exploration should be performed as close as practical to the location of the tank and should extend down to a depth at least equal to two vault radii below the vault foundation. Sufficient data should be obtained so that variability in properties can be statistically defined. The statistical evaluation of soil properties should be done within layers which are usually defined from the boring logs. Information on properties of backfill should be developed to the same degree as for the in-situ soils. Details of the exploration program are discussed further in section 7.2 .

Cyclic confined compression, resonant column or torsion testing of undisturbed soil samples should be performed so that the variation of soil properties (shear modulus and damping) with strain levels may be defined. Soil damping should be limited to 
$15 \%$

As a minimum, SSI and convolution calculations should be performed using 15 (lower bound), 50 (best estimate), and 85 (upper bound) percentile low strain soil shear moduli. These convolution studies are not required if SSI effects can be neglected by the criteria of section 6.5.1. The lower bound properties are equal to the best estimate divided by one plus the coefficient of variation and the upper bound properties are equal to the best estimate properties times one plus the coefficient of variation. The minimum coefficient of variation should be taken as 0.5. If sufficient soil data is not available to evaluate the standard deviation of the shear modulus, the coefficient of variation should be taken as 1 . The soil damping should be selected consistent with the strain values determined from the convolution analyses.

\subsection{FREE FIELD MOTION}

The objective of the calculations discussed in this section is to determine the variation of the two horizontal components of the free field ground motion over the depth of embedment of the vault. This variation should be included in the SSI calculations used to evaluate the seismic-induced motion of the tank and the soil pressures acting on the vault during a seismic event. If a site-specific study has been performed, these data will be available. In the case that the site is uniform (see Section 3.3), the DBE horizontal ground motion can be conservatively assumed to be uniform over the depth of the vault. Convolution studies are still required, however, to evaluate the magnitude of the seismic-induced soil strains which are required to determine the strain-dependent soil properties to be used in the SSI analyses. The vertical component of the free field motion can be taken as the criteria motion specified at the basemat of the vault (see section 6.4). 
A DBE time history should be developed which results in response spectra that envelope the free field spectra discussed in Chapter 3. Response spectra should be developed for the time history at all damping values of interest and these spectra should be compared with the free field criteria spectra discussed in Chapter 3. Criteria specified in ASCE 4-86 (Reference 6.1) can be used for this comparison. Special care should be taken so that the time history is baseline corrected (i.e., final velocity of the time history is zero and peak displacements are consistent with the magnitude and focal distance of the DBE).

The control point for the placement of the DBE horizontal ground motion should be taken as discussed in section 3.3. The variation of horizontal free field motions occurring at elevations within the depth of the vault should be evaluated using convolution methods associated with vertically propagating, horizontally polarized shear waves. The number and thickness of the layers to be used in the analysis should be consistent with the soil property variation with depth. The mesh size shall be sufficiently fine over the depth of the vault to provide ground motion data at the top midpoint and bottom of the vault, and be capable of transmitting frequencies containing most of the energy in the DBE and at least twice the primary system frequencies (e.g., SSI, fixed base structural, and equipment). However, the mesh does not have to transmit frequencies greater than $25 \mathrm{cps}$. Larger mesh sizes may be used if justified with a parametric study. Convolution studies should be performed using lower bound, best estimate, and upper bound soil properties. The free field motion using the three soil models shall be used as input to the SSI calculations for the corresponding soil models.

The convolution calculations should be performed accounting for the degradation of soil properties (shear modulus and hysteretic 
soil damping) with strain. The degradation models should be determined from measured properties or computed using generally accepted models. In no case should hysteretic soil damping be taken as greater than $15 \%$.

The convolution studies should be performed using in-situ soil properties unless backfill has been used and the backfill extends out an average distance of at least 3 vault radii from the vault wall. In this case, the backfill properties should be used in the convolution analysis for the upper portion of the soil column.

\subsection{VERTICAL SSI CALCULATIONS}

Vertical SSI parameters are given in Appendix $G$ and used to evaluate the significance of vertical SSI effects. The vertical SSI damping ratio $\left(\zeta_{v}\right)$ as determined in section $G .3$ is given by:

$$
\zeta_{v}=0.59\left[R_{v} \rho_{f s} /\left(H_{v} \rho_{v}\right)\right]^{1 / 2}
$$

where,

$$
\begin{aligned}
\mathrm{R}_{v}= & \text { radius of vault } \\
\mathrm{H}_{\mathrm{v}}= & \text { height of vault } \\
\rho_{\mathrm{fs}} \quad= & \text { mass density of foundation (base) soil } \\
\rho_{\mathrm{v}} \quad= & \text { average mass density of vault/tank/contents (total } \\
& \text { mass/volume) }
\end{aligned}
$$

Most of the tanks of interest have aspect ratios $\left(R_{v} / H_{v}\right)$ close to unity so that the vertical SSI damping ratios are about $60 \%$ of critical when the mass density of the vault tank system is about equal to the soil (a reasonable assumption for most vaults of interest). This damping will eliminate any significant amplification of the free field vertical motion (an amplification of about $5 \%$ of the free field vertical motion would be expected at the vertical SSI frequency). The vertical motion of the tank can therefore be taken as equal to the free field vertical motion described with the response spectrum as 
given in Chapter 3.

The vertical seismic load on the roof of the vault can be computed as the mass of the vault roof and overburden soil times an acceleration taken from the spectrum defined in chapter 3 . The acceleration should be taken from the spectrum at the vertical fixed-base frequency of the vault including the mass of the overburden soil and the flexibility of the roof of the vault. Vertical SSI calculations can be performed using either lumped parameter or finite element models. In either case, the vault model should include the mass of the overburden soil and the flexibility of the vault roof and walls. The fluid tank model should represent the masses and frequencies discussed in section 4.5. The SSI model used for the lumped parameter analysis can be taken from section G.3.

\subsection{HORIZONTAL SSI CALCULATIONS}

Methods for calculation of the combined horizontal and rocking seismic response of the vault/tank system are discusseu in this section. The cases in which the horizontal/rocking SSI effects may be neglected are first discussed and this is followed by consideration of the methods that may be used to include these SSI effects when required.

\subsubsection{Conditions for Neglecting Horizontal/Rocking SSI Effects}

Horizontal and rocking SSI effects may be neglected when the site is relatively uniform (see section 3.3 for definition of a uniform site) and when it can be shown that the amplifications of the free field motions caused by SSI effects are small. When this is the case, the vault seismic motion can be taken as uniform over the depth of the vault and expressed by the free field spectra as defined in chapter 3 .

The horizontal and rocking SSI frequencies and damping ratios are given in Appendix G. Amplifications of the free-field $6-7$ 
motion caused by the SSI effects are calculated and shown in Figure G.2 for various ratios of the vault height to the radius $\left(H_{v} / R_{v}\right)$. These data indicate that coupled horizontal/rocking SSI effects can be neglected for values of $H_{v} / R_{v}$ less than 0.5 and should be included for larger values of $H_{v} / R_{v}$.

When the SSI effects are neglected, the normal horizontal soil pressure ( $p$ ) acting on the vault can be uniformly distributed in the vertical direction and distributed (in a cosine variation) around the circumference of the vault. The magnitude of the peak pressure can be conservatively (since it neglects the contribution of shear forces acting on the vault wall) estimated based on the peak inertial force required to act on the vault wall so that the vault follows the free field motion. The result of this assumption is:

$$
p=\gamma_{v} R_{v} a_{\max } \cos \theta
$$

where,

$\gamma_{v}=$ average density of vault/tank system

$\mathrm{R}_{\mathrm{v}}=$ radius of vault

$\theta=$ angle defining location of point on perimeter of vault

$a_{\max }=$ peak free field acceleration ( $G^{\prime} s$ )

These wall pressures are in dynamic equilibrium with the inertial loads acting on the tank/vault system. Since the major portion of the inertial loads arises in the tank, the earth pressures on the vault wall are in equilibrium with the inertial loads in the tank. The stress analysis of the vault can therefore be performed by placing the earth pressures on the vault while supporting the vault in a manner that is compatible with the support conditions for the tank within the vault. The vault should be supported as a cantilever off the base and subjected to the earth pressures when the tank is supported only from the base of the vault. The vault should be treated as a 
simple beam, supported at the top and base when the tank is topsupported.

\subsubsection{Criteria for Performing Horizontal SSI Calculations}

This section covers the procedures that can be used when it is required to include horizontal/rocking SSI effects. It should be emphasized that the required outputs from these analyses are response spectra at various locations within the vault/tank system and soil pressures acting on the vault walls. A detailed stress analysis of the vault and tank may subsequently be performed using equivalent static loads developed from the spectra and pressures determined from the SSI analyses. Alternately, internal forces in the vault structure may be determined directly from the SSI analyses provided the vault is modeled in sufficient detail. In general, the tank forces should be developed from separate analyses as discussed in chapter 4 of this report. The tank analyses would use either the time histories or response spectra resulting from the SSI analyses.

The treatment of SSI effects for the waste tanks is different from the treatment of these effects for other structures such as reactor containment buildings. The geometry, mass, and stiffness of waste tanks cause vault wall SSI effects to be larger than base SSI effects. The opposite is true for most structures located at nuclear power plant facilities. This difference is significant because there are fewer uncertainties for base SSI models than for vault wall SSI models. A second difference arises because of the significance of the soil pressures exerted on the vault walls as a result of the seismic loading. The standard SSI methods are modified so that these pressures can be obtained. Both these differences require more accurate vault wall SSI models than are usually needed for evaluation of nuclear facilities. Currently, studies are underway to refine the methods discussed in this chapter and the

$$
6-9
$$


results of these studies will be incorporated into this report as they becrine available.

Two methods are available for performing the SSI calculations. The first utilizes spring/damper lumped parameter models connecting the vault and free field models to represent SSI effects. In the second method, the soil and vault are represented by a continuum modeled with discrete elements (e.g., finite elements) and the SSI effects are obtained based on compatibility zonditions at the interface. In either of these cases the solutions may be carried out in the frequency or time domain. The discretization parameters (e.g., time or frequency increment, element size, boundary locations, etc.) should be selected based on the desired frequency content of the solution. Criteria such as those contained in the US NRC standard Review Plan (Reference 6.2) or in ASCF 4-86 (Reference 6.1) may be used to satisfy these requirements. Solutions to the spring/damper lumped parameter model may be obtained by using either a time history analysis or a response spectrum analysis.: Both are discussed in the following sections. The response spectrum solution should be restricted to those cases where the soil conditions are uniform (see section 3.3).

\subsubsection{Lumped Parameter Model Using Time History Analysis}

SSI calculations may be performed using a lumped parameter spring/dashpot model to represent the conrection of the vault/tank to the free field.

\section{Specification of Free Field Motion}

At uniform sites (see secticn 3.3) the horizontal component of the free field motion may be taken as uniform and equal to the $D B E$ motion discussed in chapter 3. At nonuniform sites the horizontal component of the free field motion should be specified at the top, bottom, and several intermediate depths 
over the tank. These motions should be compatible with the DBE free field motion (see chapter 3) and the soil properties, and should be generated based on convolution methods as discussed above (Section 6.3). The sloshing motion of fluid and the relative displacement component of the seismic-induced pressure acting on the vault depend on the low frequency content of the free field motion. The time history generated to fit the criteria DBE spectra will often contain excessive low frequency energy content unless care is taken in fitting the spectra with the generated time history. This could result in overconservative predictions for sloshing motion and vault pressure.

\section{Vault Model}

The mass and stiffness characteristics of the vault should be modeled. The stiffness properties of the vault should be consistent with the current materials conditions and should include any degradation of the structure which may have occurred or will occur at the end of its service life. If uncertainties exist regarding the current material conditions, suitable variations in the model should be included in the analyses. The vault may be assumed to be rigid if the fundamental fixed base frequency of the vault is at least twice the SSI frequencies or greater than $33 \mathrm{cps}$. In general, the SSI analyses will be used to evaluate pressures actirg on the vault structure. A separate pseudo-static analysis will be used to evaluate stresses in the vault.

\section{Tank and Contents Model}

The fluid/tank model to be used in the SSI analyses should properly account for the fluid impulsive vibration mode and may include the first convective mode of the fluid. The model characteristics may be taken directly fiom the results given in Chapter 4 . The model is shown on Figure 4.6 and discussed in Section $4.3 \cdot 9$. 
The accelerations (e.g., $A_{1}$ and $A_{c 1}$ of Equation 4.32) of Chapter 4 used to find tank loads (moments and shears) and slosh heights are the accelerations of the masses (which are evaluated during the SSI calculation) of the tank model shown on Figure 4.6 . These may be used directly to perform stress analysis of the tank.

It should be noted that the tank model results in the proper total overturning moment and horizontal load applied to the vault by the inertial loads of the tank and its contents. Except for the cantilever tank, however, it does not provide the distribution of these loads to the points at which the tank is supported from the vault. This distribution must be done before the stress analysis of the vault can be performed. The detail methodology to be used in distributing the loads is discussed in section 4.3 .7 .

\section{Soil Model}

Results should be obtained for the best estimate, lower bound, and upper bound soil models with the variations taken to be the same as discussed in section 6.2. The soil properties should be compatible with soil strains as determined from the soil column convolution studies.

\section{Lumped Parameter SSI Coefficients}

The lumped parameter SSI spring/damper models should be divided into those located at the foundation of the vault and those along the side soil. Generally accepted solutions for these parameters exist and may be used for these analyses. The free field input to these models should reflect the variation in the horizontal ground motion over the depth of the tank. Backfill properties should be used to compute the side soil parameters. When large differences exist between the backfill and in-situ soil properties, Reference 6.3 may be used to obtain the side 
soil interaction parameters.

An acceptable foundation spring/damper model for circular cross section vaults is given in Appendix G. This spring/damper model may be used for "near square" (where the long plan dimension is less than 1.5 times the short dimension), hexagonal, octogonal, and similar vault cross sections based on equivalent areas. Alternate models are required for other shapes. The side soil spring/damper model may be uniformly distributed over the depth of the vault using the following spring/damper moduli:

$$
\text { Side Soil Spring Modulus }=k_{\mathrm{ss}}=4.05 \mathrm{G}_{\mathrm{ss}}
$$

Side Soil Damper Modulus $=C_{s s}=9.90 R_{v}\left(\rho_{s s} G_{s s}\right)^{1 / 2}$

where,

$$
\begin{aligned}
& \mathrm{G}_{\mathrm{ss}}=\text { Shear modulus of soil along side soil } \\
& \rho_{\mathrm{ss}}=\text { Mass density of soil along side soil } \\
& \mathrm{R}_{\mathrm{v}}=\text { Vault radius } \\
& \mathrm{k}_{\mathrm{ss}}=\text { side soil SSI spring modulus } \\
& \mathrm{c}_{\mathrm{ss}}=\text { side soil SSI damper modulus }
\end{aligned}
$$

\section{Calculation of Wall Pressures}

The pressures acting on the vault wall should be determined from the side soil forces computed from the relative motion of the vault and free field. For vaults with a circular cross section it may be assumed that the wall shear pressures are zero and that the normal pressures are distributed in a cosine variation around the circumference of the vault. The resulting pressure distribution is:

$$
\mathrm{p}_{\mathrm{n}}=\mathrm{f} \cos \theta /(\pi \mathrm{R})
$$

where,

$$
\begin{aligned}
& p_{n}=\text { normal pressure } \\
& f=\text { sidewall force at elevation of interest } \\
& \theta=\text { angle defining circumferential location on tank }
\end{aligned}
$$

Wall pressures for vaults of other shapes should be determined

$$
6-13
$$


in a manner consistent with the spring/damper models used for these geometries.

\section{Maximum Pressure cutoffs}

The response solutions may be developed based on the assumption that nonlinear effects are unimportant so that the SSI spring/damper models have constant values. The wall pressures developed from these solutions may, however, be limited by coulomb-Mohr soil strength parameters. When this is done the ductility factors used for the stress analysis of the vault (see Chapter 3) should be limited to unity. The computed peak pressures may be reduced based on the coulomb-Mohr strength parameters. The peak normal pressures may be limited by:

$$
\begin{aligned}
& p_{c}=\sigma_{v}\left[\tan ^{2}(45+\phi / 2)-1 / 2\right]+2 c \tan (45+\phi / 2) \\
& p_{t}=\sigma_{v}\left[\tan ^{2}(45-\phi / 2)-1 / 2\right]-2 c \tan (45-\phi / 2)
\end{aligned}
$$

where,

$$
\begin{aligned}
c= & \text { cohesive strength of soil } \\
p_{c}= & \text { peak compressive pressure in excess of at rest static } \\
& \text { pressure } \\
p_{t}= & \text { peak tensile pressure below static pressure } \\
\sigma_{v}= & \text { vertical normal stress in soil at depth of interest } \\
\phi= & \text { angle of internal friction in backfill soil }
\end{aligned}
$$

\section{Combination of Three Dimensional Input}

SSI solutions should be carried out for the seismic input in each of the three directions (two horizontal and vertical). The total seismic response of the vault/tank system can be computed by either sRSS of the responses computed in each of the three directions or by absolute sum of the responses in each of the three directions. In the latter case $100 \%$ of the largest response shall be combined with $40 \%$ of the response in each of the remaining two directions. 


\section{Generation of Response Spectra}

Response spectra should be generated at locations of interest using the criteria as specified in Reference 6.2 .

\subsubsection{Continuum Model Using Time History Analysis}

As an alternative to the lumped parameter method described above, the SSI calculations may be based on a continuum model of the vault/tank/soil system. Since the computer codes used to implement these solutions are usually quite complex, special care should be taken to ensure that the code being used has been verified. The following procedures of section 6.5.2.1 also apply to this Section: specification of Free Field Motion, vault Model, soil Model, Maximum Pressure cutoffs, and Generation of Response spectra.

Mesh (Element and Total size) Requirements

The mesh size and placement of boundaries should be consistent with the required frequency content of the solution. Criteria for these data may be taken from References 6.1 or 6.2 .

\section{Tank and Contents Model}

The cantilever model of the tank and its contents, discussed in section 4.3 .9 , results in the proper total overturning moment and total horizontal load applied to the vault by the tank during the seismic response. It does not, however, distribute these loads to the tank support points on the vault for the top supported tanks. A modification is required to the model of Section 4.3 .9 if this load distribution is to be used in the solution. This modification is required for most computer codes used to implement continuum solutions since the same model of the tank is used to compute the seismic response of the vault/tank system and the stresses in the vault. The computation of stresses in the vault, of course, requires that 
the tank loads are properly distributed on the vault.

A general model that can be used to represent the tank in evaluating the combined horizontal and rocking seismic response of the tank/vault system is shown on Figure 6.1. The model consists of two cantilevers, one supported from the vault at the elevation of the top tank support and the other at the base of the tank. A rotary inertia must be added at the base for the impulsive mode. The magnitude of the rotary inertia is given on column 6 of Table 4.2. This model applies to all support conditions and reduces to the model of section 4.3 .9 for the cantilever support condition.

In general two mass models are used: one representing the effects of the impulsive fluid mass and the other representing the response of the convective fluid mass. While the effects of the convective mass may not be significant, inclusion of this model allows one to determine the sloshing height of the fluid directly from the seismic response computation. The symbols shown on Figure 6.1 apply to either the impulsive or convective mode and the differences between the two modes are introduced when the parameters are numerically defined. The parameters of the model are given for the full tank which represents the most severe load case. Solutions are not available as yet for partially filled tanks which have top supports.

The distribution of fluid mass $\left(m_{\ell}\right)$ between the impulsive $\left(m_{1}\right)$ and first convective mode $\left(m_{c 1}\right)$ are given in columns 3 and 7 of Table 4.2 respectively. The distribution of mass between the top and base cantilevers is proportioned to achieve the proper force distribution between the two supports so that:

$$
m_{t}=\left(1-m_{b} / m^{*}\right) m^{*}
$$


where,

$$
\begin{aligned}
\mathrm{m}_{\mathrm{b}} / \mathrm{m}^{*}= & 1 \text { for cantilever tanks in either impulsive or } \\
& \text { convective mode } \\
= & 0.6 \text { impulsive mode for roller or hinged upper support } \\
= & \alpha_{c 1} \text { (Table } 4.4 \text { ) for convective mode top-supported tank } \\
\mathrm{m}^{*}= & \mathrm{m}_{1} \text { or } \mathrm{m}_{\mathrm{c} 1} \text { for impulsive and convective modes, } \\
& \text { respectively }
\end{aligned}
$$

The lengths of the cantilever beams in the model are determined to match the top and base support moments. These moments consist of components due to the fluid pressure acting on the basemat and fluid pressure acting on the tank wall. The resulting cantilever heights are:

$$
\begin{gathered}
h_{b}^{\prime}=[d(0)+e]\left(m_{l} / m^{*}\right) H_{t} /\left(m_{b} / m *\right) \\
h_{t}^{\prime}=d(1)\left(m_{l} / m^{*}\right) H_{t} /\left(1-m_{b} / m *\right)
\end{gathered}
$$

where,

$\mathrm{d}=$ moment coefficients to account for fluid pressure acting on the tank wall and defined in Tables 4.5 through 4.10. These coefficients depend on the tank support condition and whether the mode is impulsive or convective. Note that $d(0)$ and $d(1)$ define the moment coefficients at the lower and upper supports, respectively.

$e=$ moment coefficients to account for fluid pressure acting on basemat and defined in columns 4 and 11 of Table 4.2 for the impulsive and convective modes, respectively.

$$
H_{t}=\text { height of tank }
$$

Note that negative values of $h_{b}^{\prime}$ or $h_{t}^{\prime}$ indicate that the cantilever extends below the support rather than above. 
The correct seismic acceleration imposed on the masses of the model is obtained by matching the frequencies of the cantilever beams to the tank frequency $\left(f_{c 1}\right.$ or $\left.f_{1}\right)$ as given in sections 4.3.2.1 (convective) and 4.3.2.2 (impulsive) respectively. This is done by selecting the stiffness of the cantilever beam (EI) as:

$$
[E I]=4 \pi^{2} f^{\frac{1}{1}} L^{3} m / 3
$$

where,

[EI] = top or bottom cantilever stiffness for either impulsive or convective mode

$f \quad=$ either $f_{c 1}$ or $f_{1}$ for convective or impulsive mode respectively

$\mathrm{L}=\mathrm{h}_{\mathrm{b}}^{\prime}$ or $\mathrm{h}_{\mathfrak{t}}^{\prime}$ for the base and top cantilever models respectively

$\mathrm{m} \quad=$ top or base mass associated with the mode being considered (convective or impulsive)

If the length of the top cantilever is zero, the mass must be attached to the support with a spring of rate $\left(k_{c}\right)$ so that the tank frequency is matched. This spring rate will be:

$$
k_{c}=4 \pi^{2} f^{2} m^{*}\left(1-m_{b} / m^{*}\right)
$$

The accelerations (e.g., $A_{1}$ ) shown in chapter 4 and used to determine bending moments in the tank and fluid slosh heights can be related to computed accelerations of the top $\left(A_{t}\right)$ and base $\left(A_{b}\right)$ masses of the model by:

$$
A_{i}=A_{b}+\left(A_{t}-A_{b}\right)\left(z^{*}-h_{b}^{\prime}\right) /\left(H_{t}+h_{t}^{\prime}-h_{b}^{\prime}\right)
$$

where,

$$
\begin{aligned}
z^{*} & =\text { center of gravity of the two masses } \\
& \left.=\left[m_{t}\left(H_{t}+h_{t}{ }^{\prime}\right)+m_{b} h^{\prime}{ }_{b}\right] /\left(m_{t}+m_{b}\right)\right]
\end{aligned}
$$

As an alternate to this model, it is possible to include a detailed model (e.g., finite element model) of the tank and 
fluid in the soil/vault model. As discussed in section 4.1 , the validity of these models should be established by comparing the results for limiting cases obtained using the detailed model with results obtained using the methods discussed in chapter 4.

\section{Calculation of Wall pressures}

Many of the available computer codes do not have the option of directly providing pressures actirg on the vault walls. Such pressure data are useful in verifying the results of the computer solutions. Post processors should be developed so that the output of these codes can be used to obtain wall pressures at a time when vault member loads are close to the maximum.

\subsubsection{Lumped Parameter Model Using a Response Spectrum Analysis}

A response spectrum analysis may be performed for those vaults founded in a uniform soil medium. This method is likely to be over-conservative since phasing between the response modes is lost in the calculations and they are therefore combined in a conservative manner. This method of analysis may be used to determine soil pressures acting on the vault and forces acting on the tank. Direct spectra generation techniques may be used to determine floor response spectra within the vault/tank system. The following specifications of section 6.5.2.1 also apply to this section: specification of Free Field Motion, vault Model, Tank and contents Model, soil Model, ssI Model, and Maximum Pressure Cutoffs.

The response spectrum analysis may be applied to a model of the soil/vault/tank system satisfying the above criteria. This analysis involves: computing the modes of the system (frequency, mode shapa, modal mass, modal damping, and modal participation factor); evaluating the peak response for each of the modes; and combining the modal responses. Mode combinations should be in 
accordance with the procedures described in Reference 6.1.

\section{Calculation of Wall Pressures}

The response spectrum analysis will provide peak relative displacements and velocities between points on the vault and the free field. The peak pressures may then be obtained by multiplying these values by the side soil stiffness $\left(k_{s s}\right)$ and damping moduli $\left(c_{s s}\right)$ respectively and summing the results.

\subsection{VAULT-VAULT INTERACTION}

There is some evidence indicating that vault-vault interaction effects are not significant unless the spacing between vaults is less than one half vault radii. Additional studies are underway to confirm these conclusions and to develop definitive guidance in this area. Until such data become available, vault-vault interaction effects should be evaluated for spacings closer than one half of the vault radius. 


\section{REFERENCES}

6.1 ASCE 4-86, "Seismic Analysis of Safety Related Nuclear structures," September 1986.

6.2 "U.S. NRC Standard Review Plan", NUREG-0800.

6.3 Veletsos, A.S. and Dotson, K.W., "Horizontal Impedances for Radially Inhomogeneous Viscoelastic soil Layers", Earthquake Engineering and Structural Dynamics, Vol.16, 1988 . 
NOTATION

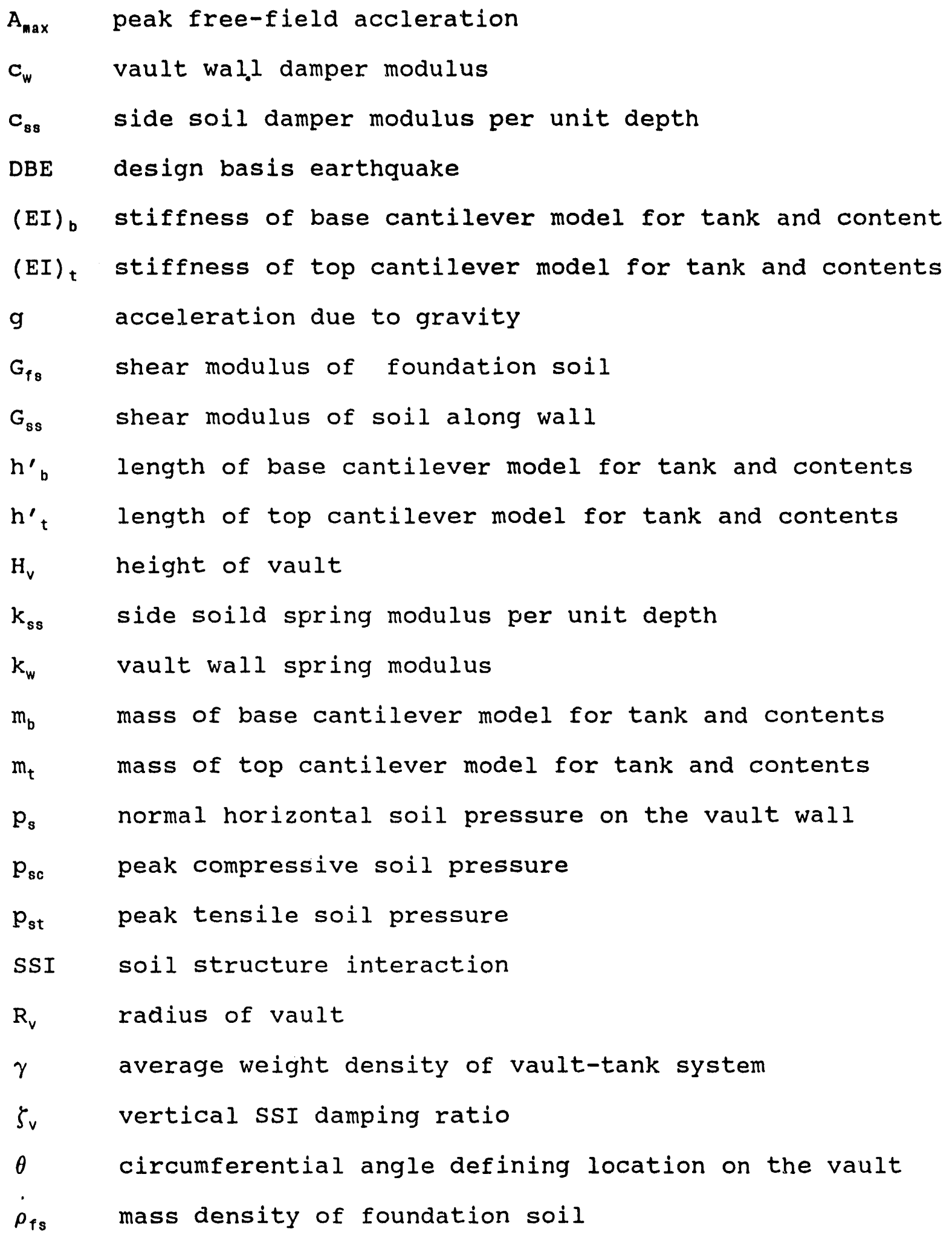

$$
6-22
$$




$\begin{array}{ll}\rho_{s s} & \text { mass density of soil along vault wall } \\ \rho_{v} & \text { average mass density of vault, tank and contents } \\ \sigma_{s v} & \text { vertical intergranular stress in soil } \\ \phi & \text { angle of internal friction in backfill soil }\end{array}$




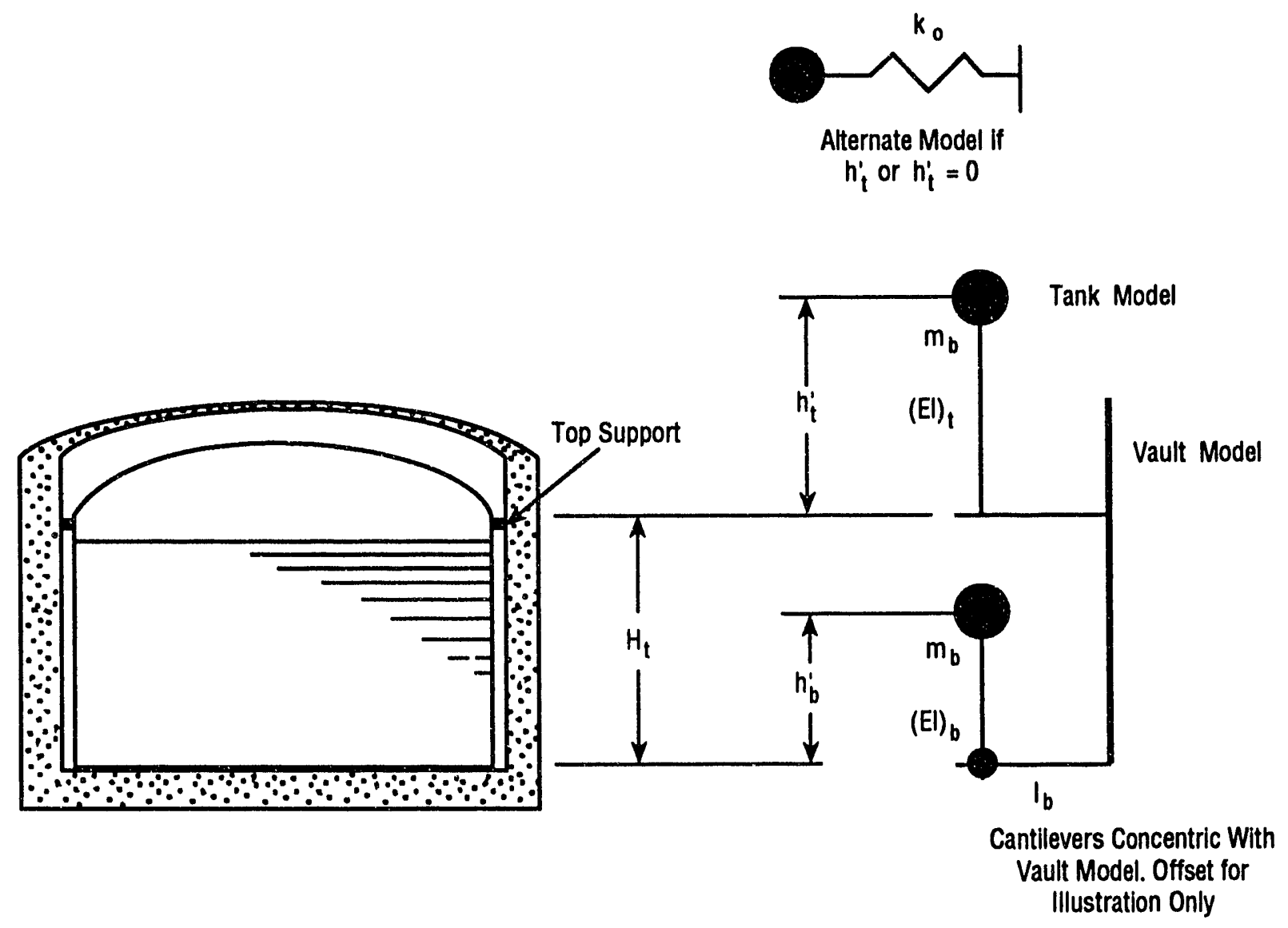

Tank Vault System

Figure 6.1 Model for Tank-Fluid System 
CRITERIA FOR UNDERGROUND PIPING

\subsection{INTRODUCTION}

The acceptable design of underground piping must demonstrate analytically the ability of the piping to withstand ary strains and stresses caused by potential seismic movement of foundation soils in conjunction with those stresses induced by other normal or accidental loadings applied to the piping. stress resultants (forces and moments) computed from these various load conditions must be suitably combined to obtain stresses and strains which can be shown to be less than the appropriate allowables. Unfortunately, current codes typically used for piping systems do not specifically mention design requirements for underground piping systems. Recommendations for such design criteria are included in this document. The references listed at the end of this document can be used to address specific issues of the analysis problem. Specifically, design recommendations appropriate for steel piping were obtained from Reference 7.23.

Potential seismic effects on underground facilities are, in general, caused by different aspects of ground movements, namely, (1) abrupt relative displacements of the ground caused by dislocation at the ground surface from fault dislocations, (2) ground failure of relatively large areas caused by liquefaction, landslides, gross surface settlements, or collapse of voids at depth, (3) transient deformation of the ground during the seismic event due to wave passage effects, and (4) transient movements of anchor points or buildings connected to the underground facilities. For construction of new facilities, zones susceptible to abrupt ground movements or ground failure should be avoided. However, for evaluation of existing facilities, the effects of these potential seismically induced movements must be suitably accounted for and incorporated into 
the evaluation. As described in Reference 7.9, rigorous analytic treatment of the response of underground facilities to these movements is in general not practical, particularly for the case of transient effects. Therefore, conservative procedures must be adopted to ensure that stresses and strains remain within the recommended design allowables.

\subsection{REQUIRED SEISMIC AND SOIL DATA}

Appropriate seismic and soils data must be assembled to allow for evaluation of the maximum responses and loadings of the underground facilities. The seismic environment must include estimates of peak ground acceleration (PGA), peak ground velocity (PGV), and peak ground displacement (PGD) defined at the ground surface appropriate for the hazard specification. Details on recommended procedures to be used to define the seismic environment at a particular site are presented in Section 3. If site specific evaluations are not available, but broad banded ground response spectra anchored to PGA are used, estimates of the PGV and PGD must be estimated from other appropriate approximations. For a particular site, the approach used to estimate these parameters must be justified.

Sufficient data should be gathered to suitably identify the foundation soils surrounding the underground components and determine their appropriate parameters. These can be gathered using standard methods of foundation investigation, namely, standard borings taking standard penetration test (SPT) drive samples, cone penetrometer testing, seismic reflection surveys, crosshole, uphole and/or downhole geophysical testing, etc. of specific interest for the program is to ascertain soils susceptible to liquefaction, densification leading to ground settlement, ground collapse at depth or near surface landslides. The investigators should be aware of the guidance provided in two publications of the Nuclear Regulatory Commission, namely, Regulatory Guides 1.132 and 1.138, (References 7.12 and 7.13)

$$
7-2
$$


which present recommendations for geotechnical investigations and laboratory testing. Such investigations must also suitably define changes of soil properties along the route of the underground facilities.

Soil properties of specific interest include:

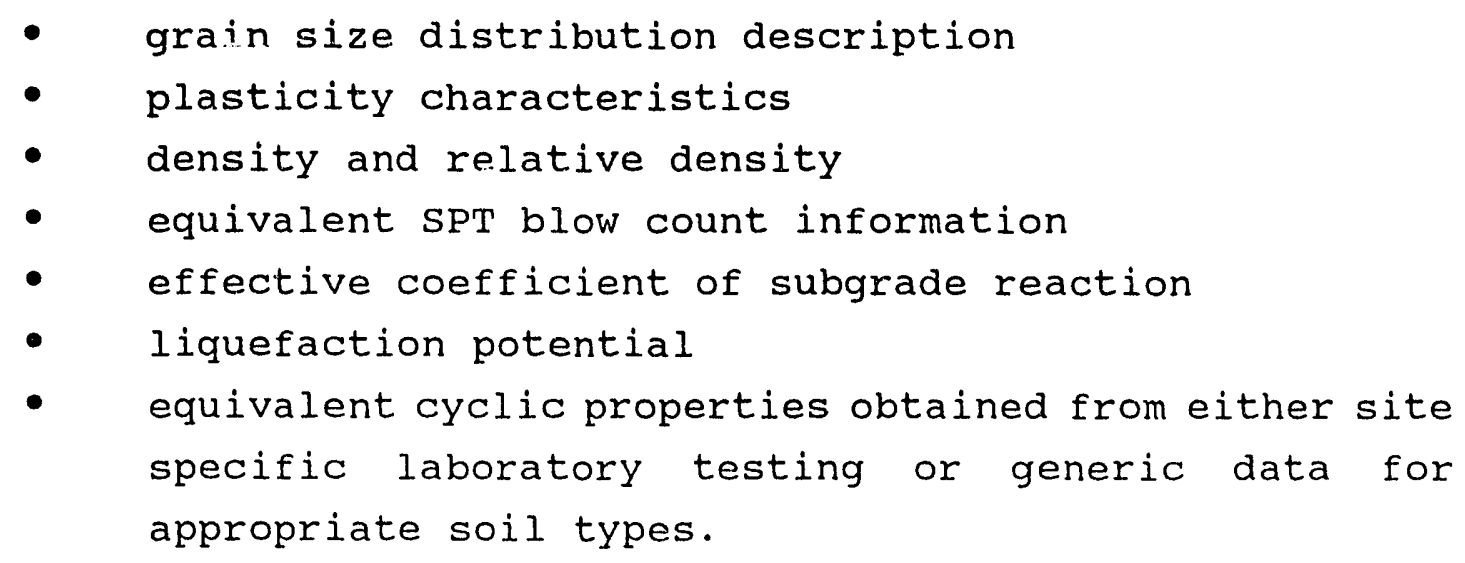

- equivalent cyclic properties obtained from either site specific laboratory testing or generic data for appropriate soil types.

Enough data must be available to allow for evaluation of the effect of seismically induced pore pressures on ground movements and the loads induced on the underground system from relative movements between the ground and the piping.

\subsection{ANALYSIS LOADS AND CONDITIONS}

When either analyzing or designing underground piping to withstand seismic effects, only those loadings which can normally be expected to occur during the event need be considered. The following load conditions should be considered where appropriate:

1. Internal pressures developed during normal operation or from accidental conditions.

2. External pressures caused by overburden soils and other surcharge loadings. The type of underground pipe, method of installation and bedding characteristics should all be accounted for when determining the effects of these 
external loads (Reference 7.15).

3. Thermal variations to which the piping will be subjected.

4. Permanent vertical settlements (total and differential) due to densification of dry or partially saturated soil from ground shaking or post-earthquake dissipation of pore pressures developed in partially saturated or saturated soils as well as settlements of soft zones or voids at depth due to reconsolidation or collapse.

5. Development of liquefaction conditions in soils immediately surrounding or below the underground pipe which may lead to permanent vertical and horizontal movements from ground failure. Possibility of flotation of underground facilities with average densities less than that of the surrounding soils must also be considered.

6. Alignment of the buried facility may extend through or adjacent to areas where slopes exist. The stability of these slopes must be assured for both normal operating conditions as well as the design seismic event including the potential effects of pore pressure development. Potential disruption of underground piping from ground failure due to slope instability and lateral spreading effects must be considered.

7. Transient differential movements due to passage of seismic ground waves as well as seismic movements of buildings and other attachment points.

If unacceptable conditions are found to develop from any of the conditions listed above, namely, from transient wave passage effects, permanent ground settlement and/or ground failure phenomena, alternate solutions must be developed to preclude failure of the underground piping, particularly for safety class piping. This approach must be followed for either new or

$$
7-4
$$


existing facilities. Such procedures can include rerouting the piping, removal and replacement of poor soil surrounding the underground piping, application of soil stabilization procedures (e.g., grouting, densification, slop stabilization, permanent dewatering of affected areas), or supporting the underground piping on alternate supports such as pile supported cradles.

\subsection{ANALYSIS PROCEDURES}

Due to the complexity of the seismic problem as well as difficulty in assessing controlling properties of foundation soils, it is recommended that conservative methods of analysis be used to estimate stresses and strains developed by each load component and condition. Suitable variation in soil properties must be included in these evaluations to account for the normal variability in soil properties. In addition, the recommendations presented herein are based on the simplified methods of analysis as summarized in References 7.1 through 7.11 which are in general use throughout the profession and which have been keyed to available empirical data. More sophisticated approaches may be used provided they are justified.

\subsubsection{Normal Operating Loads}

Stresses and strains due to internal pressure and normal temperature conditions shall be computed following standard procedures appropriate for the pipe and pipe element under evaluation.

\subsubsection{External Soil Loadings}

Standard methods of soil mechanics, such as those presented in References 7.14 and 7.15 , can be used to assess external loadings developed on underground facilities due to dead weight of surface soils as well as any design surface live loadings. The analyst should consider the combined behavior of both the foundation soils and the underground facility suitably 7-5 
accounting for soil arching and the effects of potential hard spots, to arrive at estimates of stress and strain.

\subsubsection{Transient Differential Movements}

For estimating stress resultants (forces and moments) due to transient loadings, the recommendations presented in Reference 7.10 shall be utilized as supported by the analytic techniques and descriptions presented in References 7.1 through 7.9 and 7.11. Such stress resultants induced in both long straight sections of pipe as well as at critical locations such as at bends, valves, etc. must be evaluated. For estimating transient ground displacements from wave passage effects, current procedures permit estimates due to assumed plane wave motion either across or parallel to the axis of the pipe. Assuming a sinusoidal wave of a single wave type (compression or shear) traversing long straight sections of pipe, the maximum axial ground strain is found to be

$$
\left(\epsilon_{\mathrm{a}}\right)_{\max }= \pm \mathrm{PGV} /\left(\alpha_{\epsilon} \mathrm{v}_{\mathrm{a}}\right)
$$

where $\alpha_{\epsilon}$ is either 1 or 2 depending upon whether the traversing wave type is either a shear, compression or Rayleigh wave (Reference 7.10). Values of this coefficient for each wave type are presented in Table 7.1. The parameter $v_{a}$ is the apparent wave velocity traversing the site, and PGV is the peak ground velocity as defined by the design response spectrum appropriate for the particular site.

The specific value of wave speed and wave type to be used in any particular situation is, in general, not clear and must be selected with care. If the underground pipe is located at a depth of 20 feet or more in ordinary soils, the effect of the Rayleigh wave at these depths can be considered negligible. In general, the seismic motion traversing a particular site is composed of a complex mixture of these wave types and the apparent velocity is often controlled by the deeper and higher velocity material. For example, for plane waves reaching the

$$
7-6
$$


surface at some angle $\psi$ with respect to the horizontal surface has an apparent wave velocity of $v / \cos \psi$. Thus, the apparent wave velocity can be significantly higher than the wave speed of the iocal material. For a uniform soil site overlying stiffer rock, the propagation velocity of the seismic wave at the ground surface can be strongly influenced by the wave speed in the bedrock (Reference 7.16). Based upon limited empirical observation (e.g., Reference 7.8), velocities less than about 2000 fps (Reference 7.10) lead to overly conservative strain estimates.

The maximum axial force that may be induced in long straight sections of underground pipes by the axial ground strain is controlled by the ability of the surrounding soil to transmit loads to the pipe through friction. Considering the ground wave to vary sinusoidally as it traverses the site, the maximum ground strain that can be developed will occur over a quarter wave length of the predominant seismic wave associated with the peak ground velocity. Thus, the maximum strain that can be transmitted to the underground pipe through shear is limited to

$$
\left(\epsilon_{\mathrm{a}}\right)_{\max } \leq\left(\epsilon_{\mathrm{a}}\right)_{\text {sh }}
$$

where

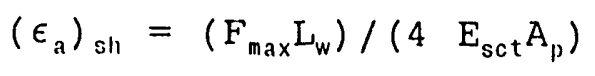

where, $L_{w}$ is the dominant wave length of the passing seismic wave, $E_{\text {sct }}$ is the secant modulus of elasticity of the underground pipe and $A_{p}$ is the net cross-sectional area of the pipe. The dominant wave length, $L_{w}$, can be estimated from the site response spectrum using the relation $v_{a} / f_{d}$, where $v_{a}$ is the apparent wave velocity and $f_{d}$ is the dominant frequency (in cps) of the site response spectrum (typically of the order of $5 \mathrm{hz}$ ).

The maximum force per unit length, $\left(F_{f}\right)_{\max }$, that can be transmitted through friction to the pipe is related to pipe 
material, surface conditions of the pipe, soil density and graduation, soil confining pressure, etc. For the general case of a soil possessing both frictional and cohesive strength components, the shear force per unit length of pipe can be estimated from:

$$
\left(F_{f}\right)_{\max }=2 \pi R_{p}\left[C_{a}+\sigma_{n} \tan \left(\phi_{a}\right)\right]
$$

where $\left(F_{f}\right)_{\max }=$ maximum friction force per unit length of pipe

$R_{p}=$ pipe radius

$\mathrm{C}_{\mathrm{a}}=$ soil adhesion (units of stress)

$\phi_{\mathrm{a}}=$ apparent angle of pipe wall friction (degrees)

$\sigma_{n}=$ average overburden pressure on pipe due to soil weight as well as surcharge loadings.

Soil properties to use in these evaluations can be estimated from laboratory test data for site-specific soils or from generic data for particular soil types. If generic data are used, suitable variation in soil properties should be used in the analyses to account for typical soil variability. In general, when evaluating transient loadings, the shear strength parameters should be obtained from consolidated-undrained test results, while consolidated-drained results can be used to assess permanent effects of relative displacement. For the typical soils, estimates of the adhesion and apparent friction angle between the pipe wall and the soil are provided in Tables 7.2 and 7.3 for the case of soils bearing against either concrete or steel underground piping.

Again assuming wave passage of sinusoidal single wave types traversing along straight runs of pipes, the maximum curvature of the ground can be estimated from (Reference 7.10) as

$$
\kappa_{\max }=\operatorname{PGA} /\left(\alpha_{k} \mathrm{v}_{\mathrm{a}}\right)^{2}
$$


where $v_{a}$ is the apparent wave speed of the seismic motion discussed previously, PGA is the maximum ground acceleration of the seismic wave and $\alpha_{k}$ is again a wave coefficient dependent on wave type and listed in Table 7.1.

The maximum forces and moments developed in long straight sections of pipe as computed above typically do not lead to the maximum stress conditions in the pipe. Rather, the controlling condition usually occurs at pipe bends and elbows as a result of differential motions developed from the wave passage effect. The effects of changes in direction, size and material of the underground structure must be considered for a complete evaluation of critical conditions. From the ground strain estimates obtained from the analyses of long straight sections of pipe, however, the forces and moments developed at these critical locations can be determined by following the usual procedures as outlined in References 7.1 through 7.9 for typical pipe elements and particular configurations. Typically, the underground piping system is analyzed as beam elements on elastic foundations requiring the assumption of coefficients of subgrade reaction for the soil pipe system. sufficient variability must be incorporated in this calculation since the parameters of the usual coefficients of subgrade reaction are not well founded by either theory or experiment.

In addition to the stresses developed in the underground piping system from these wave passage effects, a second seismic condition must be considered and that is the stresses induced in the piping system from relative movenent at anchor points and other building penetrations or attachment points. It is usual in this situation to consider a static analysis of the piping system subjected to out-of-phase anchor movements placed on the system to produce worst case conditions. In analyzing the resulting system, the procedures of beams founded on elastic foundation must again be utilized, with the same degree of 
variability required to ensure conservative estimates of stress resultants. As recominended in Reference 7.10 , the stress resultants computed for anchor point movement can be combined with those computed for wave passage effects using the SRSS method.

\subsubsection{Permanent Differential Movements}

Both horizontal and vertical long-term total and differential movements must be estimated which account for gross settlement or consolidation of foundation soils as well as potential maximum movements of building attachment points. stress resultants (forces and moments) induced by these movements shall account for induced soil pressure loadings by considering the underground piping to be supported by elastic soil, again using the assumption of a beam on an elastic foundation. The standard approaches of soil mechanics (References 7.8, 7.14 and 7.15) shall be used to estimate coefficients of subgrade reaction based on density and soil type. Again due to the lack of adequate support for these coefficients, sufficient variability must be included in the analysis to assess worst case conditions. In addition, solutions must account for variations in soil type along the length of the system as well as potential variability in the properties of these soils.

A summary of approaches to assess the potential of permanent settlements from a variety of sources is presented in Reference 7.17. For example, earthquakes have caused settlements od dry cohesionless sandy deposits which are related to their densification from the vibrating environment. Standard procedures are available (References 7.18 and 7.21 ) to estimate induced vertical strain levels from the maximum induced cyclic shear strains developed in the soil layer during the seismic loading. For saturated soils, similar procedures are available to estimate induced pore pressures developed during cyclic loading from which vertical strains can be estimated after these 
pore pressures are dissipated (References 7.19 and 7.20). The decrease in volume of the soil that occurs with dissipation of the excess pressures leads to ground settlements and possibly sand boiling. In such cases, it is presumed that maximum pore pressure ratios are developed during shaking which are low enough that complete liquefaction of the soil does not occur. When iriduced pore pressures reach levels which cause effective stresses to reach low levels, the potential for full liquefaction must be considered. If driving shear stresses are available which equal or exceed the available shear strength of the soil, complete loss of stability can develop which may lead to flow slides and settlement of heavy structures.

The induced inertial loads developed during an event can lead to cracking and movements of embankments and earth slopes, hoth with and without pore pressure effects. Previous procedures availahle to treat these problems were based on static methods by incorporating horizontal and/or vertical inertial loading components into traditional slide analyses and computing gross safety factors. Such procedures should be used with extreme caution since large errors are possible. Unless stability numbers or safety factors are sufficiently high, dynamic methods of analysis are recommended to assess slope stability. As mentioned above, rigorous analytic treatment of the response of underground facilities to these potential movements is in general not practical. Therefore, conservative procedures must be adopted to ensure that ground failure does not occur. Standard procedures to estimate liquefaction potential (such as are summarized in References 7.17) of a particular site are available to assess the importance of this phenomena.

\subsection{DESIGN RECOMMENDATIONS}

It is iritended that the criteria presented herein be consistent with the system facility use category operational and functional requirements. Basic design guidelines for all mechanical and $7-11$ 
fluid systems, both hazardous and nonhazardous, are provided in DOE Order 5430.1, "General Design Criteria Manual." For the purposes of this guideline, all underground facility components and structures are classified into two broad categories, namely, safety class and nonsafety class components. Safety class piping and components carry radioactive materials and their failure may adversely affect the environment, safety and/or health by either causing or failing to mitigate an uncontrolled release of radioactive materials. By contrast, nonsafety class systems aie all other underground piping systems which are not required for safety since their failure will not adversely affect the environment. In general, the effects of seismic loadings on these nonsafety systems need not be considered. The impact of their failure on potential failure or damage to safety class erripment must, of course, be considered.

All safety class underground piping systems from either above ground or from underground vaults or tanks shall meet all the requirements of 40 CFR 264 and 265. These systems shall be suitably shielded and provided with intermediate flush connections to satisfy radiological requirements. In general, they shall have secondary confinement and provided with leak detection capability.

\subsubsection{Concrete Conduit Requirements}

It is presumed that safety class underground piping or conduit is fabricated from steel only or from steel lining with exterior (reinforced or unreinforced) concrete to provide added strength and that no safety class piping is fabricated from (reinforced and unreinforced) concrete alone. The concrete component of any conduit or piping, of either safety or nonsafety class, shall be designed and fabricated to meet the general requirements of the current version of the ACI Code 349-85. Compressive strains developed in the concrete shall be limited to no more than $0.3 \%$. Tensile requirements shall be controlled by the amount of 
reinforcing steel added to the concrete as specified in the ACI code. If required to prevent any cracking from developing in the concrete, tensile strains may be limited to

$$
\epsilon_{\mathrm{t}}=7.5\left[\mathrm{f}_{\mathrm{c}}^{\prime}\right]^{0.5} / \mathrm{E}_{\mathrm{c}}
$$

where $f_{c}^{\prime}$ is the compressive strength and $E_{c}$ is the elastic modulus of the concrete.

\subsubsection{Steel Piping or Conduit components}

New safety class underground steel piping facilities shall be designed in accordance with $\mathrm{NC}-3600$ of the ASME Boiler and Pressure Vessel Code, Section III, Division 1, Nuclear Power Plant Components. However, for underground piping that meets the restrictions listed below, seismic loads may be evaluated as indicated in Equation (7.7) following. For piping that meets all listed restrictions, nonrepeated loadings may be evaluated by the Equation (7.8) following instead of Equation (10a) of NC3600. The following restrictions and criteria are intended to be applicable to the process piping and, if applicable, to the secondary contfinement piping outside the process piping.

\section{Restrictions :}

(a) Materials:

Materials must be carbon steels, UTS $\leq 70 \mathrm{ksi}$, listed in code Table 1-7.1 under the heading "Carbon Steels," either Type 304 or 316 austenitic stainless steels as listed in Code Table I-7.2 under the headings, "Type 304 stainless steels" or "Type 316 stainless steels."

(b) Fabrication:

All joints shall be made using through penetration welds (e.g., no threaded joints, bolted flanged joints, other mechanical joints or any type of expansion joints). 


\section{(c) Examination:}

All welded joints shall be examined in accordance with the applicable portions of $\mathrm{NC}-5200$ and meet the acceptance criteria of the applicable portions of NC-5300.

\section{(d) Embedment and Backfill:}

Bedding and backfill for underground piping shall be free of any rocks, cobbles or boulders or other extraneous materials which may damage the piping by creating hard points on the piping surface. Bedding and backfill soils shall be composed of clean sands with maximum grain sizes passing the No. 4 sieve and no more than $12 \%$ by weight passing the No. 200 sieve. A minimum of six inches of the clean sand shall be placed around the entire piping.

For new construction, bedding sands shall be compacted to $95 \%$ Standard Proctor dry density. Backfill sands shall be compacted using procedures that will not damage the pipe, and in a manner so as to provide complete coverage. Flooding methods can be used to ensure compaction and coverage if no other safety considerations will be violated.

\section{Criteria:}

(a) The effect of seismic-induced ground movements on underground piping shall meet the requirements of the equation

i $M / Z+F / A \leq 100,000$ psi

where $i=$ stress intensification factor as defined in Figure $\mathrm{NC}-3673.2(\mathrm{~b})-1$

M = the maximum range of seismic-induced moment, in inch-pounds (derived, for example, from Equation (7.5)) 


$$
\begin{aligned}
& \mathrm{Z}=\text { section modulus of pipe, }(\text { inch })^{3} \\
& \mathrm{~F}=\begin{array}{l}
\text { maximum range of seismic induced axial } \\
\text { force, in pounds. }
\end{array} \\
& \mathrm{A}_{\mathrm{p}}=\begin{array}{l}
\text { cross-sectional metal area of pipe, in } \\
(\text { inch })^{2}
\end{array}
\end{aligned}
$$

(b) The strain due to any nonrepeated anchor movement or ground settlement or combination thereof shall not exceed:

$4 \%$ for piping sections other than at branch connections ( $7.8 \mathrm{a})$

$2 \%$ for piping sections containing branch conditions

For piping with outside diameter to nominal wall thickness ratio less than 50, average strains in the pipe wall may be estimated directly from the radius of curvature of the pipe developed from the anchor movements and/or ground settlement. For piping with outside diameter to nominal wall thickness ratio exceeding 50, wrinkling may occur which may cause local strains to exceed the $4 \%$ strain limit. For such cases, it should be shown by either test data or analysis that the wrinkling does not significantly reduce the fatigue strength of the pipe.

During the transitory phase of the earthquake, the resulting earthquake moments can be computed separately for wave passage and anchor movement effects and combined by SRSS methods, while following the event, the earthquake moments can be computed from permanent displacements only, such as displacements associated with excess pore pressure dissipation or collapse of soft zones, etc. The term (F/A) in Equation (7.7) accounts for the axial induced stresses from both thermal and earthquake effects, again using sRSs methods to combine axial stresses induced by wave passage and anchor movements. 


\section{REFERENCES}

7.1 Newmark, N.M., "Problems in Wave Propagation in Soil and Rock," Proceedings of the International symposium on Wave Propagation and Dynamic Properties of Earth Materials, Albuquerque, New Mexico, August 1968.

7.2 Newmark, N.M., "Earthquake Response Analysis of Reactor Structures," Nuclear Eng. \& Design, Vol. 20, 1972.

7.3 Shah, H.H., Chu, S.L., "Seismic Analysis of Underground Structural Elements," ASCE, Journal of the Power Division, Vol. 100, No. P01, July 1974.

7.4 Yeh, G.C.K., "Seismic Analysis of Slender Buried Beams," Bulletin of the Seismological Society of America, Vol. 64, No. 5, October 1974 .

7.5 Iqbal, M.A., Goodling, E.C., "Seismic Design of Buried Piping," Second ASCE specialty Conference on structural Design of Nuclear Plant Facilities, New Orleans, LA, 1975.

7.6 Goodling, E.C., "Flexibility Analysis of Buried Piping," Joint ASME/CSME Pressure Vessels and Piping Conference, Montreal, Canada, June 1978 .

7.7 Goodling, E.C., "Seismic Stresses in Buried Elbows," ASCE National Convention, Boston, MA, 1979.

7.8 Goodling, E.C., "Buried Piping - An Analysis Procedure Update," International Symposium on Lifeline Earthquake Engineering, Fourth U. S. National Conference on Pressure Vessels and Piping Technology, ASME, Portland, OR, 1983.

7.9 "Seismic Response of Buried Pipes and Structural Components," ASCE Structural Division Committee on Nuclear structures and Materials, ASCE, New York, 1983. 
7.10 "Seismic Analysis of Safety-Related Nuclear structures and Commentary on standard for Seismic Analysis of Safety Rəlated Nuclear structures," Standard 4-86, American Society of Civil Engineers, September, 1986.

7.11 Lin, C.W., "Seismic Analysis of Buried Piping," Transactions SMIRT 11, Vol. K, p. 429, Tokyo, Japan, August 1991 .

7.12 Regulatory Guide 1.132, "Site Investigations for Foundations of Nuclear Power Plants."

7.13 Regulatory Guide 1.138, "Laboratory Investigations of Soils for Engineering Analysis and Design of Nuclear Power Plants."

7.14 Winterkorn, H.F., Fang, H.Y., "Foundation Engineering Handbook," Van Nostrand and Reinhold, 1975.

7.15 Spangler, M.G., Handy, R.L., "Soil Engineering," Fourth Edition, Harper \& Row, New York, 1982.

7.16 Newmark, N.M., Hall, W.J., "Development of Criteria for Seismic Review of Selected Nuclear Power Plants," NUREG/CR-0098, MaY 1978 .

7.17 Ferritto, J.M., "Evaluation of Earthquake Induced Ground Failure," Technical Report of Subcommittee 7, Interagency committee on seismic safety in construction, U. S. Department of Interior, Geological Survey, 1982.

7.18 Seed, H.B., Silver, M.I., "Settlements of Dry Sands During Earthquakes," Journal Geotechnical Division, ASCE, April 1972 .

7.19 Castro, G., "On The Behavior of Soils During Earthquakes - Liquefaction," Soil Dynamics and Liquefaction, A. S. Cakmak, Editor, Elsevier, 1987. 
7.20 Seed, H.B., Tokimatsu, K., Harden, L.F., Chung, R.M., "Influence of SPT Procedures in Soil Liquefaction Resistance Evaluations," Journal Geotechnical Division, ASCE, December 1985 .

7.21 Silver, M.L., Seed, H.B., "Volume Changes in Sand During Cyclic Loading," Journal SMFE Div., ASCE, September 1971.

7.22 American Concrete Institute, "Code Requirements for Nuclear Safety-Related Concrete structures (ACI 349-85) and Commentary - ACI 349R-85," Detroit, MI, 1985

7.23 Rodabaugh, E.C., Personal correspondence to Dr. K. Bandyopadhyay, Brookhaven National Laboratory, June 1992. 
Ap net cross-sectional (i.e., metal) area of pipe (square inches)

$C_{a} \quad$ soil adhesion (in units of stress)

$\mathrm{E}_{\mathrm{C}} \quad$ elastic modulus of concrete

$E_{\text {sct }} \quad$ secant modulus of elasticity of underground pipe

$f_{c}^{-} \quad$ comprehensive strength of concrete

$f_{d}$ dominant frequency of the site response spectrum (in $\mathrm{Hz}$ )

$\left(F_{f}\right)_{\max }$ maximum shear force per unit length of pipe

i stress intensification factor

$\kappa_{\max } \quad$ maximum curvature of the ground

$\mathrm{I}_{\mathrm{w}}$

length of the passing dominant seismic wave

M

maximum range of seismic-induced moment (inch-pounds)

PGA peak ground acceleration

PGD peak ground displacement

PGV peak ground velocity

$R_{p} \quad$ radius of pipe

$\mathrm{v}_{\mathrm{a}} \quad$ apparent wave velocity

$\mathrm{z}$ section modulus of pipe (cubic inches)

$\alpha_{\epsilon}, \alpha_{k} \quad$ coefficients for estimating ground strain provided in Table 7.1

$\epsilon_{\mathrm{a}} \quad$ axial ground strain

$\epsilon_{\mathrm{t}} \quad$ tensile strain in concrete

$\phi_{\mathrm{a}} \quad$ apparent angle of pipe wall friction (in degrees)

$\sigma_{r} \quad$ average overburden pressure on pipe 
Table 7.1 Seismic Coefficients for Estimating Ground strain (Reference 7.10)

\begin{tabular}{|c|c|c|c|}
\hline Coefficient & $\begin{array}{c}\text { Compression } \\
\text { Wave }\end{array}$ & Shear Wave & Rayleigh Wave \\
\hline \hline$\alpha_{c}$ & 1.0 & 2.0 & 1.0 \\
\hline$\alpha_{k}$ & 1.6 & 1.0 & 1.0 \\
\hline
\end{tabular}

Table 7.2 Apparent Friction Angle $\left(\phi_{\mathrm{a}}\right)$ in Degrees

\begin{tabular}{|l|c|c|c|}
\hline Soil Type & $\begin{array}{c}\text { Concrete Poured } \\
\text { Against Soil }\end{array}$ & $\begin{array}{c}\text { Formed } \\
\text { Concrete }\end{array}$ & $\begin{array}{c}\text { Steel } \\
\text { Pipe }\end{array}$ \\
\hline \hline 1. Sand \& gravel mixtures & $29-31$ & $22-26$ & 22 \\
\hline $\begin{array}{l}\text { 2. fm sands, silty cm } \\
\text { sands }\end{array}$ & $24-29$ & $17-22$ & 17 \\
\hline $\begin{array}{l}\text { f sands, silty fm } \\
\text { sands }\end{array}$ & $19-24$ & 17 & 14 \\
\hline $\begin{array}{l}\text { Nonplastic silts, } \\
\text { sandy silts }\end{array}$ & $17-19$ & 14 & 11 \\
\hline 5. Very stiff clays & $22-26$ & 18 & 15 \\
\hline 6. m stiff to stiff clays & $17-19$ & 13 & 10 \\
\hline
\end{tabular}

$f=$ fine, $\quad m=$ medium, $\quad c=$ coarse grain size descriptor 
Table 7.3 Effective Adhesion $\left(C_{a}\right)$ for Cohesive Soils (IN PSF)

\begin{tabular}{|l|c|c|}
\hline Soil Consistency & Cohesive Strength $C$ & Effective Adhesion $C_{2}$ \\
\hline \hline Very soft & $0-250$ & $0-250$ \\
\hline Soft & $250-50$ & $250-500$ \\
\hline Medium stiff & $500-1000$ & $500-750$ \\
\hline Stiff & $1000-2000$ & $750-950$ \\
\hline Very stiff & $2000-4000$ & $950-1300$ \\
\hline
\end{tabular}




\section{SEISMIC QUALIFICATION OF EQUIPMENT}

\subsection{GENERAL APPROACH}

The equipment required for safe operation and maintenance of the tank farms must perform its intended function at the DBE level. Not all equipment items used for normal operation are required for safety. Therefore, a list should be prepared identifying the safety-related equipment, and a seismic qualification is required for these items. Some equipment pieces may not be required to perform a function during the earthquake event but they may need to remain functional after the event; whereas, some other equipment items may be required to function during as well as after the earthquake. Such distinction of the functional requirements helps selection of the appropriate qualification approach and therefore should be made along with the equipment 1 isting.

Seismic qualification of equipment can be demonstrated employing one or more of the following approaches:

- Dynamic or Equivalent static Analysis

- Testing

- Similarity Analysis

The selection of the appropriate method depends on the functional requirements and availability of data. A structural analysis may be adequate for equipment if demonstration of the structural integrity alone ensures its functional operability. otherwise, shake table testing may be required to verify functionality especially for electrical equipment. Static testing may provide functional data for some (although very few) equipment classes, such as valves. In a similarity analysis, the qualification equipment item and level are compared with similar information available in an existing data base. The

$$
8-1
$$


dynamic similarity of the two equipment items shall be demonstrated (e.g., identical models) and the required vibration level must be enveloped by the level to which the equipment may have been qualified by a structural analysis, testing or a combination of analysis and testing, or may have successfully withstood a real earthquake for which sufficient reliable data exist.

\subsection{EXISTING STANDARDS}

The equipment qualification method discussed above are described in detail in existing literature, for example, in IEEE std 344 (Reference 8.1). Both the NRC Regulatory Guide (Reference 8.2) and the standard Review Plan (Reference 8.3) endorse the IEEE standard with certain additions and clarifications, especially for mechanical equipment. Recently, the nuclear power industry has established a data bank based on shake table testing and earthquake experience, and intends to use it generically for verification of equipment in operating power plants under a program called "Unresolved Safety Issue A-46" (Reference 8.4).

The NRC has accepted the industry approach for seismic verification of equipment in older operating power plants (Reference 8.5) but does not endorse use of the A-46 approach for qualification of equipment in new plants (Reference 8.6). Although the basic data of Reference 8.4 were derived from testing and earthquake experience and may be treated as the required data base for qualification by the method of similarity analysis, the industry criteria do not require demonstration of one-to-one similarity (between the equipment to be qualified and the equipment in the data base) as required by the IEEE std (Reference 8.1).

Since the early 70's, a large number of equipment items have been shake table tested by the manufacturers or users. Although the information constitutes a valid data base for qualification 
by the method of similarity analysis, this may not be available to a new user. Generic interpretations of the industry data are available in the existing literature (References 8.7 and 8.8 ). However, these documents do not provide as much information as is necessary to demonstrate similarity as required by the IEEE Standard (Reference 8.1). One important observation that has been made in the generic interpretation documents (References $8.7,8.8$ and 8.9 ) is that certain equipment classes by design are relatively strong and can withstand a high earthquake level provided they are adequately anchored (e.g., horizontal pumps). Therefore, if the information developed in these references is properly used, the demonstration of the similarity analysis as required by IEEE std 344 can easily be made without much rigor and expense. On the other hand, as pointed out in the generic documents, certain other equipment (e.g., electrical panels) would require a much more detailed comparison for an effective use of the similarity method.

\subsection{QUALIFICATION LEVEL}

Regardless of which one of the above three approaches (i.e., structural analysis, testing or similarity analysis) is used for qualification, the equipment shall withstand the required vibration level. For convenience, response spectra are used as a measure of the qualification level. The qualification or the capacity response spectra should be compared with the required response spectra at the location of the structure where the equipment is installed. For qualification by either testing or similarity analysis (e.g., use of experience data) if the required response spectra are computed as discussed in chapter 3 , the qualification or capacity response spectra shall envelop the required response spectra amplified by a factor as explained below in section $8.3 .1\left(\mathrm{e} . \mathrm{g} ., 1.6\right.$ for $\left.R_{R}=20\right)$. Exceptions in enveloping at certain frequencies may be justified following the procedures of IEEE std 344 (Reference 8.1 ). 


\subsubsection{Justification for RRS Amplification Factor}

When equipment is qualified by shake table testing and the DBE input to the equipment is defined by a required response spectrum (RRS) obtained by envoloping and smoothing (i.e., filling in valleys) the in-structure spectra computed at the support of the equipment by a linear elastic analysis, then in order to obtain the seismic margin defined by Equations 3.9 and $3.9 \mathrm{a}$, the equipment must be shake table tested to a test response spectrum (TRS) defined by:

$$
T R S \geq\left(\frac{T R S}{R R S}\right)_{R} R R S
$$

where the required ratio of the TRS to RRS corresponding to the desired risk reduction factor, $R_{R}$, is given below:

\begin{tabular}{|c|c|}
\hline $\mathrm{R}_{\mathrm{R}}$ & $\left(\frac{T R S}{R R S}\right)_{R}$ \\
\hline \hline 20 & 1.6 \\
10 & 1.4 \\
5 & 1.2 \\
\hline
\end{tabular}

The basis for Equations 8.1 and 8.1 a are summarized in section C.7 of Appendix C. For qualification by similarity analysis when experience data are used, it is recommended that the above factors be used unless the user chooses to justify for alternate factors. 


\section{REFERENCES}

8.1 "Recommended Practices for Seismic Qualification of Class $1 \mathrm{E}$ Equipment for Nuclear Power Generating Stations," IEEE std. 344-1987.

8.2 "Regulatory Guide 1.100," U.S. Nuclear Regulatory Commission, June 1988.

8.3 "Standard Review Plan," NUREG-800, Section 3.10, Rev. 2, U.S. Nuclear Regulatory Commission, July 1981.

8.4 "Generic Implementation Procedure (GIP) for seismic Verification of Nuclear Plant Equipment," Rev. 2, Seismic oualification Utility Group, February 1992.

8.5 "Regulatory Analysis for Resolution of Unresolved Safety Issue A-46, Seismic Qualification of Equipment in operating Plants," U.S. Nuclear Regulatory Commission, NUREG-1211, February 1987 .

8.6 "Supulemental Safety Evaluation Report No. 2 on Seismic Qualificatinn Utility Group's Generic Implementation Procedure, Revision 2, corrected February 22, 1992" attached to U.S. NRC letter, "Supplement No. 1 to Generic Letter (GL) 87-02", May 22, 1992.

8.7 Bandyopadhyay, K.K., et al., "Seismic Fragility of Nuclear Power Plant Components," NUREG/CR-4659, Vol. 4, June 1991.

8.8 EPRI Report NP-5223, Rev. 1, "Generic Seismic Ruggedness of Power Plant Equipment in Nuclear Power Plants," February 1.991 .

8.9 Kennedy, R.P., et al., "Use of Seismic Experience and Test Data to show Ruggedness of Equipment in Nuclear Power Plants," 1991. 
NOTATION

$R_{R} \quad$ risk reduction factor defined in chapter 3

RRS required response spectrum

TRS test response spectrum 


\section{APPENDIX A}

DERIVATION OF REQUIRED LEVEL OF SEISMIC DESIGN CONSERVATISM TO ACHIEVE A SPECTFIED SEISMIC RISK REDUCTION RATIO

Figure A.1 presents two representative probabilistic seismic hazard curves expressed in terms of mean annual probability of exceedance versus peak ground acceleration. Curve A represents a hazard estimate for a higher seismicity site typical of a western site. Curve B represents a hazard estimate for a lower seismicity site typical of an eastern site.

Over any ten-fold difference in exceedance probabilities, such hazard curves may be approximated by:

$$
H(a)=K_{1} a^{-K_{H}}
$$

where $H(a)$ is the annual frequency of exceedance of ground motion level " $a, " K_{1}$ is an appropriate constant, and $K_{H}$ is a slope parameter defined by:

$$
K_{H}=\frac{1}{\log \left(A_{R}\right)}
$$

in which $A_{R}$ is the ratio of ground motion levels corresponding to a ten-fold reduction in exceedance probability. The use of Equation A.1 is suggested in Reference A.1. Table A.1 shows the ground motion ratios and hazard slope parameters obtained from Figure A.1. These results are typical. For the western (higher) seismicity sites, the values of $A_{R}$ for mean hazard curves will vary from about 2.0 to 1.5 for a probability range of $10^{-3}$ to $10^{-5}$. For the eastern (lower) seismicity sites, the corresponding $A_{R}$ values will range from about 3.75 to 2.0 . Furthermore, $A_{R}$ is not constant over probability ranges that differ by an order of magnitude, with $A_{R}$ always reducing as the exceedance probability is lowered. 
In order to compute the risk reduction ratio, $R_{R}$, corresponding to any specified seismic design/evaluation criteria, one must also define a mean seismic fragility curve for a component resulting from the usage of these seismic criteria. The mean seismic fragility curve describes the probability of an unacceptable performance versus the ground motion level. This fragility curve is defined as being lognormally distributed and is expressed in terms of two parameters: a median capacity level and a composite logarithmic standard deviation $\beta$ (see Reference A.2 for further amplification). To estimate this composite logarithmic standard deviation, it is sufficient to estimate the capacity corresponding to a failure probability of $50 \%, \mathrm{C}_{50 \%}$, and the capacity associated with any one of the following failure probabilities: $1 \%, 2 \%, 5 \%$ or $10 \%$. Then, the composite logarithmic standard deviation can be computed from the ratio of these two capacity estimates. The standard deviation will generally lie within the range of 0.3 to 0.5 .

The probability, $P_{F}$, of unacceptable performances is obtained by a convolution of the seismic hazard and fragility curves. This convolution can be expressed by either:

$$
P_{F}=-\int_{0}^{+\infty}\left(\frac{d H(a)}{d a}\right) P_{F / a} d a
$$

or

$$
P_{F}=\int_{0}^{+\infty} H(a)\left(\frac{d P_{F / a}}{d a}\right) d a
$$

where $P_{F / a}$ is the conditional probability of failure given the ground motion level "a" as defined by the fragility curve of the structure or component. Assuming a lognormally distributed fragility curve with the median capacity, $C_{508}$, and logarithmic standard deviation, $\beta$, and defining the hazard exceedance probability $H(a)$ by Equation $A .1$, one obtains the following 
solution from Equation A.4:

$$
\begin{aligned}
& P_{F}=\int_{0}^{+\infty} K_{1} a^{-K_{H}}\left[\frac{1}{a \beta \sqrt{2} \pi} e^{-\frac{\left(\ln a-M^{2}\right.}{2 \beta^{2}}}\right] d a \\
& M=\ln C_{50 \%}
\end{aligned}
$$

Defining $x=\ln a$, Equation $A .5$ becomes:

$$
P_{F}=\frac{K_{1}}{\beta \sqrt{2} \pi} \int_{-\infty}^{+\infty}\left[e^{K_{H} x}\right]\left[e^{-\frac{(x-M)^{2}}{2 \beta^{2}}}\right] d x
$$

Then, solving this definite integral by the approach shown in Appendix A of Reference A.3 or other probability textbooks, one obtains:

$$
P_{F}=K_{1} e^{-k_{H} M} e^{\left(\frac{1}{2}\right)\left(K_{H} \beta\right)^{2}}
$$

or from the previous definitions of $\mathrm{M}$ :

$$
P_{F}=K_{1}\left(C_{508}\right)^{-K_{H}} e^{\left(\frac{1}{2}\right)\left(K_{H} \beta\right)^{2}}
$$

Defining $H_{D}$ as the annual frequency of exceedance of the DBE ground motion level, from Equation A.1:

$$
K_{1}=H_{D}[D B E]^{K_{H}}
$$

from which

$$
P_{F}=H_{D} \frac{e^{\left(\frac{1}{2}\right)\left(K_{H} \beta\right)^{2}}}{\left(C_{508} / D B E\right)^{K_{H}}}
$$

Equation A.10 is exact so long as the fragility is lognormally distributed and the hazard curve is defined by Equation A.1, (i.e., is linear on a $\log -\log$ plot). Equation A.10 will be used to derive the required level of seismic design conservatism to achieve any specified seismic risk reduction ratio, $R_{R}$. 
In order to accommodate ground motion ratios, $A_{R}$, ranging from 1.5 to 3.75 while achieving a given required risk reduction ratio, $R_{R}$, with a specified degree of conservatism in the seismic design, it has been observed that the DBE must satisfy both the following equations:

$$
\begin{gathered}
D B E \geq a_{P H} \\
D B E \geq f_{a} a_{P F}
\end{gathered}
$$

where $a_{P H}$ and $a_{P F}$ are the mean ground motion levels at the seismic hazard probability, $\mathrm{P}_{H}$, and probability performance goal, $P_{F}$, respectively, and $f_{a}$ is an empirically derived factor to approximately achieve the required risk reduction ratio, $R_{R}$, over a wide range of $A_{R}$ values. When the DBE is governed by Equation A.11a,

$$
H_{D}=P_{H}
$$

and thus the risk reduction ratio, $R_{R}$, between the annual frequency of exceedance of the DBE and the probability of an unacceptable performance is given by:

$$
R_{R}=\frac{H_{D}}{P_{F}}=\left(C_{508} / D B E\right) K_{H} e^{(-1 / 2)\left(K_{H} \beta\right)^{2}}
$$

Alternatively, when the DBE is governed by Equation A.11b,

$$
H_{D}=P_{F}\left[\frac{D B E}{a_{P F}}\right]^{-K_{H}}=P_{F}\left(f_{\mathrm{a}}\right)^{-K_{H}}
$$

Substituting Equation A.12b into Equation A.10 leads to:

$$
\left(f_{a}\right)^{-K_{H}}=\left(C_{50} / D B E\right)^{K_{H}} e^{(-1 / 2)\left(K_{H} \beta\right)^{2}}
$$

The required ratio $\left(C_{508} / D B E\right)$ is given by Equation $A .13 a$ when Equation A.12a produces a lower exceedance probability, $H_{D}$, than 
does Equation A.12b. When A.12b produces the lower $H_{D}$, then $\left(C_{50 \%} / D B E\right)$ is controlled by Equation A.13b.

Next, the minimum capacity, $c_{p}$, at any failure probability, $P$, required to achieve a risk reduction of $R_{R}$, can be defined by:

$$
C_{F}=F_{P R}(D B E)
$$

where $F_{P R}$ is the required factor of safety which is a function of both the probability $P$ and the risk ratio, $R_{R}$. Then, the required median capacity is:

$$
C_{508}=C_{p} e^{X_{p} \beta}
$$

where $X_{p}$ is the factor associated with the failure probability $P$ for the standard normal distribution obtained from cumulative normal probability tables as shown below:

\begin{tabular}{|c|c||c|c|}
\hline$P$ & $X_{P}$ & $P$ & $X_{P}$ \\
\hline \hline $1 \%$ & 2.326 & $15 \%$ & 1.037 \\
\hline $5 \%$ & 1.645 & $20 \%$ & 0.842 \\
\hline $10 \%$ & 1.282 & $50 \%$ & 0 \\
\hline
\end{tabular}

Combining either Equation A.13a or A.13b whichever controls with Equations $A .14$ and $A .15$, the required factor of safety, $F_{P R}$ is:

$$
\begin{gathered}
F_{P R}=\frac{N U M}{D E N} \\
N U M=\text { smaller of }\left[R_{R}^{1 / K_{H}} \text { or } 1 / f_{a}\right] \\
D E N=e^{\left[X_{P} \beta-\left(K_{H} / 2\right) \beta^{2}\right]}
\end{gathered}
$$

Tables A.2a, A. 2b, A.2C and A.2d present the maximum and minimum values of $F_{P R}$ within the range of $1.5 \leq A_{R}<3.75$ and $0.3 \leq \beta \leq$

$$
A-5
$$


0.5 required to achieve $R_{R}$ values of $20,10,5$ and 2 , respectively, for various failure probability "p" and $f_{a}$ values. Also presented in these tables are the ratios of maximum to minimum $F_{P A}$ for each condition.

As an example for $R_{k}=20, f_{a}=0.45$, and a $10 \%$ failure probability, the maximum $F_{P R}$ occurs when $A_{R}=1.847$ (i.e., $K_{11}=$ 3.752 ) and $\beta=0.5$. Thus, $N U M=2.222$ from Equation $A .17$ and the $D E N=1.188$ from Equation A.18, and this leads to the maximum $F_{P R}$ of 1.87 shown in Table A.2a for this case. Similarly, for the same case the minimum $F_{P R}$ occurs when $A_{R}=3.75$ (i.e., $\mathrm{K}_{11}=1.742$ ) and $\beta=0.5$ for which $\mathrm{NUM}=2.222, \mathrm{DEN}=1.527$ and the minimum $F_{P R}=1.46$ also shown in Table A.2a.

As another example, for $R_{R}=20, f_{a}=0.5$, and a $20 \%$ failure probability, the minimum $F_{P R}$ occurs when $A_{R}=3.75$ (i.e., $K_{11}=$ 1.742 ) and $\beta=0.4833$ for which $\mathrm{NUM}=2.0, \mathrm{DEN}=1.226$ and the minimum $F_{P R}=1.63$. However, when this case is slightly changed to a combination of $\mathrm{R}_{\mathrm{R}}=20, \mathrm{f}_{\mathrm{a}}=0.45$ and $\mathrm{a} 20 \%$ failure probability, the minimum $F_{P R}$ occurs when $A_{R}=1.5$ (i.e., $K_{H}=$ 5.679 ) and $\beta=0.3$ for which NUM $=1.695$, DEN $=0.997$ and the minimum $F_{P R}=1.70$.

Thus, the maximum and minimum $F_{P R}$ values shown in Tables A.2a through $A .2 d$ are the results of different combinations of $A_{R}$ and $\beta$ for the cases considered. In general, the entire sample space of $1.5 \leq A_{R} \leq 3.75$ and $0.3 \leq \beta \leq 0.5$ must be searched to $f$ ind the maximum and minimum values of $F_{P R}$ for each case.

It is observed in Tables A.2a through A.2d, that for each value of $R_{R}$, the ratio of the maximum to minimum values of $F_{p n}$ is minimum when the capacity corresponding to a failure probability of $10 \%$ is used. This ratio is not significantly increased for capacities corresponding to failure probabilities of $5 \%$ and $15 \%$. However, when either the median failure capacity, $\mathrm{C}_{50 \%}$, or the

$$
A-6
$$


capacity corresponding to a very low failure probablity (e.g., $C_{18}$ ) is used, the scatter of the range of $F_{P R}$ becomes much larger. This indicates that it is much less desirable to. define the required factor of conservatism, $F_{P R}$, in terms of these failure probabilities than the $10 \%$ failure probability.

In addition, the ratio of the maximum to the minimum $F_{P R}$ values is also minimum for each $R_{R}$ value when $f_{a}$ values listed in Table A.3 are used to define the DBE in Equation A.11b. Note that for $A_{A}$ values of 3.75 or less, and for $R_{R}=2$, Equation $A .11 b$ with $f_{2}$ $\leq 0.65$ never controls the DBE. Therefore, for $R_{R}=2$, the $D B E$ can always be defined by Equation A.11a and $f_{a}$ is not applicable.

In conclusion, it is recommended that the DBE level be defined to satisfy both Equations $A 11 . a$ and $A 11 . b$ using $f_{a}$ from Table A.3, and the minimum capacity required for a $10 \%$ probability of failure, $C_{10 r}$, be given by:

$$
C_{108} \geq F_{R}(D B E)
$$

Table A.4 shows the values of $F_{P A}$ required to achieve the desired $R_{A}$ value for various $A_{R}$ and $\beta$ values. The required factors of safety, $F_{R}$, provided in Table $A .3$ are roughly the midpoint values of $F_{P R}$ shown in Table A.4 with the greatest weight being placed on the values of $A_{R}$ between 1.65 and 3.25 within which the vast majority of probabilistic seismic hazard curves are expected to lie. The $F_{P R}$ values in Table A.4 vary from $86 \%$ to $110 \%$ of the required $F_{R}$ values listed in Table A.3, except for the case of $R_{A}=2$ with an unlikely very steep hazard curve (e.g., $A_{R}=1.5$ ) combined with an unlikely high logarithmic standard deviation (e.g., $\beta^{*}=0.5$ ) for which $F_{P R}$ exceeds the value shown in Table A. 3 by $21 \%$.

Equation A.19 may be alternately written as: 


$$
\begin{gathered}
C_{108} \geq 1.5 L_{s}(D B E) \\
L_{S} \approx F_{R} / 1.5
\end{gathered}
$$

where $L_{s}$ is the seismic load factor defined in Table A.3 for the specified risk reduction ratio $R_{h}$. This alternate format is used in the remainder of this report. 


\section{REFERENCES}

A.1 Sewell, R.T., G.R. Toro, and R.K. McGuire, "Impact of Ground Motion Characterization on Conservatism and Variability in Seismic Risk Estimates," Prepared for the U.S. Nuclear Regulator Commission by Risk Engineering, May 1991 (to be published by NRC as a NUREG) .

A.2 "PRA Procedures Guide," NUREG/CR-23001, Chapter 10, Vol.2, January 1983, Prepared for the U.S. Nuclear Regulatory Commission by ANS and IPEEE.

A.3 Elishakoff, I., "Probablilistic Methods in the Theory of structures," John Wiley \& Sons, 1983. 
NOTATION

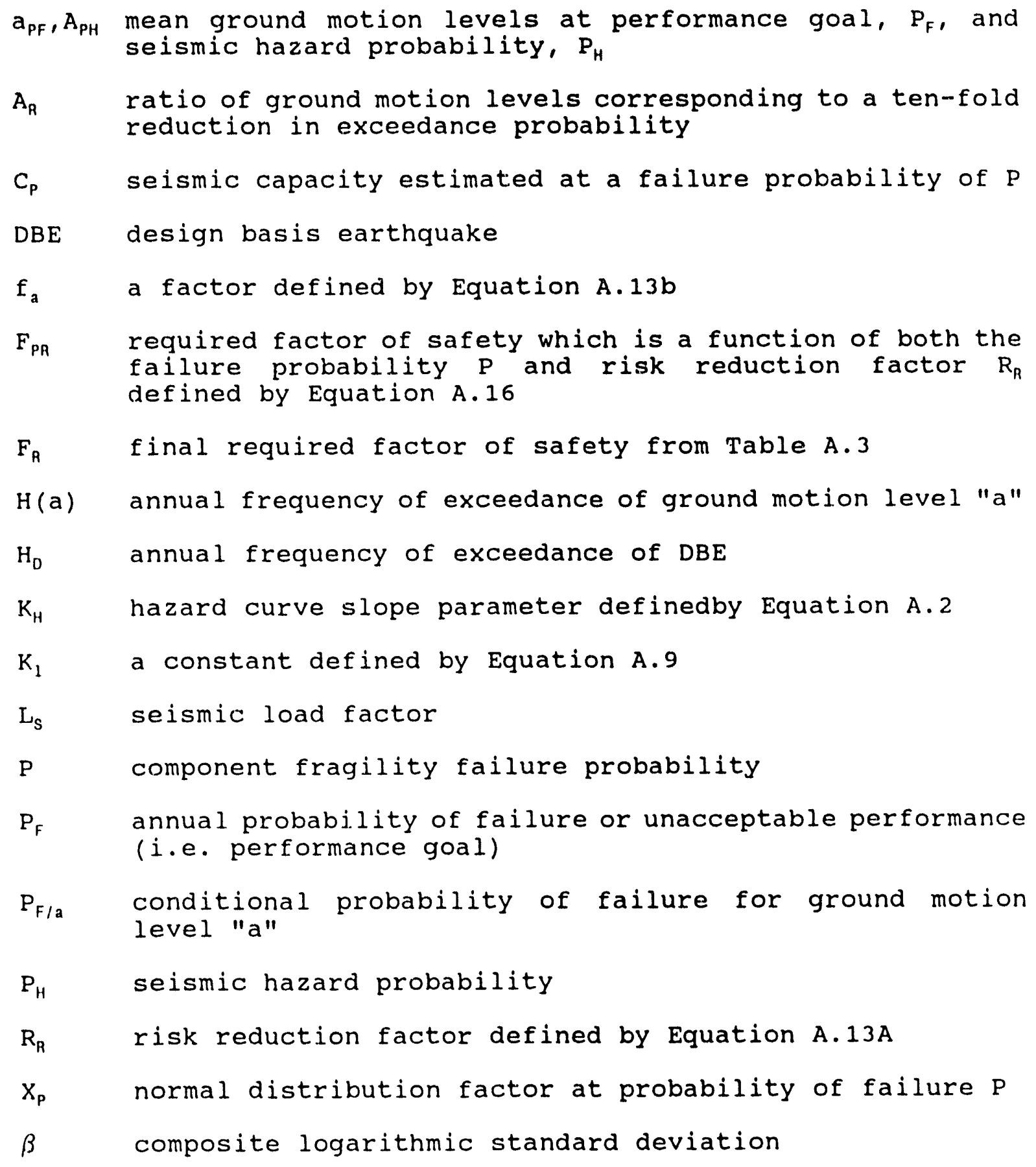


Table A.1 Typical Ground Motion Ratios and Hazard slope Parameters

\begin{tabular}{|c|c|c|c|}
\hline $\begin{array}{c}\text { Hazard } \\
\text { curve }\end{array}$ & Probability Range & $A_{A}$ & $K_{H}$ \\
\hline \multirow{2}{*}{$A$ (Western) } & $10^{-3}$ to $10^{-4}$ & 2.0 & 3.32 \\
\cline { 2 - 4 } & $10^{-4}$ to $10^{-5}$ & 1.67 & 4.49 \\
\hline \multirow{2}{*}{ B (Eastern) } & $10^{-3}$ to $10^{-4}$ & 2.31 & 2.75 \\
\cline { 2 - 4 } & $10^{-4}$ to $10^{-5}$ & 2.13 & 3.05 \\
\hline
\end{tabular}

$$
A-11
$$


Table A.2a Maximum and Minimum Required safety Factors $F_{P A}$ to Achieve a Risk Reduction Ratio of $R_{h}=20$ for Capacities $C_{p}$ Defined at Various Failure Probabilities and Various $f_{a}$ Values

Parameter Range: $1.5 \leq A_{R} \leq 3.25,0.3 \leq \beta \leq 0.5$

\begin{tabular}{|c|c|c|c|c|}
\hline \multirow{2}{*}{$\begin{array}{c}\text { Probability } \\
\text { of } \\
\text { Failure }^{\mathrm{a}}\end{array}$} & \multicolumn{4}{|c|}{$F_{P R}$ Range $^{b}$} \\
\hline & $\mathrm{f}_{\mathrm{a}}=0.50$ & $\mathrm{f}_{\mathrm{a}}=0.45$ & $\mathrm{f}_{\mathrm{a}}=0.40$ & $\mathrm{f}_{\mathrm{a}}=0.35$ \\
\hline 18 & $\frac{1.21}{0.78}=1.55$ & $\frac{1.31}{0.86}=1.52$ & $\frac{1.44}{0.97}=1.48$ & $\frac{1.62}{1.05}=1.54$ \\
\hline $5 \%$ & $\frac{1.51}{1.09}=1.39$ & $\frac{1.61}{1.21}=1.33$ & $\frac{1.77}{1.34}=1.32$ & $\frac{1.98}{1.34}=1.48$ \\
\hline $10 \%$ & $\frac{1.82}{1.31}=1.39$ & $\frac{1.87}{1.46}=1.28$ & $\frac{1.98}{1.49}=1.33$ & $\frac{2.21}{1.49}=1.48$ \\
\hline $15 \%$ & $\frac{2.05}{1.48}=1.39$ & $\frac{2.11}{1.60}=1.32$ & $\frac{2.24}{1.60}=1.40$ & $\frac{2.43}{1.69}=1.52$ \\
\hline $20 \%$ & $\frac{2.26}{1.63}=1.39$ & $\frac{2.33}{1.70}=1.37$ & $\frac{2.47}{1.70}=1.45$ & $\frac{2.68}{1.70}=1.58$ \\
\hline $50 \%$ & $\frac{3.45}{2.16}=1.60$ & $\frac{3.55}{2.19}=1.62$ & $\frac{3.76}{2.19}=1.72$ & $\frac{4.08}{2.19}=1.86$ \\
\hline
\end{tabular}

a at which the capacity $c_{p}$ is computed

b Key to read table: $\frac{M_{\mathrm{M}} F_{\mathrm{PR}}}{\mathrm{MinF}_{\mathrm{PR}}}=$ Ratio

Lowest ratio case 
Table A.2b Maximum and Minimum Required Safety Factors $F_{P R}$ to Achieve a Risk Reduction Ratio of $R_{h}=10$ for Capacities $C_{p}$ Defined at Various Failure probabilities and Various $f_{a}$ Values

Parameter Range: $1.5 \leq A_{A} \leq 3.25,0.3 \leq \beta \leq 0.5$

\begin{tabular}{|c|c|c|c|c|}
\hline \multirow{2}{*}{$\begin{array}{c}\text { Probuility } \\
\text { Failure }\end{array}$} & \multicolumn{4}{|c|}{$F_{\mathrm{PR}}$ Range $^{\mathrm{b}}$} \\
\cline { 2 - 5 } & $\mathrm{f}_{\mathrm{a}}=0.55$ & $\mathrm{f}_{\mathrm{a}}=0.50$ & $\mathrm{f}_{\mathrm{a}}=0.45$ & $\mathrm{f}_{\mathrm{a}}=0.40$ \\
\hline \hline $1 \%$ & $\frac{1.08}{0.71}=1.52$ & $\frac{1.16}{0.78}=1.49$ & $\frac{1.26}{0.86}=1.47$ & $\frac{1.39}{0.92}=1.51$ \\
\hline $5 \%$ & $\frac{1.34}{0.99}=1.35$ & $\frac{1.42}{1.09}=1.30$ & $\frac{1.54}{1.18}=1.31$ & $\frac{1.71}{1.18}=1.45$ \\
\hline $10 \%$ & $\frac{1.61}{1.19}=1.35$ & $\frac{1.61}{1.31}=1.23$ & $\frac{1.72}{1.32}=1.30$ & $\frac{1.91}{1.32}=1.45$ \\
\hline $15 \%$ & $\frac{1.82}{1.35}=1.35$ & $\frac{1.82}{1.42}=1.28$ & $\frac{1.90}{1.42}=1.34$ & $\frac{2.05}{1.42}=1.44$ \\
\hline $20 \%$ & $\frac{2.00}{1.48}=1.35$ & $\frac{2.00}{1.50}=1.33$ & $\frac{2.09}{1.50}=1.39$ & $\frac{2.25}{1.50}=1.50$ \\
\hline $50 \%$ & $\frac{3.05}{1.94}=1.57$ & $\frac{3.05}{1.94}=1.57$ & $\frac{3.19}{1.94}=1.64$ & $\frac{3.43}{1.94}=1.76$ \\
\hline
\end{tabular}

a at which the capacity $c_{p}$ is computed

$b$ Key to read table: $\frac{\text { MaxF }_{P R}}{M_{i n F_{P R}}}=$ Ratio

$\square$ Lowest ratio case 
Table A.2C Maximum and Minimum Required Safety Factors $F_{P R}$ to Achieve a Risk reduction Ratio of $R_{h}=5$ For Capacities $C_{p}$ Defined at Various Failure Probabilities and Various $f_{a}$ Values

Parameter Range: $1.5 \leq A_{R} \leq 3.25,0.3 \leq \beta \leq 0.5$

\begin{tabular}{|c|c|c|c|c|}
\hline \multirow{2}{*}{$\begin{array}{c}\text { Probability } \\
\text { of }\end{array}$} & \multicolumn{4}{|c|}{$F_{P R}$ Range $^{\mathrm{b}}$} \\
\cline { 2 - 5 } & $\mathrm{f}_{\mathrm{a}}=0.65$ & $\mathrm{f}_{\mathrm{a}}=0.60$ & $\mathrm{f}_{\mathrm{a}}=0.55$ & $\mathrm{f}_{\mathrm{a}}=0.50$ \\
\hline \hline $1 \%$ & $\frac{0.91}{0.60}=1.52$ & $\frac{0.96}{0.65}=1.48$ & $\frac{1.02}{0.71}=1.44$ & $\frac{1.10}{0.77}=1.43$ \\
\hline $5 \%$ & $\frac{1.19}{0.84}=1.42$ & $\frac{1.19}{0.91}=1.31$ & $\frac{1.25}{0.99}=1.26$ & $\frac{1.36}{1.05}=1.30$ \\
\hline $10 \%$ & $\frac{1.42}{1.01}=1.41$ & $\frac{1.42}{1.09}=1.30$ & $\frac{1.42}{1.17}=1.21$ & $\frac{1.51}{1.17}=1.29$ \\
\hline $15 \%$ & $\frac{1.61}{1.14}=1.41$ & $\frac{1.61}{1.23}=1.31$ & $\frac{1.61}{1.26}=1.28$ & $\frac{1.63}{1.26}=1.29$ \\
\hline $20 \%$ & $\frac{1.77}{1.26}=1.40$ & $\frac{1.77}{1.33}=1.33$ & $\frac{1.77}{1.33}=1.33$ & $\frac{1.77}{1.33}=1.33$ \\
\hline $50 \%$ & $\frac{2.70}{1.66}=1.63$ & $\frac{2.70}{1.71}=1.58$ & $\frac{2.70}{1.71}=1.58$ & $\frac{2.70}{1.71}=1.58$ \\
\hline
\end{tabular}

a at which the capacity $C_{p}$ is computed

b Key to read table: $\frac{M_{\mathrm{Pax}} \mathrm{F}_{\mathrm{PR}}}{\mathrm{MinF}_{\mathrm{PR}}}=$ Ratio

$\square$ Lowest ratio case 
Table A.2d Maximum and Minimum Required Safety Factors $F_{P R}$ to Achieve a Risk Reduction Ratio of $R_{h}=2$ for Capacities $C_{p}$ Defined at Various Failure Probabilities and Various $f_{a}$ Values

Parameter Range: $1.5 \leq A_{R} \leq 3.25,0.3 \leq \beta \leq 0.5$

\begin{tabular}{|c|c|c|c|c|}
\hline \multirow{2}{*}{$\begin{array}{c}\text { Probabity } \\
\text { of } \\
\text { Failure }^{\mathrm{a}}\end{array}$} & \multicolumn{4}{|c|}{$F_{P R}$ Range $^{b}$} \\
\hline & $\mathrm{f}_{\mathrm{a}}=0.80$ & $\mathrm{f}_{\mathrm{a}}=0.75$ & $f_{a}=0.70$ & $f_{a}=0.65$ \\
\hline $1 \%$ & $\frac{0.73}{0.49}=1.49$ & $\frac{0.74}{0.52}=1.42$ & $\frac{0.78}{0.56}=1.39$ & $\frac{0.80}{0.56}=1.43$ \\
\hline $5 \%$ & $\frac{1.01}{0.68}=1.49$ & $\frac{1.01}{0.73}=1.38$ & $\frac{1.01}{0.78}=1.29$ & $\frac{1.01}{0.79}=1.28$ \\
\hline $10 \%$ & $\frac{1.21}{0.82}=1.48$ & $\frac{1.21}{0.87}=1.39$ & $\frac{1.21}{0.94}=1.29$ & $\frac{1.21}{0.95}=1.27$ \\
\hline $15 \%$ & $\frac{1.37}{0.93}=1.47$ & $\frac{1.37}{0.99}=1.38$ & $\frac{1.37}{1.04}=1.32$ & $\frac{1.37}{1.04}=1.32$ \\
\hline $20 \%$ & $\frac{1.51}{1.02}=1.48$ & $\frac{1.51}{1.09}=1.39$ & $\frac{1.51}{1.11}=1.36$ & $\frac{1.51}{1.11}=1.36$ \\
\hline $50 \%$ & $\frac{2.30}{1.35}=1.70$ & $\frac{2.30}{1.42}=1.62$ & $\frac{2.30}{1.42}=1.62$ & $\frac{2.30}{1.42}=1.62$ \\
\hline
\end{tabular}

a at which the capacity $C_{p}$ is computed

b Key to read table: $\frac{M a x F_{P R}}{M i n F_{P R}}=$ Ratio

Lowest ratio case 
Table A.3 DBE Factors, Factors of Safety, and Seismic Load Factors Required to Achieve Various Risk Reduction Ratios

\begin{tabular}{|c|c|c|c|}
\hline $\begin{array}{c}\text { Risk Reduction } \\
\text { Ratio, } \mathrm{R}_{\mathrm{R}}\end{array}$ & DBE Factor, $\mathrm{f}_{\mathrm{a}}$ & $\begin{array}{c}\text { Required } \\
\text { Factor of } \\
\text { Safety, } F_{\mathrm{R}}\end{array}$ & $\begin{array}{c}\text { Seismic Load } \\
\text { Factor, } L_{S}{ }^{1}\end{array}$ \\
\hline 20 & 0.45 & 1.70 & 1.15 \\
\hline 10 & 0.50 & 1.50 & 1.00 \\
\hline 5 & 0.55 & 1.30 & 0.87 \\
\hline 2 & N.A. ${ }^{2}$ & 1.00 & 0.67 \\
\hline
\end{tabular}

${ }^{1} L_{\mathrm{s}} \approx \mathrm{F}_{\mathrm{R}} / 1.5$

${ }^{2} \mathrm{~N} . \mathrm{A}$. = Not applicable 


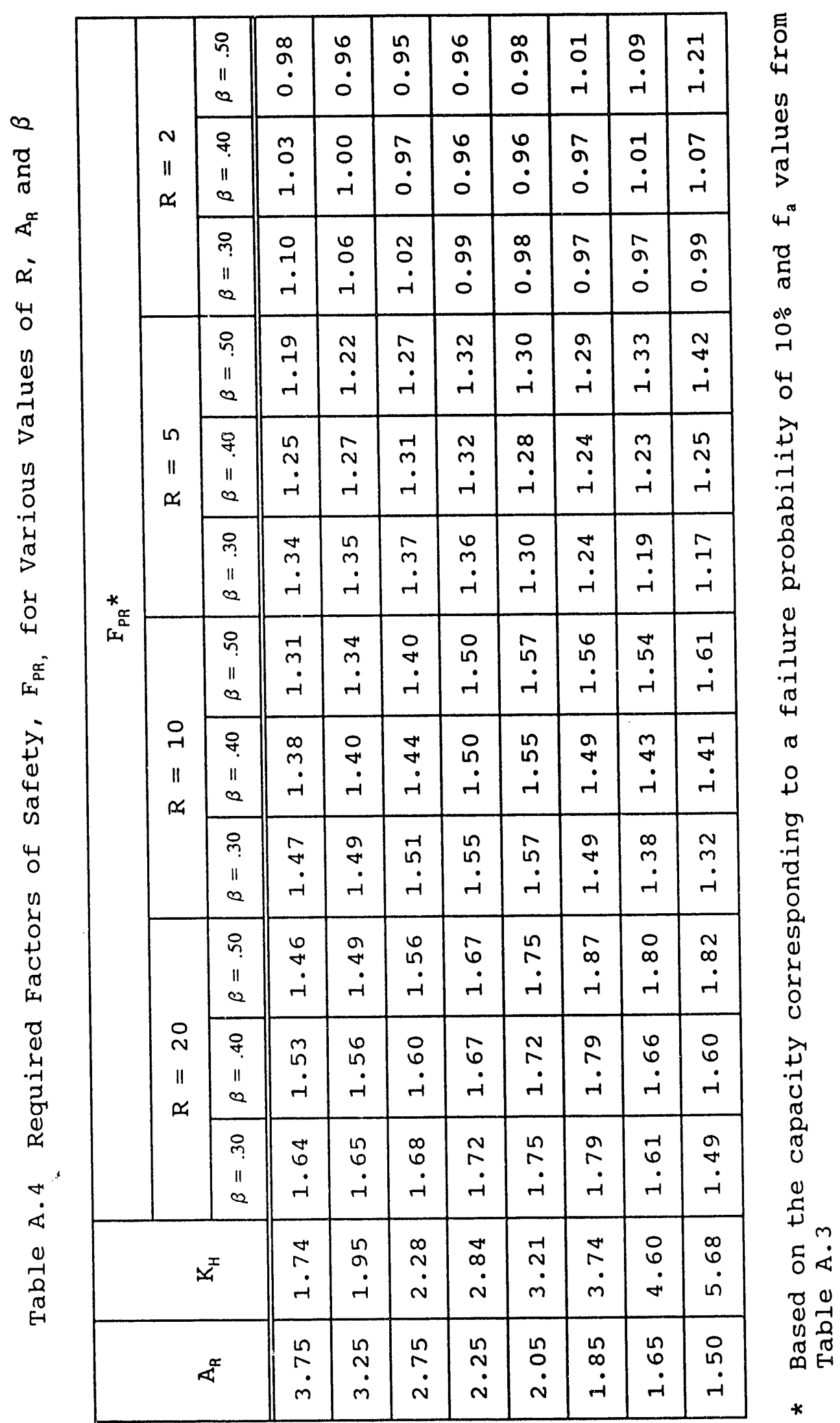




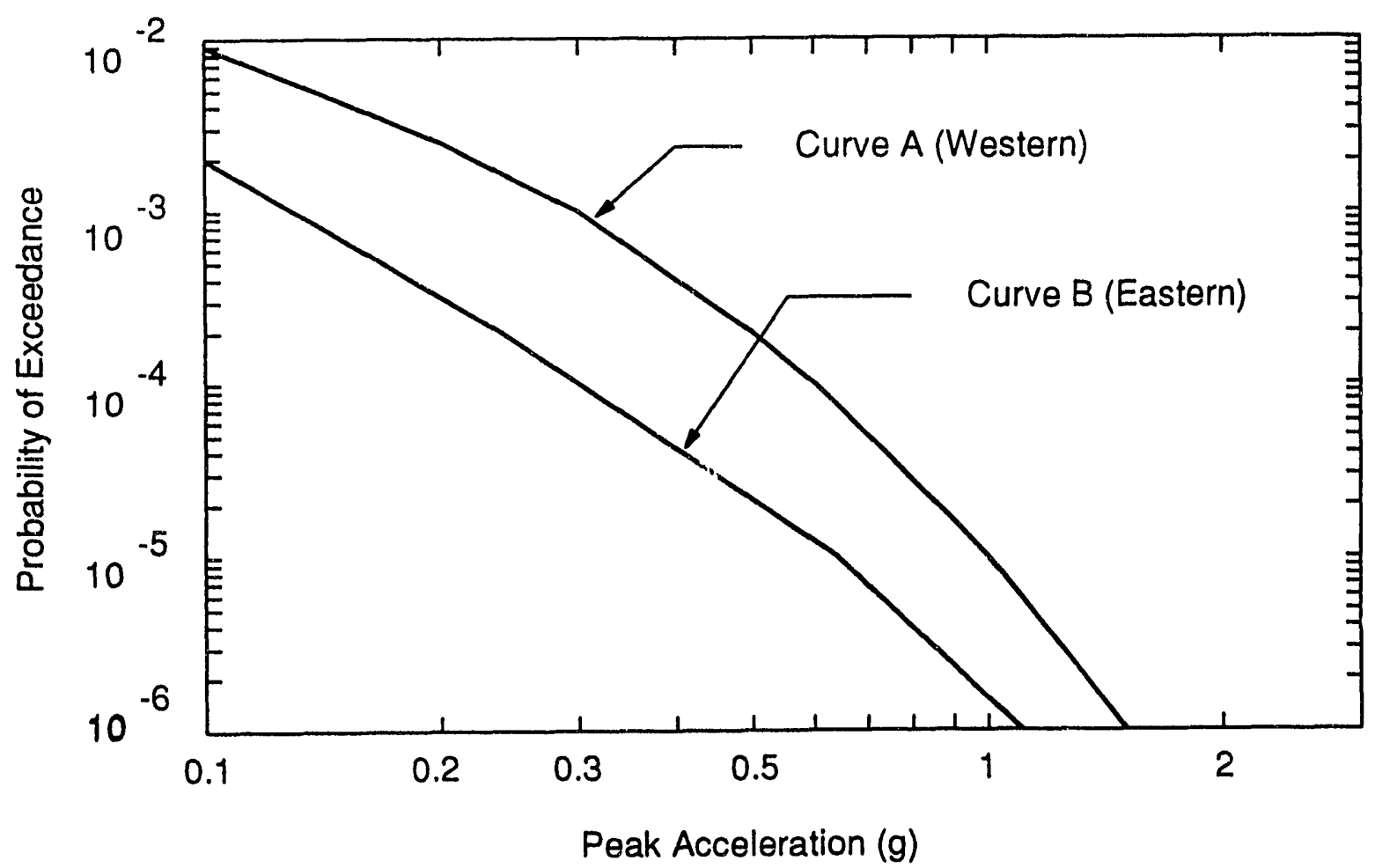

Figure A.1 Typical Probabilistic Seismic Hazard Curves

$$
A-18
$$


VALIDATION OF BASIC SEISMIC DESIGN CRITERIA OF ÁPPENDIX A

Actual hazard curves are not perfectly linear when plotted on a log-log scale as was assumed in Appendix A (for example, see Figure A.1). Therefore, Equation A.1, which was used to derive Equation $A .10$ and the results in Appendix $A$, is only an approximation of an actual hazard curve. Essentially for all hazard curves $A_{R}$ decreases (i.e., $K_{H}$ increases) as the exceedance probability is lowered, and this is exhibited by the slight downward concave shape of the hazard curves in Figure A.1. The combined effect of using Equation A.1 to define the hazard curve, and the use of the required factor of safety $F_{R}$ values defined in Table A.3 which approximate the values provided in Table A.4 will be shown in this appendix using both hazard curves $A$ and $B$ from Figure A.1.

For any shape of a hazard curve, the probability of unacceptable performance, $P_{F}$, may be obtained by numericaliy integrating either Equation A.3 or A.4. Thus, from Equation A.3:

$$
P_{F}=\sum_{i=1}^{\infty}\left[H\left(a_{i}\right)-H\left(a_{i+1}\right)\right] P_{F /\left(a_{c}\right)_{1}}
$$

where $\left(a_{c}\right)_{1}$ is the ground motion level at the centroid of the area enveloped by $a_{1}$ and $a_{1+1}$ and defined by:

$$
\left(a_{c}\right)_{i}=\frac{\int_{a_{1}}^{a_{1+1}} H(a) a d a}{\int_{a_{1}}^{a_{1+1}} H(a) d a}
$$

and $P_{F /\left(a_{c}\right)_{1}}$ is the conditional failure probability at ground motion level $\left(a_{c}\right)_{i}$. Assuming a piecewise linear hazard curve defined locally by Equation $A .1$ between $a_{1}$ and $a_{1+1}$, and defining 
the local slope parameter $\mathrm{K}_{\mathrm{H}_{1}}$ by:

$$
K_{H_{1}}=\frac{\log \left(H\left(a_{i}\right) / H\left(a_{i+1}\right)\right)}{\log \left(a_{i+1} / a_{i}\right)}
$$

one redefines $\left(a_{c}\right)_{1}$ from Equation (B.2) as follows:

$$
\left(a_{C}\right)_{i}=\frac{\left(1-K_{H_{i}}\right)\left[a_{i+1}^{\left(2-K_{H_{1}}\right)}-a_{i}^{\left(2-K_{H_{1}}\right)}\right]}{\left(2-K_{H_{i}}\right)\left[a_{i+1}^{\left(1-K_{H_{i}}\right)}-a_{i}^{\left(1-K_{H_{i}}\right)}\right]}
$$

The use of Equation B.4 to define $\left(a_{c}\right)_{1}$ improves the accuracy of Equation B. 1 over that obtained using the midpoint acceleration and thus permits the use of larger acceleration steps.

The hazard exceedance values versus peak ground accelerations from Figure A.1 are numerically presented in Table B.1 for seismic hazard curves $A$ and $B$. Results are presented in Tables B. $2 \mathrm{a}$ and B.2b for hazard curves $A$ and $B$, respectively, to show how the actual resultant performance level, $P_{F}$, compares with the desired target level. The results are provided for three sets of seismic hazards and risk reduction ratios. Table B.3 presents an example for solution of Equation B.1 for the case of seismic hazard curve $B, P_{H}=1 \times 10^{-3}, R_{R}=10$ and $\beta=0.4$. This illustrates how the $P_{F}$ results presented in Tables $B .2 a$ and $B .2 b$ were obtained.

For the 18 cases considered in Tables B. $2 \mathrm{a}$ and B. $2 \mathrm{~b}$ following the basic criteria of Appendix $A$, the actual resultant performanse level varies from $72 \%$ to $119 \%$ of the desired target performance goal. This excellent prediction of failure probabilities validates the basic criteria of Appendix A.

\section{B. 1 CONCLUSION}

The performance goals are accurately achieved over a wide range of hazard and fragility curves when the following conditions are 
satisfiea:

1. The DBE is defined from probabilistic hazard curves by

- Equations A.11a and A.11b where $f_{a}$ is defined as a function of $R_{R}$ in Table A.3.

2. The required seismic capacity for a failure probability of $10 \%, C_{10}$, is defined by Equation A.19 where $F_{R}$ is also defined as a function of $R_{R}$ in Table A.3. 


\section{REFERENCE}

B.1 Sewell, R.T., Toro, G.R. and McGuire, R.K., "Impact of Ground Motion Characterization on conservatism and Variability in Seismic Risk Estimates," Prepared for the U.S. Nuclear Regulatory Commission by Risk Engineering, May 1991 (To be published by NRC as a NUREG).

$$
\mathrm{B}-4
$$


NOTATION

a

$a_{p F}$

$\left(a_{0}\right)_{1}$

$\mathrm{C}_{\mathrm{p}}$

DBE

$\mathrm{H}(\mathrm{a})$

$\mathrm{K}_{\mathrm{H}_{1}}$

$\mathrm{P}_{\mathrm{F}}$

$P_{F /\left(a_{c}\right)}$

$P_{H}$

$\mathbf{R}_{\mathrm{R}}$

ground motion level "a"

ground motion at performance level

ground motion level at centroid of area enveloped by $a_{1}$ and $a_{1+1}$

seismic capacity at a failure probability of $P$

design basis earthquake

annual frequency of exceedance of ground motion level "a"

hazard curve slope parameter defined by Equation B. 3

annual probability of failure or unacceptable performance (i.e. performance goal)

Conditional probability of failure at ground motion

the seismic hazard (i.e., annual frequency of exceedance) associated with a reference-level earthquake, in some cases the DBE.

risk reduction factor 
Table B.1 Probabilities for Hazard Curves A and B from Figure A.1

\begin{tabular}{|c|c|c|c|}
\hline \multicolumn{2}{|r|}{ Curve A } & \multicolumn{2}{|r|}{ Curve B } \\
\hline $\begin{array}{c}\text { Acceleration a } \\
(\mathrm{g})\end{array}$ & $\begin{array}{c}\text { Exceedance Probability H(a) } \\
\left(10^{-5}\right)\end{array}$ & $\begin{array}{c}\text { Acceleration a } \\
(\mathrm{g})\end{array}$ & $\begin{array}{l}\text { Exceedance Probability H(a) } \\
\left(10^{-5}\right) \\
\end{array}$ \\
\hline 0.14 & 500 & 0.07 & 500 \\
\hline 0.23 & 200 & 0.10 & 200 \\
\hline 0.30 & 100 & 0.13 & 100 \\
\hline 0.38 & 50 & 0.17 & 50 \\
\hline 0.50 & 20 & 0.24 & 20 \\
\hline 0.60 & 10 & 0.30 & 10 \\
\hline 0.71 & 5 & 0.38 & 5 \\
\hline 0.87 & 2 & 0.51 & 2 \\
\hline 1.00 & 1 & 0.64 & 1 \\
\hline 1.14 & 0.5 & 0.78 & 0.5 \\
\hline 1.33 & 0.2 & 0.97 & 0.2 \\
\hline 1.49 & 0.1 & 1.12 & 0.1 \\
\hline
\end{tabular}




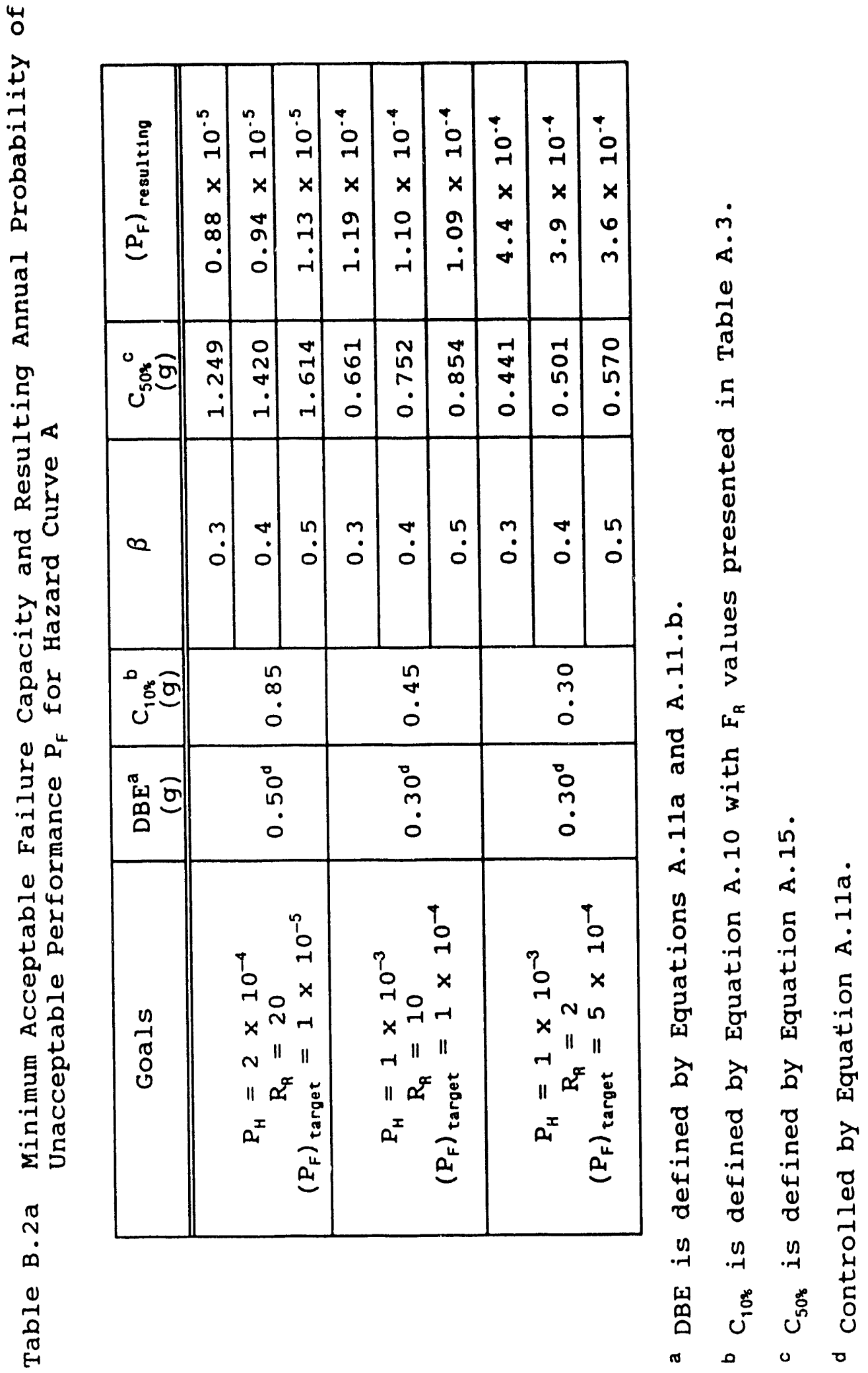




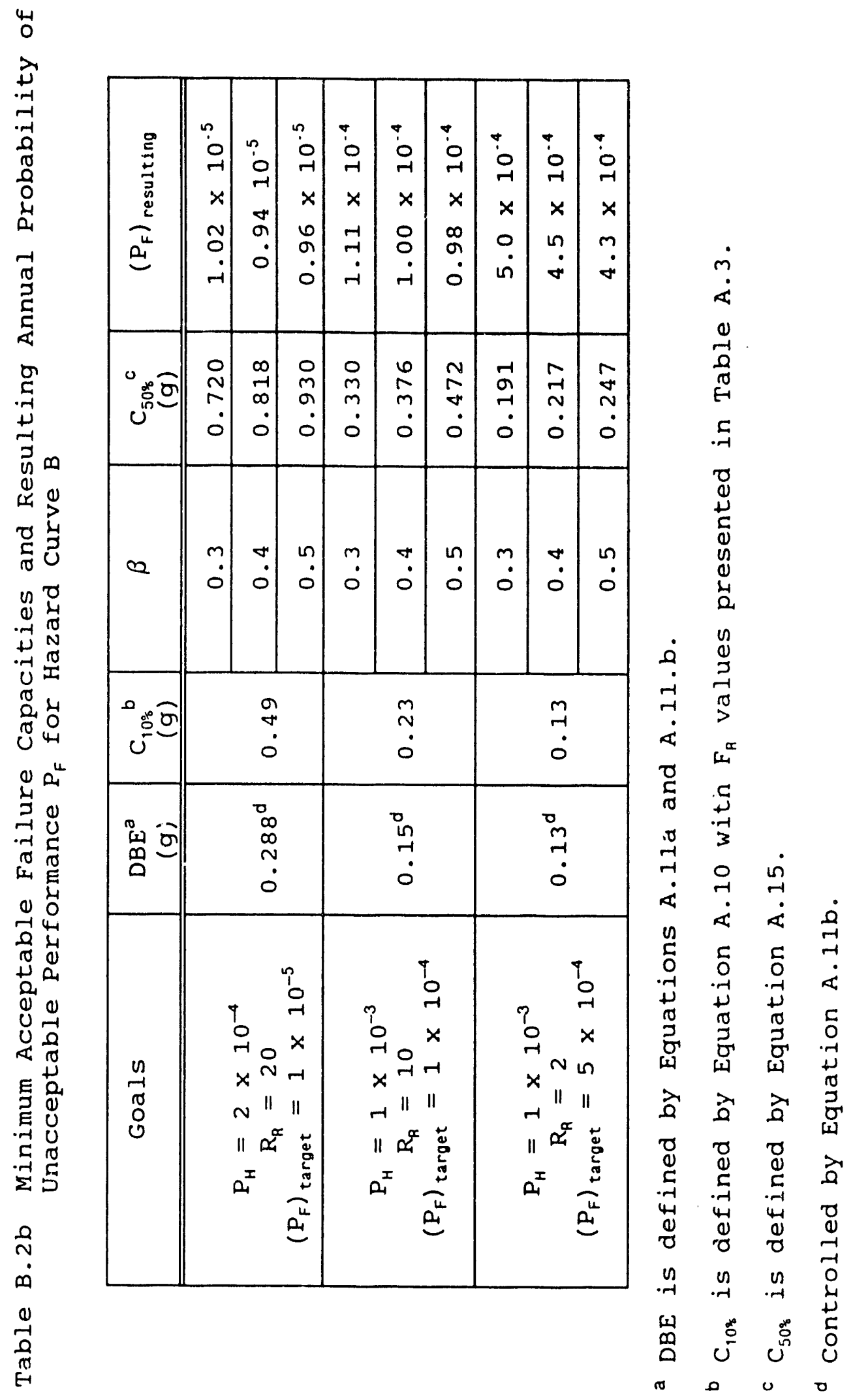


Table B.3 Soidtion of Equation B.1 for Hazard Curve B, $\mathrm{P}_{\mathrm{H}}=1 \times 10^{-3}, \mathrm{R}_{\mathrm{A}}=10, \mathrm{C}_{508}=0.376 \mathrm{~g}, \beta=0.40$

\begin{tabular}{|c|c|c|c|c|c|}
\hline $\begin{array}{l}\text { Acceleration } \\
\text { a } \\
(\mathrm{g})\end{array}$ & $\begin{array}{c}\text { Exceedance } \\
\text { Probability } \\
\mathrm{H}(\mathrm{a}) \\
\left(10^{-5}\right)\end{array}$ & $\begin{array}{c}\text { Acceleration } \\
\text { at Centroid } \\
a_{c} \\
(\mathrm{~g})\end{array}$ & $\begin{array}{c}(1) \\
\text { Conditional } \\
\text { Failure } \\
\text { Probability } \\
P_{F / a_{c}}\end{array}$ & $\begin{array}{c}(2) \\
\text { Probability } \\
\text { Hazard } \\
\text { Within Range } \\
{\left[\mathrm{H}(\mathrm{a})-\mathrm{H}\left(\mathrm{a}_{\mathrm{i}+1}\right)\right]} \\
\left(10^{-5}\right)\end{array}$ & $\begin{array}{c}(1) x \\
(2) \\
\left(10^{-5}\right)\end{array}$ \\
\hline \multirow[t]{2}{*}{0.07} & 500 & & & & \\
\hline & & 0.0828 & 0.0000775 & 300 & 0.02 \\
\hline \multirow[t]{2}{*}{0.10} & 200 & & & & \\
\hline & & 0.113 & 0.00133 & 100 & 0.13 \\
\hline \multirow[t]{2}{*}{0.13} & 100 & & & & \\
\hline & & 0.148 & 0.00988 & 50 & 0.49 \\
\hline \multirow[t]{2}{*}{0.17} & 50 & & & & \\
\hline & & 0.200 & 0.0573 & 30 & 1.72 \\
\hline \multirow[t]{2}{*}{0.24} & 20 & & & & \\
\hline & & 0.266 & 0.193 & 10 & 1.93 \\
\hline \multirow[t]{2}{*}{0.30} & 10 & & & & \\
\hline & & 0.355 & 0.386 & 5 & 1.93 \\
\hline \multirow[t]{2}{*}{0.38} & 5 & & & & \\
\hline & & 0.435 & 0.642 & 3 & 1.93 \\
\hline \multirow[t]{2}{*}{0.51} & 2 & & & & \\
\hline & & 0.568 & 0.849 & 1 & 0.85 \\
\hline \multirow[t]{2}{*}{0.64} & 1 & & & & \\
\hline & & 0.700 & 0.940 & 0.5 & 0.47 \\
\hline \multirow[t]{2}{*}{0.78} & 0.5 & & & & \\
\hline & & 0.858 & 0.980 & 0.3 & 0.29 \\
\hline \multirow[t]{2}{*}{0.97} & 0.2 & & & & \\
\hline & & 1.036 & 0.994 & 0.1 & 0.10 \\
\hline \multirow[t]{2}{*}{1.12} & 0.1 & & & & \\
\hline & & & & 0.1 & 0.10 \\
\hline
\end{tabular}

$P_{F}=\Sigma(1) \times(2)=9.96 \times 10^{-5}$ 


\section{APPENDIX C}

\section{DEMONSTRATION THAT SEISMIC CRITERIA ACHIEVE \\ DESIRED HAZARD TO RISK FEDUCTION RATIO}

\section{1 INTRODUCTION}

If $F_{S}$ is defined as the median seismic factor of safety, then

$$
F_{S}=\frac{C_{508}-D_{n s_{508}}}{D_{s e_{508}}} F_{\mu_{500}}
$$

where $C_{50 \%}, D_{n s} 50 \%, D_{s e} 50 \%$, and $F_{\mu}$ 50\% are rnedian estimates of the capacity, non-seismic demand, seismic demand, and inelastic energy absorption factor, respectively. In turn,

$$
\begin{aligned}
C_{508} & =F_{C} C_{C} \\
D_{n s_{508}} & =F_{n s} D_{n s} \\
D_{s e_{508}} & =D_{s e} / F_{x} \\
F_{\mu_{508}} & =F_{i} F_{\mu D}
\end{aligned}
$$

where $C_{c}, D_{n s}, D_{s e}$ and $F_{\mu D}$ are the capacity, non-seismic demand, seismic demand, and inelastic energy absorption factor, respectively, computed in accordance with the guidance of Chapter $3 ;$ and $F_{C}, F_{n s}, F_{r}$, and $F_{1}$ are the estimated median factors of conservatism associated with the guidance of chapter 3 for each of these terms. Combining Equations C.1 and C.2 and rearranging:

$$
F_{S}=\frac{F_{r} F_{i}\left[F_{C}-F_{n s}\left(\frac{D_{n s}}{C_{C}}\right)\right]}{\left[1-\left(\frac{D_{n s}}{C_{C}}\right)\right]}
$$

The variability of this factor of safety may be defined in terms of its logarithmic standard deviation $\beta_{f s}$ and given by: 


$$
\beta_{f s}=\left(\beta_{x}^{2}+\beta_{i}^{2}+\beta_{c s}^{2}\right)^{1 / 2}
$$

where $\beta_{r}, \beta_{1}$, and $\beta_{c s}$ are the logarithmic standard deviations for the response, inelastic energy absorption, and seismic capacity, respectively. In turn, $\beta_{\mathrm{cs}}$ may be approximated by:

$$
\beta_{c s}=\frac{\left\{\left(F_{C} \beta_{C}\right)^{2}+\left[F_{n s} \beta_{n s}\left(D_{n s} / C_{C}\right]^{2}\right\}^{1 / 2}\right.}{F_{C}-F_{n s}\left(D_{n s} / C_{C}\right)}
$$

where $\beta_{\mathrm{c}}$ and $\beta_{\mathrm{ns}}$ are the logarithmic standard deviations for the capacity and non-seismic demand, respectively.

Based on Equations A.15 and A.20 of Appendix A, the median factor of safety $F_{S_{R q d}}$ required to achieve the desired risk reduction ratio is given by:

$$
F_{S_{R q d}}=1.5 L_{S} e^{1.282 \beta_{f s}}
$$

The ratio of $\mathrm{F}_{\mathrm{S}}$ to $F_{S_{R q d}}$ defines the adequacy of the deterministic seismic criteria presented in Chapter 3 :

$$
R_{f s}=\frac{F_{S}}{F_{S_{\text {Rqd }}}}
$$

The value of $R_{f s}$ should be close to unity. If it is substantially less than unity, the criteria are nonconservative. If it substantially exceeds unity, the criteria are more conservative than necessary.

In order to evaluate $R_{f s}$, factors of conservatism and variabilities must be estimated for the seismic demand (response), non-seismic demand, capacity and inelastic energy absorption factor (ductility). Such estimates are made in the following subsections. 


\section{2 SEISMIC DEMAND (RESPONSE)}

As stated in section 3.4, the seismic demand computed by an elastic analysis should be obtained in accordance with the requirements of ASCE 4-86 (Reference C.5), except that mean input spectral amplifications are to be used instead of meanplus-one-standard-deviation amplifcation factors. Based upon Reference C.8, the ratio of mean-plus-one-standard-deviation to mean spectral acceleration amplification factor averages about 1.22 over the $7 \%$ to $12 \%$ damping range applicable for most structures. In addition, as noted in its foreword, ASCE 4-86 is aimed at achieving about a $10 \%$ probability of the actual seismic response exceeding the computed response, given the occurrence of the DBE. Thus, the median factor of safety for the response, $F_{r}$, can be estimated from:

$$
F_{x}=\frac{e^{1.28 \beta_{x}}}{1.22}
$$

Past seismic probabilistic risk assessments (e.g., Reference C.7), indicate a logarithmic standard deviation for the response variation, $\beta_{r}$, of about 0.30 for structures and about 0.35 for equipment mounted on structures. Thus:

\begin{tabular}{|c|c|c|}
\hline & Structure & Equipment \\
\hline \hline$F_{r}$ & 1.20 & 1.28 \\
\hline$\beta_{r}$ & 0.30 & 0.35 \\
\hline
\end{tabular}

\section{3 NON-SEISMIC DEMAND}

The load combination criteria of section 3.8 state that the best-estimate non-seismic demand $D_{n s}$ should be combined with the seismic demand. Since $D_{n s}$ is a best estimate, $F_{n s}=1.0$, i.e., there is no conservatism introduced. The variability of nonseismic demand is expected to be reasonably low, i.e., $\beta_{n s}$ is 
expected to be less than about 0.20. Thus, for this demonstration:

$$
\begin{aligned}
& F_{n s}=1.0 \\
& \beta_{n s}=0.20
\end{aligned}
$$

However, because of a high degree of uncertainty on $\beta_{\text {ns }}$, results will also be presented for $\beta_{n s}=0.40$ to show the lack of sensitivity of the values of $\beta_{n s}$.

\section{4 INELASTIC ENERGY ABSORPTION FACTOR}

The inelastic-factored seismic demand $D_{s 1}$ is defined by Equation 3.4 where the seismic load factor $L_{s}$ is given by Equation $3.4 \mathrm{a}$, and the inelastic energy absorption factor $F_{\mu D}$ is given by Equation 3.8. The resulting median inelastic factor of conservatism is:

$$
F_{i}=L_{s}\left(\frac{F_{\mu 508}}{F_{\mu 58}}\right)
$$

or:

$$
F_{i}=L_{S}\left(e^{1.65 \beta_{i}}\right)
$$

The logarithmic standard deviation of $F_{1}, \beta_{1}$, will increase with increasing $F_{\mu 5 \%}$. For a low-ductility failure mode where $F_{\mu 5 \%}$ is conservatively specified to be 1.0 , in order to be consistent, $\beta_{1}$ must be set to zero since $F_{\mu}$ cannot drop below 1.0. However, for a ductile failure mode ior which $F_{\mu 5 \%}=1.75, \beta_{1}$ is estimated to be about 0.20 . This estimate corresponds to $F_{\mu 50 \%}=2.4$ and $F_{\mu 18}=1.5$ which are reasonable for $F_{\mu 5 \%}=1.75$. For this demonstration, both ductile and low-ductility failure modes will be investigated with the following $F_{1}$ and $\beta_{1}$ factors: 


\begin{tabular}{|c|c|c|}
\hline & Low-Ductibility Case & Ductile Case \\
\hline \hline$F_{u 54}$ & 1.0 & 1.75 \\
\hline$\beta_{1}$ & 0 & 0.20 \\
\hline$F_{1}$ & $\mathrm{~L}_{s}$ & $1.4 \mathrm{~L}_{\mathrm{S}}$ \\
\hline
\end{tabular}

\section{5 CAPACITY}

Past seismic probabilistic risk assessment studies indicate that the logarithmic standard deviation, $\beta_{c}$, for the capacity factor is typically about 0.20 . The conservatism in the capacity factors based on the minimum strengths specified in the design codes is substantial and increases with increasing $\beta_{c}$. Also, in order to avoid low-ductility failure modes, the median factor of safety $F_{c}$ for such modes should be much greater than for ductile failure modes.

\section{5.1 Low-Ductility Failure Modes}

The capacities based on minimum strengths specified in the codes, $\mathrm{C}_{\mathrm{c}}$, are very conservative for low-ductility failure modes. This point will be illustrated by considering longitudinal shear failure of a fillet weld connection. The transverse shear capacity of a fillet weld exceeds the longitudinal shear. capacity, yet the code capacity is the same in both directions. Therefore, in this example, the longitudinal shear failure mode produces a lower factor of safety for the capacity than the transverse shear failure mode.

Based upon extensive testing of fillet welds under longitudinal shear reported in References $\mathrm{C} .1$ and C.4, the median shear strength, $\hat{\tau}_{w}$, of the fillet weld can be defined in terms of the median ultimate strength, $\hat{\sigma}_{u}$, of the electrode by:

$$
\hat{r}_{w}=0.84 \hat{\sigma}_{U}
$$

with a logarithmic standard deviation for equation error, $\beta_{\text {eqn }}$, C -5 
of 0.11. The median ultimate strength is defined in terms of the minimum value of the nominal tensile strength specified in the code, $F_{E X X}$, by:

$$
\hat{\sigma}_{U}=1.1 F_{E X X}
$$

with a logarithmic standard deviation for material, $\beta_{\text {mat }}$, of 0.05 . In addition, a logarithmic standard deviation of 0.15 due to fabrication tolerances, $\beta_{\mathrm{fab}}$, should be considered for normal welding practice. The shear capacity $\tau_{c}$ specified in AISC-LRFD (Reference C.2) for the limit state strength approach for design is:

$$
\tau_{C}=0.75(0.6) F_{E X X}
$$

Thus the median capacity factor of safety $F_{c}$ is:

$$
F_{C}=\frac{\hat{\tau}_{W}}{\tau_{C}}=\frac{1.1(0.84)}{0.75(0.6)}=2.05
$$

and the logarithmic standard deviation, $\beta_{c}$, for $F_{c}$ is estimated to be:

$$
\begin{aligned}
\beta_{c} & =\left(\beta_{\text {eqn }}^{2}+\beta_{\text {mat }}^{2}+\beta_{\text {fab }}^{2}\right)^{1 / 2} \\
& =\left[(0.11)^{2}+(0.05)^{2}+(0.15)^{2}\right]^{1 / 2}=0.19
\end{aligned}
$$

An investigation of several other low-ductility failure modes indicates similar results. Therefore, for low-ductility failure modes, the following $F_{c}$ and $\beta_{c}$ are judged to be reasonable and will be used in this demonstration:

$$
\begin{aligned}
& F_{c}=2.0 \\
& \beta_{c}=0.20
\end{aligned}
$$

\section{5.2 Ductile Failure Modes}

An investigation of several ductile failure modes indicates that when the conservatism of material strengths (Section 3.6), code capacity equations (Section 3.7), and seismic strain-rate

$$
c-6
$$


effects are considered, the code capacities have at least a $98 \%$ probability of exceedance. Thus:

$$
F_{C}=e^{2.054 \beta_{c}}
$$

Assuming a typical $\beta_{c}$ of $0.20, F_{c}$ is about 1.50. Therefore, the following are judged reasonable and will be used in this demonstration for the ductile failure modes:

$$
\begin{aligned}
& F_{c}=1.5 \\
& \beta_{c}=0.20
\end{aligned}
$$

\section{6 COMPARISON OF FACTOR OF SAFETY OF SEISMIC CRITERIA WITH REQUIRED FACTOR OF SAFETY}

The individual median factors of conservatism $F_{r}, F_{n s}, F_{C}$ and $F_{1}$ and corresponding logarithmic standard deviations estimated in Sections C.2 through C.5 are summarized in Table C.1. Using these estimates, the median seismic factor of safety $F_{S}$ (from Equation C. 3 ) and the required factor of safety $F_{\text {sRqd }}$ (from Equation C.6) are shown in Tables C.2 and C.3 for the lowductility and ductile failure cases, respectively, for $\left(D_{n s} / C_{c}\right)$ from 0 to 0.6 . In order to satisfy non-seismic load combinations and acceptance criteria, the expected non-seismic demand $D_{n s}$ should not exceed $60 \%$ of the code strength capacity $C_{c}$. Therefore, Tables C. 2 and C. 3 cover the full expected range of $\left(D_{n s} / C_{c}\right)$. Both the required factor of safety, $F_{\text {SRqd, }}$ and $F_{1}$ used in Equation C.3 to define the achieved factor of safety, $F_{S}$, are proportional to the seismic load factor $L_{s}$. Therefore, $L_{s}$ does not influence the comparison. Tables $C .2$ and $C .3$ are for $L_{S}=$ 1.0 , but the resulting ratio $\left(R_{f s}\right)$ of $F_{S}$ to $F_{\text {sfqd }}$ is also applicable for other seismic load factors.

For the ductile failure mode (Table C.3), the achieved factor of safety and required factor of safety are in close agreement over the entire range of $\left(D_{n s} / C_{c}\right)$. Similar close agreements exist for the low-ductility failure mode (Table C.2) up to $\left(D_{n s} / C_{c}\right)=0.4$.

$$
C-7
$$


For values of $\left(D_{n s} / C_{c}\right)$ beyond 0.4 and low-ductility failure modes, the seismic criteria of Chapter 3 become more conservative than desired. However, the conservatism cannot be removed without becoming nonconservative in other cases if simple deterministic seismic criteria are to be maintained.

In order to study the sensitivity of these conclusions to the assumed value of $\beta_{n s}=0.20$ shown in Table c.1, the low ductility and ductile failure mode cases shown in Tables $C .2$ and $c .3$, respectively, are repeated for $\beta_{n s}=0.40$ with all other parameters held at the values shown in Table C.1. The achieved safety factors $F_{S}$ shown in Tables C. 2 and $C .3$ are not influenced by $\beta_{n s}$ i.e., they remain unchanged. At $\left(D_{n s} / C_{c}\right)=0$, the required factors of safety, $F_{\text {SRqd, }}$ are also not influenced by $\beta_{\text {ns }}$ so that they also remain unchanged. The largest change occurs for $F_{\text {shad }}$ at $\left(D_{n s} / C_{c}\right)=0.6$. At this value, for the low ductility failure mode, $F_{\text {SRqd }}$ is increased to 2.67 for $\beta_{n s}=0.4$ versus 2.58 shown in Table C.2 for $\beta_{n s}=0.2$. Similarly, for the ductile failure mode, $F_{\text {SRqd }}$ is increased to 3.07 versus 2.88 shown in Table C. 3 . In both cases, $F_{\text {SRqd }}$ remains below the achieved factor of safety, $F_{s}$, and the conclusions of the previous paragraph remain unaltered. In fact, the agreement between $F_{S}$ and $F_{\text {spqd }}$ is improved over the entire range of $\left(D_{n s} / C_{c}\right)$ values. Therefore, even when the non-seismic demand is highly uncertain, only the best-estiamte (no intentional conservatism) non-seismic demand should be combined with the seismic demand.

\section{C.7 MINIMUM REQUIRED RATIO OF TRS TO RRS FOR EQUIPMENT QUALIFIED BY TEST}

For equipment qualified by test, the minimum ratio of the TRS to the RRS needed to achieve the seismic margin specified by Equations 3.9 and 3.10 is defined by: 


$$
(T R S / R R S)=\frac{1.5 L_{S} e^{1.282 \rho_{s s}}}{F_{Y} F_{C}}
$$

where $\beta_{p s}$ is defined by Equation $C .4$ and $F_{r}$ and $F_{c}$ are defined in Equation C.2. Estimates of the median response factor of safety $F_{r}$ and variability for equipment are presented in Equation C.9.

An estimate of the median capacity factor of safety $F_{c}$ is impossible to make for equipment qualified by proof testing. All that can be estimated from such a test is a lower bound on $F_{c}$, and even this estimate is difficult. standard test procedures use broader frequency content and longer duration input than is likely from an actual earthquake; and to pass the test, the equipment must function during and after such input. Therefore, $F_{c}$ must substantially exceed unity. However, such tests do not typically address the possible sample-to-sample variability in the seismic capacity of the tested equipment, because it is typical to test only one sample of a component (except three samples for relays). Based upon Appendices $J$ and $Q$ of Reference C.9, it is judged that such qualification testing provides somewhere between $90 \%$ and $98 \%$ confidence of acceptable equipment performance at the TRS level, or failure probabilities for equipment that passed such a test between $2 \%$ and $10 \%$. Thus:

$$
F_{c} \geq e^{x_{p} \beta_{c}}
$$

where $x_{p}$ is the standard normal distribution factor associated with an assumed failure probability. Based upon a review of fragility results presented by Bandyopadhyay et al. (Reference c.6), $\beta_{c}$ is estimated to be about 0.20 for equipment qualified by testing.

Therefore, for equipment qualified by testing:

$$
\beta_{f s}=\left(\beta_{r}^{2}+\beta_{c}^{2}\right)^{1 / 2}=\left((0.35)^{2}+(0.20)^{2}\right)^{1 / 2}=0.40
$$


Thus, from Equation C.21:

\begin{tabular}{|c|c|c|c|}
\hline $\begin{array}{c}\text { Assumed } \\
\text { Failure } \\
\text { Probability } P\end{array}$ & $X_{p}$ & $\begin{array}{c}\text { Lower Bound } \\
F_{c}\end{array}$ & (TRS/RRS) / $L_{s}$ \\
\hline \hline $2 \%$ & 2.054 & 1.5 & 1.3 \\
$5 \%$ & 1.645 & 1.4 & 1.4 \\
$10 \%$ & 1.282 & 1.3 & 1.5 \\
\hline
\end{tabular}

Using the midpoint value within this range:

$$
(T R S / R R S)=1.4 L_{S}
$$

and :

\begin{tabular}{|c|c|c|}
\hline$R_{\mathrm{R}}$ & $\mathrm{L}_{\mathrm{S}}$ & $(\text { TRS / RRS })_{\mathrm{R}}$ \\
\hline \hline 20 & 1.15 & 1.6 \\
10 & 1.00 & 1.4 \\
5 & 0.87 & 1.2 \\
\hline
\end{tabular}




\section{REFERENCES}

C.1 Fisher, J.W., et al., "Load and Resistance Factor Design criteria for Connections" Vol. 104, ST9, Journal of structural Division, ASCE, pp. 1427-1441, September 1978.

C. 2 "Load and Resistance Factor Design", American Institute of steel Construction, 1st Edition, 1986.

C.3 "Specification for Design, Fabrication and Erection of structural steel for Buildings, Allowable Stress Design and Plastic Design", American Institute of steel Construction, 9th Edition, 1989.

C.4 "Static Tensile Strength of Fillet Welded Lap Joints in steel". International Institute of Weld, IIW Document XV242-68 of International Test Series, 1968.

C.5 ASCE Standard 4-86. "Seismic Analysis of Safety-Related Nuclear structures and Commentary". American Society of Civil Engineers, 1986.

C. 6 Bandyopadhyay, K.K., et al., "Seismic Fragility of Nuclear Power Plant Components", Vols. 1-4, NUREG/CR-4659, Nuclear Regulatory Commission, 1986-1991.

C.7. "Seismic Fragilities of Civil structures and Equipment Components at the Diablo Canyon Power Plant", QA Report Number 34001.01-R014, Pacific Gas \& Electric Co., San Francisco, September 1988 .

C. 8 Newmark, N.M., and W.J. Hall, Development of Criteria for Review of Selected Nuclear Power Plants, NUREG/CR-0098, U.S. Nuclear Regulatory Commission, 1978.

C.9 "A Methodology for Assessment of Nuclear Power Plant Seismic Margin," EPRI NP-6041-1-SL, Revision 1, Electric Power Research Institute, August 1991.

$$
c-11
$$


NOTATION

$\mathrm{C}_{\mathrm{c}} \quad$ capacity based on code formula or stresses

$C_{p} \quad$ seismic capacity estimated at a failure probability of p

$D_{n s} \quad$ non-seismic demand

$D_{n s} 50$ median estimate of the non-seismic demand

$D_{\text {se }} \quad$ seismic demand based on elastic analysis

$D_{\text {se } 50 r}$ median estimate of seismic demand $D_{8 e}$

$\mathrm{F}_{\mathrm{c}} \quad$ median capacity factor of conservatism associated with $\mathrm{C}_{\mathrm{c}}$

$F_{\text {Exx }} \quad$ minimum code nominal tensile strength of electrode

$F_{1}$ median inelastic factor of conservatism associated with $F_{\mu D}$

$F_{n s} \quad$ median non-seismic demand factor of conservatism associated with $D_{n s}$

F $\quad$ median response factor of conservatism associated with $D_{\text {se }}$

$F_{s} \quad$ median seismic factor of safety

$F_{S \text { Aqd }}$ required median factor of safety

$F_{\mu \text { 50 }}$ median estimate of inelastic energy absorption factor

$F_{\mu D} \quad$ inelastic energy absorption factor

$F_{\mu p} \quad$ inelastic energy absorption factor specified at a failure probability level of $p$

$R_{f s} \quad F_{S} / F_{S}$ Rqd

$S_{F} \quad$ scale factor

$x_{p} \quad$ normal distribution factor at failure probability $p$

$\beta_{\mathrm{c}} \quad$ logarithmic standard deviation for capacity

$\beta_{c s} \quad$ logarithmic standard deviation for seismic capacity

$\beta_{\text {eqn }} \quad$ logarithmic standard deviation for equation 


$\begin{array}{ll}\beta_{\mathrm{fab}} & \begin{array}{l}\text { logarithmic standard deviation for fabrication } \\ \beta_{\mathrm{fs}}\end{array} \\ \beta_{1} & \begin{array}{l}\text { logarithmic standard deviation for factor of safety } \\ \text { absorption factor }\end{array} \\ \beta_{m a t} & \text { logarithmic standard deviation for welding material } \\ \beta_{n s} & \text { logarithmic standard deviation for non-seismic demand } \\ \beta_{r} & \text { logarithmic standard deviation for response } \\ \partial_{u} & \text { median ultimate strength of electrode } \\ \tau_{c} & \text { code shear capacity of weld } \\ \hat{\tau}_{w} & \text { median shear strength of fillet weld }\end{array}$


Table C.1 Estimated Factors of Conservatism and Variability

\begin{tabular}{|c|c|c|}
\hline $\begin{array}{c}\text { Factor of Safety and } \\
\text { Logarithmic Standard } \\
\text { Deviation }\end{array}$ & $\begin{array}{c}\text { Low } \\
\text { Ductility Mode } \\
F_{u 55}=1.0\end{array}$ & $\begin{array}{c}\text { Ductile Mode } \\
F_{u 5 \%}=1.75\end{array}$ \\
\hline $\begin{array}{c}\text { Seismic Demand } \\
\text { (Response) } \\
F_{r} \\
\beta_{r}\end{array}$ & 1.2 & 1.2 \\
\hline $\begin{array}{c}\text { Non-Seismic } \\
\text { Demand } \\
F_{n s} \\
\beta_{n s}\end{array}$ & 0.3 & 0.3 \\
\hline $\begin{array}{c}\text { Capacity } \\
F_{c}\end{array}$ & 1.0 & 1.0 \\
$\beta_{c}$ & 0.2 & 0.2 \\
\hline $\begin{array}{c}\text { Inelastir Energy } \\
\text { Absorption } \\
F_{i}\end{array}$ & 2.0 & 1.5 \\
$\beta_{1}$ & 0.2 & 0.2 \\
\hline
\end{tabular}


Table C.2 Comparison of Achieved Safety Factor with Required Safety Factor for Low-Ductility Failure Mode $\left(\mathrm{F}_{\mu 5 \%}=1.0 ; \mathrm{L}_{\mathrm{S}}=1.0\right)$

\begin{tabular}{|c|c|c|c|c|c|}
\hline$D_{\mathrm{ns}} / \mathrm{C}_{\mathrm{c}}$ & $\beta_{\mathrm{cS}}$ & $\beta_{\mathrm{fs}}$ & $\begin{array}{c}\text { Required } \\
\text { Safety Factor } \\
\mathrm{F}_{\mathrm{SBad}}\end{array}$ & $\begin{array}{c}\text { Achieved } \\
\text { Safety Factor } \\
\mathrm{F}_{\mathrm{S}}\end{array}$ & $\begin{array}{c}\mathrm{R}_{\mathrm{fs}}= \\
\mathrm{F}_{\mathrm{S}} / \mathrm{F}_{\mathrm{SRqd}}\end{array}$ \\
\hline \hline 0 & 0.20 & 0.36 & 2.38 & 2.40 & 1.01 \\
\hline 0.1 & 0.21 & 0.37 & 2.40 & 2.53 & 1.05 \\
\hline 0.2 & 0.22 & 0.37 & 2.42 & 2.70 & 1.12 \\
\hline 0.3 & 0.24 & 0.38 & 2.45 & 2.91 & 1.19 \\
\hline 0.4 & 0.25 & 0.39 & 2.48 & 3.20 & 1.29 \\
\hline 0.5 & 0.27 & 0.41 & 2.53 & 3.60 & 1.42 \\
\hline 0.6 & 0.30 & 0.42 & 2.58 & 4.20 & 1.63 \\
\hline
\end{tabular}


Table C.3 Comparison of Achieved Safety Factor with Required
Safety Factor for Ductile Failure Mode $\left(F_{\mu 5 \%}=1.75\right.$; $\left.L_{s}=1.0\right)$

\begin{tabular}{|c|c|c|c|c|c|}
\hline$D_{n s} / C_{c}$ & $\beta_{C S}$ & $\beta_{f s}$ & $\begin{array}{c}\text { Required } \\
\text { Safety Factor } \\
F_{\text {SBad }}\end{array}$ & $\begin{array}{c}\text { Achieved } \\
\text { Safety Factor } \\
F_{S}\end{array}$ & $\begin{array}{c}R_{f s}= \\
F_{s} / F_{\text {SRqd }}\end{array}$ \\
\hline \hline 0 & 0.20 & 0.41 & 2.54 & 2.52 & 0.99 \\
\hline 0.1 & 0.21 & 0.42 & 2.57 & 2.61. & 1.02 \\
\hline 0.2 & 0.23 & 0.43 & 2.60 & 2.73 & 1.05 \\
\hline 0.3 & 0.25 & 0.44 & 2.64 & 2.88 & 1.09 \\
\hline 0.4 & 0.28 & 0.46 & 2.70 & 3.08 & 1.14 \\
\hline 0.5 & 0.32 & 0.48 & 2.77 & 3.36 & 1.21 \\
\hline 0.6 & 0.36 & 0.51 & 2.88 & 3.78 & 1.31 \\
\hline
\end{tabular}




\section{APPENDIX D \\ GUIDANCE ON ESTIMATING THE INELASTIC \\ ENERGY ABSORPTION FACTOR $\mathrm{F}_{\mu}$}

\section{1 INTRODUCTION}

It is recognized that the inherent seismic resistance of a welldesigned and constructed structure is usually much greater than that expected based on an elastic analysis. This occurs largely because the nonlinear behavior is mobilized to limit the imposed forces.

Two general methods currently exist for treating the nonlinear behavior of a structure. One approach is to perform a time history nonlinear analysis and compare the maximum element demand ductility to a conservative estimate of its ductility capacity. An alternate means of accounting for the inelastic energy dissipation of civil structures and equipment at response levels above yield is the use of an inelastic energy absorption factor $F_{\mu}$, based on a ductility modified inelastic response spectrum approach (References D.1 through D.4).

In general, the analyst would first make an estimate of a permissible inelastic distortion corresponding to about a $5 \%$ failure probability level. For example, for a low-rise concrete shear wall or concentric braced frame structure, a permissible total story distortion of $0.4 \%$ of the story height for in-plane drift would provide an adequately low probability of severe structural distress, and thus would result in an adequately conservative distortion criterion for overall structural failure (Reference D.5). However, such a distortion would result in severe cracking of a low rise concrete shear wall structure such that if there were safety related equipment mounted off the wall, the anchorage on this equipment might fail. To protect such anchorage, permissible total story distortions would more 
appropriately be limited to the range of $0.2 \%$ to $0.25 \%$ of the story height for low rise concrete shear walls. Once a permissible distortion has been selected, the inelastic energy absorption factor $F_{\mu}$ may be determined from nonlinear analysis of an appropriate model of the structure using multiple realistic input time histories. First, the input time history is scaled to a level at which the elastic-computed demand is equal. to the yield (or ultimate) capacity. Then, the input is further scaled until the distortion resulting from a time history nonlinear analysis reaches a permissible value. The inelastic energy absorption factor $F_{\mu}$ is equal to this additional scaling factor.

Alternately, a simplified nonlinear analysis procedure may be used at least for cantilever type structures. First, the analyst must estimate the nonlinear deformed shape of the structure corresponding to the maximum permissible distortion being reached in the story with the highest value of the ratio of the demand to the capacity. Then the system ductility $\mu$ is estimated from:

$$
\mu=\frac{\sum W_{i} \delta_{r_{i}}}{\sum W_{i} \delta_{\theta_{i}}}
$$

where $W_{1}$ is the inertial weight applied at each story of the structure, $\delta_{T i}$ is the total displacement of story "i" (relative to the base) when the total distortion in the critical story reaches a permissible level, and $\delta_{\mathrm{e} 1}$ is the elastic displacement of story "i" (relative to the base) corresponding to a unit value of the ratio of the elastic demand to the capacity for the critical story. For a single story, Equation D.1 simplifies down to a story ductility, $\mu_{s}$, of: 


$$
\mu_{s}=\frac{\delta_{T}}{\delta_{y}}
$$

where $\delta_{T}$ is the total permissible story displacement and $\delta_{y}$ is the yield displacement (demand/capacity equals unity). However, for multi-story structures, $\mu$ from Equation D.1 is always less than $\mu_{s}$ from Equation D.2 except when the nonlinear distortions are spxead throughout the structure which is very unlikely. The following equation can be used to relate $\mu$ to $\mu_{s}$ :

$$
\mu=1+F_{k}\left(\mu_{s}-1\right)
$$

where $F_{k}$ is a reduction factor to convert a story ductility estimate to a system ductility estimate. For a well designed structure in which the ratio of the demand to the capacity does not differ by more than a factor of about 1.3 over the structure height, $F_{k}$ will typically range from 0.5 to 0.75 . In these cases, Equation D. 3 may be used with a conservatively estimated $F_{k}$ of 0.5 in lieu of Equation D.1 or nonlinear time history analyses.

Once the permissible system ductility $\mu$ has been established, many approaches can be used for estimating $F_{\mu}$. For broad, smooth input spectra and moment-frame structures with essentially full elasto-plastic nonlinear hysteretic loops, either the NewmarkHall (Reference D.6) or Riddell-Newmark (Reference D.3) approach is commonly used. However, for concrete shear wall structures or braced frames which have severely pinched hysteretic loops, Kennedy, et al. (Reference D.4) have shown that these approaches are likely to be slightly nonconservative. For such structures, the approach of Reference D.4 is preferred.

The following provides an example application of this simplified nonlinear analysis procedure for estimating $F_{\mu}$ for a concrete shear wall structure. 
For purposes of this illustration, a three-story structure with the properties shown in Figure D.1 will be used. This figure shows the weights, $w$, at each story, the elastic stiffnesses, $K$, and ultimate capacities, $v_{u}$, for the walls between story levels. This structure has a fundamental frequency $f$ of $8.25 \mathrm{~Hz}$.

Assuming a damping parameter $\zeta$ of $7 \%$, for a reference $1.0 \mathrm{~g}$ NUREG/CR-0098 median spectrum (Reference D.6), at $f$ equal to $8.25 \mathrm{~Hz}$ the elastic spectral acceleration is:

$$
S_{A}(f, \zeta)=1.86 g
$$

and the elastic response of this structure is given in Table D.1. For this reference spectrum response, the ratio of the elastic demand to the capacity ranges from 1.02 for the first story wall to 1.32 for the second story. Thus yielding will initially occur in the first story wall, and the elastic displaced shape at the onset of yielding is given by $\delta_{e}$ in Table D.1. Note in Table D.1 that the minimum value of $v_{u} / V_{r}$ (i.e., 1.02) is used to calculate $\delta_{e}$ since this corresponds to the first element which reaches yield (i.e., level 1).

\section{2 COMPUTATION OF SYSTEM DUCTILITY}

In accordance with the recommendations given above, a permissible total story distortion of $0.4 \%$ of the total story height will be selected for the critical first story. Thus:

$$
\delta_{T_{1}}=0.004(22 \mathrm{ft})(12 \mathrm{inch} / \mathrm{ft})=1.06 \mathrm{inch}
$$

and the story ductility $\mu_{s}$ from Equation D.2 is:

$$
\mu_{s}=\frac{1.06}{0.147}=7.2
$$

From Equation D.3, the system ductility $\mu$ is expected to lie within the range of:

$$
\mu=4.1 \text { to } 5.6
$$

$$
D-4
$$


However, a more accurate estimate of $\mu$ may be obtained from Equation D.1 after estimating the inelastic deformed shape. A slightly conservative estimate of the inelastic deformed shape may be obtained by assuming that all of the nonlinear drift occurs in the story with the lowest ratio of the capability to the demand (the first story for this example). The other stories retain the same differential drifts as given by $\delta_{e}$ in Table D.1. Thus:

$$
\begin{aligned}
& \delta_{T_{1}}=1.06 \text { inch } \\
& \delta_{T_{2}}=1.12 \text { inch } \\
& \delta_{T_{3}}=1.22 \text { inch }
\end{aligned}
$$

and from Equation D.1:

$$
\mu=\frac{6300(1.22)+2100(1.12)+2500(1.06)}{6300(0.309)+2100(0.211)+2500(0.147)}=4.6 \text { (D.8) }
$$

\section{3 COMPUTATION OF INELASTIC ENERGY ABSORPTION FACTOR}

For concrete shear wall structures, it is recommended that the inelastic energy absorption factor $F_{\mu}$ be computed by the effective frequency/effective damping approach of Reference D.4, as summarized herein. For this example, it will be assumed that the force-deflection relationship on initial loading is elasticperfectly-plastic with an ultimate capacity $V_{u}$. Thus, the ratio of secant to elastic frequency is given by:

$$
\left(f_{s} / f\right)=\sqrt{1 / \mu}=\sqrt{1 / 4.6}=0.466
$$

Then, the effective frequency is given by:

$$
\left(f_{\theta} / f\right)=(1-A)+A\left(f_{s} / f\right)
$$

where,

$$
A=C_{f}\left[1-\left(f_{s} / f\right)\right] \leq 0.85
$$

For ground motions with strong durations greater than one second, $C_{f}$ may be approximated as 2.3. Thus, for ( $\left.f_{s} / f\right)$ less than or equal to 0.63 one may take $A$ equal to 0.85 . For this

$$
\mathrm{D}-5
$$


example:

$$
\begin{gathered}
\left(f_{e} / f\right)=0.15+0.85(0.466)=0.546 \\
f_{\theta}=0.546(8.25 \mathrm{~Hz})=4.5 \mathrm{~Hz}
\end{gathered}
$$

The effective damping $\zeta_{e}$ may be estimated from:

$$
\zeta_{\theta}=\left(f_{s} / f_{e}\right)^{2}\left[\zeta+\zeta_{h}\right]
$$

where $\zeta$ is the elastic damping ( $7 \%$ in this case) and $\zeta_{\mathrm{h}}$ is the pinched hysteretic damping which can be approximated by:

$$
\zeta_{h}=118\left[1-\left(f_{s} / f\right)\right]=118(.534)=5.98
$$

for strong durations greater than one second. Thus, for this example:

$$
\zeta_{e}=\left(\frac{.466}{.546}\right)^{2}[12.9 \%]=9.4 \%
$$

For the reference $1.0 \mathrm{~g}$ NUREG/CR-0098 spectrum, at $\mathrm{f}_{\mathrm{e}}=4.5 \mathrm{~Hz}$ and $\zeta_{e}=9.4 \%$, the spectral acceleration is given by:

$$
S_{A}\left(f_{e}, \zeta_{\theta}\right)=1.68 \mathrm{~g}
$$

and the inelastic energy absorption factor is given by:

$$
F_{\mu}=\left[\frac{f_{e}}{f_{s}}\right]^{2} \frac{S_{A}(f, \zeta)}{S_{A}\left(f_{\theta}, \zeta_{\theta}\right)}=\left[\frac{.546}{.466}\right]^{2}\left[\frac{1.86}{1.68}\right]=1.52
$$


REFERENCES

D.1 Villaneuva, A.S., "Ductility Reduction Factors for Earthquake Design," Reprint 3209, ASCE Spring Convention, Pittsburgh, Pennsylvania, 1978.

D.2 Newmark, N.M., "A Response Spectrum Approach for Inelastic Seismic Design of Nuclear Reactor Facilities," Proceedings from 3rd International Conference on structural Mechanics in Reactor Technology, SMiRT, Berlin, September 1975.

D.3 Riddell, R., and Newmark, N.M., "statistical Analysis of the Response of Non-linear systems subjected to Earthquakes", Department of Civil Engineering, Report UILU 79-2016, Urbana, Illinois, August 1979.

D.4 Kennedy, R.P., et al., Engineering Characterization of Ground Motion - Task 1, Effects of Characteristics of FreeField Motion on Structural Response, NUREG/CR-3805, Nuclear Regulatory Commission, May 1984.

D.5 Kennedy, R.P., et al., "Probabilistic Evaluation of the Diablo Canyon Turbine Building, Seismic Capacity Using Nonlinear Time History Analyses", Pacific Gas and Electric Company, December 1988, Report No. 1643.01.

D.6 Newmark, N.M. and Hall, W.J., "Development of Criteria for Seismic Review of selected Nuclear Power Plants", NUREG/CR0098, Nuclear Regulatory Commission, May 1978. 


\section{NOTATION}

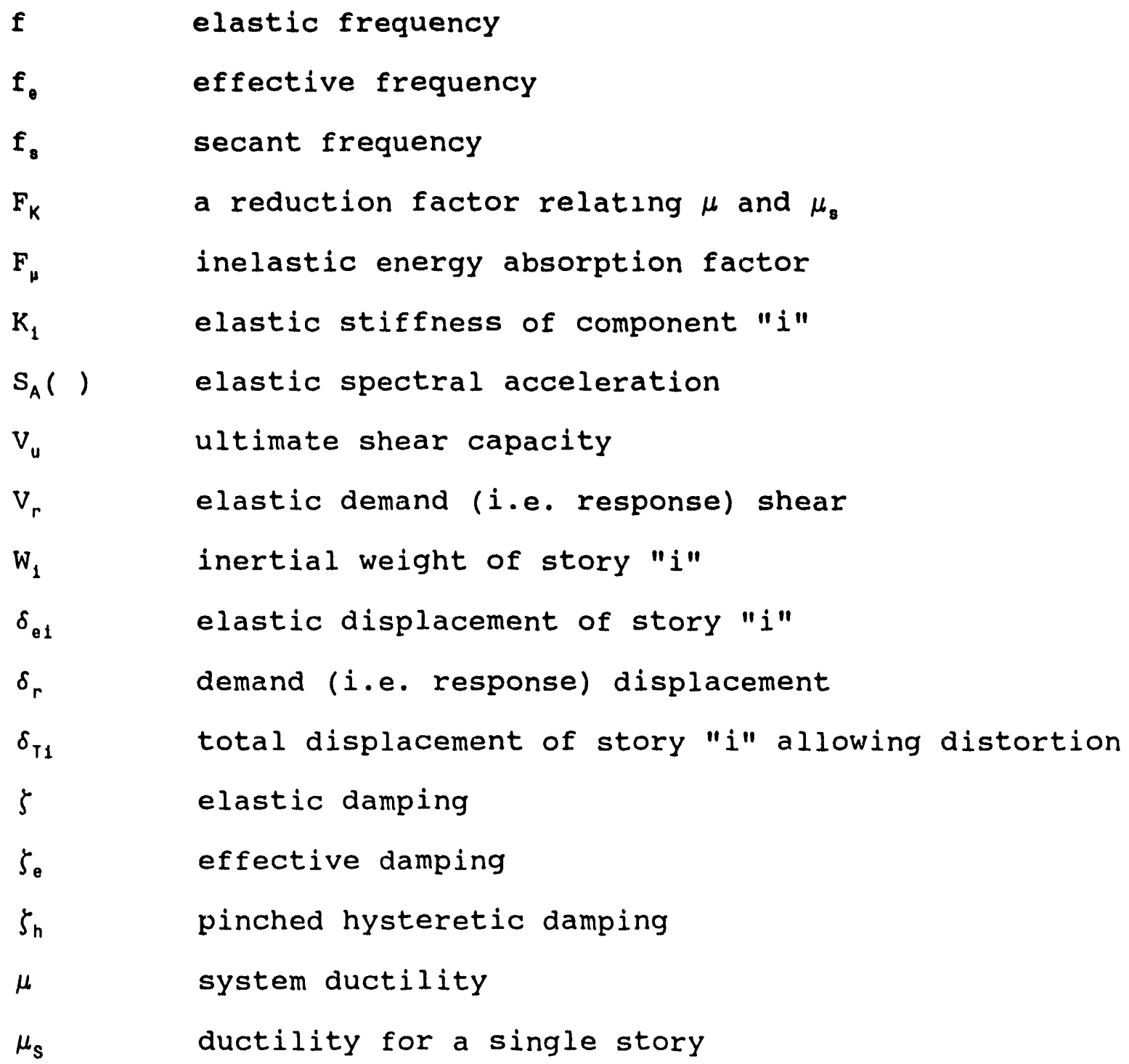


Table D.1 Elastic Response to Reference $1.0 \mathrm{~g}$ NUREG/CR-0098 Spectrum ( $7 \%$ Damping)

\begin{tabular}{|c|c|c|c|c|}
\hline \multirow[b]{2}{*}{ Level } & \multicolumn{2}{|c|}{ Demand } & \multirow{2}{*}{$\begin{array}{c}\text { Capacity/ } \\
\text { Demand } \\
V_{u} / V_{r}\end{array}$} & \multirow{2}{*}{$\begin{array}{c}\text { Yield } \\
\text { Displacement } \\
(\text { inch }) \\
\delta_{e}=\delta_{r}\left(V_{u} / V_{r}\right)\end{array}$} \\
\hline & $\begin{array}{c}\text { Displacement } \\
\delta_{r} \text { (inch) }\end{array}$ & $\begin{array}{c}\text { Shear } \\
V_{r} \text { (kips) }\end{array}$ & & \\
\hline 3 & 0.304 & 13,400 & 1.24 & 0.310 \\
\hline 2 & 0.208 & 16,400 & 1.32 & 0.212 \\
\hline 1 & 0.145 & 18,900 & 1.02 & 0.147 \\
\hline
\end{tabular}




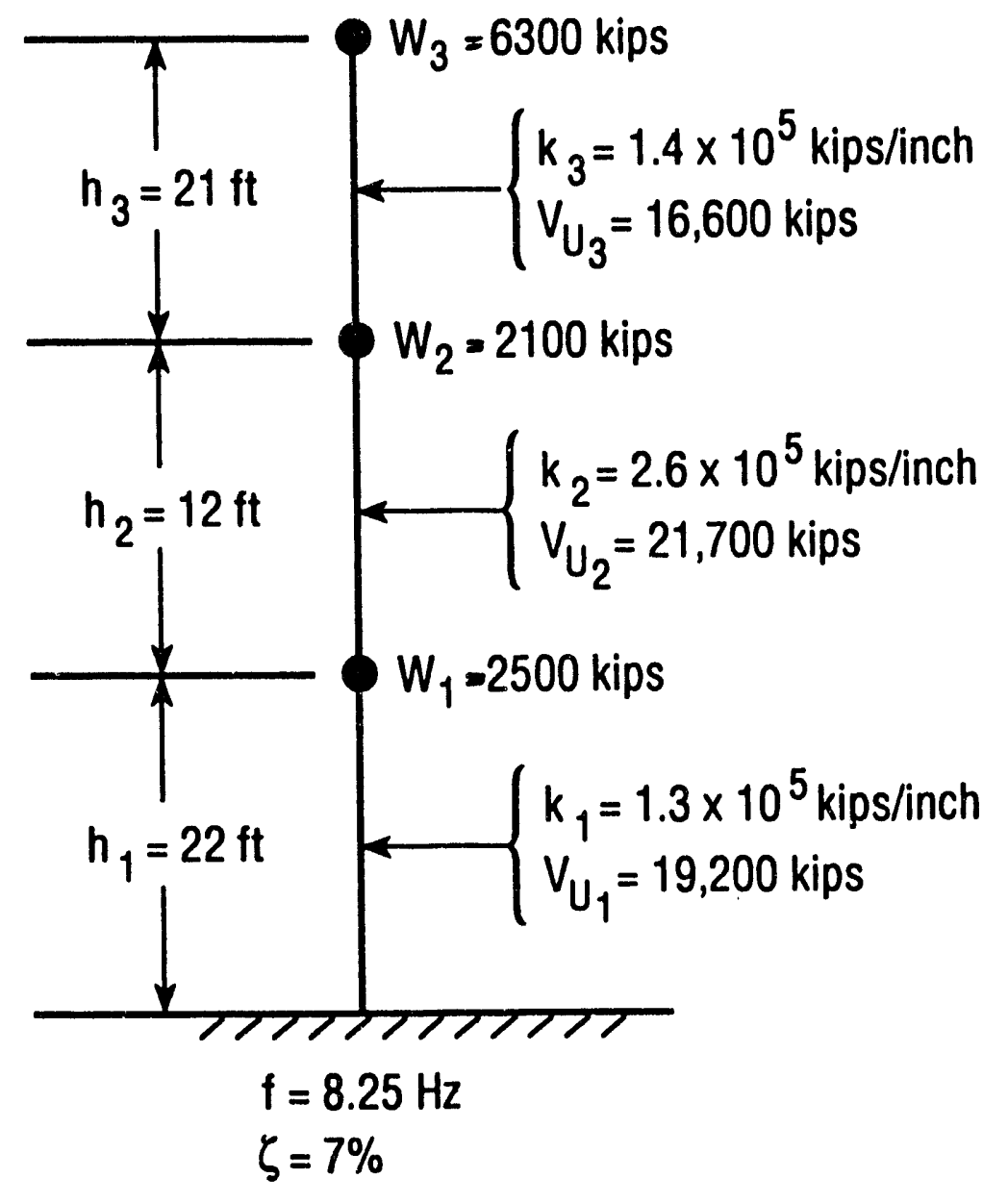

Figure D.1 Three story Shear Wall structure 


\section{APPENDIX E}

\section{MEMBRANE SOLUTIONS FOR TOP-CONSTRAINED TANKS}

The solutions presented herein are for the in-plane membrane forces induced in circular cylindrical tanks subjected to static radial pressures of the form

$$
p(\eta, \theta)=a_{\odot} \rho, R S_{A} \cos \theta
$$

and

$$
p(\eta, \theta)=a_{n}\left[\cos \frac{n \pi}{2} \eta\right] \rho, R S_{A} \cos \theta
$$

in which $a_{0}$ and $a_{n}$ are arbitrary constants, $n$ is an odd integer, and the remaining notation in the above and following equations is the same as that employed in chapter 4. The tanks are presumed to be of uniform wall thickness and supported at the base such that both their circumferential and radial displacement components vanish. The following support conditions are considered for the top boundary:

- A roller support, for which no axial forces can develop and the circumferential displacements vanish; and

- A hinged support, for which both the axial and circumferential displacements vanish.

With the membrane theory being employed, the conditions of vanishing radial displacement for a rigid support cannot be satisfied.

The forces evaluated are the transverse shear across normal sections, $V(\eta)$, and the corresponding bending moment, $M(\eta)$. These forces are related to the circumferential shear per unit of length of the tarik wall, $\mathrm{N}_{z \theta}$, and the corresponding axial force per unit of length, $\mathrm{N}_{z}$, by 


$$
N_{z \theta}(\eta, \theta)=\frac{V(\eta)}{\pi R} \sin \theta
$$

and

$$
N_{z}(\eta, \theta)=\frac{M(\eta)}{\pi R^{2}} \cos \theta
$$

For the uniform axial distribution of the pressure defined by Equation E.1, the results are as follows. For the roller support,

$$
V(\eta)=\left(\eta-\Gamma_{r}\right) a_{0} m_{p} S_{A}
$$

and

$$
M\left(\eta:=(1-\eta)\left[\frac{1}{2}(1+\eta)-\Gamma_{r}\right] a_{o} m_{l} H_{l} S_{A}\right.
$$

in which

$$
r_{I}=\frac{1.5\left(2+v_{t}\right)+\frac{5}{8}\left(H_{Q} / R\right)^{2}}{6\left(1+v_{t}\right)+\left(H_{\ell} / R\right)^{2}}
$$

For the hinged support,

$$
V(\eta)=(\eta-0.5) a_{0} m_{l} S_{A}
$$

and

$$
M(\eta)=\left[-\frac{\eta^{2}}{2}+\frac{\eta}{2}-\frac{1}{12}+v_{t}\left(\frac{R}{H_{l}}\right)^{2}\right] a_{0} m_{l} H_{l} S_{A}
$$

For the cosine distribution of loading represented by Equation E.2, the corresponding resuits are: For the roller support,

$$
V(\eta)=\frac{2}{n \pi}\left[\sin \frac{n \pi}{2} \eta-\frac{2}{n \pi} \Gamma_{r}\right] a_{n} m_{l} S_{A}
$$

and 


$$
M(\eta)=\frac{4}{n^{2} \pi^{2}}\left[\cos \frac{n \pi}{2} \eta-(1-\eta) \Gamma_{r}\right] a_{n} m_{l} H_{l} S_{A}
$$

in which

$$
\Gamma_{r}=3 \frac{\left(2+v_{t}\right)+\frac{4}{n^{2} \pi^{2}}\left(H_{\ell} / R\right)^{2}}{6\left(1+v_{t}\right)+\left(H_{\ell} / R\right)^{2}}
$$

For the hinged support,

$$
V(\eta)=\frac{2}{n \pi}\left[\sin \frac{n \pi}{2} \eta-\frac{2}{n \pi} \Gamma_{h}\right] a_{n} m_{l} S_{A}
$$

and

$$
M(\eta)=\frac{4}{n^{2} \pi^{2}}\left\{\cos \frac{n \pi}{2} \eta-\Gamma_{h}(\eta-0.5)-\frac{2}{n \pi}\left[\frac{4}{n^{2} \pi^{2}}-v_{t}\left(\frac{R}{H_{l}}\right)^{2}\right]\right\} a_{n} m_{l} H_{l} S_{A}
$$

in which

$$
\Gamma_{h}=3 \frac{8+(4+n \pi) v_{t}+\frac{4}{n^{2} \pi^{2}}(4-n \pi)\left(H_{\ell} / R\right)^{2}}{24\left(1+v_{t}\right)+\left(H_{\ell} / R\right)^{2}}
$$




\section{APPENDIX F}

AN EXAMPLE FOR DETERMINATION OF SEISMIC RESPONSE AND CAPACITY OF A FLAT BOTTOM VERTICAL LIQUID STORAGE TANK

\section{F.I INTRODUCTION}

The steps required for computation of the seismic response and capacity of flat-bottom vertical storage tanks are illustrated in this Appendix considering an example tank as shown in Figure F.1. The tank radius $R$ is 25 feet, while the liquid height $H_{\ell}$ is 20.4 feet, with the overall tank height to the top of the dome roof being 30.5 feet. The tank sits on a concrete mat foundation. Initially the tank will be assumed to be unanchored. However, for capacity comparison purposes, the tank will subsequently be assumed to be anchored by eight 2-inch diameter $A 307$ bolts spaced at 45 degrees. The tank shell is SA240-Type 304 stainless steel. Since this is an atmospheric storage tank (no internal pressure), the tank head, side wall, and base plate thicknesses are thin which is typical for these tanks. The fluid contained in this tank has a specific gravity of 1.15 and weighs $2880 \mathrm{kips}$ while the combined tank side wall and roof weight is:

$$
W_{t}=55.7 \mathrm{kips}
$$

acting at the center of gravity at a height $h_{t}=15.6$ feet. Therefore the tank weight is negligible compared to the fluid weight. The static pressures $p_{\text {st }}$ at various distances $z$ above the tank base are listed in Table F.2.

It will be assumed that the Design Basis Earthquake (DBE) horizontal ground motion response spectrum at the base of the tank is given by a $0.25 \mathrm{~g}$ NUREG/CR-0098 (Reference F.1) median aniplification soil-site response spectrum shown in Figure F.2. The amplification factors as a function of damping are shown in Table F.1. It will also be assumed that the vertical spectrum is 
$2 / 3$ of the horizontal. The peak horizontal ground velocity and displacement at the base of the tank will be taken as 12 inches/second and 9 inches, respectively. The seismic load factor $L_{s}=1.15$ associated with a risk reduction ratio $R_{R}$ of 20 , will be used.

\section{F.2 SEISMIC RESPONSE}

As noted in Chapter 5 , the seismic response evaluation should provide estimates of each of the following:

1. The overturning moment in the tank shell immediately above the base plate of the tank. This moment is then compared with base moment capacity which is governed by a combination of shell buckling arid anchor bolt yielding or failure and generally governs the seismic capacity of the tank.

2 The overturning moment applied to the tank foundation through a combination of the tank wall and the base plate. This moment is only needed for tanks founded on soil sites where a foundation failure mode should be investigated and is generally obtained as part of the SSI evaluation. It seldom governs the seismic capacity.

3. The base shear beneath the tank base plate. This base shear is compared to the horizontal sliding capacity of the tank. For atmospheric tanks with a radius greater than 15 feet it seldom controls the seismic capacity.

4. The moment in the tank wall at locations where the wall is thinner than at the base (such as what occurs at 9 feet above the base in Figure F.1), and at the location of maximum moment if such a location is away from the base as would be the case for a tank laterally supported at the top of the sidewall as well as at the base. 
5. The hydrostatic pressure $p_{s t i}$ the seismic-induced hydrodynamic pressure due to the horizontal input component (combination of impulsive and convective modes) $p_{d h}$ i and the hydrodynamic pressures due to the vertical input component $p_{d v}$. It is a common design practice to compare these combined pressures with the membrane hoop capacity of the tank walls at one foot above the base and each location where the wall thickness changes. In addition, the pressure at the base is needed for the base moment and shear capacity calculations. Thus, for the example, these combined pressures are needed at 0,1 , and 10 feet above the base of the tank. These combined pressures essentially never govern the seismic capacity of a properly designed tank.

6. The fluid slosh height. This slosh height is compared with the freeboard above the top of the fluid to verify the validity of the assumption of a free-fluid surface in the response analysis.

In estimating each of these response quantities at least two horizontal modes of combined fluid-tank vibration and one vertical mode of fluid vibration should be considered. The two horizontal response modes should include the fundamental impulsive mode for which the response of the tank wall and roof are coupled together with the portion of the fluid contents which move in unison with the wall, and at least the fundamental sloshing (convective) mode of the fluid.

\section{F.2.1 Horizontal Impulsive Response}

The horizontal impulsive mode natural frequency $f_{1}$ may be estimated from Equation 4.13 of Chapter 4 . For a stainless steel tank, $E_{t}=27,700 \mathrm{ksi}$ and $\gamma_{t}=\rho_{t} g=490 \mathrm{lb} / \mathrm{ft}^{3}$ from which $\sqrt{E_{t} / \rho_{t}}=16,200 \mathrm{ft} / \mathrm{sec}$. The ratio of the liquid height to tank 
radius, $\left(H_{\ell} / \mathrm{R}\right)=20.4 / 25=0.816$. The average wall thickness $t_{a}$ over the lower two-thirds of the liquid height (recommended for use in chapter 4) is estimated to be about 0.291 inch from which the $t_{a} / R=0.00097$. For a fluid with a specific gravity of 1.15 , the ratio of liquid to tank material mass densities $\rho_{\ell} / \rho_{t}=1.15$ $(0.127)=0.146$. From 'Table 4.3 of Chapter 4 for a "free" top support condition and $\mathrm{H}_{\ell} / \mathrm{R}=0.816,\left(\mathrm{C}_{1}\right)_{\mathrm{r}}=0.0833$. Correcting for $t_{a} / R=0.00097$ and $\rho_{\ell} / \rho_{t}=0.146$ by using Equation 4.15 of Chapter 4 leads to:

$$
C_{i}=0.0833[127(0.00097) /(0.146)]^{1 / 2}=0.077
$$

Thus, from Equation 4.13 of Chapter 4, the natural frequency can be calculated as follows:

$$
\bar{f}_{i_{f a}}=\frac{0.077(16,200 \mathrm{ft} / \mathrm{sec})}{2 \pi(20.4 \mathrm{ft})}=9.7 \mathrm{~Hz}
$$

This natural frequency is the "best-estimate" natural frequency for a fully-anchored tank and is accordingly defined by appropriate notations.

In order to account for the frequency uncertainty in accordance with the requirement of section 3.4 , the following natural frequency bands are recommended for three anchorage conditions:

$$
\begin{aligned}
& f_{i_{f a}}=(0.85 \text { to } 1.15) \bar{f}_{i_{f a^{\prime}}} \text { for a fully anchored tank } \\
& f_{i_{p a}}=(0.8 \text { to } 1.1) \bar{f}_{i_{f a^{\prime}}} \text { for a partially anchored tank (F.3) } \\
& f_{i_{u}}=(0.75 \text { to } 1.05) \bar{f}_{i_{f a^{\prime}}} \text { for an unanchored tank }
\end{aligned}
$$

Thus, for this unanchored tank, the horizontal impulsive natural frequency is expected to lie in the range of: 


$$
f_{i}=7.3 \mathrm{~Hz} \text { to } 10.2 \mathrm{~Hz}
$$

and the highest spectral acceleration from this range should be used to define the horizontal impulsive response. In order to define the impulsive mode spectral acceleration $\left(S_{A}\right)_{1}$ in addition to the frequency $f_{1}$, a damping value is needed. In accordance with the guidance provided in Table 3.2, a $4 \%$ damping value is chosen for this impulsive mode. Thus, from Figure F.2 and Table F. 1:

$$
\left(S_{A}\right)_{i(\leq 8.0 \mathrm{~Hz}, 48)}=2.28(0.25 \mathrm{~g})=0.57 \mathrm{~g}
$$

At a distance $z$ above the base, the maximum horizontal impulsive pressure $p_{1}$ is defined from Equation 4.22 of Chapter 4 to be:

$$
p_{i}(\eta)=c_{i}(\eta)\left(S_{A}\right)_{i} \rho_{R} R
$$

or

$$
\begin{aligned}
p_{i}(\eta) & =c_{i}(\eta)(0.57)(1.15)\left(62.41 \mathrm{bs} / f t^{3} / 144 \mathrm{inch}^{2} / f t^{2}\right)(25 f t) \\
& =c_{i}(\eta)(7.10 \mathrm{psi})
\end{aligned}
$$

where $C_{1}(\eta)$ is a function of $\eta=z / H_{\ell}$ and $H_{\ell} / R$ as given by Table 4.1 of Chapter 4 . For $\mathrm{H}_{\ell} / \mathrm{R}=0.816$ :

$\begin{array}{rll}z(f t) & \eta & c_{1}(\eta) \\ 0 & 0 & 0.64 \\ 1 & 0.049 & 0.64 \\ 10 & 0.49 & 0.53\end{array}$

The resulting horizontal impulsive mode pressures $p_{1}$ are given in Table F.2.

The maximum overturning moment occurs at the tank base. The horizontal impulsive mode base moment $M_{i \ell}$ due to the liquid can be obtained from Equation 4.32 of Chapter 4 as follows:

$$
M_{i \ell}=0.4\left(\frac{m_{i}}{m_{\ell}}\right) m_{\ell}\left(S_{A}\right)_{i} H_{\ell}
$$

$$
F-5
$$


or

$$
M_{l}=0.4\left(\frac{m_{i}}{m_{l}}\right)(2880 \mathrm{kips})(0.57)(20.4 f t)=\left(\frac{m_{i}}{m_{l}}\right)(13,400 \mathrm{kips}-\mathrm{ft})
$$

where 2880 kips is the total liquid weight, and $\left(m_{1} / m_{l}\right)$ may be obtained from Table 4.2 of Chapter $A$. For $H_{l} / R=0.816,\left(m_{1} / m_{l}\right)$ $=0.471$. Thus:

$$
M_{i l}=0.471(13400 \mathrm{kip}-f t)=6310 \mathrm{kip}-f t
$$

The additional horizontal impulsive moment due to the tank shell weight is:

$$
M_{i t}=m_{t}\left(S_{A}\right)_{i} h_{t}=55.7 \mathrm{kip}(0.57)(15.6 \mathrm{ft})=500 \mathrm{kip}-\mathrm{ft}(\mathrm{F} .8)
$$

where $m_{t}$ is the tank mass and $h_{t}$ is its center of gravity height. Thus:

$$
M_{i}=M_{i l}+M_{i t}=6810 \mathrm{kip}-f t
$$

Similarly the impulsive mode base shear is given by:

$$
V_{i}=\left[\left(\frac{m_{i}}{m_{l}}\right) m_{l}+m_{t}\right]\left(S_{A}\right)_{i}
$$

which leads to:

$$
V_{i}=805 \mathrm{kips}
$$

\section{F.2.2 Horizontal Convective (sloshing) Mode Response}

The fundamental convective mode natural frequency $f_{c 1}$ is given by Equation 4.11 of chapter 4 with $n=1$ where $\lambda_{1}$ is defined by Equation 4.5 . Thus:

$$
f_{c 1}=\sqrt{\frac{1.50 f t / \sec ^{2}}{R} \tanh \left(1.841 H_{\ell} / R\right)}
$$

or for $R=25$ feet and $\left(H_{\ell} / R\right)=0.816$ : 


$$
f_{c 1}=0.233 \mathrm{~Hz}
$$

In accordance with Table 3.2 , the convective mode is damped $0.5 \%$ of critical damping. Thus, from Figure F.2 and Table F.1:

$$
\left(S_{A}\right)_{C 1(0.233 \mathrm{~Hz}, 0.58)}=0.100 \mathrm{~g}
$$

From Equation 4.22 of Chapter 4 , the fundamental convective mode pressures are:

$$
p_{C 1}(\eta)=C_{C 1}(\eta)\left(S_{A}\right)_{C 1} \rho R
$$

or

$$
\begin{aligned}
p_{C 1}(\eta) & =c_{C 1}(\eta)(0.100)(1.15)\left(62.41 \mathrm{bs} / \mathrm{ft}^{3} / 144 \mathrm{inch}^{2} / f t^{2}\right)(25 \mathrm{ft}) \\
& =c_{C 1}(\eta)(1.25 \mathrm{psi})
\end{aligned}
$$

where $c_{c 1}(\eta)$ can be obtained from Equation 4.4 of chapter 4 . For $\mathrm{n}=1$ and $\mathrm{H}_{\ell} / \mathrm{R}=0.816$ :

$\begin{array}{cll}z(f t) & \eta & c_{c 1}(\eta) \\ 0 & 0 & 0.355 \\ 1 & 0.049 & 0.356 \\ 10 & 0.49 & 0.456\end{array}$

The resulting fundamental convective mode pressures $p_{c 1}$ are given in Table F.2.

The second convective mode pressures are less than $20 \%$ of the first convective mode pressures which in themselves are small. Thus, all higher convective modes may be ignored. In fact, from a practical standpoint, even the first convective mode pressures are negligible.

The fundamental convective mode base moment $\mathrm{M}_{\mathrm{C1}}$ can be obtained from Equation 4.32 of Chapter 4 to be:

$$
M_{C 1}=\left(\frac{m_{C 1}}{m_{l}}\right)\left(\frac{h_{C 1}}{H_{l}}\right) m_{l}\left(S_{A}\right)_{c 1} H_{l}
$$

or 


$$
M_{C 1}=\left(\frac{m_{C 1}}{m_{l}}\right)\left(\frac{h_{C 1}}{H_{l}}\right)(2880 \mathrm{kips})(0.100)(20.4 f t)=\left(\frac{m_{C 1}}{m_{l}}\right)\left(\frac{h_{C 1}}{H_{l}}\right)(5880 \mathrm{kip}-f t)
$$

where both $\left(m_{c 1} / m_{\ell}\right)$ and $\left(h_{c 1} / H_{\ell}\right)$ are given in Table 4.2 of chapter 4. For $\mathrm{H}_{\ell} / \mathrm{R}=0.816,\left(\mathrm{~m}_{\mathrm{c} 1} / \mathrm{m}_{\ell}\right)=0.504$ and $\left(\mathrm{h}_{\mathrm{c} 1} / \mathrm{H}_{\ell}\right)=0.577$. Thus:

$$
M_{C 1}=0.504(0.577)(5880 \mathrm{kip}-f t)=1710 \mathrm{kip}-\mathrm{ft} \quad(\mathrm{F} .16)
$$

Similarly:

$$
V_{C 1}=\left(\frac{m_{c 1}}{m_{l}}\right) m_{l}\left(S_{A}\right)_{c 1}=145 \text { kips }
$$

Lastly, from Equation 4.51 of Chapter 4 , the fundamental convective mode slosh height $h_{s 1}$ is:

$$
h_{s 1}=0.837 R\left[\frac{\left(S_{A}\right)_{C 1}}{g}\right]=2.09 f t
$$

\section{F.2.3 Vertical Liquid Mode Response}

Hydrodynamic pressures due to the fundamental vertical liquid mode should be estimated at critical locations on the tank wall. This vertical mode natural frequency $f_{v}$ may be estimated from Equation 4.48 and Table 4.3 of Chapter 4 in a manner analogous to that shown in section F.2.1 for the horizontal impulsive mode. Thus, the "best-estimate" vertical mode natural frequency $\bar{f}_{v_{f a}}$ for a fully-anchored tank is given by:

$$
\bar{f}_{V_{f a}}=9.9 \mathrm{~Hz}
$$

Correcting for frequency uncertainty for an unanchored tank using the factors of Equation F.3, the vertical mode natural frequency is expected to lie in the range of:

$$
f_{\mathrm{v}}=7 \quad 4 \mathrm{~Hz} \text { to } 10.4 \mathrm{~Hz}
$$

Again, $4 \%$ damping is used for this mode and the highest vertical

$$
\mathrm{F}-8
$$


spectral acceleration in this frequency range is:

$$
\left(S_{A}\right)_{V(\leq 8.0 \mathrm{~Hz}, 48)}=(2 / 3)(2.28)(0.25 \mathrm{~g})=0.38 \mathrm{~g}
$$

At any distance $z$ above the base, the vertical mode pressure $p_{v}$ is given by Equation 4.47 of Chapter 4 to be:

$$
p_{v}(\eta)=0.8\left[\cos \frac{\pi}{2} \eta\right]\left(S_{A}\right)_{V} \rho_{l} H_{l}
$$

or

$$
\begin{aligned}
p_{v}(\eta) & =0.8\left[\cos \frac{\pi}{2} \eta\right](0.38)(1.15)\left(62.41 \mathrm{bs} / f t^{3} / 144 \mathrm{in.} .^{2} / f t^{2}\right)(20.4 f t) \\
& =\left[\cos \frac{\pi}{2} \eta\right](3.09 \mathrm{psi})
\end{aligned}
$$

The resulting vertical mode pressures $p_{v}$ are given in Table F. 2 .

The effective tank weight $w_{\text {te }}$ is obtained by adjusting the actual tank weight by the probable effect $(40 \%)$ of the vertical earthquake component at the time of maximum moment and shear based on Newmark 100\%-40\%-40\% Rule (Reference F.1). Thus:

$$
W_{t e}=W_{t}\left[1 \pm 0.4 \frac{A_{v}}{g}\right]
$$

where $A_{v}$ is the peak vertical ground acceleration $\left(A_{v}=0.167 \mathrm{~g}\right.$ for this example). Thus, for this eximple:

$$
W_{t e}=55.7 \mathrm{kips}[1 \pm 0.067]=52.0 \mathrm{kips} \text { to } 59.4 \mathrm{kips}(\mathrm{F} .24)
$$

\section{F.2.4 Combined Demand (Response)}

For the hydrodynamic pressure loadings, the probable combined horizontal input hydrodynamic pressures $p_{d n}$ are obtained by the SRSS combination of $\mathrm{p}_{1}$ and $\mathrm{p}_{\mathrm{c} 1} ;$ the combined vertical input hydrodynamic pressures $p_{d v}$ are just $p_{v} ;$ and the combined total hydrodynamic pressures $p_{d}$ are obtained by the SRSS combination of $p_{d h}$ and $p_{d v}$. The total inelastic factored demand pressures $p_{t i}$ are then given by Equation 5.4 of Chapter 5 which is: 


$$
p_{t i}=p_{s t}+\frac{L_{s} p_{d}}{F_{\mu D}}
$$

where for a risk reduction factor $R_{A}$ of $20, L_{S}=1.15$, and $F_{\mu D}=$ 1.5 for the hoop capacity failure mode from Table 3.3. Each of these combined pressures are shown in Table F.2.

The probable combined base moment $M_{d}$ and base shear $V_{d}$ demands are given by the sRSS combination of the impulsive and convective mode demands. Thus:

$$
\begin{aligned}
& M_{d}=\left[M_{i}^{2}+M_{c 1}^{2}\right]^{1 / 2}=7020 \mathrm{kip} \mathrm{ft} \\
& V_{d}=\left[V_{i}^{2}+V_{c 1}^{2}\right]^{1 / 2}=818 \mathrm{kips}
\end{aligned}
$$

These values are less than $3 \%$ greater than from the impulsive mode alone which illustrates the relative unimportance of the convective mode.

To obtain the total inelastic demand base moment $M_{t i}$ and base shear $V_{t i}$, the combined demands ( $M_{d}$ and $V_{d}$, respectively) can be divided by $F_{\mu D}=1.25$ from Table 3.3 and must be multiplied by the appropriate $L_{S}$ from Equation $3.4 \mathrm{a}$ (i.e., $L_{S}=1.15$ for $R_{R}=$ 20). Thus $\left(L_{S} / F_{\mu D}\right)=0.92$ and:

$$
\begin{aligned}
& M_{t i}=\left[\frac{L_{s} M_{d}}{F_{\mu D}}\right]=6460 \mathrm{kip} \mathrm{ft} \\
& V_{t i}=\left[\frac{L_{S} V_{d}}{F_{\mu D}}\right]=752 \mathrm{kips}
\end{aligned}
$$

Lastly, the combined slosh height response $h_{s r}$ can be taken as equal to the fundamental convective mode slosh height $h_{s 1}$ :

$$
h_{s y}=h_{s 1}=2.09 \text { feet }
$$

\section{F.3 LAPACITY ASSESSMENTS}

This example capacity assessment is performed in accordance with the guidance of chapter 5 .

$$
\mathrm{F}-10
$$




\section{F.3.1 slosh Height Capacity}

As noted in Section 5.2, the slosh height response, $h_{\mathrm{sr}}$ should be compared with the slosh height capacity, $h_{s c}$. From Equation 5.1, the required slosh height capacity $h_{S C}$ for a risk ratio $R_{R}$ of 20 (i.e., $L_{F}=1.15$ ) is given by:

$$
h_{S C} \geq 1.6 L_{s} h_{s t}=1.6(1.15)(2.09 \mathrm{ft})=3.85 \text { feet (F.29) }
$$

whereas, the available slosh height capacity from Equation 5.2 is:

$$
h_{s C}=h_{C}+\frac{h_{d}}{4}=1.6+\frac{8.5}{4}=3.72 \text { feet }
$$

Therefore, this tank does not have a sufficient freeboard margin of safety to provide a seismic risk reduction ratio $R_{R}$ of 20 which requires $a L_{s}$ of 1.15 in accordance with Equation 3.9a. In fact, the available seismic load factor $L_{s}$ is only $3.72(1.15) / 3.85=1.11$ which from Equation 3.9a would correspond to a seismic risk reduction ratio $R$ of about 17 . If this increased seismic risk of unacceptable performance cannot be justified and accepted, then either (1) a more sophisticated response analysis which accounts for the partial roof confinement of the free liquid surface for an earthquake amplified by a factor of $1.5 \mathrm{~L}_{\mathrm{s}}=1.7$ must be performed and an acceptable risk reduction ratio is demonstrated; or (2) the maximum liquid height must be reduced to 20.2 feet (a 0.2 foot reduction) to enable $h_{s c}$ to pass Equation F.29. In most cases, this last option is preferable. Even though the slosh height capacity is inadequate, this example will be continued to illustrate the remainder of the capacity assessment. 


\section{F.3.2 Hoop Tension Capacity}

The pressure capacity $p_{c}$ based on the hoop tension is given by Equation 5.3. For SA240-Type 304 stainless steel, $\sigma_{c}=37.5 \mathrm{psi}$, and the resulting pressure capacities $p_{c}$ are listed in Table F.2 for $t_{t w}=5 / 16$ inch $(z=1.0$ foot $)$, and $t_{t w}=1 / 4$ inch $(z=10$ feet). These pressure capacities $p_{c}$ exceed the total inelastic factored demand pressures $p_{t 1}$ by a very substantial margin as shown in Table F.2. Therefore, the hoop tension capacity is easily adequate.

\section{F.3.3 Maximum Permissible Axial Compression in Tank Wall}

The "elephant-foot" buckling axial stress capacity $\sigma_{\text {be }}$ is given by Equation 5.5. For SA240-Type 304 stainless steel, $\sigma_{\text {ye }}=37.5$ $\mathrm{ksi}$ and $E_{t}=27,700 \mathrm{ksi}$. The pressure $p_{\mathrm{m}}$ for use in Equation 5.5 is the probable maximum pressure given by Equation 5.6 where $p_{s t}$, $\mathrm{p}_{\mathrm{dh}}$, and $\mathrm{p}_{\mathrm{dv}}$ are from Table F.2 at the locations being considered $(z=1.0$ and 10.0 feet $)$. Thus:

\begin{tabular}{|c|c|c|c|c|c|}
\hline $\begin{array}{c}z \\
(f e e t)\end{array}$ & $\begin{array}{c}t_{t w} \\
\text { inches) }\end{array}$ & $R / t_{t w}$ & $\begin{array}{c}p_{m x} \\
(p s i)\end{array}$ & $s_{1}$ & $\begin{array}{c}\sigma_{b e} \\
(k s i)\end{array}$ \\
\hline \hline 1.0 & $5 / 16$ & 960 & 15.46 & 2.4 & 11.7 \\
\hline 10.0 & $1 / 4$ & 1200 & 9.87 & 3.0 & 10.6 \\
\hline
\end{tabular}

Similarly, the "diamond" buckling axial stress capacity $\sigma_{b d}$ is given by Equation 5.7 using the above properties except that $\sigma_{y}$ $=30 \mathrm{ksi}$, and $\mathrm{p}_{\mathrm{n}}$ is the minimum probable maximum pressure given by Equation 5.8 .

Thus:

\begin{tabular}{|c|c|c|}
\hline $\begin{array}{c}z \\
(\mathrm{feet})\end{array}$ & $\begin{array}{c}\mathrm{p}_{\mathrm{mn}} \\
(\mathrm{psi})\end{array}$ & $\begin{array}{c}\sigma_{\mathrm{bd}} \\
(\mathrm{ksi})\end{array}$ \\
\hline \hline 1.0 & 13.00 & 8.31 \\
\hline 10.0 & 8.09 & 6.65 \\
\hline
\end{tabular}


The maximum permissibie axial compression $C_{b}$ is given by Equation 5.9 with $\sigma_{b}$ being the lesser of $\sigma_{b e}$, or $\sigma_{b d}$. Thus:

\begin{tabular}{|c|c|c|}
\hline $\begin{array}{c}z \\
(\text { feet })\end{array}$ & $\begin{array}{c}\sigma_{\mathrm{b}} \\
(\mathrm{ks} 1)\end{array}$ & $\begin{array}{c}\mathrm{C}_{\mathrm{b}} \\
(\mathrm{kips} / \text { inch) }\end{array}$ \\
\hline \hline 1.0 & 8.31 & 1.94 \\
\hline 10.0 & 6.65 & 1.24 \\
\hline
\end{tabular}

(F.31)

The value of $c_{b}$ at $z=1.0$ foot should also be used at the tank base $(z=0)$.

\section{F.3.4 Moment Capacity Away From Tank Base}

At a location along the cylindrical wall away from the base, the moment capacity is given by Equation 5.10 where $P_{a}$ is equal to the upper bound estimate of the effective tank weight $w_{\text {te }}$ from Equation F.24 corrected for the distance $z$ above the base. Thus:

\begin{tabular}{|c|c|c|c|c|}
\hline $\begin{array}{c}z \\
\text { (feet) }\end{array}$ & $\begin{array}{c}\mathrm{P}_{\mathrm{a}} \\
\text { (kips) }\end{array}$ & $\begin{array}{c}\mathrm{C}_{\mathrm{b}} \pi \mathrm{R}^{2} \\
\text { (kip-ft) }\end{array}$ & $\begin{array}{c}\underline{\mathrm{P}}_{\mathrm{a}} \mathrm{R} \\
2 \\
\text { (kip-ft) }\end{array}$ & $\begin{array}{c}\mathrm{M}_{\mathrm{C}} \\
\text { (kip-ft) }\end{array}$ \\
\hline \hline 1.0 & 57.3 & 45,710 & 720 & 44,990 \\
\hline 10.0 & 38.5 & 29,220 & 480 & 28,740 \\
\hline
\end{tabular}

$(\mathrm{F} .32)$

These moment capacities greatly exceed the maximum inelastic factored moment demand at the base $M_{t i}=6460 \mathrm{kip}$-ft from Equation F.27. Therefore, it is unnecessary to find moment demands at other locations in the cylindrical wall since such demands will be less than $M_{t i}$. The cyclindrical wall has more than adequate moment capacity.

If the tank were fully anchored, $M_{C}=44,990 \mathrm{kip}$-ft would also represent the moment capacity at the base. However, it will be shown in section F.3.6 that to develop this fully anchored 
condition at the base requires an unreasonably large number of anchor bolts.

\section{F.3.5 Anchorage Capacity At Tank Base}

For this unanchored tank, there is no anchorage capacity at the tank base. However, for illustration purposes, it will also be assumed that this tank is anchored by eight 2-inch diameter A307 bolts spaced at 45 degrees. The capacity of such anchors must be checked for each of the five potential failure modes listed in section 5.6. However, for this alternate example it will be assumed that the anchor-bolt tensile capacity is the weakest failure mode.

The AISC-LRFD (Reference F.2) code limit state capacity for an A307 anchor bolt is:

$$
T_{c b}=0.75(45 \mathrm{ksi}) A_{b}
$$

where $A_{b}$ is the nominal cross-sectional area of the bolt. For a 2 -inch diameter bolt, $A_{b}=3.14$ square inches and:

$$
T_{c b}=106 \mathrm{kips}
$$

\section{F.3.6 Anchorage Requirement for Fully Anchored Tank}

If the example tank were anchored by 2-inch diameter A307 bolts with $T_{c b}=106$ kips, the maximum angular spacing $\theta_{b}$ for these bolts to provide a fully-anchored tank is given by Equation 5.11. Thus:

$$
\theta_{b} s\left(360^{\circ}\right) \frac{T_{c b}}{2 \pi R C_{b}}=\left(360^{\circ}\right) \frac{106 \mathrm{kips}}{2 \pi(300 \text { inches })\left(1.94 \frac{\mathrm{kips}}{i n c h}\right)}=10.4^{\circ}
$$

which would result in at least 35 of these bolts around the circumference of the tank. This number of bolts is both unrealistic and unnecessary. Instead, a lesser number of bolts or even no bolts can be used if a lesser base moment capacity 
defined in section 5.8 for partially anchored or unanchored tanks is acceptable.

\section{F.3.7 Base Moment Capacity of Unanchored Tank}

In order to estimate the base moment capacity of an unanchored tank, it is first necessary to estimate the fluid hold-down forces (Section 5.10.2) and the maximum permissible uplift displacement (Section 5.9). Section 5.10 .2 recommends that the fluid hold-down capacity be estimated from Equation 5.29. Since both the tank wall and tank base have the same thickness of $5 / 16$ inch and for SA240-type 304 stainless steel $\sigma_{y e}=37.5 \mathrm{ksi}$, the plastic moment capacities from Equation 5.30 are:

$$
M_{p b}=M_{p w}=\frac{37.5 \mathrm{ksi}(5 / 16 i n c h)^{2}}{4}=0.916 \mathrm{kip} \text {-inch } / \text { inch }
$$

The shell parameter $\kappa$ is given by:

$$
K=\left[\left(R / t_{t w}\right) \sqrt{3\left(1-v_{t}^{2}\right)}\right]^{1 / 2}=39.8
$$

Therefore, from Equation 5.32 the horizortal component of the membrane tension in the base plate is:

$$
F_{h}=\frac{37.5 \mathrm{ksi}(5 / 16 i n c h)}{2(39.8)}+\frac{0.916 \mathrm{kips}(39.8)}{300 i n c h}=0.269 \mathrm{kip} / \text { inch (F.38) }
$$

The fluid pressure $p$ should conservatively be taken as the probable minimum pressure computed from Equation 5.26 using the demand pressure at the base $(z=0)$ from Table F.2. Thus at $\theta=0$ :

$$
p_{\theta=0}=10.17 \mathrm{psi}-4.56 \mathrm{psi}-0.4(3.09 \mathrm{psi})=4.37 \mathrm{psi}
$$

With these values for $M_{p b}, M_{p s}, F_{h}$, and $p$, from Equation 5.29 and after combining terms the fluid hold-down force at $\delta=\delta_{0}$ (i.e., $\theta$ o) is:

$$
T_{f o}=0.127 \frac{k i p s}{i n c h}\left[1+\left(\frac{\delta_{0}}{6.81 i n c h}\right)\right]^{1 / 2}
$$

Equation 5.19 limits $\delta_{0}$ to $(0.1 L)$ where $L$ is the uplifted length

$$
\mathrm{F}-15
$$


computed from Equation 5.28. Thus, for various $\delta_{0}$ values:

\begin{tabular}{|c|c|c|c|}
\hline $\begin{array}{c}\delta_{0} \\
\text { (inch) }\end{array}$ & $\begin{array}{c}T_{\text {fo }} \\
\text { (kip/inch) }\end{array}$ & $\begin{array}{c}\mathrm{L} \\
\text { (inch) }\end{array}$ & $\begin{array}{c}\text { Upper Limit } \\
\delta_{0} \\
\text { (inch) }\end{array}$ \\
\hline \hline 2.0 & 0.144 & 33.0 & 3.30 \\
3.0 & 0.152 & 34.8 & 3.48 \\
3.6 & 0.156 & 35.8 & 3.58 \\
\hline
\end{tabular}

In many cases, $\delta_{0}$ is limited by tolerable displacements for piping or other components attached to the tank wall. Great precision is unnecessary in establishing the permissible uplift displacement $\delta_{0}$ because $\mathrm{T}_{\mathrm{fm}}$ is only mildly influenced by $\delta_{0}$. For this example, it will be assumed that:

$$
\begin{gathered}
\delta_{0}=3.0 \text { inches } \\
\mathrm{T}_{\mathrm{fo}}=0.152 \mathrm{kips} / \text { inch }
\end{gathered}
$$

At the neutral axis $\theta=\theta_{n}, \delta_{0}=0$ and from Equation 5.26:

$$
\mathrm{p}_{\theta=\theta n} \geq 10.17 \mathrm{psi}-0.4(3.09 \mathrm{psi})=8.93 \mathrm{psi}
$$

Therefore, from Equation 5.29:

$$
\mathrm{T}_{\mathrm{fn}}=0.181 \mathrm{kips} / \mathrm{inch}
$$

It is conservative to assume that the fluid hold-down force varies linearly from $\mathrm{T}_{\mathrm{fn}}$ at $\theta=\theta_{\mathrm{n}}$ to $\mathrm{T}_{\mathrm{fo}}$ at $\theta=0$. Thus, from Equation 5.15 :

$$
\Delta T_{f}=0.152 \frac{k i p s}{i n c h}-0.181 \frac{k i p s}{i n c h}=-0.029 \frac{k i p s}{i n c h}
$$

Now the maximum axial compressive stress $C_{m}^{\prime}$ and the base moment capacity are computed from Equations 5.12 and 5.13 for any given neutral axis angle $\theta_{n}$, with $w_{t}=52.0 \mathrm{kips}$ which, for conservatism, is taken as the minimum $w_{\text {te }}$ from Equation F.24. The axial compressive stress must be limited to not exceed $c_{b}=$ 2.56 kips/inch from Equation F.31.

Table F.3 presents the computed base moment capacity $\mathrm{M}_{\mathrm{C}}$ as a 
function of the neutral axis angle $\theta_{n}$. Note that $M_{c}$ is relatively insensitive to $\theta_{n}$ so that great precision is unnecessary in finding $\theta_{n}$. The unanchored tank base moment capacity is:

$$
M_{C}=8,650 \mathrm{kip}-\mathrm{ft}
$$

This base moment capacity is only a small fraction of the fully anchored base moment capacity of $44,990 \mathrm{kip}-\mathrm{ft}$ given by Equation F.32. However, this unanchored moment capacity exceeds the inelastic factored base moment demand $M_{t 1}=6460 \mathrm{kip}-\mathrm{ft}$ given in Equation F.27. Thus, this unanchored tank has an adequate base moment capacity.

\section{F.3.8 Base Moment Capacity of Partially Anchored Tank}

For the alternate partially anchored tank with eight 2-inch diameter $\mathrm{A} 307$ anchor bolts at $45^{\circ}$ spacing around the tank, it is recommended that the fluid hold-down forces be computed in accordance with section 5.10.1.

With $E_{s}=27,7000 \mathrm{ksi}, R=300$ inches, $t_{t w}=t_{t b}=5 / 16$ inch, and $\mathrm{H}_{\ell} / \mathrm{R}=0.816$, from Equations 5.20 and 5.20a:

$$
\begin{aligned}
\mathrm{K} & =77.41 \mathrm{kip}-\mathrm{inch} \\
\kappa & =39.83 \\
\mathrm{~K}_{\mathrm{s}} & =20.56 \mathrm{kips} \\
\frac{M_{f x}}{p_{\theta}} & =27.50 \mathrm{inch}^{2}
\end{aligned}
$$

With these values, for various uplift lengths L:

\begin{tabular}{|c|c|c|c|c|}
\hline $\begin{array}{c}\mathrm{L} \\
\text { (inch) }\end{array}$ & $\begin{array}{c}\mathrm{T}_{\mathrm{f}} / \mathrm{p} \\
\text { (inch) }\end{array}$ & $\begin{array}{c}\delta / \mathrm{p} \\
\text { (inch/psi) }\end{array}$ & $\begin{array}{c}\mathrm{M}_{\mathrm{f}} / \mathrm{p} \\
\left.\text { inch }^{2}\right)\end{array}$ & $\begin{array}{c}\mathrm{M}_{+} / \mathrm{p} \\
\left(\text { inch }^{2}\right)\end{array}$ \\
\hline \hline 8.885 & 6.66 & 0 & 19.7 & 2.5 \\
12.0 & 8.11 & 0.0033 & 25.4 & 7.6 \\
15.0 & 9.78 & 0.0107 & 34.2 & 13.6 \\
18.0 & 11.57 & 0.0243 & 46.2 & 20.7 \\
21.0 & 13.42 & 0.0464 & 61.4 & 28.7 \\
24.0 & 15.32 & 0.0798 & 79.6 & 37.7 \\
25.0 & 15.96 & 0.0940 & 86.4 & 40.9 \\
\hline
\end{tabular}


At $\theta=0, \delta_{0}$ is limited by Equation 5.18. For the example anchored tank, it will be assumed that the effective bolt length $\left(h_{e}\right)=$ 36 inches. Therefore:

$$
\delta_{0} \leq 0.01 \text { (36 inches) }=0.36 \text { inch }
$$

Also, at $\theta=0, \mathrm{p}_{\theta=0}=4.37 \mathrm{psi}$ as we computed in Equation F.39. For this value of $\mathrm{p}_{\theta=0}$ and $\delta_{0}$ :

$$
\delta_{o} / p=\frac{0.36 i n c h}{4.37 \text { psi }}=0.0824
$$

which from Equation F.45 corresponds to an uplift length $L=$ 24.2 inches for which:

$$
\begin{gathered}
T_{\text {fo }}=15.4 \text { inch }(.00437 \mathrm{ksi})=0.067 \frac{\mathrm{kips}}{i n c h} \\
M_{f}=80.9 \mathrm{in}^{2}(.00437 \mathrm{ksi})=0.354 \frac{\mathrm{kip}-i n c h}{i n c h}
\end{gathered}
$$

This $M_{f}$ is well below $M_{p b}=0.916 \frac{\text { kip-inch }}{\text { inch }}$ from Equation F. 36 . At $\theta=\theta_{n}, \delta_{\theta n}=0$ and $p_{\theta=\theta n}=8.93 \mathrm{psi}$ as was computed in Equation F.42. For these values, from Equation F.45 the uplift length $L$ $=8.885$ inches for which:

$$
T_{\text {fn }}=6.66 \text { inch }(.00893 \mathrm{ksi})=0.059 \frac{\mathrm{kips}}{i n c h}
$$

Again, it is conservative to assume that the fluid hold-down force varies linearly from $\mathrm{T}_{\mathrm{fn}}$ at $\theta=\theta_{\mathrm{n}}$, to $\mathrm{T}_{\mathrm{fm}}$ at $\theta=0$. Thus from Equation 5.15:

$$
\Delta T_{f}=0.067 \frac{k i p s}{i n c h}-0.059 \frac{k i p s}{i n c h}=0.008 \frac{k i p s}{i n c h}
$$

The anchor bolt tension $T_{t 1}$ for anchor bolt "i" can be estimated from Equation 5.16 with $K_{b}$ from Equation 5.17 of: 


$$
K_{b}=\frac{\delta_{o} A_{b} E_{b}}{h_{\theta}}=\frac{0.36 i n\left(3.14 i n^{2}\right)(29,000 \mathrm{ksi})}{36 \text { inches }}=911 \mathrm{kips} \text { (F.51) }
$$

In most situations, the bolt pretension $T_{b p}$ should be taken as zero since even when an initial pretension is installed, it is likely to be lost after a few years.

Again, $w_{t}=52.0 \mathrm{kips}$ which is the minimum $w_{\text {te }}$ from Equation F.24 and the axial compressive stress $C_{m}^{\prime}$ must be 1 imited to $C_{b}=2.56$ kips/inch from Equation F.31.

Table F.4 presents the computed base moment capacity $M_{c}$ from Equations 5.12 and 5.13 as a function of $\theta_{n}$. Again note that $M_{c}$ is relatively insensitive to $\theta_{n}$ so that great precision is unnecessary in finding $\theta_{n}$. The base moment capacity for the partially anchored tank is:

$$
M_{c}=22,640 \mathrm{kip}-\mathrm{ft}
$$

This base moment capacity is 2.6 times the base moment capacity of $8,650 \mathrm{kip}-\mathrm{ft}$ for the unanchored tank given by Equation F.44, but is only $50 \%$ of the base moment capacity of $44,990 \mathrm{kip}$-ft for the fully anchored tank given by Equation F.32. These examples illustrate the influence of anchorage on the base moment capacity.

\section{F.3.9 Base Shear Capacity}

The base shear capacity $v_{c}$ is given by Equations $5.33,5.34$, and 5.35. Conservatively set $w_{t}=52.0 \mathrm{kips}$ which is the minimum $w_{\text {te }}$ from Equation F.24. $\Sigma \mathrm{T}_{\mathrm{bi}}=0$ for an unanchored tank, and:

$$
\mathrm{p}_{\mathrm{a}}=\mathrm{p}_{\mathrm{st}}-0.4 \mathrm{p}_{\mathrm{dv}}=10.17 \mathrm{psi}-0.4(3.09 \mathrm{psi})=8.93 \mathrm{psi}
$$

from the $z=0$ case in Table F.2. Then, from Equation 5.34:

$$
\mathrm{W}_{\mathrm{e}}=52.0 \mathrm{kips}+.00893 \mathrm{ksi} \pi(300 \mathrm{inch})^{2}=2577 \mathrm{kips}
$$

Assuming a coefficient of friction (COF) of 0.70 , from Equation 5.33 :

$$
\mathrm{F}-19
$$




$$
V_{c s}=0.70[2577 \mathrm{kips}]=1804 \mathrm{kips}
$$

Then, from Equation 5.35:

$$
\mathrm{V}_{\mathrm{c}}=0.75[1804 \mathrm{kips}]=1353 \mathrm{kips}
$$

This base shear capacity is greater than the inelastic factored base shear demand $V_{t i}=752 \mathrm{kips}$ given in Equation F.27. Therefore, this unanchored tank has an adequate base shear capacity. 


\section{REFERENCES}

F.1 Newmark, N.M. and Hall, W.J., "Development of Criteria for Seismic Review of Selected Nuclear Power Plants", NUREG/CR0098, Nuclear Regulatory Commission, May 1978.

F.2 American Institute of Steel Construction, "Manual of steel Construction, Load \& Resistance Factor Design", LRFD, First Ed., Chicago, Illinois, 1986. 
NOTATION

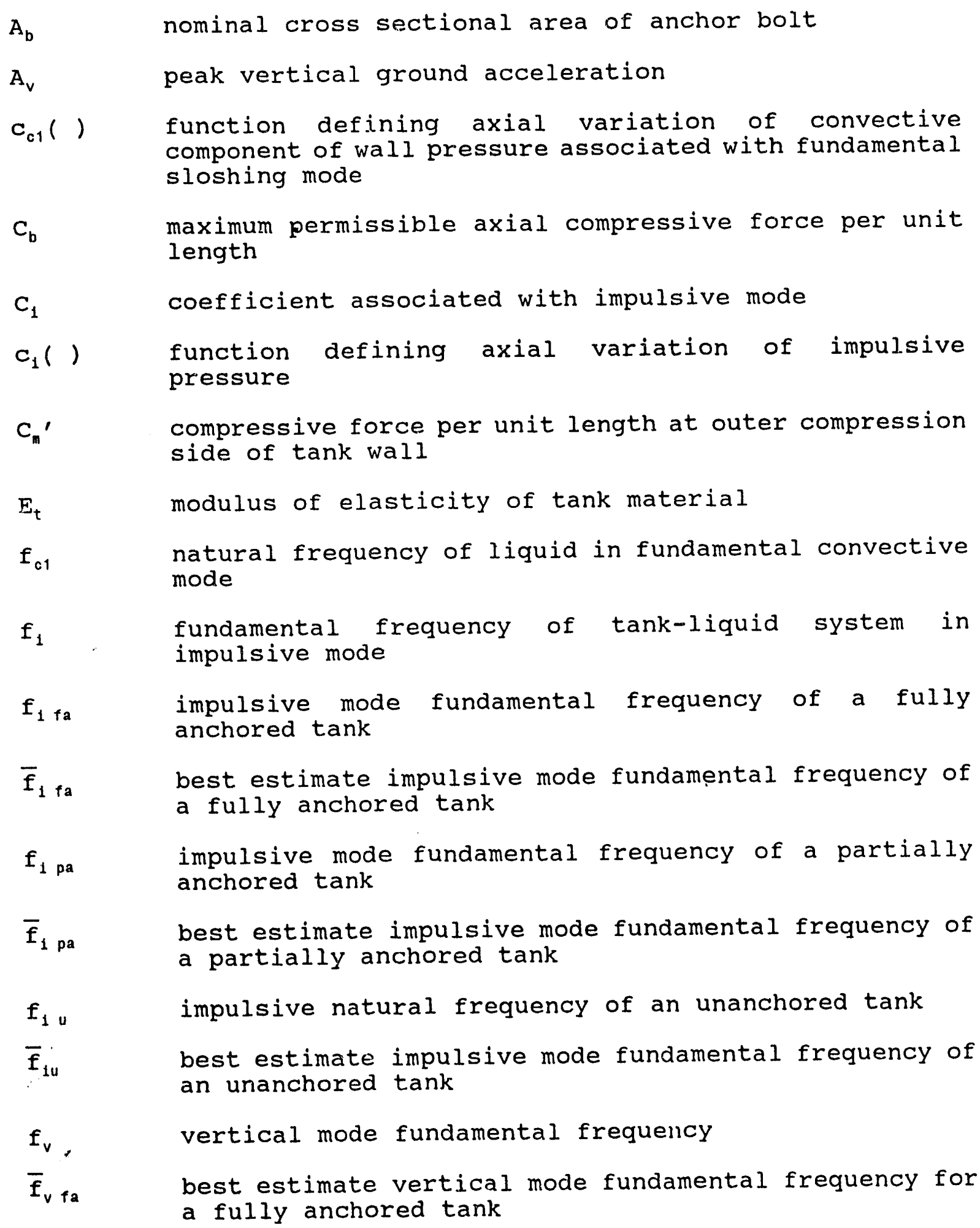




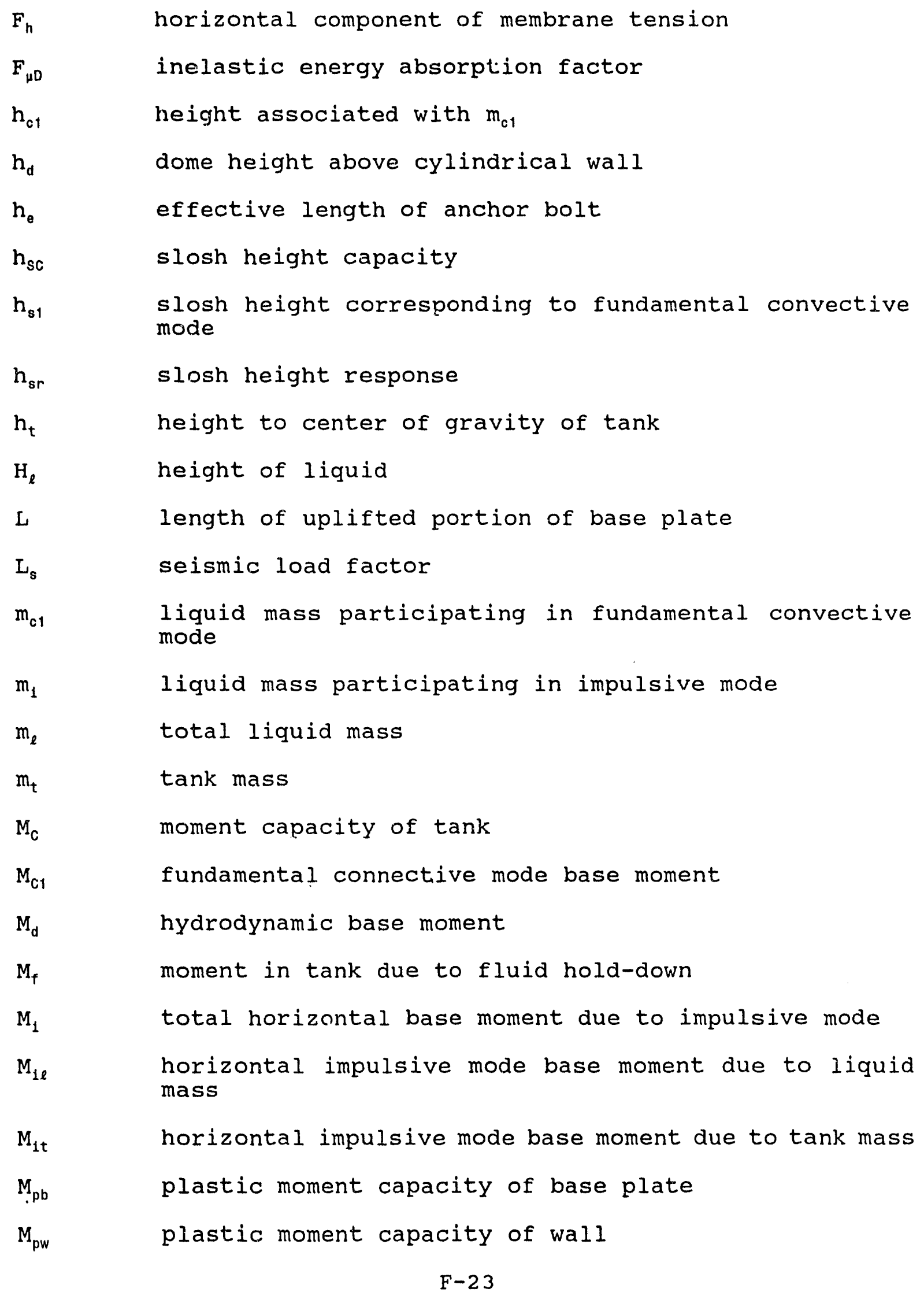




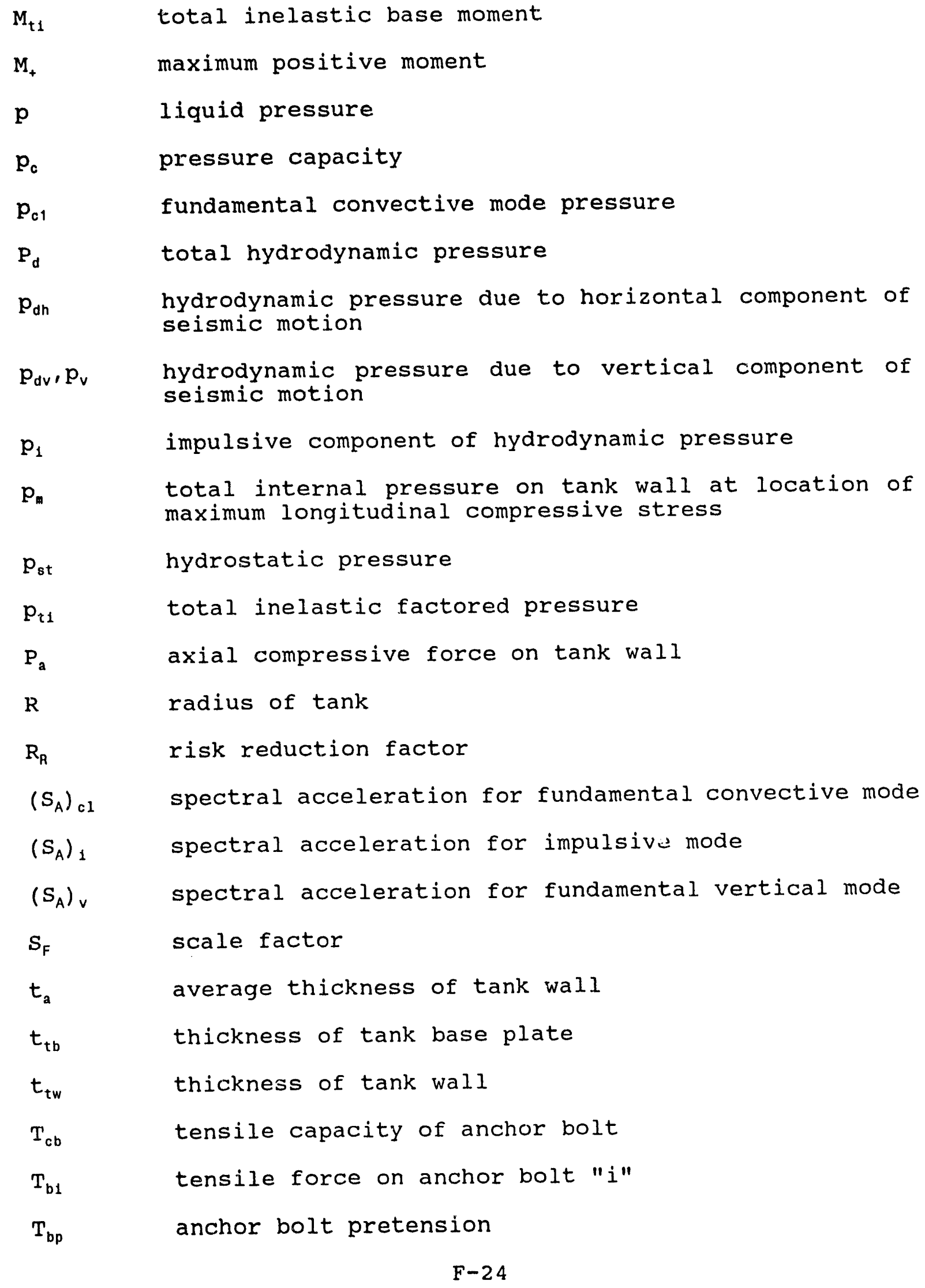


$\mathrm{T}_{\mathrm{fo}} \quad$ fluid hold-down tensile force at outer tension side of tank wall

$\mathrm{T}_{\mathrm{fn}} \quad$ fluid hold-down force at neutral axis

$\mathrm{V}_{\mathrm{c}}$

base sliding shear capacity using code coefficient

$\mathrm{V}_{\mathrm{c} 1}$

base shear corresponding to fundamental convective mode

$\mathrm{V}_{\mathrm{d}} \quad$ total hydrodynamic base shear

$\mathrm{V}_{1}$

base shear corresponding to impulsive mode

$\mathrm{V}_{\mathrm{cs}}$

nominal base sliding hsear capacity

$\mathrm{V}_{\mathrm{t} 1}$

total inelastic base shear

$\mathrm{w}_{\mathrm{t}}$

weight of tank

$W_{\text {te }}$

effective weight of tank

$\mathbf{z}$

vertical distance above the base

$\gamma_{\mathrm{t}}$

specific weight of tank material

$\delta_{0}$

uplift height at outer tension. side of tank wall

$\theta$

circumferential angle

$\theta_{\mathrm{b}}$

circumferential angle between anchor bolts

$\theta_{\mathrm{n}}$

circumferential angle to neutral axis

$\kappa$

shell parameter

$\lambda_{1}$

first root of first derivative of Bessel function of first kind and first order

$\rho_{\ell} \quad$ mass density of liquid

$\rho_{\mathrm{t}}$

mass density of tank material

$\sigma_{\mathrm{b}}$

governing axial stress capacity of tank wall considering buckling modes

$\sigma_{b d}$

axial stress capacity of tank wall in "diamond" buckling mode

axial stress capacity of tank wall in "elephant-foot" buckling mode 


$\begin{array}{ll}\sigma_{c} & \text { hoop membrane stress capacity } \\ \sigma_{y} & \text { code minimum yield stress } \\ \sigma_{y e} & \text { effective yield stress }\end{array}$


Table F.1 Spectral Amplification Factors for Horizontal Elastic Response

\begin{tabular}{|c|ccc|}
\hline $\begin{array}{c}\text { Damping, } \\
\% \text { Critical }\end{array}$ & Acceleration & $\begin{array}{c}\text { Median }(50 \%) \\
\text { Velocity }\end{array}$ & Displacement \\
\hline \hline 0.5 & 3.68 & 2.59 & 2.01 \\
1 & 3.21 & 2.31 & 1.82 \\
2 & 2.74 & 2.03 & 1.63 \\
3 & 2.46 & 1.86 & 1.52 \\
5 & 2.12 & 1.65 & 1.39 \\
7 & 1.89 & 1.51 & 1.29 \\
10 & 1.64 & 1.37 & 1.20 \\
20 & 1.17 & 1.08 & 1.01 \\
\hline
\end{tabular}


Table F.2 Hydrostatic and Hydrodynamic Pressures at Various Locations Above Base

\begin{tabular}{|c|c|c|c|c|c|c|c|c|c|c|}
\hline \multirow{2}{*}{$\begin{array}{l}\text { Height } \\
\text { above } \\
\text { base } \\
z \text { (ft.) }\end{array}$} & \multirow{2}{*}{$\eta=\mathrm{z} / \mathrm{H}_{\ell}$} & \multicolumn{8}{|c|}{$\begin{array}{c}\text { Demand (Response) } \\
\text { (psi) }\end{array}$} & \multirow{2}{*}{$\begin{array}{c}\text { Capacity } \\
\text { (psi) } \\
p_{c}\end{array}$} \\
\hline & & $p_{s t}$ & $p_{i}$ & $\mathrm{p}_{\mathrm{ct}}$ & $p_{v}$ & $\mathrm{p}_{\mathrm{dh}}$ & $p_{d v}$ & $\mathrm{p}_{\mathrm{d}}$ & $p_{i i}$ & \\
\hline 0 & 0 & 10.17 & 4.54 & 0.44 & 3.09 & 4.56 & 3.09 & 5.51 & 14.39 & \\
\hline 1 & .049 & 9.67 & 4.54 & 0.44 & 3.08 & 4.56 & 3.08 & 5.50 & 13.89 & 39.06 \\
\hline 10 & .490 & 5.18 & 3.76 & 0.57 & 2.22 & 3.80 & 2.22 & 4.40 & 8.55 & 31.25 \\
\hline \multicolumn{11}{|c|}{$p_{d h}=\left[p_{i}^{2}+p_{c 1}^{2}\right]^{1 / 2}$} \\
\hline \multicolumn{11}{|c|}{$p_{d v}=p_{v}$} \\
\hline \multicolumn{11}{|c|}{$p_{d}=\left[p_{i}^{2}+p_{c 1}^{2}+p_{v}^{2}\right]^{1 / 2}$} \\
\hline & & & & $t i=$ & $\frac{{ }_{s} p_{d}}{F_{\mu D}}$ & $p_{s t}$ & & & & \\
\hline \multicolumn{11}{|c|}{$L_{s}=1.15$} \\
\hline & & & & & $=1$ & & & & & \\
\hline
\end{tabular}


Table F.3 Base Moment Capacity for The Unanchored Tank

$\mathrm{C}_{\mathrm{b}}=1.94 \mathrm{kips} / \mathrm{inch} \quad \mathrm{W}_{\mathrm{t}}=52.0 \mathrm{kips} \quad \mathrm{T}_{\mathrm{fn}}=0.181 \mathrm{kips} / \mathrm{inch}$ $\Delta \mathrm{T}_{\mathrm{f}}=-0.029 \mathrm{kips} / \mathrm{inch} . \quad \mathrm{R}=25$ feet $=300$ inches $\quad \Sigma \mathrm{T}_{\mathrm{b} 1}=0$

\begin{tabular}{|c|c|c|c|c|c|c|}
\hline $\begin{array}{c}\text { Trial } \\
\theta_{n}\end{array}$ & $C_{1}$ & $c_{2}$ & $C_{3}$ & $C_{4}$ & $\begin{array}{c}C_{m}^{\prime} \\
(k i p s / \\
\text { inch })\end{array}$ & $\begin{array}{c}M_{c} \\
(k i p- \\
\text { feet })\end{array}$ \\
\hline \hline 2.80 & 4.40 & .449 & 6.74 & 1.60 & 2.42 & 8,700 \\
\hline 2.75 & 3.84 & .513 & 5.83 & 1.61 & 2.08 & 8,670 \\
\hline 2.70 & 3.41 & .576 & 5.13 & 1.62 & 1.81 & 8,640 \\
\hline
\end{tabular}

$M_{c}=8,650$ kip-ft 


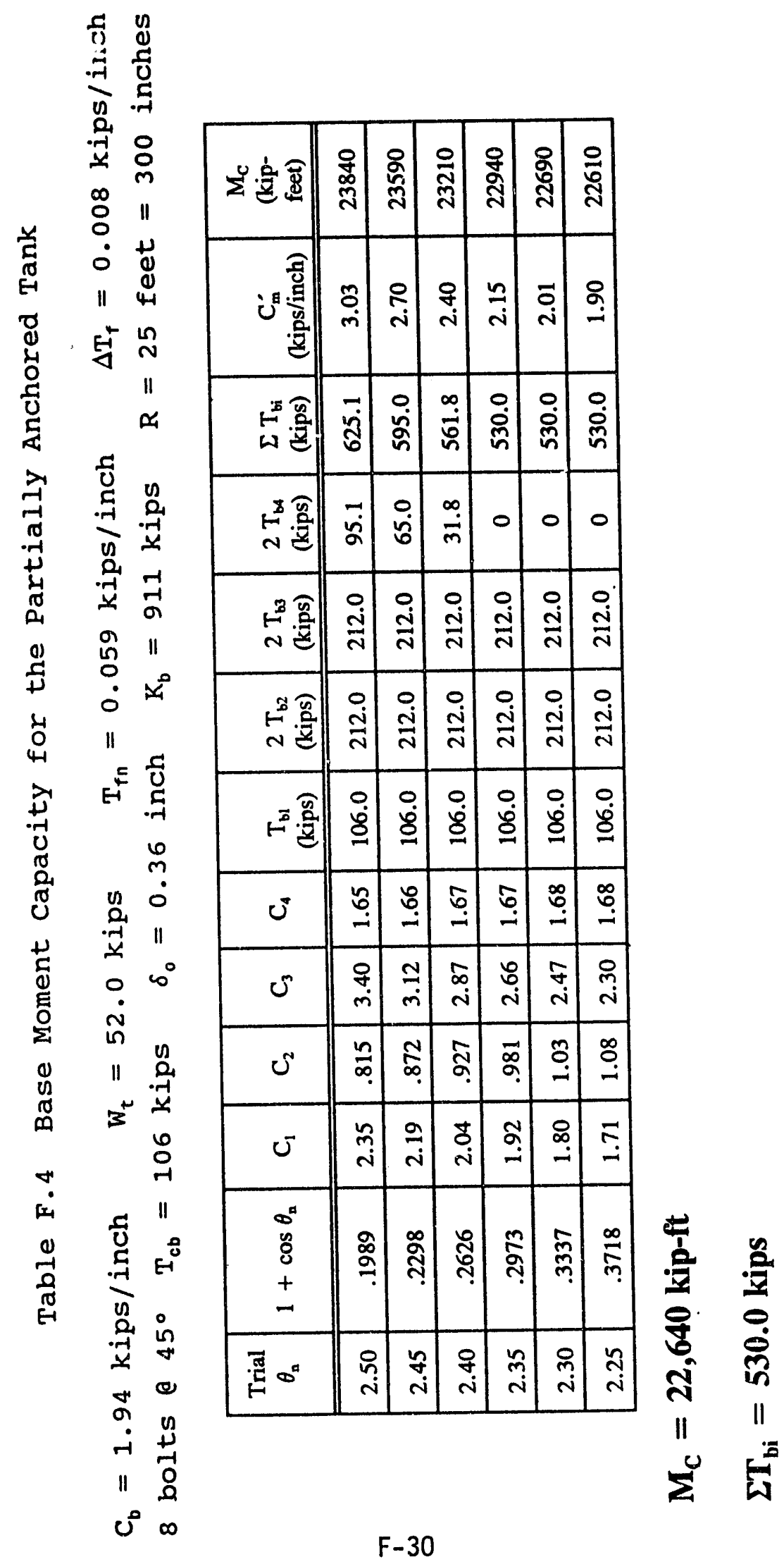




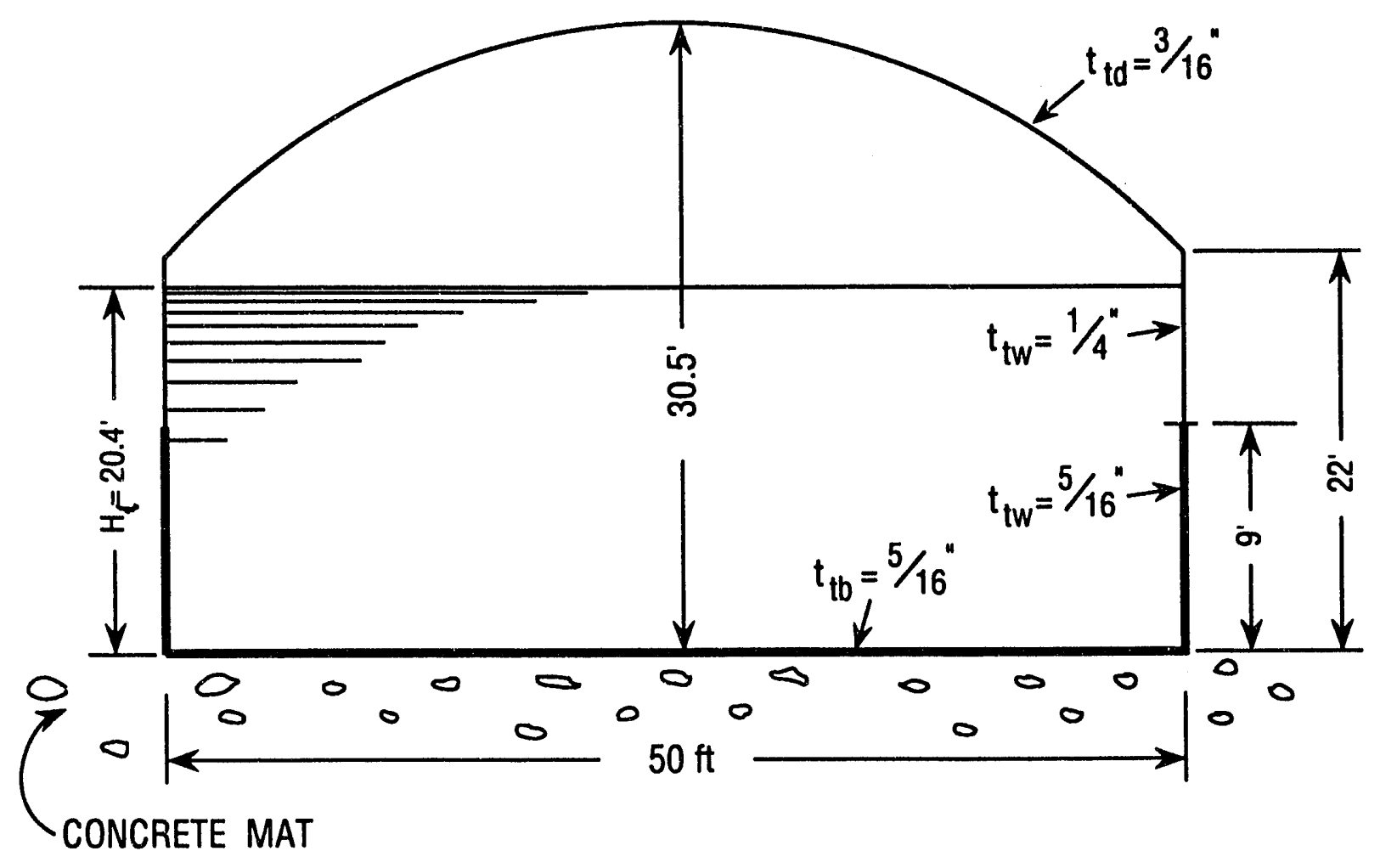

Figure F.1 Example Tank

F-31 


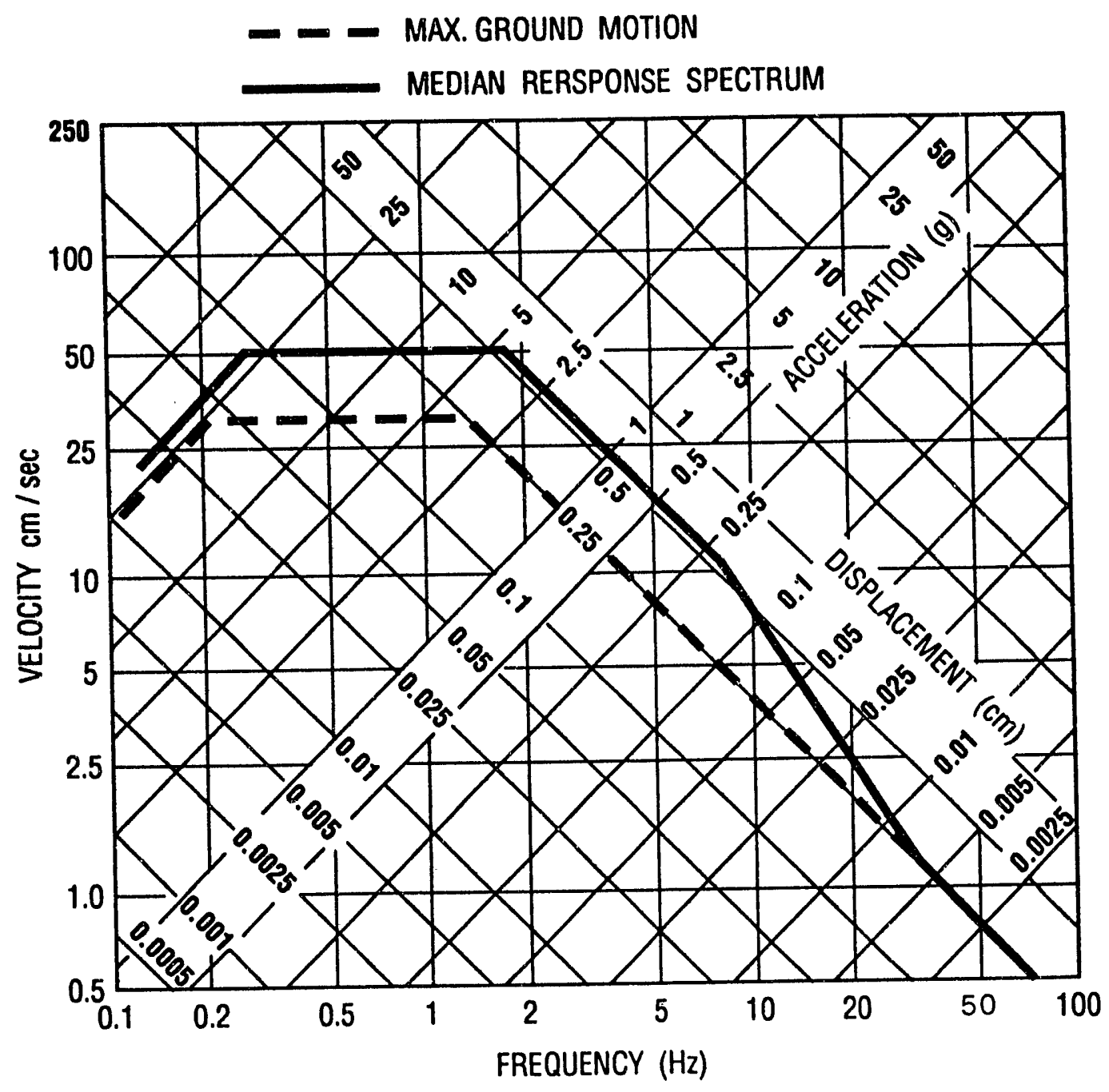

Figure F.2 Elastic Design Spectrum, Horizontal Motion, $(0.25 \mathrm{~g}$ Max. Accel., 5\% Damping) 


\section{APPENDIX G \\ LUMPED PARAMETER SSI ANALYSES}

\section{G. 1 INTRODUCTION}

Lumped parameter models approximate the dynamic loadings on underground cylindrical structures due to dynamic free-field displacements by assuming that the radial loading on the structure can be represented with three components:

(a) a free-field component that would exist if the underground structure were replaced by the soil,

(b) a component dependent on the displacement of the structure relative to the free-field displacement, and

(c) a component dependent on the velocity of the structure relative to the free-field velocity.

This type of soil-structure interaction law has a long history of use in estimating response of underground structures to either static or dynamic loadings. Investigations of buckling pressures for underground culverts were performed in References G.1 through G.5 representing the resistance of the soil with equivalent radial springs whose stiffness is related to the elastic modulus of the surrounding soil.

This formulation, as applied to dynamic wave passage effects, has been correlated with experimental results obtained from dynamic load tests (References G.5 through G.10). The primary focus of these studies was the evaluation of loads acting on underground silos and tunnels, developed by passing ground shock waves from nuclear blast effects. In later years, exact analytic solutions obtained for the response of a rigid circular tunnel subjected to a seismic event indicate interaction parameters which are similar in form and magnitude to the earlier results 
obtained from the experimental wave passage studies. These latter analytic formulations have been used to estimate loads on nuclear plant facilities (References G.11 and G.18) and loads on underground cylindrical piles (References G.13 and G.14) resulting from seismic ground motions.

The SSI parameters associated with a lumped parameter model are discussed in this Appendix. Both horizontal/rocking parameters and vertical parameters are provided. Analyses are also developed in this Appendix indicating the vault system configurations for which the SSI effects can be expected to be insignificant.

\section{G. 2 HORIZONTAL/ROCKING SSI COEFFICIENTS}

Reference G.12 presents one such method of evaluating the SSI effects on underground structures. This methodology has been extensively used in the design of nuclear power plant facilities and has been subject to experimental verification (References G.16 and G.17). This method is specifically referred to in ASCE 4-86 (Reference G.14). Of course, other equally acceptable methods are available. The SSI model is shown in Figure G.1 with the SSI forces ( $F$ and $M$ ) acting at the center of gravity of the underground structure and in terms of the deformations ( $u$ and $\psi$ ) of the structure's center of gravity relative to the ground.

The following definitions are provided (Reference G.12) for SSI forces:

$$
\begin{aligned}
& \mathrm{F}=\mathrm{K}_{\mathrm{uu}} \mathrm{u}+\mathrm{K}_{\mathrm{u} \psi} \psi+\mathrm{c}_{\mathrm{uu}} \dot{\mathrm{u}}+\mathrm{c}_{\mathrm{u} \psi} \psi \\
& \mathrm{M}=\mathrm{K}_{\mathrm{u} \psi} \mathrm{u}+\mathrm{K}_{\psi \psi} \psi+\mathrm{c}_{\mathrm{u} \psi} \dot{\mathrm{u}}+\mathrm{c}_{\psi \psi} \psi
\end{aligned}
$$

Each of the SSI coefficients (e.g., $K_{u u}, C_{u u}$, etc.) are divided into a component developed from the base SSI effects denoted by an additional "b" subscript (e.g., $\mathrm{K}_{\text {uub }}$ ) and sidewall SSI effects denoted by an additional "s" subscript (e.g., $\mathrm{K}_{\mathrm{uus}}$ ). Both

$$
G-2
$$


frequency-dependent and frequency-independent parameters are specified in Reference G.12. The values of the frequencyindependent coeffieients, for a Poisson's ratio $(\nu)$ of $1 / 3$ are:

$$
\begin{aligned}
& \mathrm{K}_{\mathrm{uub}}=4.83 \quad \mathrm{G}_{\mathrm{fs}} \mathrm{R}_{\mathrm{v}} \\
& K_{v \psi b}=\left[2.50+4.83\left(Z_{0} / R_{v}\right)^{2}\right] G_{f s} R_{v}{ }^{3} \\
& \mathrm{~K}_{\mathrm{u} \psi \mathrm{b}}=-4.83 \quad \mathrm{G}_{\mathrm{fs}} \mathrm{R}_{\mathrm{v}} \mathrm{Z}_{\mathrm{o}} \\
& C_{\text {uub }}=3.00 \mathrm{v}_{\mathrm{fs}} \rho_{\mathrm{fs}} R_{\mathrm{v}}{ }^{2} \\
& C_{u \psi b}=\left[0.43+3.00\left(Z_{0} / R_{v}\right)^{2}\right] v_{f s} \rho_{f s} R_{v}{ }^{4} \\
& C_{u v b}=-3.00 v_{f s} \rho_{f s} R_{v}^{2} Z_{0} \\
& \mathrm{~K}_{\mathrm{uus}}=4.05 \mathrm{G}_{\mathrm{ss}} \mathrm{H}_{\mathrm{v}} \\
& K_{v v s}=4.05 G_{s s} R_{v}{ }^{2} H_{v}\left[0.33\left(H_{v} / R_{v}\right)^{2}+\left(Z_{0} / R_{v}\right)^{2}-H_{v} Z_{0} / R_{v}{ }^{2}\right] \\
& \mathrm{K}_{\mathrm{uys}}=-4.05 \quad \mathrm{G}_{\mathrm{ss}} \mathrm{H}_{\mathrm{v}}\left[\mathrm{Z}_{\mathrm{o}}-0.5 \mathrm{H}_{\mathrm{v}}\right] \\
& C_{u u s}=9.90 \mathrm{v}_{s s} \rho_{s s} R_{v} H_{v} \\
& C_{\psi v s}=9.90 \mathrm{v}_{s s} \rho_{s s} R_{v}{ }^{3} H_{v}\left[0.33\left(H_{v} / R_{v}\right)^{2}+\left(Z_{0} / R_{v}\right)^{2}-H_{v} Z_{0} / R_{v}{ }^{2}\right] \\
& C_{u \psi s}=-9.90 \quad v_{s s} \rho_{s s} R_{v} H_{v}\left[Z_{0}-0.5 H_{v}\right]
\end{aligned}
$$

where,

$\rho_{\mathrm{ss}}, \rho_{\mathrm{fs}}=$ mass density of side and foundational (base) soils, respectively

$\mathrm{G}_{\mathrm{ss}}, \mathrm{G}_{\mathrm{fs}}=$ shear modulus of side and foundation (base) soils, respectively

$v_{s s}, v_{f s}=$ shear wave velocity of side and foundation (base) soils, respectively

$R_{v}=$ radius of vault

$\mathrm{H}_{\mathrm{v}}=$ height of vault

$\mathrm{Z}_{0}=$ height of vault $C G$ above foundation.

It should be noted that the moment coefficients for the side soil ( $K_{\psi w s}$ and $C_{\psi w s}$ ) have been modified to eliminate the moment contribution from the shear forces acting along the vault walls. It is expected that the soil will not have sufficient strength to develop these forces. 
The equations of motion for a rigid vault system shown in Figure G.1 are as follows:

$$
\begin{gathered}
m_{v} \ddot{u}+c_{u u} \dot{u}+c_{u \psi} \psi+k_{u u} u+k_{u \psi} \psi=-m_{v} \ddot{x} \\
J_{v} \ddot{\psi}+c_{u \psi} \dot{u}+c_{\psi \psi} \psi+k_{u \psi} u+k_{\psi \psi} \psi=0
\end{gathered}
$$

where,

$\mathbf{x}$ = free field seismic motion

$M_{v}=$ combined mass of vault, tank, and contents

$J_{v}=$ combined rotary inertia about center of gravity of vault, tank, and contents.

Coefficients are the sum of the base and sidewall contributions as defined in Equation G.2.

The significance of horizontal/rocking SSI effects is evaluated by considering the steady state response (described by Equation G.3) of the vault subjected to an input of:

$$
x=x_{0} \sin \omega t
$$

The solution is found for the case where the combined mass of the vault, tank, and contents is distributed uniformly throughout the vault volume. For this case the mass and rotary inertia are:

$$
\begin{gathered}
\mathrm{m}_{v}=\pi \rho_{v} \mathrm{R}_{v}{ }^{2} \mathrm{H}_{v} \\
\mathrm{~J}_{v}=\mathrm{m}_{v}\left[\mathrm{H}_{v}{ }^{2} / 12+\mathrm{R}_{v}{ }^{2} / 4\right]
\end{gathered}
$$

where, $\rho_{\mathrm{v}}=$ average mass density of the vault, tank, and contents.

It is further assumed that the average mass density is equal to that of the soil. When these assumptions are made, the solution to Equation G.3 is a function of two non-dimensional parameters $\left(H_{v} / R_{v}\right.$ and $\left.\omega R_{v} / v_{f s}\right)$. Solutions are obtained for ranges in these non-dimensional parameters with the results shown on Figure G. 2 .

$$
\mathrm{G}-4
$$


The amplification (i.e., $x / x_{0}$ ) is plotted as a function of the non-dimensional frequency. The peak amplification occurs at the system non-dimensional frequency which ranges from 1 to 3 for the values of $H_{v} / R_{v}$ considered in the example. Moreover, the system frequency increases as $H_{v} / R_{v}$ decreases. The rocking and translational frequencies are quite close while the rocking frequency is slightly higher. As expected, the rocking effect decreases with $\mathrm{H}_{v} / \mathrm{R}_{\mathrm{v}}$. The SSI effects are relatively important for $H_{v} / R_{v}$ values greater than 0.75 (amplification of about 1.2 at the center of gravity and 1.3 at the top for $H_{v} / R_{v}=0.75$ ), and insignificant for $H_{v} / R_{v}$ values less than 0.5 (amplification less than 1.2). It is also interesting to note that the response at the top of the vault is greater than the response at the base for frequencies less than the SSI frequencies and less for higher frequencies.

These results are based on the assumptions that the vault is rigid, the mass is uniformly distributed throughout the vault volume, and that the average density of the vault-tank-content system equals that of the soil. The above conclusions would be expected to be valid for the flexible vault unless the fixedbase vault frequency is close to the SSI frequencies. One would expect the SSI effects to be more important in this case than for the rigid vault. A slight variation of distribution of the material throughout the vault (other than uniform) probably has a small effect on the above conclusions. The SSI effects would be expected to be less significant for a vault-tank-content system with a lower density than they would be for the case where this density is equal to the soil density.

\section{G. 3 VERTICAL SSI COEFFICIENTS}

The vertical SSI coefficients are taken from ASCE 4-86 (Reference G.14) and are as follows:

$$
\begin{gathered}
K_{v}=4 \quad G_{f s} R_{v} /(1-\nu) \\
G-5
\end{gathered}
$$




$$
C_{v}=0.85 \quad K_{v} R_{v} / v_{f s}
$$

(G.5)

The vertical SSI frequency $\left(f_{v}\right)$ and damping ratio $\left(\zeta_{v}\right)$ based on these SSI coefficients and the vault mass (Equation G.4) can be shown to be as follows for Poisson's ratjo $\nu=1 / 3$ :

$$
\begin{gathered}
f_{v}=\left[K_{v} / m_{v}\right]^{1 / 2} /(2 \pi)=0.22\left[R_{v} \rho_{f s} /\left(H_{v} \rho_{v}\right)\right]^{1 / 2} v_{f s} / R_{v} \\
\zeta_{v}=C_{v} /\left(4 \pi f_{v} m_{v}\right)=0.59\left[R_{v} \rho_{f s} /\left(H_{v} \rho_{v}\right)\right]^{1 / 2}
\end{gathered}
$$


REFERENCES

G.1 Luscher, U., Hoeg, K., "The Interaction Between a structural Tube and the surrounding soil," Air Force Weapons Laboratory Report No. RTD-TDR-63-3109, 1964 .

G.2 Cheney, J.A., "Bending and Buckling of Thin Walled open Section Rings," Journal, EMD, ASCE, EMG, 1964.

G.3 Meyerhof, G.G., Baikie, L.A., "Strength of steel Culvert Sheets Bearing Against Compacted Sand Backfill," Highway Research Board, 1963.

G.4 Forrestal, M.J., Herrmann, G., "Buckling of a Long Cylindrical shell surrounded by an Elastic Medium," ASCE, october 1964 .

G.5 Dorris, A.F., "Response of Horizontally Oriented Buried Cylinders to static and Dynamic Loadings," WES Corps of Engineers Tech. Report No. 1-682, Julý 1965.

G. 6

Robinson, R.R., "Investigation of silo and Tunnel Linings," Air Force Weapons Laboratory Report No. AFSWC-TDR-62-1, March 1962.

G.7 Costantino, C.J., Robinson, R.R., Salmon, M.A., "A Simplified Soil-Structure Interaction Model to Investigate the Response of Buried Silos and Cylinders," Proceedings symposium on Sojl-structure Interaction, University of Arizona, september 1964.

G.8 Costantino, C.J., Wachowski, E., "Response of Buried silos and Internal systems to Ground Shock," Proceedings International symposium on the Use of Electronic Digital Computers in structural Engineering, University of Newcastle-Upon-Tyne, September 1966. 
G.9 Costantino, C.J., Marino, R.L., "Response of Cylindrical Shells Encompassed with Isolation Materials to a Plane Pressure Pulse," IIT Research Institute No. M6096, for the Air Force Weapons Laboratory, June 1965.

G. 10

G.11

Costantino, C.J., Vey, E., "Response of Crushable Foam Encased Buried Cylinders," Journal, Soil Mechanics Division, ASCE, Vol. 95, No. SM5, September 1969.

"Computer Analysis for Rapid Evaluation of Structures CARES," Brookhaven National Laboratory, NUREG/CR-5588, 1989 .

G.12 Beredugo, Y.O. and Novak, M. "Coupled Horizontal and Rocking Vibration of Embedded Footings, "Canadian Geotechnical Journal, Vol. 9, 1972.

G.13

Gazetas, G., "Foundation Vibrations," Foundation Engineering Handbook, 2nd Edition, Van Nostrand Reinhold, 1991.

G. 14

ASCE 4-86, "Seismic Analysis of Safety Related Nuclear Structures," September 1986.

G.15

U.S. NRC Standard Review Plan, NUREG-0800.

G.16

Tseng, W.S. and Hadjian, A.H., "Guidelines for Soil-Structure Interaction Analysis," for Electric Power Research Institute Project 2225-9, June 1991.

G.17

Hadjian, A.H., Howard, G.E. and Smith, C.B., "A Comparison of Experimental and Theoretical Investigations of Embedment Effects on Seisinic Response," 3rd SMiRT, September 1975.

G. 18

Hadjian, A.H., "Bechtel Topical Report, Seismic Analyses of Structures and Equipment for Nuclear Power Plants," BC-TOP-4, August 1980.

$$
\text { G-8 }
$$


$\mathrm{C}_{\text {uu }}$

Cut

$\mathrm{C}_{v}$

$C_{4}$

$f_{v}$

F

$\mathrm{G}_{\text {ss }}$

$\mathrm{G}_{\text {fs }}$

$\mathrm{H}_{\mathrm{v}}$

$\mathrm{K}_{\mathrm{uu}}$

$\mathrm{K}_{\mathrm{u}}$

$\mathrm{K}_{\mathrm{v}}$

$K_{44}$

$J_{v}$

$\mathrm{m}_{\mathrm{v}}$

M

$R_{v}$

u

$t$

$\mathrm{V}_{\text {ss }}$

$\mathrm{V}_{\text {fs }}$

$\zeta_{v}$

$\mu$

$\rho_{\text {ss }}$ horizontal SSI damping coefficient

horizontal/rocking coupled SSI damping coefficient

vertical SSI dampirig coefficient

rocking sSI damping coefficient

SSI vertical frequency

SSI force

shear modulus of sidewall soil

shear modulus of base soil

height of vault

horizontal SSI stiffness coefficient

horizontal/rocking coupled SSI stiffness coefficient

vertical sSI stiffness coefficient

rocking SSI stiffness coefficient

combined rotary interia about $C G$ of vault, tank and content

combined mass of vault, tank and content

SSI moment

radius of vault

rigid body horizontal displacement of vault center of gravity relative to ground

time

shear wave velocity of sidewall soil

shear wave velocity of (base) soil

SSI damping ratio due to vertical motion

Poisson's notion of base soil

mass density of sidewall soil 


$\begin{array}{ll}\rho_{\mathrm{fs}} & \text { mass density of base soil } \\ \rho_{v} & \text { average mass density of vault, tank and content } \\ \psi & \text { rotation of vault relative to ground } \\ \omega & \text { circular frequency }\end{array}$

G-10 


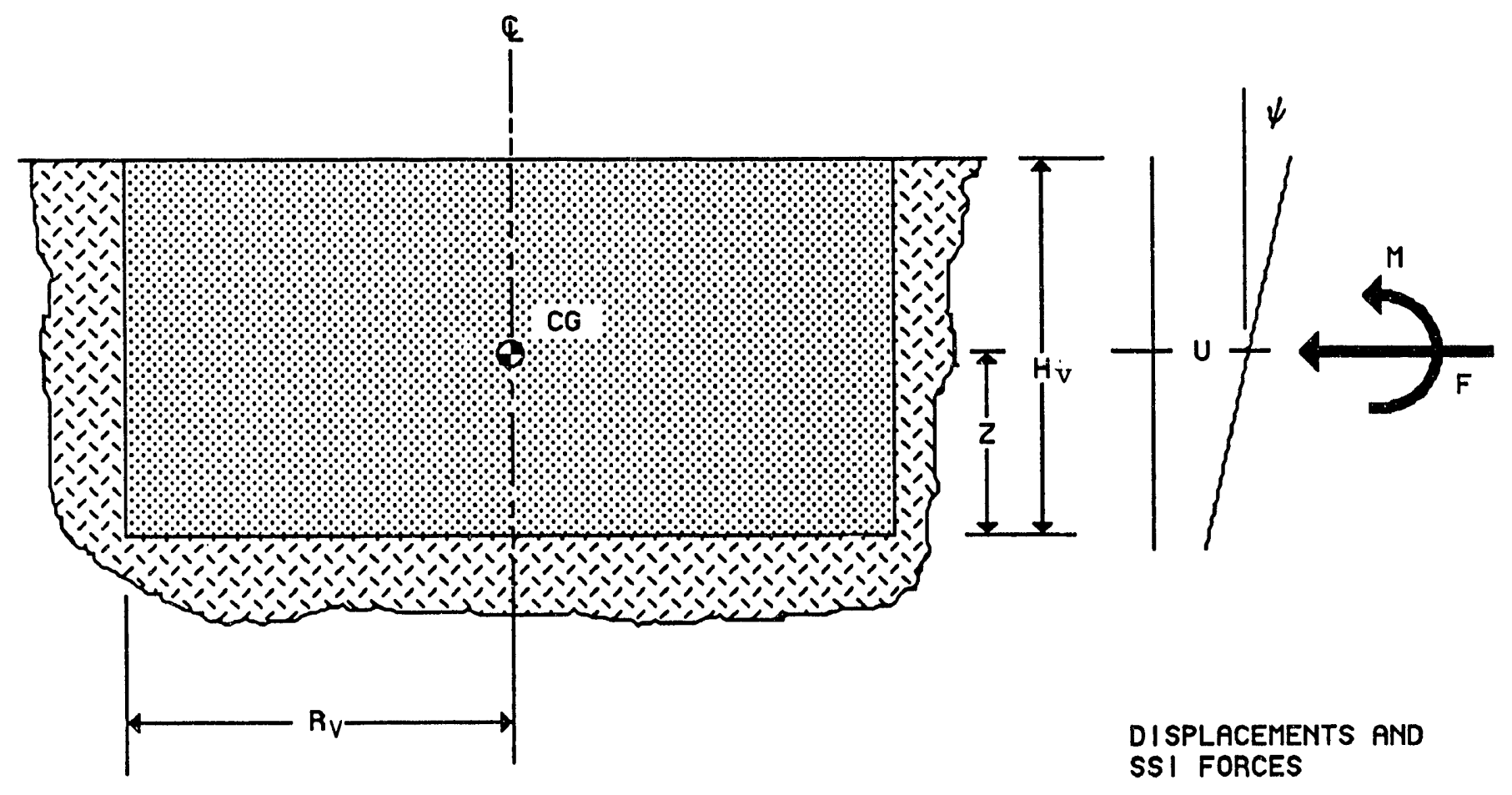

Figure G.1 Lumped Parameter SSI Model G-11 


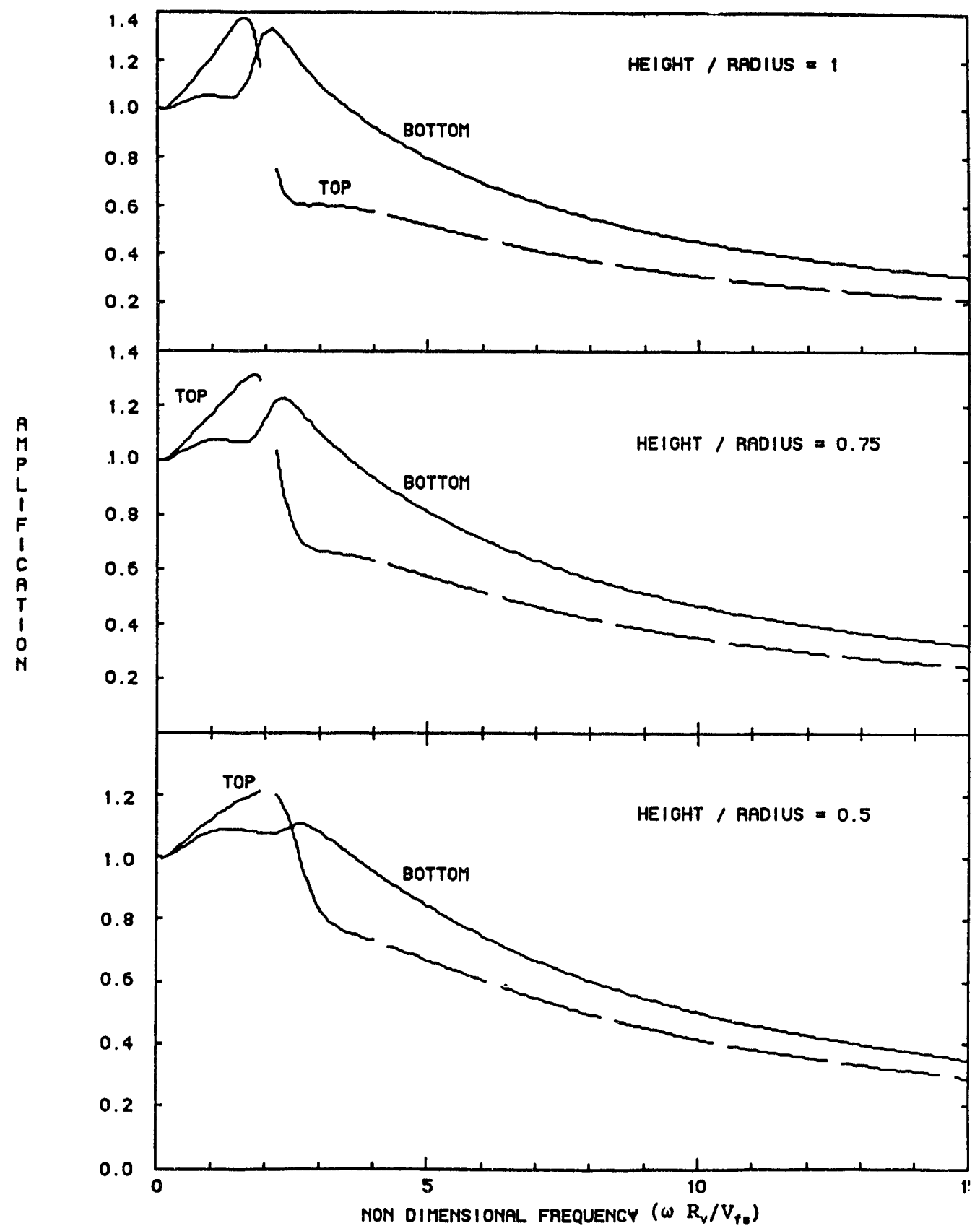

Figure G.2 Amplification of Free Field Motion Resulting From SSI Effects

$$
\text { G-12 }
$$



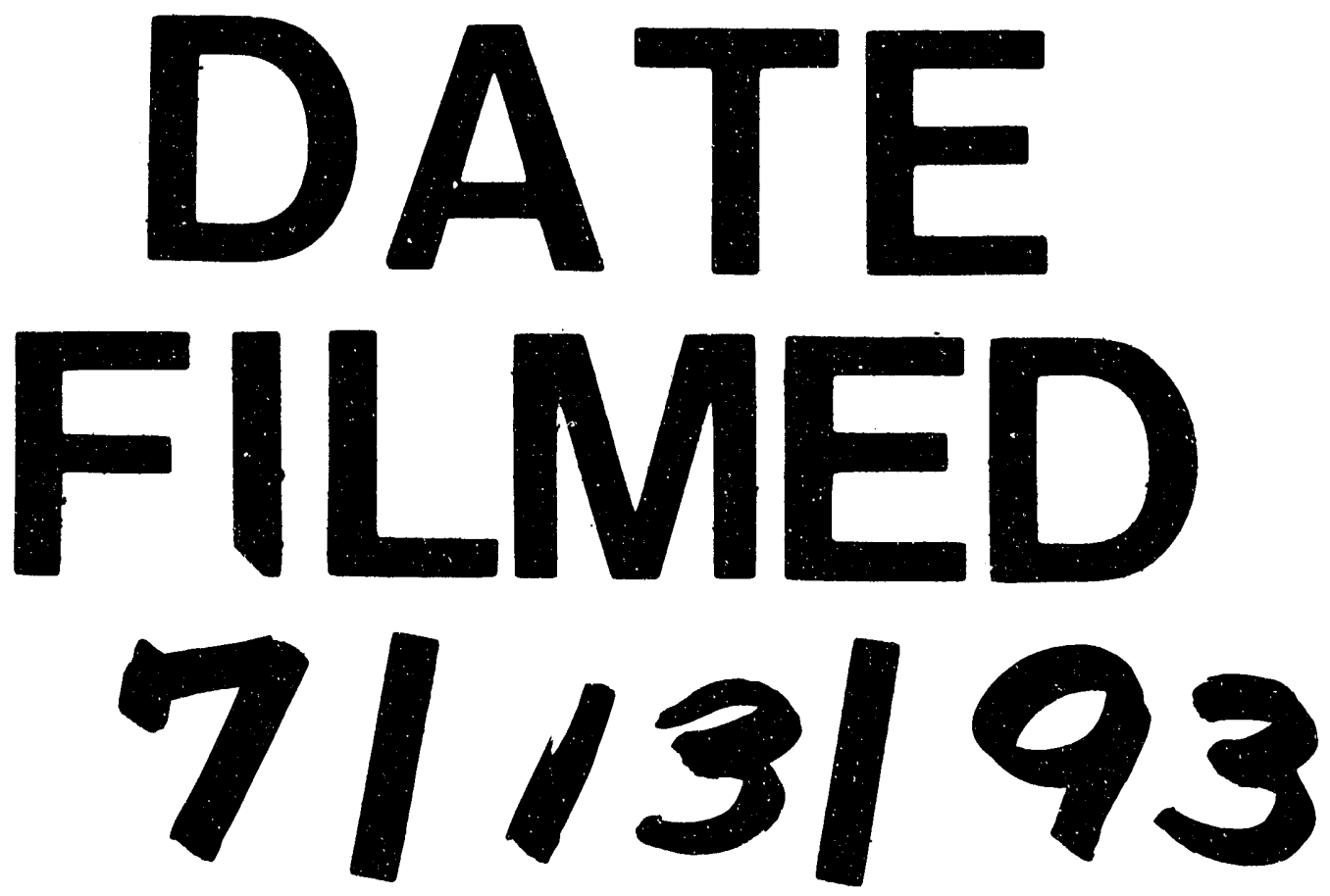
